University of Louisville

ThinkIR: The University of Louisville's Institutional Repository

Electronic Theses and Dissertations

$12-2016$

\title{
Crime and culture : a thematic reading of Sherlock Holmes and his adaptations.
}

\author{
Britney Broyles \\ University of Louisville
}

Follow this and additional works at: https://ir.library.louisville.edu/etd

Part of the American Popular Culture Commons, Asian American Studies Commons, Chinese Studies Commons, Cultural History Commons, Literature in English, British Isles Commons, Other Arts and Humanities Commons, Other Film and Media Studies Commons, and the Television Commons

\section{Recommended Citation}

Broyles, Britney, "Crime and culture : a thematic reading of Sherlock Holmes and his adaptations." (2016). Electronic Theses and Dissertations. Paper 2584.

https://doi.org/10.18297/etd/2584

This Doctoral Dissertation is brought to you for free and open access by ThinkIR: The University of Louisville's Institutional Repository. It has been accepted for inclusion in Electronic Theses and Dissertations by an authorized administrator of ThinkIR: The University of Louisville's Institutional Repository. This title appears here courtesy of the author, who has retained all other copyrights. For more information, please contact thinkir@louisville.edu. 
CRIME AND CULTURE:

A THEMATIC READING OF SHERLOCK HOLMES AND HIS ADAPTATIONS

\author{
By \\ Britney Broyles \\ B.A., University of Louisville, 2008 \\ M.A., University of Louisville, 2012

\begin{abstract}
A Dissertation
Submitted to the Faculty of the

College of Arts and Sciences of the University of Louisville in Partial Fulfillment of the Requirements

for the Degree of
\end{abstract}

Doctor of Philosophy in Humanities

Department of Comparative Humanities

University of Louisville

Louisville, KY

December 2016 
Copyright 2016 by Britney Broyles

All rights reserved 

CRIME AND CULTURE:

\title{
A THEMATIC READING OF SHERLOCK HOLMES AND HIS ADAPTATIONS
}

\author{
By \\ Britney Broyles \\ B.A., University of Louisville, 2008 \\ M.A., University of Louisville, 2012
}

Dissertation Approved on

November 22, 2016

by the following Dissertation Committee:

Dr. Simona Bertacco

Dr. Susan Griffin

Dr. Mary Rosner

Dr. Caroline Reitz 


\section{DEDICATION}

This dissertation is dedicated to

my husband, Joshua Caudill, for all his patience and help

and my papaw, John Stein,

who always encouraged me to use my imagination

and pursue knowledge. 


\section{ACKNOWLEDGEMENTS}

I would like to thank my dissertation advisor, Dr. Simona Bertacco, for all her help, thought-provoking suggestions, and tireless support. I would also like to thank my other committee members, Dr. Susan Griffin and Dr. Mary Rosner, without whose comments and suggestions this caliber of work would not have been possible. Thank you to Dr. Griffin for introducing me to Alexander Welsh's George Eliot and Blackmail, which inspired the framework for this project - the analysis of types of crime. I would like to thank the entire committee for their timely response to my exhaustive drafts.

I am extremely grateful to Dr. Caroline Reitz, my outside reader, for her unique perspective on the intersection of ethnicity, empire, and national identity in the detective genre and willingness to collaborate on this project. Her scholarship has provided a model for the serious critical analysis of popular culture attempted in this dissertation.

I want to thank Dr. Michael Johmann for introducing me to Arthur Conan Doyle's Sherlock Holmes stories. His class on Victorian Popular Culture was foundational in engendering in me a love of the late nineteenth century. Dr. Johmann has been an important influence on my academic interests and a tremendous mentor throughout my graduate career.

I offer my deepest thanks to all of my family who have been supportive of my continued education, patient with my long discussions of detectives and art, and forgiving of the missed family celebrations spent working on films, papers, and grading. 
Finally, I want to thank my husband, Joshua Caudill, who has never faltered in pushing me to pursue my ambitions and never give up. Without him I would not be where I am today; he is my rock. 


\section{ABSTRACT \\ CRIME AND CULTURE: \\ A THEMATIC READING OF SHERLOCK HOLMES AND HIS ADAPTATIONS \\ Britney Broyles}

November 22, 2016

This dissertation focuses on the adaptation of Arthur Conan Doyle's Sherlock Holmes character and stories into the television shows Sherlock and Elementary on air today. The project will consider three central questions: 1) Why is this Victorian detective hero still popular in the twenty-first century and what has remained constant and still resonates with modern audiences? 2) Both television shows transport Holmes in time by setting their narratives in the present day; therefore, what has been changed in this process of adaptation? 3) How do these changes represent shifts in our cultural thinking about important aspects of humanistic inquiry? The dissertation is organized around types of crime with each chapter devoted to a different crime that will bring to the fore specific themes central to the chapter. Chapter one is focused on the crime of murder and considers the intersection of reason and emotion. The detective character has been considered, throughout the history of the genre, as an exemplar of rational thinking. To what degree does Holmes make use of irrational methods and how does he understandseemingly without experiencing - human emotion that often motivates criminal behavior. Chapter two examines the crime of smuggling and the representation of the East (with a specific focus on China). Since smuggling is a crime that crosses borders, it highlights the 
relationship between countries or the relationship between national and international contexts. Chapter three considers the crimes of the powerful in order to focus on the relationship within society between those with power and money and those without such resources. More specifically, this chapter examines the representation of social class, the government, and corporations and the potential culpability (within the diegesis) of such powerful institutions. Finally, chapter four is centered on the crime of blackmail in order to examine the relationship between public and private identities and information. This chapter addresses how the television shows have updated the understanding of public and private in response to digital technologies and the proliferation of online media. Doyle uses print media throughout the stories while the television shows take advantage of the internet and broadcast media. 
TABLE OF CONTENTS

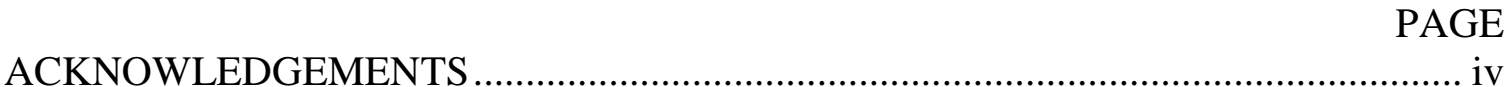

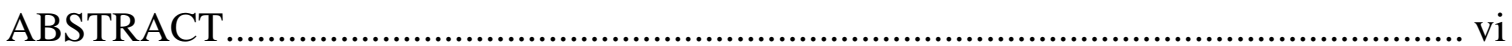

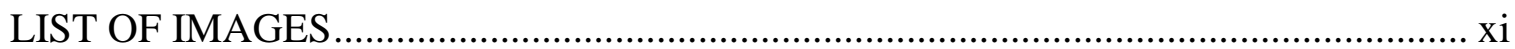

\section{INTRODUCTION}

1 Why Holmes

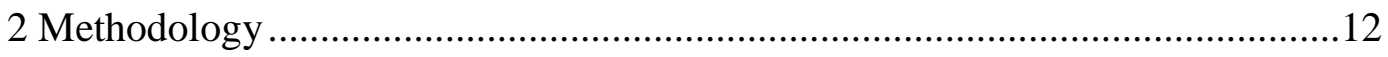

3 Rebranding Sherlock Holmes ..................................................................14

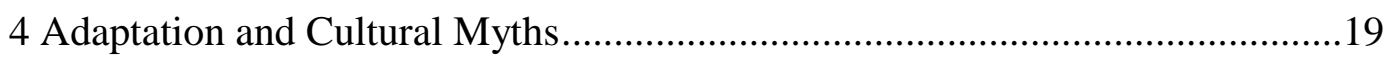

CHAPTER I—“THE SCARLET THREAD OF MURDER”: REASON, EMOTION, AND SHERLOCK HOLMES

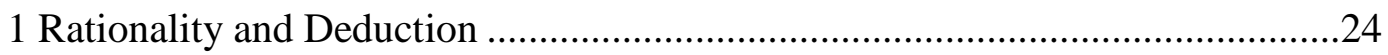

2 Sherlock Holmes as Automaton.............................................................26

2.1 Cognitive and Emotional Empathy ...............................................30

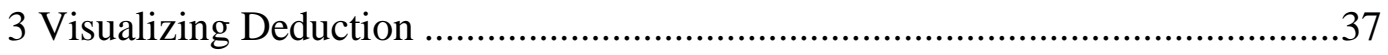

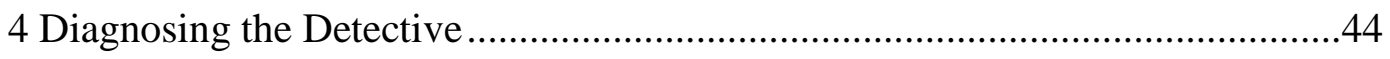

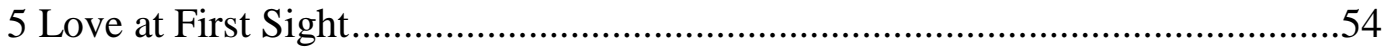

6 Irene Adler: The Woman, the Dominatrix, the Heroine ..................................59

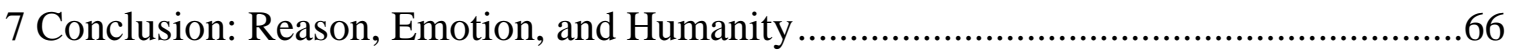

CHAPTER II-TEA AND OPIUM: SHERLOCK HOLMES, SMUGGLING, AND THE CHINESE

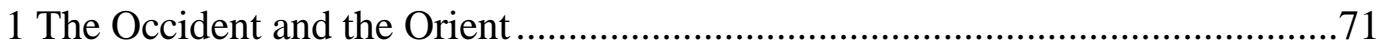


2 China and the West: Drugs, Disease, and Death ...........................................74

3 Representing China in Sherlock and Elementary.........................................86

3.1 Sherlock's Aesthetic of Opposition ...............................................88

3.2 Elementary's Articulations of Ethnicity: Joan and Jun.....................105

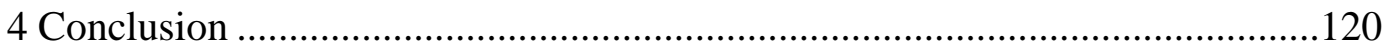

CHAPTER III - THE CRIMES OF THE POWERFUL: SOCIAL CLASS, THE STATE, AND CORPORATIONS

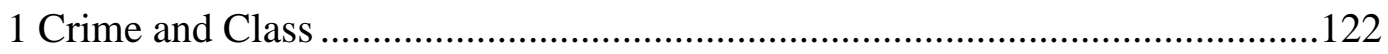

2 Mr. Sherlock Holmes, the Consulting Detective .......................................124

2.1 An Analysis of The Hound of the Baskervilles...............................130

3 Sherlock, Mycroft, and the War on Terror ..................................................138

4 Sherlock, Moorland, and Corporate America ...........................................147

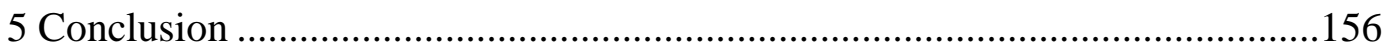

CHAPTER IV—SHERLOCK HOLMES AND METAFICTION: BLACKMAIL, JOURNALISM, AND DETECTION

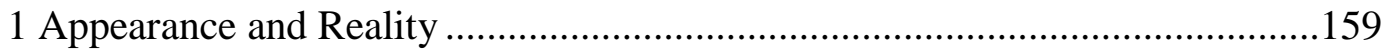

2 Holmes and Metafiction in the Nineteenth Century ...................................163

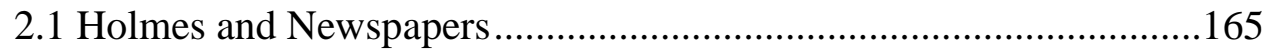

2.2 Holmes and Blackmail ............................................................172

2.3 Holmes and Milverton ...........................................................174

3 Sherlock and Metatelevision in the Digital Age ..........................................183

3.1 Magnussen and Ownership ...................................................189

3.2 Kleinfelter, Whistleblowing, and Hacktivism ..............................203 


\section{APPENDICES}

Appendix A: Title Abbreviations for Doyle Sherlock Holmes Stories ................236

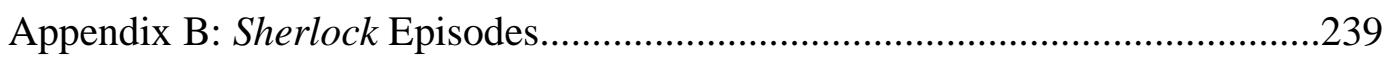

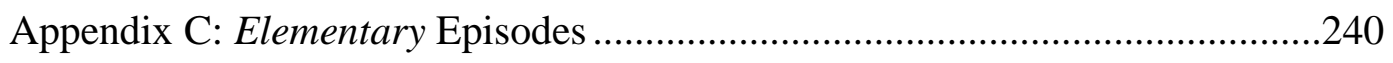

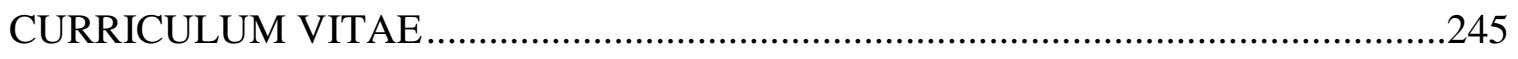




\section{LIST OF IMAGES}

IMAGE PAGE

\section{INTRODUCTION}

1. IMAGE 0-1: Still frames from Sherlock's title sequence ..................................15

2. IMAGE 0-2: Still frames from Elementary's Rube-Goldberg machine in the title

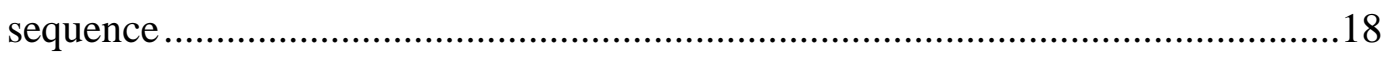

\section{CHAPTER I}

3. IMAGE 1-1: Sherlock searches the weather application (Sherlock 1:1) ...............38

4. IMAGE 1-2: Sherlock investigates Jennifer Wilson's coat (Sherlock 1:1) ..........41

5. IMAGE 1-3: Sherlock considers "rache" as a possible meaning (Sherlock 1:1)...42

6. IMAGE 1-4: Sherlock decides Rachel was the intended meaning (Sherlock 1:1)

7. IMAGE 1-5: Sherlock discovers a missing trace based on the symmetry of the

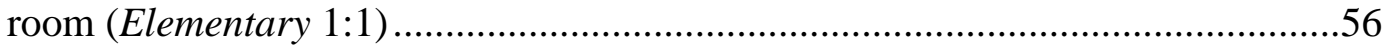

8. IMAGE 1-6: Sherlock demonstrates the distance of Eileen's attacker (Elementary 1:1)

9. IMAGE 1-7: Sherlock discusses the concept of love with Bella, the computer

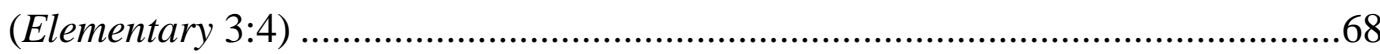

\section{CHAPTER II}

10. IMAGE 2-1: Soo Lin's teapot demonstration (Sherlock 1:2) 
11. IMAGE 2-2: Zhi-zhu on ribbons during the Golden Dragon Circus performance (Sherlock 1:2)......

12. IMAGE 2-3: Joan Watson goes jogging in NYC (Elementary 1:1)

13. IMAGE 2-4: General Shan in Peking Opera makeup at Yellow Dragon Circus performance (Sherlock 1:2)

14. IMAGE 2-5: Owner of Mahjong gambling house in NYC's Chinatown (Elementary 1:9)

15. IMAGE 2-6: Jun Annunzio, "wife of the murder victim (Elementary 1:9)

16. IMAGE 2-7: NYC's Chinatown (Elementary 1:9) 114

\section{CHAPTER III}

17. IMAGE 3-1: Directly before the audience sees this shot, John says to Mary, "There's an east wind coming." (Sherlock 3:3)

18. IMAGE 3-2: John asks of the mysterious caller, "How are you doing this?" (Sherlock 1:1)

19. IMAGE 3-3: Sherlock has just gained access to the classified files on the HOUND Project and the information on the computer screen he's looking at overlays his image. (Sherlock 2:2).

20. IMAGE 3-4: In between smacking his chewing gum Sherlock interrupts the introductions of the bank's board members: "Yup, you're all chief of something. What do you want?" (Elementary 1:4) 151

21. IMAGE 3-5: In response to questions about A. Peer's first exposé on Merrill Grand, Buckner responds, "Toproxefin was an embarrassing chapter... for me and for the whole company. But it was never willful fraud, not at the corporate level. 
Sometimes when there's that much money at stake, you develop a kind of selective deafness." (Elementary 2:18)

\section{CHAPTER IV}

22. IMAGE 4-1: Illustration by Howard K. Elcock from ILLU

23. IMAGE 4-2: “Charles Augustus Milverton. Illustration by Sidney Paget 175

24. IMAGE 4-3: Picture message from Sherlock to Joan to practice "flash analysis" (Elementary 2:3) 184

25. IMAGE 4-4: News anchor reporting on Moriarty's trial in (Sherlock 2:3)..... 186

26. IMAGE 4-5: Joan watching skateboard videos posted online (Elementary

27. IMAGE 4-6: Charles Augustus Magnussen (Sherlock 3:3)

28. IMAGE 4-7: Magnussen analyzes John Garvie for a weakness (Sherlock 3:3)

29. IMAGE 4-8: Newspaper headlines illustrating Sherlock's growing fame (Sherlock

30. IMAGE 4-9: Sherlock as seen by Mycroft (Sherlock 3:3) .200

31. IMAGE 4-10: Kleinfelter in the press (Elementary 2:3) .206

32. IMAGE 4-11: Everyone via chat as Tim Sherrington threatens Joan with violence (Elementary 2:24) .214

33. IMAGE 4-12: Sherlock watches Ezra Kleinfelter's arrest on the news (Elementary $2: 3)$ .219

34. IMAGE 4-13: Sherlock going over Zooss's GPS tracking information on its users (Elementary 3:18) .223 


\section{INTRODUCTION}

\section{WHY HOLMES?}

In the months leading up to the 2012 Olympics in London, Sherlock Holmes was awarded the Guinness Book World Record for most portrayed literary human ${ }^{1}$ character in film and television. When awarded, the detective had appeared on screen 254 times portrayed by over seventy-five different actors. The awarding of the record demonstrates how "his detective talents are as compelling today as they were 125 years ago" (Claire Burgess, Guinness World Record adjudicator). While the Sherlock Holmes character has been popular since Sir Arthur Conan Doyle originally wrote his stories, there has been a resurgence in Sherlock Holmes's appearances in recent years. After the Warner Brothers' blockbuster, starring Robert Downey Jr., in 2009, the US and UK have been busy releasing a new movie or television adaptation each year. ${ }^{2}$ By 2012 when the character was given the world record, the BBC's Sherlock was releasing its second season ${ }^{3}$ and CBS was debuting their new adaptation, Elementary. Sherlock Holmes has been removed from the historical past and placed in the twenty-first century in these two television versions.

\footnotetext{
${ }^{1}$ The most adapted literary character is Dracula.

2 Warner Brothers' Sherlock Holmes (2009); BBC's Sherlock (2010); Warner Brothers' Sherlock Holmes: A Game of Shadows (2011); CBS's Elementary (2012-); Sherlock, Series 2 (2012); Sherlock, Series 3 (2014); BBC's Mr. Holmes (2015); Warner Brothers' Sherlock Holmes 3 (in the making, release date unannounced).

${ }^{3}$ I will use the American television terminology. Series will refer to the entire television show and season will be used to refer to a set of episodes released during the same television year.
} 
Adapting Sherlock Holmes is certainly not a novel endeavor, but to set this icon of British identity, born at the height of the empire, in a postmodern, globalized, digital world is certainly a new chapter in adapting this detective. Many critics have argued that part of the important cultural work of detective narratives has been the construction and strengthening of conceptions of national identity. Citing Sherlock Holmes stories as an example, J. Hillis Miller argues that "We need the 'same' stories over and over [...] as one of the most powerful, perhaps the most powerful, of ways to assert the ideology of our culture (72)." Just as the cultural power of Shakespeare is often deployed in present day adaptations to shore up a sense of national identity (Hutcheon 151); so too can adaptation of Sherlock Holmes set in the present day give new life to imperialist ideologies in the name of patriotic fervor and national pride. Considering the range of American Sherlock adaptations, what is the connection between the Holmes stories and the American context? What, if any, national myths are being produced by transposing the detective to the United States? By transporting Holmes to the current epoch, outmoded ideologies may be superficially updated to be proved still relevant or, alternatively, the new adaptation (experienced, for many viewers, in contrast to the nineteenth-century stories) may question and talk back to this inheritance. It is important to investigate what parts of the Doyle stories are repeated and which parts are varied. This "repetition with variation" (Hutcheon 116), characteristic of both adaptations and remakes, demonstrates the "unfinished cultural business" (Braudy 331) with which the Holmes narratives are engaged. Elementary and Sherlock demand critical inquiry into their continuations, transpositions, and even inversions of the Holmes narratives that have participated in this crucially important social and cultural work. The focus of this project 
is not a point by point weighing of the textual fidelity of each televisual incarnation, but, rather, the careful examination of larger themes present in all three series which may elucidate the dialogue created with the originating texts, and essentially, the past since adaptation, as Hutcheon argues, may be viewed as an "ongoing dialogue with the past" (116).

Sir Arthur Conan Doyle's sixty narratives about the Great Detective have given birth to two radically different modern day Sherlocks. I will argue that the generation of these diametrically opposed progeny stems from the ambivalence of the character in Doyle's canon, his "remarkable level of tantalizing opacity" (Faye 5). The stories were written over the course of forty years and Doyle never intended for his detective to last that long; he wanted to write more "serious" literature. He famously killed Holmes in 1893 with his death at the Reichenbach Falls only to bring him back a decade later when he was offered a substantial amount of money to continue the detective's investigations. In light of Doyle's resistance to continuing the popular detective stories, his undervaluing of the narratives, and Watson's non-chronological publishing of the investigations, the stories resist an analysis which would focus on the development of the detective within his own lifetime. Sherlock Holmes evades complete understanding and frustrates this desire that is central to the enjoyment of detective fiction itself. As Lynette Porter writes in the most recent anthology published on the BBC's Sherlock "Readers and audiences, not to mention scholars and critics, continue to analyze who Sherlock Holmes is or has become and why and how his identity has been formed in a specific way" (Location 44). Holmes is the enigma which remains long after the dénouement. 
When a character reaches such mythic proportions, as Holmes has, one must ask what is being adapted: the popular conception of Holmes or Doyle's Holmes? The detective is so phenomenally popular and has generated the production of so many various incarnations that many audiences are familiar with the character without ever having read any of Doyle's short stories or novels. Additionally, certain stories within the canon have become extremely popular (such as, "The Adventure of the Speckled Band," "A Scandal in Bohemia," or The Hound of the Baskervilles) to the neglect of the others. By subtracting out the most popular and frequently adapted stories and creating an image of the character and his world based solely on a fraction of the whole, much of this ambivalence, the tensions, and the contradictions which exist when the stories are viewed as a set, are elided. The popular stories are popular for certain reasons: they reinforce the class, gender, race biases and position Holmes as a less ambivalent, and, I argue, less conventionally real character. Real people are not understood as acting in predictable and consistent ways over the course of their lives, mythic characters do.

This project began with my understanding that Doyle's Holmes stands as an exemplar of rationality and the idea that an analysis of the character would be a fruitful exercise in critiquing the failings of Enlightenment thought as well as of the British imperial project, ${ }^{4}$ which it supported. The first theme I wanted to elucidate from the original stories and assess in these televisual versions was reason. In recent years, critics have argued that Doyle's detective is not a purely rational being (as he famously claims) but rather employs several skills in his method that have traditionally been seen as

\footnotetext{
${ }^{4}$ Although Irish, Doyle was an avid supporter of the British imperial project. He was knighted in 1902 for his non-fiction pamphlet, The Boer War, and its impetus of renewing patriotic fervor for imperial expansion in Africa, which had waned in recent years.
} 
antithetical to rational thought, such as creative thinking and imagination (see Frank 2003; Konnikova 2013). Additionally, however, I wished to understand how a detective so focused on cold rationality was able to understand (without experiencing) the emotions which drive people to commit crime. The Cartesian dualism which has dominated Western understandings of the mind and body for centuries became an entry point for my investigation of Holmes and the focus of the first chapter.

The second central theme that I knew needed to be included was truth. The detective figure and the accompanying critical inquiries into his development have largely focused on epistemological concerns. The detective is the one charged with entering a community thrown into chaos by the unknown and recovering the truth of what has happened. A powerful impetus for critical examination for the genre has been the way detective narratives lay bare the project of reading itself, the establishment of ways of knowing. The criminal and detective have become metaphors for the relationship between author and reader. The criminal writes the crime that the detective must solve in a way similar to the reader's attempts to understand the author's text. The reader must reconstruct the line of thinking that the author has put forth and attempt to solve the crime before the dénouement just as the detective attempts to "read" the scene of the crime and apprehend the perpetrator. In addition, the successive periods of detective fiction have increasingly been defined by their relationship to truth. In the wake of the world wars, the British detective story remained faithful to the genre's dependence on a successful dénouement and the comforting reassurance accompanying such a narrative strategy. The largely conservative politics of the Golden Age detective writers depended on the establishment of a singular and unequivocal truth. In contradistinction, successive periods 
in the genre have complicated this pursuit. The American hard-boiled detective is characterized by a cynical attitude toward power and his control over the dissemination of "truth"; in these narratives the truth is often found beneath a façade of respectability. Post-colonial and feminist detective novels splinter the grand narrative of the white, rational, male detective and offer alternative ways of seeing the truths of human life. And postmodern detective narratives stymie efforts toward recovering the truth and turn inward to the problems of the detective's own selfhood: the constructed nature of identity and the complications inherent to the pursuit of truth itself. An investigation of truth and its relationship to structures of power in society, thus, became another major supporting pillar of the study I would undertake.

Birthed from this initial interest in reason and truth in the canon and the recent television shows, the project developed into a thematic analysis with each chapter focused on a specific and culturally significant theme. Initially I had intended to organize each chapter around the "methods of detection" both in the nineteenth century and today, taking up a line of thought brought to my attention in Sherlock Holmes and Transmedia Fandom. In their anthology, Stein and Busse claim "The new, millennial Sherlock still uses the standard processes of deduction made famous by Conan Doyle, but at the same time he unpacks contemporary crimes via digital tools" (Stein and Busse 11). The emphasis in this anthology is the updating in Sherlock of Holmes's methods for the digital world. As Moffat argues, "a modernized retelling would allow the viewer 'to see the original stories the way the original reader would have read them - as exciting, cutting edge, contemporary stories, as opposed to these relics they've become'" (Barnes 168). But the sheer scope of the material being analyzed made such an analysis 
impractical. Doyle's four novels and fifty-six short stories, Sherlock's twelve episodes, and Elementary's ninety-six episodes made for one hundred and sixty-eight installments to be considered!

Eventually I lit upon an alternative organizational framework which has provided a concrete, specific, and arguably better angle for reflection: each chapter would focus on a specific crime which would, in turn, offer a lens to examine the central themes highlighted above. As detective novel writer Nicolas Freeling has argued,

Murder, and any other crime, is not a part of entertainment, but an integral part of life. We are all murderers, we are all spies, we are all criminals, and to choose a crime as the mainspring of a book's action is only to find one of the simplest ways of focusing eyes on our life and our world. (qtd. in Symons 170)

Organizing this project around different types of crimes, which in fact mirrors the way detective stories themselves are constructed, has provided a richer framework for analysis than I ever imagined for it has laid bare what I take to be questions central of humanistic study. Chapter one, on reason and emotion, looks at the most violent (and, in the television shows, most prevalent) crime: murder. While a central aspect of the Holmes character has been his status as outsider, Sherlock and Elementary represent the detective as more incapable of normative social interactions than Doyle's stories. Sherlock provides a psychological explanation for non-normative facets of his personality: the detective has Asperger's Syndrome. Elementary, on the other hand, chooses to read new theories of neuroscience, which argue the impossibility of the purely rational human thought, onto the detective character. In addition, throughout season one, Sherlock's refusal to express emotion or create meaningful relationships stems from the trauma and grief he experienced after the death of his ex-lover, Irene Adler. This chapter uses terms 
of social psychology (cognitive and emotional empathy) to assess the three different versions of the character and the role emotion plays in crime detection.

Chapter two, on Western conceptions of "the Orient," is focused on smuggling and illegal immigration (crimes that cross borders). Although China shows up briefly and marginally in the original stories by Doyle, the East functions as an important symbol of danger, mystery, and mysticism. I examine these brief allusions to China and their relationship to the stories as a whole. And although Doyle's stories do not focus on China extensively, the new television shows add ethnically Chinese characters. Sherlock's representation of criminality as a foreign intrusion is most clearly enunciated in its portrayal of Chinese characters in "The Blind Banker." This is further exacerbated by the adaptation into a visual medium and the series falls into drawing from a stock of Orientalizing imagery. In contrast, Elementary casts a Chinese-American actress (Lucy Liu) as Watson with whom the audience usually identifies and directly confronts this problematic inheritance of orientalism. Both television shows are more focused on China and Chinese characters than the original canon but tackle this contact in dramatically different ways.

Chapter three employs a Marxist framework to consider the relationship between crime and power. I apply Frank Pearce's concept "crimes of the powerful" to investigate the opposition between those with power in capitalist societies and everyone else (the haves and the have nots, if you will). In the nineteenth century context this means an analysis of social class. In the present day it means an investigation of the power in terms of corporations and governments. While the Holmes archetype is often co-opted by modern television programs to serve the needs of the government and establishment (for 
instance, Spencer Reid in Criminal Minds), there is a sense in which the original character defied governmental and legal structures of power. The implications of his critical position as a "consulting detective" is crucial here. And while many scholars have been quick to argue that Holmes's occupation choice is a reflection of his desire to work for and in the interest of the wealthy, I argue this characterization is complicated when we expand our view to all the stories rather than the most commonly-read ones. In Sherlock, the detective works even more closely with the British government than in the original stories and Mycroft's extended role is an indication of such developments since he is representative of the government. In contradistinction, Elementary highlights the detective's anti-establishmentarianism, the seeds of which have always been a part of the Sherlock Holmes character. Once again Elementary provides a psychological rationale for this central feature of his persona. Sherlock's strong dislike of corporate America and the perception that capitalism's prioritization of profit is detrimental to other aspects of society stems from his trying relationship with his father (Moorland Holmes), an international consultant to corporations and governments alike.

Chapter four, on truth and untruths, is organized around the crime of blackmail. Chapter one and two are related in that chapter one's focus on rational, Enlightenment thinking and systems of ordering helped foster theories of racial difference and the related field of early criminology which is the central issue in chapter two. Additionally, the weighing of Holmes's potential class biases (taken up in chapter three) are predicated on his reinforcement of the status quo and unfair treatment of lower class criminals while blackmail (the focus of chapter four) is emblematic of the attempts of the underprivileged to exert control over those in power within society. Blackmail becomes most dangerous 
to those who exert an influence in the community and have a public presence that may be disgraced.

Having explored reason, ethnic difference, and structures of power, my project now turns to an interrogation of our methods of knowing. How and to what degree is truth constructed and complicated in the Sherlock Holmes stories? This chapter examines the division between public and private by looking at the crime of blackmail. In addition, the concept of metafiction and the role of the media (often as metanarratives embedded in the main narrative) are considered. Our interactions with the media and the democratization of publishing platforms made available by the internet ensure the proliferation of narratives, often about the same topic and often conflicting. The media, thus, represents a continued challenge to weigh the truthfulness of a narrative. A central narrative feature of the Doyle stories is their weaving together of various narratives. Watson may begin the story but often the client enters and tells his or her story, eyewitnesses relate their relevant accounts, newspaper articles are shared and all exist as metanarratives within the main adventure. Like chapter two, this chapter is grounded in specific historical circumstances. First, I examine Holmes's vehement hatred of the blackmail king, Charles Augustus Milverton. What makes him worse than other villainous characters in the canon? How does blackmail earn Holmes's greatest hatred? Next I turn to an investigation of the fusion of this character and the real life media mogul, Rupert Murdoch, into Sherlock's Charles Magnussen. In considering Elementary, I stray from an examination of the most directly adapted episode ("Dead Man's Switch," 1:20) to look instead at "We are Everyone" (CITE) which, I argue, is more central to the present day examination of public and private realms. 
During the course of this project I have encountered several other challenges, the most important of which has been the large size of the Holmes oeuvre as well as the fact that Arthur Conan Doyle's stories have generated extensive critical scholarship over the decades. I have attempted to bring in the most relevant materials in terms of secondary writings but, rather than an exhaustive review of the critical literature available, my analysis has focused on building on touchstones fundamental to the themes and crimes analyzed. Another challenge has been that the television shows are still in production. Elementary's season five begins this October and Sherlock's season four is scheduled to air in spring of 2017. In this regard as well, this project represents a first chapter in the consideration of the narrative arcs fostered in both series which are ongoing. It is impossible to tell what new developments will surface in both in regards to the thematic concerns here elucidated but I have attempted to develop a framework for understanding the underpinning structures for the cultural work undertaken in each.

A final challenge to this analysis has been the transcoding of the stories from a textual to a televisual medium. Various media rely on alternative strategies for storytelling, and the same story will by necessity be told differently in the transposition to another form. As Linda Hutcheon explains, adaptation often entails "a transcoding into a different set of conventions" (33). Each medium has its own "language" with which it constructs meaning and this transposition changes the story being told in important ways. For instance, one of the aspects brought out in this transition from telling to showing (from the written stories to the visual medium of television) is the changed point of view. In the original stories, the narration was filtered through Watson's perspective; Holmes had "a chronicler to insulate him from our direct scrutiny" (Brownson 27). Instead, 
Sherlock and Elementary provide the viewer with direct access to observing Sherlock, his eccentricities as well as his magnificent feats. As a result, these adaptations nurture a more intimate perspective on the detective, a trend signaled most obviously by the audience's and other character's move from referring to him as "Holmes" to "Sherlock." This is in line with the critical understanding of the television medium itself. As many critics have argued, the reception conditions of television viewing creates a seemingly more intimate experience than film since it takes place within our homes on a smaller screen, is dominated by three-quarter frontal shots, and is viewed in between and during the daily activities of our lives. In this dissertation I continue this distinction and use "Holmes" to refer to the character in the nineteenth century stories by Doyle and "Sherlock" to refer to the televisual versions today.

\section{METHODOLOGY}

I have already mentioned several important critical theories that inform the methodology employed in this dissertation. The figure of the detective, narratology (the ordering of the parts and importance of the dénouement), a close reading of the transcoding process as well as of the construction of the fictional story, genre studies (the development of the detective story since Doyle), and thematic analysis (as an organizing structure) are all important to the arguments put forth in successive chapters. At times, I have also drawn on gender analysis. In chapter one, for instance, I look at the interpretation of Irene Adler (who has been variously adapted as the closest Holmes comes to a romantic relationship). In chapter two with the focus on representations of Chinese characters (which are mostly women) postcolonial considerations undergird my attention to the exoticization of East Asian women in Western media. And in chapter 
four, I briefly look at the culturally constructed vulnerability and decreased mobility of women in the nineteenth century and its inversion in the blackmailed figure of Lady Smallwood in Sherlock.

In addition, I focus on characterization (both the detective and importantly, the depiction of criminality) by employing Dennis Porter's analysis of the "character sketch" in detective fiction. In discussing the change of medium from telling to showing with regard to often adapted Victorian novella, The Strange Case of Jekyll and Hyde, Hutcheon explains "Because of mode change, these various versions had to show—and thus to 'figure'- that evil physically, and the means they have chosen to do so are revealing of the historical and political movements of their production" (28). Chapter two and three focus heavily on visual and textual representations of criminality. As Dennis Porter has argued, in detective fiction, the character sketch is a visual and moral representation that the reader or viewer depends on to form their opinions of the characters and the world they inhabit which are being presented. Related to the representation of criminality, I also bring in theories of "the father of criminology," Cesare Lombroso, which were contemporary with Doyle's writing and propagated the understanding, which dominated the field for decades, that evil within may be signaled by outward appearance. Contextual analysis, including but not limited to issues of concurrent scientific theories of criminals and detection, are an important part of my methodology.

Every chapter attempts to provide relevant historical context for the respective series but chapter two and four draw more heavily on concurrent events that inform or influence the reception of the narratives. If, as Hutcheon argues, "context conditions 
meaning" (145), how have the various historical contexts of the three series renegotiated the meaning of the stories being told? In chapter two, I examine the imperial and economic context of the Opium Wars. Additionally, I bring issues central to the representation of Chinese ethnicity in the twenty-first century such as the inheritance of Orientalist imagery (especially important in the change of medium to visual representation) and the phenomenon of Western adoption from China. In chapter four, I consider the proliferation of newspapers in the nineteenth century and their increasingly important role as disseminators of truth as well as the growing concern about blackmail and its late addition to the legal code. In the twenty-first century context I inspect the way Sherlock draws on the controversial media magnate Rupert Murdoch and Elementary's appropriation of Edward Snowden's story and whistleblowing.

\section{REBRANDING SHERLOCK HOLMES}

In order to highlight some of the most crucial differences between Sherlock and Elementary I want to turn briefly to the opening sequence provided at the beginning of each episode (starting after the pilots). Title sequences have been an important part of the branding of a television show. In Theodor Adorno's article "How to Look at Television," he defines the 'halo effect' as the set of expectations a viewer brings to watching a television show "before a single word is spoken" (227). I would like to look at the opening credits as a way that the show sets up a certain aesthetic that informs and is put in dialogue with what is to follow. In recent decades, the title sequence has fallen out of favor in order to devote more time to the episode itself. However, a few television shows have decided to resurrect this element once so central to the evocation of the show's aesthetic. Sherlock and Elementary both make use of the title sequence in order to 
demonstrate the detective's perspective, although they use very different visual stratagems. By examining the title sequences of both shows, the substantial differences in the adaptation of the Sherlock Holmes character and the larger themes of both series may be better understood. ${ }^{5}$

The title sequences of both television shows were created with the objective of offering the audience a glimpse into Sherlock's successful method of detection but the visual strategies each employ could not be more different. Sherlock's opening begins with aerial establishing shots of the city of London and ends with an extreme close-up of

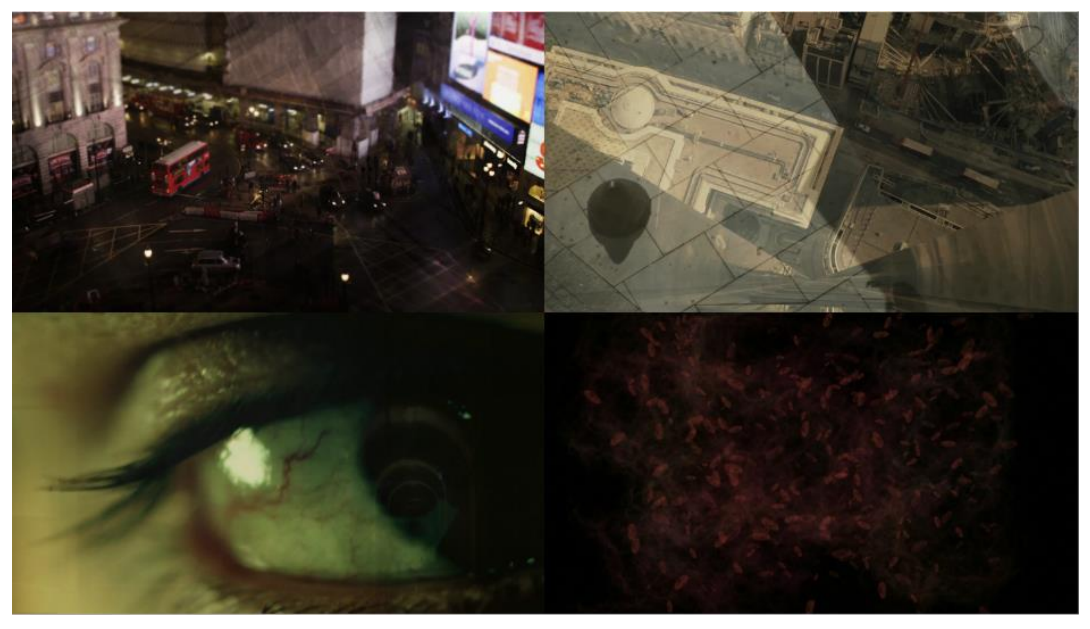

a drop of blood under a microscope (IMAGE 01). The emphasis is on the importance of sight and vision to the detective's method. IMAGE 0-1: Still frames from Sherlock's title sequence.

The sequence even contains images of two "eyes": the London Eye and a human eye. Peter Anderson Studio, the company commissioned to create Sherlock's opening, explains on their website, "The title sequence aims to highlight Sherlock's unique way of seeing the world, allowing the viewer a brief moment inside his head where extreme detail is everything." Anderson explained that the "tilt shift" technique used for the aerial shots made it seem like "He's looking at people as little insects." The sequence begins with the macrocosmic view and

\footnotetext{
${ }^{5}$ I do not have time in this brief introduction to consider the use of music but instead focus solely on the visual elements put forth in each.
} 
ends with the microscopic world of atoms. The time-lapse photography of the aerial shots demonstrates the sheer quantity of people moving through London's hectic streets, each with their own lives and networks of connections and possibilities. According to Siegfried Kracauer, film's preoccupation with the urban street may be understood in terms of its inherent affinities with the medium: the fortuitous, the indeterminate, and what he terms the "flow of life." Elaborating on the last of the three, he writes that "Each [individual on the street] has a story, yet the story is not given. Instead, an incessant flow of possibilities and near-intangible meanings appears" (72). It is the evocation of a grand network of interrelated lives, even if the interrelatedness is spatial alone. The aerial shot in the opening, therefore, serves to emphasize the sheer magnitude of all that Sherlock sees and understands. Many of the shots are taken from rooftops, and, at the end of season two, Sherlock jumps from a rooftop (rather than a waterfall) in his struggle against Moriarty. If it wasn't clear to the audience before "The Reichenbach Fall," it is after: Sherlock occupies the position of the camera in the opening sequence. The image of the blood droplet at the conclusion of the opening mimics the movement from the beginning. The people moving through the streets on their way to work, home, and play are replaced by the various cells moving at a frenetic pace within the blood sample. The synchronicity between the movement in the two images signals the detective's continuity of vision and purpose. And here, the viewer is placed in the position of the detective: we see with his eyes and we see what he sees. This sequence lays bare an epistemological and social phenomenon central to the Western perspective: the emphasis on seeing as a way of knowing. As Itaru Hirano (curator of the Museum of Modern Art in Saitama, Japan) has claimed 
Originally, the sense of sight was part of an indivisible whole and thus not easily separated from the other senses. But with the development of the visual media, this wholeness was lost and the visual sense became separated and refined as a superior tool for understanding the world around us [...] Through visual media, the idea that 'seeing' is the same as 'knowing' has become widespread, reflecting the special status of the visual sense. ("The Privileged Visual Sense")

Through vision as a way of knowing, the detective has the ability to affect the outcome of human lives on a grand scale. The opening sets up Sherlock as a Panopticon figure, an "unseen seer," with the responsibility of maintaining order and whose power derives specifically from his preternatural sight, here, emphasized in the primarily visual medium of television.

While Sherlock's opening provides the audience with a simulation of the detective's way of seeing the world, Elementary's opening is focused on presenting his unique way of thinking. As Simon Clowes, the creative director at Prologue responsible for the concept design, explains, he "wanted to communicate how Sherlock Holmes' mind works in the non-traditional sense of detective work." Arriving late to the project, Clowes was aware the client had suggested an opening sequence which focused on the changed location of the adaptation, New York City. He decided to take a different approach and chose a Rube-Goldberg machine ${ }^{7}$ to visually symbolize Sherlock's mental processes: a chain of cause and effect leading up to the crime which the detective uncovers each episode. Logistically speaking, an establishing shot demonstrating how the parts relate to the whole (like the effect of Sherlock's extreme close-ups and aerial views) was not possible in Elementary's opening. Prologue commissioned five separate rolling

\footnotetext{
${ }^{6}$ Although in this medium, Sherlock is seen by the television audience but retains his elusiveness to the other characters as in the Doyle stories, such as The Hound of the Baskervilles.

${ }^{7}$ An over-engineered machine designed to complete a simple task.
} 
ball machines to be

featured in the title

sequence in addition to

the mechanisms

featuring murder

weapons. In short, the

apparatuses were

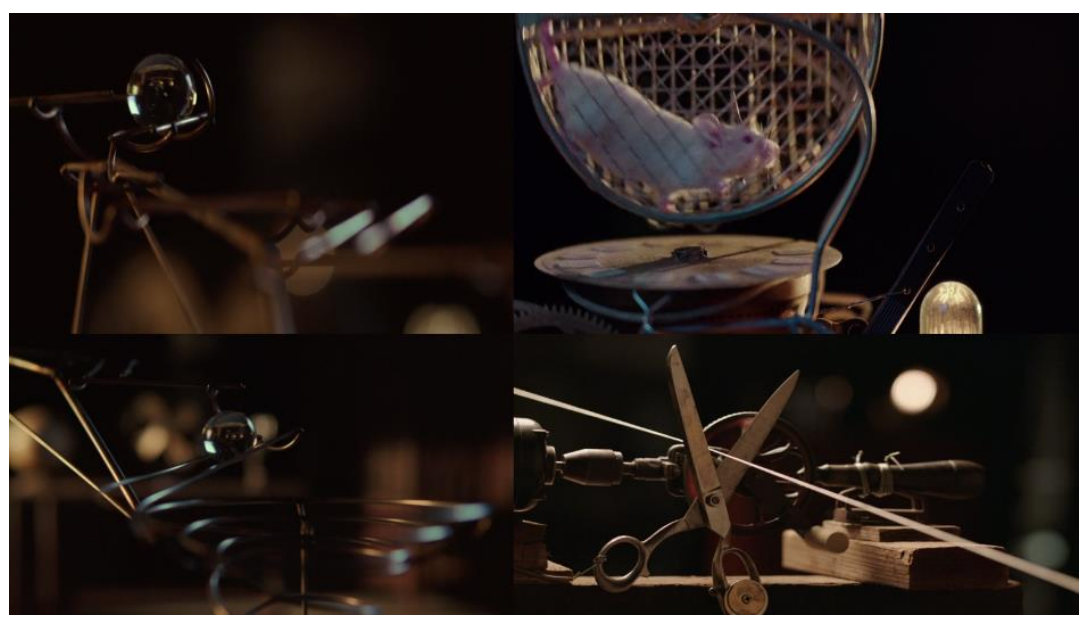

separate pieces edited

IMAGE 0-2: Still frames from Elementary's Rube-Goldberg machine in the title sequence.

together to appear as one continuous contraption (IMAGE 0-2). The effect of the series of close-ups without a wide shot of how they all fit together has very different ideological implications for the halo. Understanding this sequence in the context of four seasons of the show and almost 100 episodes, the halo effect talks back to the inheritance of Holmes as the rational genius who reinstates order by the dénouement of the story or episode. This dialogue takes place in several ways. First, the sheer number of crimes, criminals, and clues over the course of 100 episodes makes understanding the "whole," and each episode's relationship to that whole, challenging. Second, Sherlock's totalizing vision and superior intellect are balanced in this series by his attempts to collaborate with others. Elementary's Sherlock admits his own faults and shortcomings while learning from these recognitions. Furthermore, Joan Watson moves from sober companion to protégé ${ }^{8}$ to partner through the series. Finally, the show makes use of partially unsuccessful dénouements in order to establish that this version of the detective simply takes each case as it comes to him and tries to make what little difference he can. This idea is embedded

\footnotetext{
${ }^{8}$ In season three, Sherlock returns from London with another protégé, Kitty Winter.
} 
throughout the series but it is clearly enunciated in this exchange from season four when Joan confronts Sherlock about threatening their previous disgruntled neighbor, Mr. Garby:

SHERLOCK: May I point out that by the time Mr. Garby vacated his premises, you had been living here for almost two years.

JOAN: What, you're trying to blame this on me?

SHERLOCK: I'm saying there's plenty of blame to go around.

JOAN: You are the one who makes all the noise.

SHERLOCK: And you're the one who never stops me. Why? Because you know that the work I do is important. It's for-

JOAN: Okay, if you say it's for the greater good, I am gonna punch you. (Elementary 4:13)

Joan criticizes Sherlock for trying to think in terms of the grand scale or the superior morality of considering his work for the "greater good." The scale is small and episodic rather than vast and totalizing. Joan and Sherlock do the best they can with what they have and in each case that comes their way. There is no sense of complete closure or the grand scale as in Sherlock which functions more as a unified whole.

\section{ADAPTATION AND CULTURAL MYTHS}

Upon completion of this study, I have come to the conclusion that the adaptation of Sherlock Holmes and the cultural ideologies which underpin the narratives are drastically different in Sherlock and Elementary but both find precedence in Doyle's original stories because of the underlying ambivalences in the long-running series. Julian Symons argues there are essentially two traditions in representing crime "The first is conservative, supporting authority, making the implicit assertion that agents are fighting to protect something valuable in society. The second is radical, critical of authority, claiming that agents perpetuate, and even create, false barriers between 'Us' and 'Them'" (225). Sherlock is exemplary of the former and Elementary, the latter; however, both 
share the same textual source: Arthur Conan Doyle's sixty Sherlock Holmes narratives. I argue the seeds for both traditions may be found in Doyle's Sherlock Holmes stories and this is a main reason for the continued adaptation of these narratives.

Sherlock's updating for the twenty-first century is a superficial modernization. His look and technology have been changed but many of the dangerous imperialist ideologies are still being perpetuated. His status as an icon of British national identity and the circumstances of production (the series is produced mainly by the BBC) partially help to explain the attitude of reverence and tribute to the original stories. The show's creators (Mark Gatiss and Steven Moffat) are admittedly fanboys of Doyle's stories as well as the other famous touchstone filmic adaptations. Sherlock is a continuation of the British detective story and its conservative political stance to reinforce a sense of nationality in a world changed by globalization. The disappearance of national borders under the growing force of globalization often engenders a redrawing of these borders and a shoring up of the national identity constructed by an iconic figure like Sherlock Holmes. Sherlock is visually stunning and compositionally speaking, more unified than Elementary. With only three episodes per season (versus Elementary's twenty-four), the relationship between each episode and the overall series, in Sherlock, is more easily understood. These circumstances related to its mode of reception mean that the music, visuals, and plot are all more united in their pursuit of a totalizing vision, a unified whole. But this cinematographic unity is ultimately detrimental to the larger ideologies it presents. With fewer episodes, there are fewer representations of criminality and the totality of life and driving motivations is simplified in the process. Dangerous trends emerge from this 
simplification, which comes from fewer episodes, most notably the trend toward representing criminals as foreign and distinctly Other.

In contrast, Elementary represents a more fundamental reassessment of the Holmes stories. This show is most interesting for the way it talks back to the originating source texts. As Hutcheon writes, "the urge to consume and erase the memory of the adapted text or to call it into question is as likely as the desire to pay tribute by copying" (7). In this case, I argue Elementary is less calling into question Doyle's original detective stories than the inherited myth of Sherlock Holmes that has been perpetuated by his history of adaptation. Rather than a continuation, Elementary's updating of the Holmes stories is an explosion outward. The series is not just an adaptation of Sherlock Holmes and an updating of his methods of detection, it is an integration of the successive developments of the genre. It incorporates the cynicism toward capitalism and the status quo found in the American hard-boiled. The post-colonial detective story's reflection on the inheritance of imperialism and theories of racial difference which supported such conquests are contained within its episodes. The postmodern introspection is incorporated and can be seen prominently in Johnny Lee Miller's character's participation of the Narcotics Anonymous. It's true that Elementary is less visually stunning than Sherlock refraining from the dramatic recoloring of the latter (which tends to idealize the world depicted) and instead choosing the conventional and drab coloring of the police procedural (the CBS staple ${ }^{9}$ ). But the vast number of episodes and the ethnically diverse cast have allowed for a more inclusive and complicated depiction of criminality and morality. Elementary problematizes the easy categorizations which Sherlock seems to

\footnotetext{
${ }^{9}$ CBS's tremendously popular CSI franchise is now enormous, including five different television shows (CSI: Crime Scene Investigation, CSI: Miami, CSI: NY, CSI: Cyber, and NCIS).
} 
offer and talks back to the inherited tradition of Sherlock Holmes as the superior white, male genius. Riz Ahmed, British actor and star of the recent HBO crime drama The Night of (which problematizes institutional racism in the American justice system), has said

America uses its stories to export a myth of itself, just like the UK. The reality of Britain is vibrant multiculturalism, but the myth we export is an all-white world of lords and ladies. Conversely, American society is pretty segregated, but the myth it exports is of a racial melting-pot, everyone solving crimes and fighting aliens side by side.

The fine line which Elementary must toe is its participation in a different kind of myth, the myth of America as a melting pot in which skin color, gender, religion, etc. have become invisible. In a time and country divisively torn by these differences, the danger is to provide reassurance that these problems of privilege, inequality, and justice have been solved.

For the longest time I believed the popularity of Sherlock Holmes was tied to his Victorian trappings: his deerstalker, his meerschaum, his carriage rides through foggy gas lit streets. I thought that Holmes was popular in the same way that Dracula, Jekyll and Hyde, and any number of other numerously adapted characters from the Victorian Era were popular. My understanding was that the obsession was with the setting he occupied (that time and place) as much as the character. And while that's a part of the interest, it's not the whole story as these updated Holmes adaptations demonstrate.

When Holmes steps into our present day world and becomes a hero in the here and now, we have to ask ourselves why? Why now? What is the appeal of transporting him to our time? Working on this project has caused me to re-evaluate the enduring popularity of this character and Doyle's original stories as well. It is of crucial importance when a character that employs Enlightenment thinking and imperialist 
methods is brought back to life after the devastation of such tactics have wrought their misery in two world wars. The great detective was at the cutting edge of science in his day and with so many decades of research on mental illness, ethnicity, economic disparity, and the technological developments which have fundamentally altered our understanding of identity, we have to ask ourselves: have these intervening developments been incorporated into his method? Or has Holmes fallen back on the rhetoric of crime and strategies of detection from Victorian England? 


\section{CHAPTER I \\ “THE SCARLET THREAD OF MURDER": REASON, EMOTION, AND SHERLOCK HOLMES}

\section{RATIONALITY AND DETECTION}

There is a strong tendency to define Sherlock Holmes as "a deerstalker, a magnifying glass and a capacity for reasoning, not a human being” (Symons 135).

Throughout the detective's sixty adventures, Holmes continually espouses his view that his work is an objective science and that emotional attachments would hinder his purely rational method. In The Sign of Four, after Watson calls him an "automaton-a calculating machine," Holmes responds "The emotional qualities are antagonistic to clear reasoning” (235). But how can a purely rational man correctly read suspects, victims, and criminals and weigh their often emotional motivations for crime? This chapter explores two central questions. First, can Sherlock Holmes understand emotion without experiencing it? Second, what role does emotion play in murder and its detection by Sherlock Holmes? I examine these same two questions in the original Arthur Conan Doyle's stories, Benedict Cumberbatch's portrayal in Sherlock, and John Lee Miller's depiction in Elementary. This chapter's focus is murder, the most prevalent crime in Doyle's original stories, occurring in twenty-seven of the sixty stories (O’Brien xix). These murders are methodical killings rather than crimes of passion, which means they require careful rational planning, but are often motivated by strong underlying emotions. 
Therefore, they provide an excellent means to examine this crucial nexus of reason and emotion. I focus primarily on the first installment of each incarnation (A Study in Scarlet, "A Study in Pink," and Elementary's "Pilot") but also bring in important scenes and passages from throughout each series. I argue that in Doyle's original stories, a theory of human nature reliant on Cartesian dualism is represented in which characters act in either rational or irrational ways while Sherlock Holmes restrains his emotions. In Sherlock, the deduction is visualized through the use of onscreen text and the idea that Holmes may have a personality disorder or ASD (Autism Spectrum Disorder) ${ }^{10}$ is represented as an explanation for his unacceptable social behavior and heightened reasoning. Finally, in Elementary, reason and emotion are not represented as antithetical: the source of Holmes's renunciation of emotional attachment stems mainly from a past trauma. In both Sherlock and Elementary, there is a development in the audience's understanding of Holmes's emotional side. In the first season of both television shows, Holmes says he is purely rational but this initial declaration is later proven wrong through his own words and actions. In order to examine the dichotomy between Holmes's cold, rational personality and his astute understanding of the feelings of others and, hence, motives, I draw on two terms from social psychology: cognitive empathy and emotional empathy (Hodges and Myers 296). Cognitive empathy is the ability to correctly read and understand the emotions of others while emotional empathy is the ability to feel and respond to another's emotional state.

\footnotetext{
${ }^{10}$ In the DSM (Diagnostic and Statistical Manual of Mental Illnesses), Asperger's Syndrome is currently categorized as a disorder along the Autism Spectrum. Elementary directly confronts this problematic categorization when Sherlock briefly dates Fiona Helbron. In "A View with a Room" (4:12), Fiona explains "They say autism exists on a spectrum but it's really just a collection of different disorders." She then tells Sherlock she prefers the term "neuro-typical."
} 


\section{SHERLOCK HOLMES AS AUTOMATON}

Numerous books have been dedicated to explaining Sherlock Holmes's method, ranging from academic to popular culture to self-help. ${ }^{11}$ Holmes identifies his method as a science, "The Science of Deduction and Analysis." Both chapter two of A Study in Scarlet and chapter one of The Sign of Four bear the title "The Science of Deduction" underscoring this point. In the former, before Watson or the reader ever meet Holmes, he is first described by Stamford as "too scientific" and "cold-blooded" (19). From the outset, then, Holmes's method is characterized as a rational and objective one. When, in the second novel, Holmes takes issue with what he sees as Watson's romanticized publication of their first case, he further clarifies "Detection is, or ought to be, an exact science, and should be treated in the same cold and unemotional manner" (SIGN 217). This echoes Watson's own words in the first novel: “'you have brought detection as near an exact science as it ever will be brought in this world"' (STUD 69). In The Scientific Sherlock Holmes: Cracking the Case with Science and Forensics, James F. O'Brien enumerates the range of sciences employed by the detective (including forensic science, chemistry, anatomy, botany, physics, geology, and meteorology) throughout Doyle's sixty stories and explains the waning popularity of the later stories as resulting from fewer references to scientific pursuits.

\footnotetext{
${ }^{11}$ Several titles published in 2015 illustrate this continued interest in the great detective's method: Ron White's Mind Palace: How to Memorize and Surmise Like Sherlock Holmes (2015), Hannah Rogers's A Guide to Deduction: The Ultimate Handbook for Any Aspiring Sherlock Holmes or Doctor Watson (2015), Stefan Cain's Becoming Sherlock: The Power of Observation \& Deduction (2015), Kelvin I. Jones's The Criminological Sherlock Holmes (2015), John Radford's The Intelligence of Sherlock Holmes and Other Three Pipe Problems: Psychological Studies of the Great Detective and His Companion Dr. Watson (2015).
} 
Part of the popularity of Doyle's stories, then, lies in the author's use of cutting edge technologies put to practical ends. During the nineteenth century, the court system underwent an epistemological shift from reliance on eyewitness and character testimonies to material evidence verified by scientific means. In Detective Fiction and the Rise of Forensic Science, Ronald R. Thomas examines the way early detective stories, Doyle's Sherlock Holmes tales included, employed newly developed technologies, such as photography and fingerprinting, in their investigations to establish identity and the "truth" of what has happened in the past. Holmes explains his reliance on physical evidence in reading people's occupations and habits, “'By a man's finger nails, by his coat-sleeve, by his boot, by his trouser knees, by the callosities of his forefinger and thumb, by his expression, by his shirt cuffs - by each of these things a man's calling is plainly revealed"” (STUD 40-41).

In The Adventures of Sherlock Holmes: Detecting Social Order, Rosemary Jann provides an extensive survey of this dependence on physical signs in Holmes's deductive process. In the field of criminology today, this method is called Behavioral Evidence Analysis (BEA). It is "an idio-deductive method of crime scene analysis and criminal profiling that requires the examination and interpretation of individual case-related physical evidence, victimology, and crime scene characteristics" (Turvey 134). Idiographic profiling is a method which focuses solely on the evidence found in a single case and is opposed to the inductive method of nomothetic profiling, which seeks to make generalized rules from specific cases. Holmes most often relies on the idiographic 
but sometimes employs nomothetic profiling as well. Behavioral Evidence Analysis is Joseph Bell's ${ }^{12}$ method for medical diagnosis applied to the world of detection.

But Sherlock Holmes's definition of his method is not a complete picture. For instance, his use of imagination ${ }^{13}$ opens up avenues to consider the irrational. Jann writes, "If we contrast Holmes with the police, we can see that Doyle permits a wider scope for intuition and imagination in the private detective's reasoning" (47). Holmes allows for a broader range of possibilities by including the improbable in addition to the statistically probable and even remarks that he relies on a touch of intuition, "I have a kind of intuition that way" (STUD 42). In Detective Fiction and the Nature of Evidence, Lawrence Frank argues that nineteenth-century narratives of detection employed the same sort of backward (or speculative) reasoning as many of the newly developed sciences (such as cosmology, paleontology, geology, and evolutionary biology). ${ }^{14}$ These new sciences required the researcher to reason backward along the causal chain from material evidence in the present to the precipitating causes in the past: "Like the geologist or the paleontologist, the detective explains a fact or an event by placing it within a chronological series, he then imaginatively transforms it into a chain of natural causes and effects, leading backward in time to some posited originating moment" (157). Holmes actually uses the "chain" 15 as a metaphor for his work, in his article "The Book of Life" he writes, "So all life is a great chain, the nature of which is known whenever we

\footnotetext{
${ }^{12}$ Joseph Bell was a mentor of Conan Doyle at University of Edinburgh, who he later credited as the inspiration for Holmes's method of rapid-fire deductions from a stranger's physical appearance.

${ }^{13}$ In The Hound of the Baskervilles Holmes explains how he uses imaginative thought "Say, rather, into the region where we balance probabilities and choose the most likely. It is the scientific use of the imagination, but we have always some material basis on which to start our speculations" [emphasis added] (436).

${ }^{14}$ Many of these are scientific fields mentioned earlier which are discussed in O'Brien's study of science in Doyle's stories.

${ }^{15}$ Chapter nine of The Sign of Four is entitled "A Break in the Chain."
} 
are shown a single link of it" (STUD 40). Holmes reiterates this metaphor at the conclusion of the case. He says "'You see, the whole thing is a chain of logical sequences without a break or flaw"' [emphasis added] (217) and then he describes how each link of his deductions connected to form this chain. Imagination is necessary in order to generate numerous narratives with which to explain the traces left behind in the present. Thus, Frank writes, "Sherlock Holmes's scientific use of the imagination reveals the way in which the detective is never only the rationalist and the empiricist" (183).

After Holmes explains to Watson in the beginning of The Sign of Four that detection is and should be treated as a science, the second point he makes concerns exactly what Frank, and Holmes himself, labels "backward" or "analytic reasoning," which the latter explains by means of a linear metaphor. He says, "the only point in the case which deserved mention was the curious analytic reasoning from effects to causes, by which I succeeded in unravelling it" [emphasis added] (95). The use of "unravel" is important here. The verb "unravel" occurs seven times in this novel ${ }^{16}$ to describe Holmes's deductions and the original title for A Study in Scarlet was A Tangled Skein (Lycett 121). Holmes has already defined analytic reasoning by means of the metaphor of the train in the denouement of the novel

"Most people, if you describe a train of events to them, will tell you what the result would be. They can put those events together in their minds, and argue from them that something will come to pass. There are few people, however, who, if you told them a result, would be able to evolve from their own inner consciousness what the steps were which led up to that result. This power is what I mean when I talk of reasoning backward, or analytically." (STUD 197-198)

\footnotetext{
${ }^{16}$ Twice in The Sign of Four, three more times in The Adventures of Sherlock Holmes (BERY, SPEC, IDEN), and once in The Memoirs of Sherlock Holmes (SILV) to describe his deductive method.
} 
Holmes argues that most people can "put events together in their minds" and logically "argue from them" what will happen but to reverse the order of this "train" requires an added effort of "inner consciousness" that is rare.

\subsection{Cognitive and Emotional Empathy}

Having examined how reason, science, and even imagination are central to the method of Sherlock Holmes, it will be easier to examine to what degree Holmes employs cognitive and emotional empathy. In the original Sherlock Holmes stories by Arthur Conan Doyle, the detective has a high degree of cognitive empathy but is described by Watson as not experiencing emotional empathy. In other words, he is extremely adept at perceiving emotions and even thoughts of others (a high degree of empathetic accuracy) but he does not feel the same emotions as those around him (or is immune to emotional contagion). O'Brien argues that "As he did with objects, Holmes could also make deductions about people" (23). O'Brien explains that there were three major influences on Holmes's method: Doyle's own medical training, his tutelage under Dr. Joseph Bell, and Edgar Allan Poe's Detective Dupin stories. ${ }^{17}$

The detective's inheritance from Joseph Bell and Doyle's medical training has already been identified in his reliance on what is now called Behavioral Evidence Analysis. I would argue that emotion is similarly understood in these stories in medical terms as indicated by physical signs ${ }^{18}$ or symptoms. ${ }^{19}$ Within the sixty original stories,

\footnotetext{
17 “The Murders in the Rue Morgue" (1841), “The Mystery of Marie Roget” (1842), “The Purloined Letter" (1844)

18 "I seemed to discern some signs of emotion upon the butler's white face" [emphasis added] (HOUN 469); "Horner, who had shown signs of intense emotion" [emphasis added] (BLUE 205); "Dr. Mortimer, who had begun to show signs of some strong emotion" (HOUN 410); "Holmes showed signs of irresolution" (STUD 118)

${ }^{19}$ When Lucy Ferrier falls in love with Jefferson Hope, her "blushing cheek" and "bright eyes" are described as "symptoms" (STUD 145). Additionally, Holmes's impatience is clear by its "symptoms" (STUD 115).
} 
the guilty, the innocent, and even Holmes himself show signs of emotion. If showing emotion is both a natural human reaction displayed by the innocent and a sign of underlying criminal guilt, then it becomes crucial that the signs of emotion be read correctly.

\subsection{1 "The Veil of Human Emotion"}

As a case study to understand how Holmes uses cognitive empathy I would like to focus on the murder of Enoch Drebber in A Study in Scarlet. This is the same story that O’Brien quotes to support his statement that Holmes is an expert at reading people; however, O'Brien does not offer an explanation of precisely how this works. There are two central ways that Holmes uses cognitive empathy in crime investigation. The first is a sort of statistical analysis, or nomothetic profiling. Through this method, Holmes's vast knowledge of the history of crime is applied to the case at hand. A large part of his understanding of human emotion and criminal motivations comes through this knowledge of the annals of crime. Stamford even remarks that Holmes was a "walking calendar of crime" (STUD 23). In this case, Holmes is able to match the appearance of the word rache, written in blood, to a similar case involving secret societies. Holmes dismisses Lestrade's theory that it was meant to spell the name "Rachel" in favor of the German noun, rache (meaning "revenge"). In this way, he compares the crimes he's working to what has been done before and what motivated past crimes can shed light upon his own investigation. Although revenge is eventually revealed to be Jefferson Hope's motive, ${ }^{20}$

\footnotetext{
${ }^{20}$ In Part 1, Enoch Drebber and Joseph Strangerson are murdered by Jefferson Hope for the murders of John and Lucy Ferrier. In Part 2, which actually occurs prior to the first narration, the "Avenging Angels" kidnap John Ferrier and Lucy Ferrier is kidnapped and forced to marry Enoch Drebber (which indirectly results in her death) in retaliation for their flight from Salt Lake City. Thus one revenge story begets another.
} 
the case, as it turns out, has no connection to Germany or secret societies. But Holmes almost immediately dismisses this allusion to a previous crime as an intended ruse, since it does not match with the other evidence he uncovers. Holmes's conclusion is based on the way the letter " $\mathrm{A}$ " is written in the "German fashion" rather than the "Latin character" (69), the fact that political assassins would kill and flee but this murderer stayed around (as indicated by footprints all over the room), and the emotions written on the murder victim's features. This is another distinction that separates the work of the detective from that of the objective scientist. For Holmes in this case, "The truth lies not 'beyond' the domain of deception, it lies in the 'intention,' in the intersubjective function of the very deception" (Zižek 56-57). In other words, Holmes not only deduces what rache was intended to evoke (revenge rather than Rachel) but he further deduces its "intersubjective function," which is to deceive the police.

The second way that Holmes employs cognitive empathy is through his direct reading of human features for signs of emotion. In this way, Holmes displays a high degree of Emotional Intelligence.

[Emotional Intelligence (or EI)] refers to the processes involved in the recognition, use, understanding, and management of one's own and others' emotional states to solve emotion-laden problems and to regulate behavior. EI, in this tradition, refers to an individual's capacity to reason about emotions and to process emotional information to enhance reasoning. (Brackett and Salovey 293)

Emotional intelligence is not antithetical to rational thought but actually "enhances reason." As Holmes explains in "The Resident Patient," "The features are given to man as the means by which he shall express his emotions"' (RESI 632). In the denouement of A Study in Scarlet, Holmes explains his deductions at the crime scene of Enoch Drebber's murder. One of the most important discoveries in this causal chain is the "hatred" and 
"fear" frozen on Enoch's face which indicate to Holmes that the poison was forced on him and he knew what was coming. These indications of extreme emotion in the victim coupled with what Holmes perceives as the killer's "methodical revenge" (STUD 199) and presence of the wedding ring help Holmes decide that the case hinges on a "dead or absent woman" (STUD 199) rather than a political assassination.

Sherlock Holmes's cognitive empathy, and especially the perception of emotional states, is central to his deductive method. As Watson explains, Holmes often uses his emotional intelligence in "drawing the veil from men's motives and actions" (SCAN 5). This is confirmed, when Watson reads Holmes's article "The Book of Life" and expresses his incredulity:

The writer [Holmes] claimed by a momentary expression, a twitch of a muscle or a glance of an eye, to fathom a man's inmost thoughts. Deceit, according to him, was an impossibility in the case of one trained to observation and analysis. (STUD 39)

When a later story, "The Resident Patient," was collected in The Memoirs of Sherlock Holmes, Doyle inserted a section at the beginning of the story, which was previously published in "The Cardboard Box."21 This excerpt contains both a reference to Detective Dupin's method ${ }^{22}$ (acknowledging his own detective's inheritance from the Poe stories) in addition to a display of Holmes's own cognitive empathy. The latter is exhibited by explaining his understanding of Watson's own train of thought which he garnered from reading the changes in his facial expressions (CARD 423-424, RESI 631). This

\footnotetext{
${ }^{21}$ This excerpt originally appeared in the Strand Magazine in January 1893, in the story "The Cardboard Box" which was later omitted from the British version of The Memoirs of Sherlock Holmes published by George Newnes, Limited in the 1894 edition and instead inserted in "The Resident Patient."

${ }^{22}$ In "The Murders in the Rue Morgue," Dupin answers the narrator's unspoken thoughts, which takes him quite off guard, and he demands an explanation of how this was done, "Tell me, for Heaven's sake,' I exclaimed, 'the method - if method there is - by which you have been enabled to fathom my soul in this matter"” [emphasis added] (Poe 120).
} 
demonstration shows that Holmes has a high degree of empathetic accuracy, which is here confirmed by Watson. Empathetic accuracy "refers to the degree to which people can accurately infer the specific content of other people's thoughts and feelings" (Ickes and Mast 294). Holmes also reads Watson's thoughts at the beginning of “The Adventure of the Dancing Men."

\subsection{2 "A Brain without a Heart"}

After considering how the skill of cognitive empathy is central to Holmes's method of crime investigation, it is now time to turn to the language used to describe Holmes's own emotional life. In "The Adventure of the Greek Interpreter", when Watson learns that Holmes indeed has a brother (Mycroft), he reflects at the beginning of the story on the detective's reluctance to discuss or even enjoy a personal or social life:

During my long and intimate acquaintance with Mr. Sherlock Holmes I had never heard him refer to his relations, and hardly ever to his own early life. This reticence upon his part had increased the somewhat inhuman effect which he produced upon me, until sometimes I found myself regarding him as an isolated phenomenon, a brain without a heart, as deficient in human sympathy as he was pre-eminent in intelligence. His aversion to women and his disinclination to form new friendships were both typical of his unemotional character, but not more so than his complete suppression of every reference to his own people. I had come to believe that he was an orphan with no relatives living, but one day, to my very great surprise, he began to talk to me about his brother. (GREE 635)

Here the reader learns that Holmes has an "aversion to women," a "disinclination to form new friendships" and never talks about his "own people" (his family). All three have led to Watson's view of Holmes as "inhuman," "unemotional," and "deficient in human sympathy." Sympathy "involves the experience of being moved by, or responding in tune with, another person" (Hodges and Myers 296). Sympathy is related to emotional empathy rather than cognitive. But what should be made clear is that the reader's 
understanding of the famous detective is always filtered through Watson's point of view, which is emphasized by Watson's phrases "I found myself regarding him" and "I had come to believe." And although he is continually represented by Watson as "a brain without a heart," Holmes's suppression of an emotional life does not mean he is incapable of feeling normal human emotions. On the contrary, there are several times throughout the stories when a glimpse of the detective's capacity for experiencing emotion is apparent. For instance, in A Study in Scarlet, Holmes expresses impatience and disappointment when Mrs. Hudson's terrier does not at first die from the poison pill (115). These emotions are not the "strong emotions" that many clients and suspects exhibit throughout the other stories but this frustration is at least described in superlative terms: "So great was his emotion" (STUD 115). In "The Adventure of the Devil's Foot," Holmes expresses gratefulness and is apologetic to Watson. Again, in superlative terms, Watson explains "I have never seen so much of Holmes's heart before" (DEVI 1414). In "The Adventure of the Six Napoleons," Lestrade praises Holmes's skills on behalf of himself and Scotland Yard and Watson carefully observes and records Holmes's response, again in superlative terms: "it seemed to me that he was more nearly moved by the softer human emotions than I had ever seen him. A moment later he was the cold and practical thinker once more" [emphasis added] (SIXN 1063). Although these instances when Holmes's own "veil of emotion" is pulled back are brief, rare, and often accompanied by a reassertion of his rational nature, Watson's use of superlative language makes them important to a full understanding of Holmes's capacity for emotion.

How does one reconcile Holmes's displays of emotion with the predominant characterization that he is "a brain without a heart"? Holmes's reticence to cultivate a 
private, emotional life is represented as a conscious choice of emotional restraint pushed to an extreme. Watson explains Holmes's opinion at the beginning of "A Scandal in Bohemia":

But for the trained reasoner to admit such intrusions into his own delicate and finely adjusted temperament was to introduce a distracting factor which might throw a doubt upon all his mental results. Grit in a sensitive instrument, or a crack in one of his own high-power lenses, would not be more disturbing than a strong emotion in a nature such as his. [emphasis added] (SCAN 5)

In Doyle's original stories, experiencing emotion is not only represented as antithetical to reason but as potentially dangerous and threatening; it is an "intrusion" and "distracting factor" that may cast "doubt upon all his mental results." This becomes clear by examining the way emotion is described throughout the other stories. In "The Yellow Face," Mr. Grant Munro is described as being "under the influence of extreme emotions" [emphasis added] (YELL 464-465). In "The Adventure of the Beryl Coronet," when Holmes's client (Alexander Holder) first enters 221B Baker Street, he is "fighting against his emotion" (320) and proceeds to describe "a trouble which is enough to unseat [his] reason" (321). As Brent Turvey explains in Criminal Profiling: An Introduction to Behavioral Evidence Analysis, "profilers must [...] approach cases objectively and methodically" and "know themselves" or they "risk transference of their own issues, needs, and morality into a profile" (139). This risk of transference may also be one of the dangers that Holmes wishes to avoid.

To conclude, in Arthur Conan Doyle's Sherlock Holmes stories, the detective relies not only on science and reason but also imagination and cognitive empathy. And although he is quite capable of experiencing emotions, he consciously chooses to practice emotional restraint. Additionally, he avoids developing a personal life, which could 
threaten his method by casting doubt on his deductions or through transference of his own emotions and motivations upset his understanding of the criminal mind he is tracking. The distinctions between cognitive and emotional empathy become more pronounced in the current television adaptations, which take unique interpretations in reconciling this "isolated phenomenon" (GREE 635), which is Holmes's character.

\section{VISUALIZING DEDUCTION}

There are two "features of interest" 23 in considering the nexus of reason and emotion in Sherlock: the use of onscreen text as a visualization of deduction and the various characters' psychological diagnoses of the detective. First, I consider the use of onscreen text. The visualization of the deductive process through the use of onscreen text functions in two ways: the navigation of databases and an illustration of thought processes. The first use of onscreen text simulates for the audience Sherlock's navigation of digital technology as a tool in his deductions. Although Holmes is still engaged in many of the scientific pursuits detailed in the original stories, ${ }^{24}$ his most noteworthy tool in this series is digital technology. Often this digital navigation occurs as a sort of second stage to Sherlock's method. Building off of physical evidence recovered from crime scenes, Sherlock turns to his cell phone's internet capabilities to access the limitless information available at his fingertips. After examining Jennifer Wilson's body in "A Study in Pink," Sherlock navigates a series of menus in a weather application (IMAGE 11), surgically targeting the specific information he needs and determining that she had

\footnotetext{
${ }^{23}$ A phrase used often by the detective in the original stories (SIGN 95 and 121, IDEN 76, YELL 449, CROO 584).

${ }^{24}$ When Stamford introduces Watson to Sherlock at Bart's Hospital, he is still conducting experiments on post-mortem bruising patterns (STUD 19).
} 


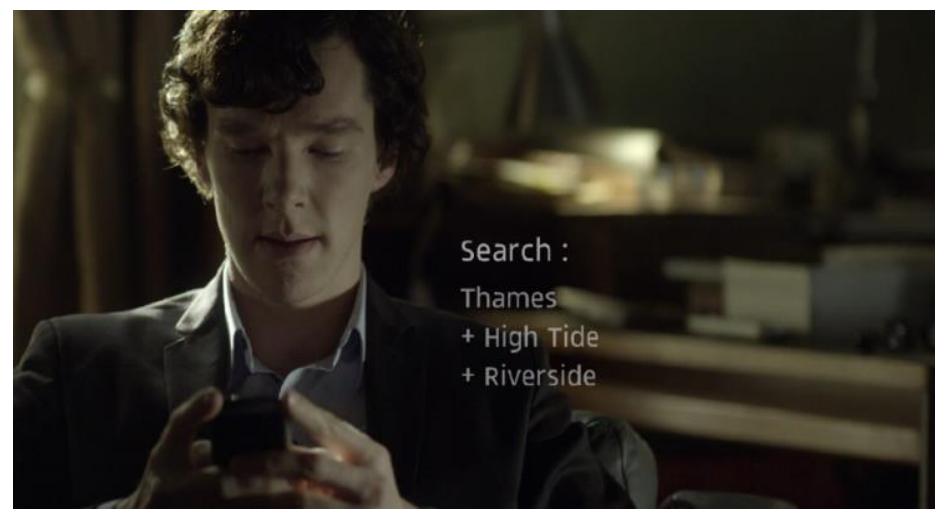

come from Cardiff (the only

location that fit the type of

weather required and within the

time and distance radius dictated

by other details). Another

instance of Sherlock's digital

IMAGE 1-1: Sherlock searches the weather application (Sherlock 1:1)

navigation or research methods is his adept use of search engines. Louisa Ellen Stein and

Kristina Busse point out that "the show makes us privy to his use of operations (search and filter), as his navigation of search engines manifests as text layers on the screen" (12). Being able to glean information with such precision usually pays off in efficiency and may mean the difference between life and death. Another possible option for this scene would have been to show the Blackberry's electronic screen itself. In scenes such as this, something may be lost in focusing the camera's entire attention on the electronic screen and that is the characters' expressions and body language. Benedict Cumberbatch is especially expressive in an effort to project the internal thought processes of his deductions through his facial features, mercurially exhibiting a quick succession of emotions in the span of mere seconds. Often times, the use of text onscreen allows the audience to watch how the characters react and emote during their interactions with technology.

Second, perhaps even more important than demonstrating Sherlock’s digital navigation of databases as an investigative tool, onscreen text offers the audience a glimpse inside the thought processes of the detective. Alan Barnes claims in Sherlock Holmes On Screen, "the miracle of A Study in Pink is that it incorporates these modern- 
day counterparts to Doylean devices quite naturally, as if nothing has changed in 123 years since Doyle's Study in Scarlet" (170). But the use of text onscreen to visualize deduction and the accompanying shift in point of view does change the formal features of the mysteries. While in Doyle's original stories, "the reader, along with Watson, is left in the dark as to Holmes's line of deduction until the conclusion when Holmes provides a comprehensive explanation of his reasoning" (Sparling 203), in Sherlock, the viewer is following the deductive process as it unfolds. When Doyle was approached about staging the Sherlock Holmes stories, he "decided that Holmes was 'not fitted for dramatic representation. His reasonings and deductions (which are the whole point of the character) would become an intolerable bore upon the stage"” (Lycett 199). The first episode of Sherlock in production was the third of the first season, "The Great Game." It was during the filming of this episode that new director, Paul McGuigan, came up with the idea to use the textual layer on top of the image, which was then worked in to the previous episodes in the first season. Gatiss says, "“It all started with not wanting to do a voiceover or montage [...] but still wanting to show Sherlock's thought processes"” (Adams 23). Although Doyle was proved wrong about his pronouncement that the detective's investigations would be unsuccessful as performances, after almost one hundred and thirty years representing Holmes's method is still a central challenge in adapting these stories to a visual medium. Furthermore, this visualization of deduction through onscreen text indicates not only a clever solution to a continual problem in Sherlockian adaptations but also an important shift in point of view in both Sherlock and Elementary. While in the original stories the majority of the cases (including the characterization of Holmes) are narrated through the perception of Watson, in both of 
these television adaptations the audience is given direct perception of the detective without an intermediary character's narration.

The best scene to analyze in order to show Sherlock's crime scene observations is probably his examination of Jennifer Wilson's body in “A Study in Pink." In this first episode, the show's creators showcase a variety of ways that the onscreen text will be used so the audience may keep up in the faster sequenced episodes, such as "The Great Game." What Sherlock actually does at a crime scene is like a visual interrogation. He builds a model from the physical data that is provided to determine potential scenarios. Items that individuals use daily are especially beneficial to Sherlock's method; patterns of human behaviors are almost inscribed in the physical signs of usage that they bear. By the state of Jennifer Wilson's wedding band, in relation to the pristine condition of the rest of her regularly-cleaned jewelry, Sherlock is able to determine she had been unhappily married for over ten years. By her regular removal of the wedding band he is able to infer that she was a serial adulteress. This is so believable and impressive because film often capitalizes on the fact that "traces of human strivings are as visible on inanimate objects as they are on the body itself' (Arnheim 143). These traces represent what it is like to leave a mark on the world; that they serve as the only way to speak after our death becomes especially important in the context of a murder. Additionally, the textual layer often has the benefit of revealing new information. For instance, during this sequence, Sherlock rubs his hand across Jennifer Wilson's pink coat. When he pulls his hand up, he rubs his fingers together and the word "Wet" appears onscreen (IMAGE 1-2). Here the textual layer of the visuals is offering viewers information unavailable to them. The viewer cannot feel her jacket for himself and procure this tactile data (wetness) and they 
may or may not realize that

the sheen on the plastic

glove is meant to convey

wetness. In this way, the

text offers the viewer

something that may be

only partially or poorly

conveyed by the visuals; it

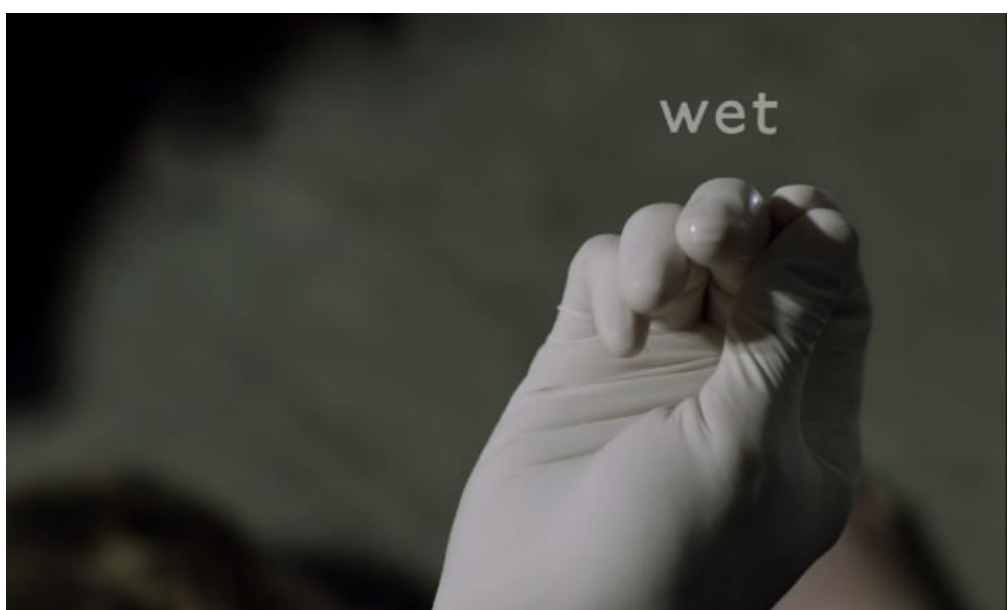

IMAGE 1-2: Sherlock investigates Jennifer Wilson's coat (Sherlock 1:1)

supplements the visuals with other sense data.

In these static uses of the font (i.e., "Wet") a single word appears onscreen and then disappears with very little movement. The digital navigations of the weather application is an obvious exception to this but this animation is to some extent still prescribed by the given layout of the menus and submenus. There are other instances, however, when the onscreen text serves to map out the thought processes inside Sherlock's head by animating the text. A perfect illustration of this function may again be drawn from the investigation of the crime scene where Jennifer Wilson's body is found in "A Study in Pink." Sherlock turns to the examination of the letters she scratched into the wooden floor before expiring and the animation of the text helps the audience follow Sherlock's train of thought step-by-step.

First, Sherlock assumes Jennifer intended to spell rache, which is projected over the scratched letters on the wood floor and accompanied by the sound of scratching nails but he quickly rejects this possibility. The fact that he abandoned this initial idea is signified by a reverse shot of Benedict Cumberbatch as Sherlock with the superimposed 


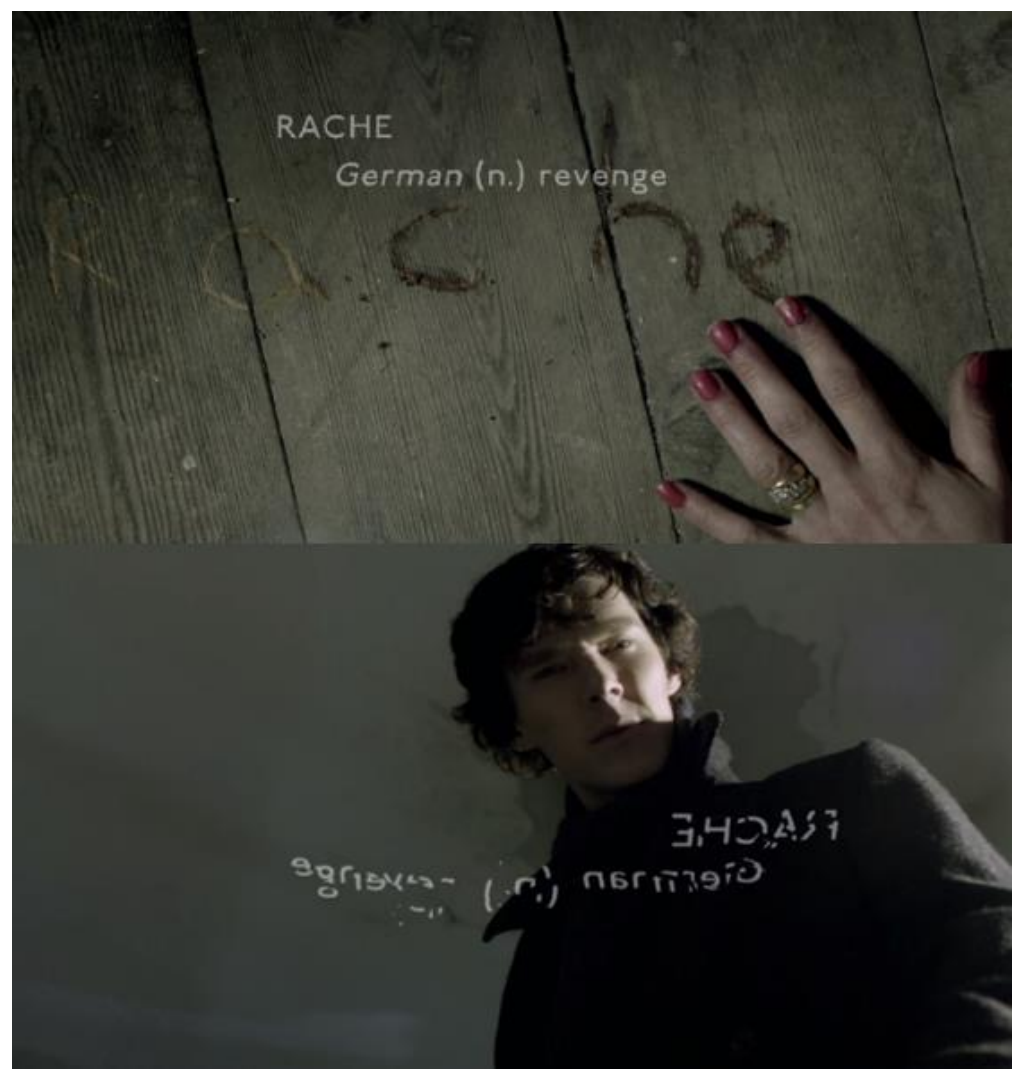

IMAGE 1-3: Sherlock considers "rache" as a possible meaning (Sherlock 1:1) text breaking apart and

disappearing (IMAGE 1-3).

The camera cuts back to the

wood floor and this time

each letter is overlaid with

its equivalent in a textual

layer and a letter wheel (for

a potential fifth letter)

appears on the right

(IMAGE 1-4). Sherlock is

assuming that perhaps

Jennifer was unable to

finish writing the word. The wheel begins to spin as the detective tries out all the possible combinations before finally landing on "L." Was the word Jennifer was scratching the name "Rachel"? This is what Sherlock infers and the person familiar with Doyle's $A$ Study in Scarlet, a viewer experiencing the adaptation as adaptation (Hutcheon 21), will realize the show has flipped these possible solutions; it was rache that the victim had intended in the original.

Sherlock, by placing the viewer in the detective's subjectivity (revealing his thought processes through onscreen text), is able to highlight the way perception works as an interaction between external stimuli and internal thought. Teresa de Lauretis writes "perception entails a making of judgments based on inference and prediction, a testing for consistency, the proving or disproving of expectations elicited by contextual and situation 
clues" (61). De Lauretis

argues that our judgments

are predicated on

"inference and prediction"

underscoring that the

process of observation is a

lot more complicated than

merely looking out into the

world and seeing reality;

gaps in information are

inferred and expectations

are projected and either

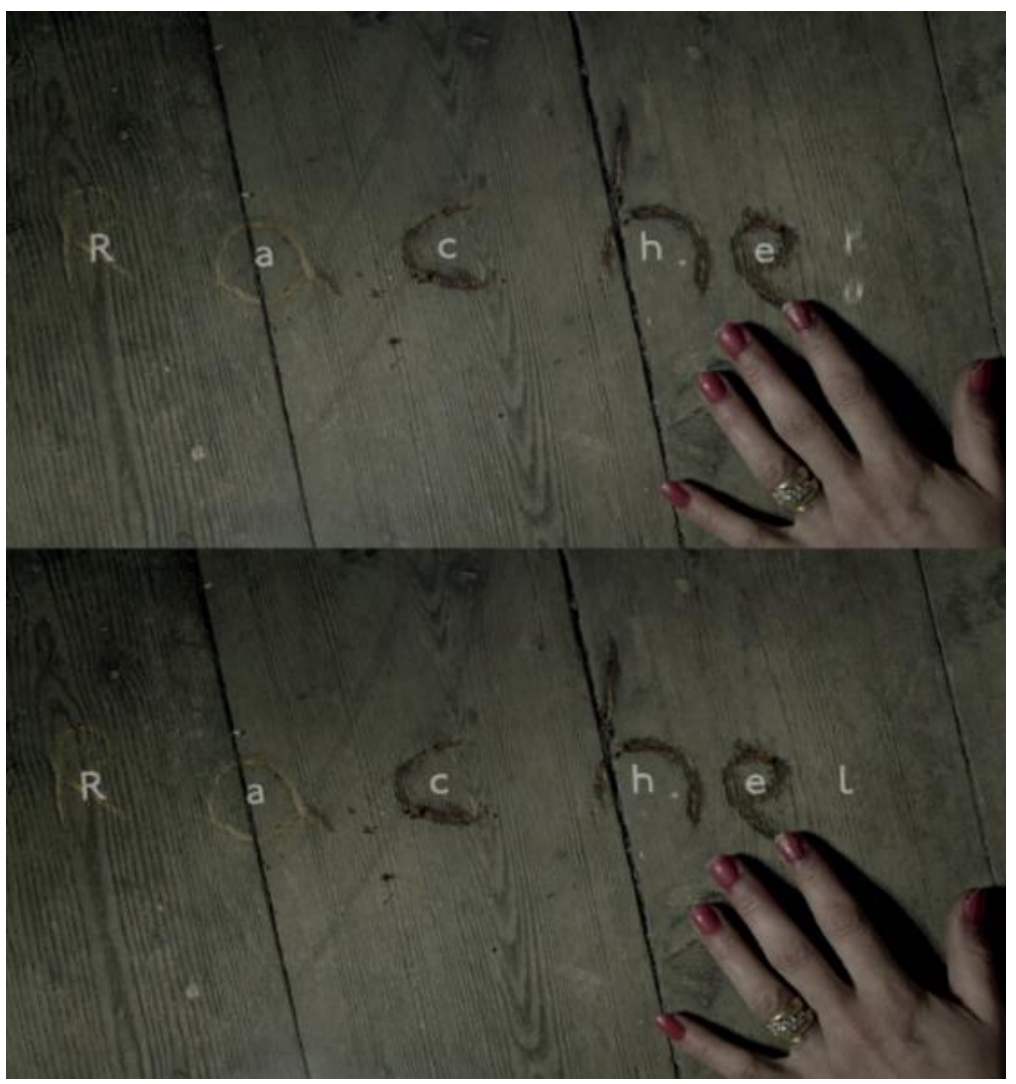

IMAGE 1-4: Sherlock decides Rachel was the intended meaning (Sherlock 1:1)

proved or disproved in a continuous cycle. In "A Study in Pink, Sherlock exemplifies this method of "proving and disproving" perfectly when he asks John if any details of his deductions about John's cell phone were incorrect. If perception itself is a series of deductions, then Sherlock is revealing the very interplay of mental processes and sense perception, how humans observe the world by perceiving stimuli and make educated guesses about outcomes based on such information in its fusion of the visual, audial, and textual layers.

Sherlock modernizes the Victorian detective that Doyle created by updating his technological tool kit and adding digital expertise to his superior intelligence. More important than the addition of the technology is how the technology is displayed and the narrative functions that it serves. The addition of a layer of onscreen text, far from stifling 
cognitive interplay for the viewer, highlights the ontology of the digital image as capable of manipulation. Many times the textual layer adds some new information to the audio and visuals creating a new complexity between the elements. Furthermore, perception itself is a process of communication between sense organs and the brain which is a lot more complex than a simple one way signal, often making inferences and predictions based on limited information. For many reasons, investigation has always been a popular motif in film: its focus on observable material clues, the connection to science and evocation of endlessness, and now its ability to lay bare the relationship between cognition and sense perception. In Alan Barnes's introduction to Sherlock Holmes On Screen, he writes,

The confluence between the creation of Holmes and the coming of film means that it would be possible, if one so desired, to observe almost every historical, cultural, and technological development in the moving image purely through the changing representations of Sherlock Holmes. (8)

The BBC's Sherlock continues this tradition by adding the digital chapter to the narrative of Sherlock Holmes adaptations.

\section{DIAGNOSING THE DETECTIVE}

Sherlock employs digital technology to represent the detective's rational method of deduction but it also offers several psychological diagnoses which seek to explain the detective's complicated relationship to emotion. In Sherlock, three explanations are given to reconcile Sherlock's extreme rationality with his perceived lack of empathy: psychopathy, sociopathy, and Asperger's Disorder. Interestingly enough, all three of these psychological disorders are differentiated by their relationship to cognitive and emotional empathy. The first two, psychopathy and sociopathy, are both antisocial 
personality disorders. ${ }^{25}$ The third, Asperger's Disorder, is an Autism Spectrum Disorder. Someone with an antisocial personality disorder has a high degree of cognitive empathy but very little emotional empathy, whereas those on the Autism Spectrum are believed to have a lesser degree of cognitive empathy but a higher degree of emotional empathy. In other words, someone with an antisocial personality disorder is adept at reading and understanding the emotions of others but does not experience emotional contagion; they do not sympathetically feel the emotions that those around them are experiencing. This difference between understanding but not feeling makes the person with antisocial personality disorder potentially dangerous since they may manipulate the feelings of those around them to achieve their own ends. In contrast, those that fall on the Autism Spectrum have a hard time recognizing or understanding the emotions of those around them but if they do correctly identify someone else's emotion, then they sympathetically experience the emotional state of another. The difference between Sherlock Holmes's capacity for cognitive and emotional empathy becomes central to understanding the detective in Sherlock.

The idea that Sherlock may have an antisocial personality disorder is introduced from the first episode of the series, "A Study in Pink." Two Scotland Yard police officers, Sally Donovan and Anderson, both refer to Sherlock Holmes as a psychopath. After Sherlock comically leaves Watson behind at a crime scene, Donovan attempts to offer Watson a "bit of advice", to stay away from Sherlock:

\footnotetext{
${ }^{25}$ A stronger case could be made that Sherlock is a psychopath due to his high intelligence and seemingly lack of traumatic or abusive childhood. Sherlock's parents make brief appearances in the third season, "The Empty Hearse" (3:1) and "His Last Vow" (3:3) and are briefly discussed by Sherlock and Mycroft throughout the series. In "A Study in Pink" the brothers discuss their attempt to get the two children to make friends. Mycroft later reveals that they live in Oklahoma and are line-dancers ("His Last Vow").
} 
You know why he's here? He's not paid or anything. He likes it. He gets off on it. The weirder the crime, the more he gets off. And you know what? One day just showing up won't be enough. One day we'll be standing round a body and Sherlock Holmes'll be the one that put it there.

This does echo one of Watson's musings in The Sign of Four, "I could not but think what a terrible criminal he would have made had he turned his energy and sagacity against the law, instead of exerting them in its defense" (277). The doubling between criminal and detective in Sherlock will be further considered when assessing Sherlock's capacity for emotional empathy. When Watson confronts Sherlock later in the episode about Donovan's comments, he chalks it up to a love of danger and adventure,

JOHN. She said...You get off on this. You enjoy it. SHERLOCK. And I said "dangerous" and here you are.

The second time that Sherlock is called a psychopath in this episode is when the police have come to investigate 221B Baker Street on an anonymous tip that Sherlock has possession of Jennifer Wilson's luggage, again indicting him as the murderer. This idea is also presented in A Study in Scarlet, when Holmes responds to John Rance's assertion that Holmes's deductions prove he must have been present and a witness to what has transpired. Holmes says “"Don’t go arresting me for the murder [...] I am one of the hounds and not the wolf"' (73). To Anderson's accusation in Sherlock, the detective retorts, 'I'm not a psychopath, Anderson. I'm a high-functioning sociopath. Do your research." Sherlock does share two symptoms with an antisocial personality disorder: a lack of personal attachment and a total disregard for social rules or standards of behavior. First, I will examine his lack of attachment.

Immediately preceding Donovan's declaration that Sherlock Holmes is a psychopath, she clarifies that Watson cannot be a friend of his, since he has no friends. 
This is further illustrated by the skull that Sherlock keeps around to talk with. Sherlock calls the skull a "friend" and then compares Watson to the function of the skull, which Mrs. Hudson has confiscated. Later, when Sherlock and John discuss the former's arch enemy, the conversation again circles back to a discussion of personal attachments:

JOHN. People don't have arch enemies. [...] There are no arch-enemies in real life. Doesn't happen.

SHERLOCK. Doesn't it? Sounds a bit dull.

JOHN. So who did I meet?

SHERLOCK. What do real people have, then, in their 'real lives'?

JOHN. Friends; people they know; people they like; people they don't like ... Girlfriends, boyfriends...

SHERLOCK. Yes, well, as I was saying-dull.

The arch enemy they are discussing is later revealed to be Sherlock's brother, Mycroft. Sherlock's remark here that having friends is "dull" may be evidence that he has an antisocial personality disorder. Although in discussion with Mycroft, Sherlock is represented as more humane than his brother who remarks, "Oh yes. Friends. Of course, you go in for that sort of thing now." Sherlock's developing partnership, and resulting friendship, with John Watson over the course of three seasons could be evidence that he is capable of forming personal attachments but even those with antisocial personality disorder have been known to form an attachment to an individual or small group of people. Therefore, his best man's toast in "The Sign of Three" (3:3) is not necessarily indicative that this diagnosis is faulty. His toast may, however, be further proof of his misreading of human emotion, or a lack of cognitive empathy since the wedding guests begin crying at his words and he tentatively asks "“Did I do it wrong?"”

Second, the complete disregard for rules of social behavior is clearly evidenced throughout this first episode. Sherlock repetitively expresses excitement and morbid fascination at the prospect of suicide, murder, and death. When informed that a note has 
been left at the murder scene of Jennifer Wilson, Sherlock responds, “'Brilliant! Yes! Ah, four serial suicides, and now a note! Oh, it's Christmas!" Sherlock expresses untoward glee when informed that Rachel Wilson is long dead. John also rebukes Sherlock for calling a murder investigation "fun". Lestrade, who presumably is the most familiar with Sherlock's eccentricities, expresses astonishment at Sherlock's "love" of serial killers. Finally, Mrs. Hudson outright rebukes him for not being "decent":

SHERLOCK. Impossible suicides? Four of them? There's no point sitting at home when there's finally something fun going on! MRS HUDSON. Look at you, all happy. It's not decent. SHERLOCK. Who cares about decent? The game, Mrs. Hudson, is on!

Within the framework of the show, Sherlock's complete disregard for social rules is as much a source for comedy as it is an indication of a sociopathic or psychopathic condition. Furthermore, the viewer's pleasure is also derived from the prospect of adventure, mystery, and crime, just as it is for John and Sherlock. Thus, Sherlock's morbid fascination directly parallels that of the audience watching the plot unfold.

There is a strong indication that this diagnosis of antisocial personality disorder does not correctly identify Sherlock Holmes's relationship to reason and emotion: the repeated instances where Sherlock fails to demonstrate cognitive empathy. Granted, some of these failed instances concern homosexuality, which could be a potential blind spot for the detective. He seems completely unaware of the various innuendos voiced by other characters concerning a romantic or sexual relationship between him and John. The first insinuation is voiced by Mrs. Hudson when Sherlock and John examine 221B Baker Street and the second is when they are on a stakeout at Angelo's restaurant. Sherlock seems completely unaware of what is being hinted at with the "second bedroom" and the 
“romantic candle." In addition, the only part of his deduction about John's cell phone which proves incorrect is that it previously belonged to John's lesbian sister, Harry. ${ }^{26}$

There are two further examples from this episode that seem to point to a lack of cognitive empathy: Molly Hooper's lipstick and date offer and the circumstances concerning Rachel Wilson's relationship to the case. With respect to the latter, the mysterious rache written on the wall at Jennifer Wilson's crime scene is revealed in the episode to be Rachel, the name of the murder victim's stillborn daughter. When the significance of "Rachel" is discovered, Sherlock fails to see why Jennifer used her dying moments to write this piece of information and his remark serves, for Anderson, as a further indication that Sherlock has an antisocial personality disorder. ${ }^{27}$ Sherlock does not understand how Jennifer could still be upset about the death of her daughter, "'Yeah, but that was ages ago. Why would she still be upset?'” He then pauses and notices that everyone has gone silent and motionless in the room. "Not good?" he tentatively asks. His question draws attention to his perceived failure to correctly understand human emotion, or a lack of cognitive empathy. Ironically, Sherlock's lack of empathy winds up leading to the break in the case, for "Rachel" was also the password to her cell phone (her intended meaning in scratching it into the floor). Sherlock is then able to track it back to the murderer using the phone's GPS. The show's dynamics here seem to be confirming the detective's own stance on reason and emotion: "All emotions, and in particular love,

\footnotetext{
${ }^{26}$ Sherlock remarks in his later exchange with John, which reveals this incorrect deduction, that "There's always something" that he misses. Therefore, the fact that he misses the gender of the previous owner could just indicate that Holmes is never perfect. However, when taken together with the insinuations about a homosexual relationship between himself and John, it's more probable that same sex relationships are a blind spot in the detective's reasoning process.

${ }^{27}$ Although here he goes back on his original claim of psychopathy and confirms Sherlock's self-diagnosis of sociopath, "Why would she think of her daughter in her last moments? Yup-sociopath; I'm seeing it now."
} 
stand opposed to the pure, cold reason I hold above all things" 28 ("The Sign of Three" 3:3). It is Sherlock's lack of empathy, his refusal to rely on emotion as a solution, which pushes him to understand a rational reason that Jennifer Wilson would have left "Rachel" for the investigating detectives.

So far, the discussion of Sherlock's capacity for cognitive empathy has revolved around the comments and deductions of those in his social circle and the analysis of victims. In these instances, Sherlock continually fails to read and understand their emotions; however, the detective does exhibit a high degree of cognitive empathy in reading the emotional motivations of Jefferson Hope, the criminal in this episode. As Joel Black explains in The Aesthetics of Murder, "the literary figure of the detective typically was and continues to be an extraordinary, marginal figure who frequently bears a closer resemblance to the criminal he pursues than to the police officers with whom he supposedly collaborates" (43). This statement indeed holds true for this first episode of Sherlock, both Donovan and Anderson, those who label Sherlock with antisocial personality disorder, are criminal investigators with Scotland Yard. As already mentioned, John and Sherlock discuss how many characters in the episode assume Sherlock is the murderer. The doubling motif of criminal and detective is both a staple of the literary genre and the most important instance in this episode where Sherlock demonstrates his capacity for cognitive empathy.

In A Study in Scarlet, Jefferson Hope attributes his use of two pills (one poison and one harmless) as his modus operandi for exacting vengeance to chance, providence,

\footnotetext{
${ }^{28}$ This is an echo of Holmes's pronouncement in The Sign of Four, "But love is an emotional thing, and whatever is emotional is opposed to that true cold reason which I place above all things. I should never marry myself, lest I bias my judgment." (SIGN 378).
} 
or God. Here, the scenario is different on two counts. First, Hope is not relying on chance to determine the outcome of events. He explains to Sherlock: "'You're not playin' the numbers, you're playin' me. Did I just give you the good pill or the bad pill? Is it a bluff? Or a double-bluff? Or a triple-bluff?"' This statement hearkens back to Edgar Allan Poe's Detective Dupin story, "The Purloined Letter" in which the detective's success is determined by his ability to think like his opponent and stay one step ahead: “'It is merely,' I said, 'an identification of the reasoner's intellect with that of his opponent"' (Poe 191). To explain his reading of Minister M, Dupin uses the example of the game of even and odd, in which the sole object is to determine if the number of marbles behind the back of the opponent is an even or odd sum. As already mentioned, Watson is several times witness to Holmes's ability to "fathom a man's inmost thoughts" (STUD 39). In the rewriting of Hope's modus operandi, then, the first episode of Sherlock builds on this central tenet of detective fiction, the detective and criminal's constant pursuit to understand the mind of one another and stay always one step ahead.

Second, Hope's motivation has been altered. Hope is still dying from an aneurism (STUD 181) but this time his motivation is not exacting revenge for past wrongs as in $A$ Study in Scarlet, but rather, providing money for his children after his death. Hope's central motivation is not bitterness at his impending death but love, as Sherlock correctly identifies, “'You didn’t just kill four people because you're bitter. Bitterness is a paralytic. Love is a much more vicious motivator. Somehow this is about your children."” Sherlock knows Hope has children since he had spotted a photograph of them earlier in his cab. Ultimately, the episode refuses to reveal if Sherlock was able to outwit Jefferson Hope since John shoots Hope in the head before either have a chance to ingest their 
respective pills. However, Sherlock is able to correctly identify love as the emotional impetus for Hope's crimes, thereby demonstrating a high degree of empathetic accuracy in understanding the criminal mind.

The third diagnosis for the great detective comes from a conversation between John Watson and Inspector Lestrade in "The Hounds of Baskerville" (2:2). John and Sherlock have travelled outside of London, to Dartmoor, to investigate a government research facility. In the episode, Lestrade joins the duo in Dartmoor. John and Lestrade have a momentary discussion before Sherlock interrupts:

JOHN. You know he's actually pleased you're here. [...] Secretly pleased. LESTRADE. Is he? That's nice. I suppose he likes having all the same faces back together. Appeals to his... his... JOHN. Asperger's?

Although Watson is an army doctor and not a specialist in psychological disorders, his rather brief allusion to Sherlock's potential Autism Spectrum Disorder (ASD) has become the most popular explanation for Sherlock's representation of the character. ${ }^{29}$ The episode aired on May 13, 2012 and in December of 2013, in an article in The Telegraph, representatives from the National Autistic Society in the UK claimed several television characters, ${ }^{30}$ including Sherlock's portrayal of the detective, as representations of autism in the media. Since then, the internet has exploded with articles from the average fan to psychologists weighing in to answer the question "Does Sherlock Have Autism?" Curiously, the example cited in The Telegraph demonstrating Cumberbatch's portrayal in

\footnotetext{
${ }^{29}$ In spite of the fact that there seems to be much more evidence supporting a diagnosis of antisocial personality disorder, as previously elaborated. None of Sherlock's deductions really seem to hinge on his empathetic mirroring of another's emotional state, unlike the dynamics of Elementary, which will be considered next.

${ }^{30}$ Saga Noren from The Bridge, Derek from Derek, Roy Cropper in Coronation Street, and Maurice Moss in The IT Crowd were among the other characters cited in The Telegraph article.
} 
Sherlock as autistic is actually an example from Johnny Lee Miller's portrayal in Elementary. ${ }^{3 l}$ When Steven Moffat (one of the creators of Sherlock) was asked at Crimefest 2013 whether Sherlock has a condition such as ASD, he seems to negate this diagnosis:

Sherlock is content playing along with people saying that he does, because that's easier. I think he's more interesting than that, I think he has chosen his path. He wants to be the highest intelligence on the planet so he has removed all distractions. I think his brain is so interesting that the rest of his body isn't of interest to him.

Watson's pronouncement has fueled a heated and ongoing debate about representing mental illness in the media. The problem here is the problem that arises in the media with any underrepresented group of people: the few come to represent the many. As Mat Greenfield points out in his article, "We Shouldn't View Sherlock as an Autistic Savant," "if Sherlock is autistic (as is generally believed) then it's an over-simplified, romanticised, and distinctly pop-culture version of ASD." The real danger, as Greenfield goes on to explain, is that parents with recently diagnosed children with ASD will expect their children to be "geniuses with a quirky forthrightness unencumbered by social inhibition." As with any group of people, and also true of ASD, people exist on a spectrum and should not be compared to a stereotypical mold made famous by television pop culture. Unintentionally, then, the NAS's claim that these characters, Sherlock included, are autistic may "adversely influence the public understanding of autism spectrum disorders" (Greenfield) rather than positively influencing the generation of more positive and varied representations, as they had perhaps originally intended.

\footnotetext{
31 "Robyn Steward, an autism consultant and trainer and ambassador for the NAS, said: 'Sherlock really focuses on one thing, for example in the latest series there is an episode where his brother comes over to New York and they are supposed to be going for dinner but Sherlock says we can't, we are working on this case - it is an unnecessary distraction"' (Dixon).
} 


\section{LOVE AT FIRST SIGHT}

In the first episode of Elementary, when Joan Watson and Sherlock Holmes initially meet, their exchange centers on the use of the brain and the heart. As Joan attempts to explain that Sherlock's father has employed her to look after him, he interrupts her with a heartfelt confession:

JOAN. My name is Joan Watson. I've been hired by your father to be your sober companion. He told me he was going to e-mail you about me. I'm here to make the transition from your rehab experience to the routine of your everyday life as smoothSHERLOCK. Do you believe in love at first sight? JOAN. Um...

SHERLOCK. I know what you're thinking: the world is a cynical place, and I must be a cynical man, thinking a woman like you would fall for a line like that. Thing is... it isn't a line, so please hear me when I say this. I have never loved anyone as I do you right now... in this moment.

A bewildered Joan drops her purse and Sherlock hits play on one of the many television sets arranged in the room. The man on the television repeats the same speech verbatim. What began as a declaration of spontaneous love ends as a display of Sherlock's intellectual prowess. Additionally, this version of the detective admits he regularly has sexual intercourse but for "neurochemical reasons." As he explains to Joan, “'Full disclosure - I actually find sex repellent. All those fluids and all the sounds, but my brain and my body require it to function at optimum levels, so I feed them as needed. You're a doctor; you understand." The intersection of reason and emotion is once again taken up in this adaptation of Doyle's famous detective. Although this Sherlock also seems to espouse a view that emotion is dangerous to rational judgment, as I argue, the use of cognitive and emotional empathy are central to his method. In this section of the chapter, I will not treat reason and emotion separately because in this adaptation they are not represented as antithetical. Instead of a psychological disorder, Sherlock's disdain of 
emotional attachments stems (at least partly ${ }^{32}$ ) from the trauma of his perceived loss of the woman he loved (Irene Adler/Moriarty) and the precipitating substance abuse that has now led to his partnership with Joan Watson. ${ }^{33}$ This interpretation of Sherlock Holmes embraces current trends in neuroscience that argue emotion and reason are inextricably intertwined in cognitive processes. As Antonio Damasio argues in Descartes' Error: Emotion, Reason, and the Human Brain (1994), "reason may not be as pure as most of us think it is or wish it were, that emotions and feelings may not be intruders into the bastion of reason at all: they may be enmeshed in its networks, for worse and for better" (xii). Remember, Watson wrote that emotions for the "trained reasoner" were "intrusions" (SCAN 5) and here Damasio is refuting this view, "may not be intruders."

In the first episode, Sherlock and Joan investigate the murder of Amy Dampier. At the crime scene, Sherlock declares to Watson that "every wretched hive of depravity and murder in this city" is his "place of business." In this episode, Dr. Mantlo, a psychologist and wife of the deceased, uses Peter Saldua ${ }^{34}$, his patient with a history of sexual assault, to kill her. The underlying motive is money and Dr. Mantlo's cold objectivity is represented as reprehensible. The missing trace is used several times in this episode. When Sherlock enters the crime scene, the body of Amy Dampier itself is missing. When Sherlock discovers her body in a hidden safe room, he does not greet the discovery with glib excitement. Instead he simply says, "Sometimes I hate it when I'm right." In addition, a missing ring box, implied by the symmetry of the room (IMAGE 1-

\footnotetext{
${ }^{32}$ His complicated relationship with his domineering father may also prove to be a source of his awkward social interactions and refusal to connect with others in meaningful ways.

${ }^{33}$ While Joan originally enters Sherlock's life as his sober companion, a job she eventually quits for crime detection.

${ }^{34}$ Peter Saldua is murdered during the investigation
} 
5) and a dustless space at the scene of the crime demonstrates that a murder and not a

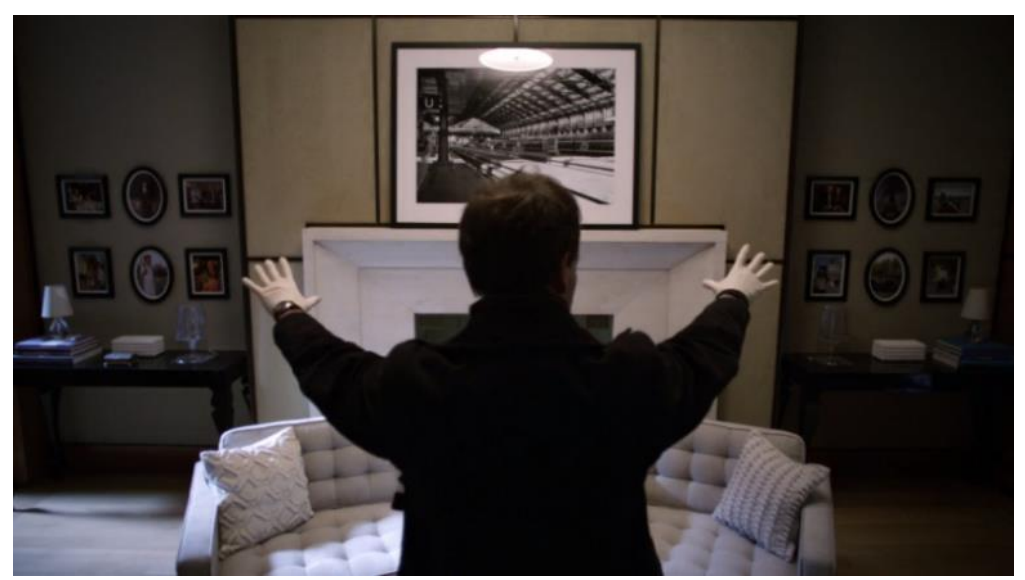

IMAGE 1-5: Sherlock discovers a missing trace based on the symmetry of the room (Elementary 1:1) kidnapping has occurred.

After reaching out to

Amy's friends and

procuring photos of her

pre-plastic surgery,

Sherlock stumbles onto a

trifling detail that becomes

important. The fact that she has surgically removed a mole "she turned her head to

feature $[\ldots]$ whenever her picture was taken" leads to the revelation that her plastic

surgery was encouraged by her husband, so that she would fit with Peter Saldua's type.

Finally, Peter Saldua's phone, on which he took to recording his sessions with Dr.

Mantlo, is the crucial missing evidence that, once found, breaks the case and proves

Mantlo's involvement.

After some research, Sherlock finds a physically similar victim of sexual assault who also had a jewelry box stolen as a trophy but survived the attack, Eileen Renfro. In the course of questioning her about the attacker's mask, Sherlock demonstrates a total lack of emotional empathy for what she has experienced:

EILEEN. What about it [the attacker's mask]?

SHERLOCK. Was it ski, Mexican wrestling, paper plate?

EILEEN. Ski.

SHERLOCK. Good. Excellent. So, you got a good look at his eyes. Oh, correct me if I'm wrong, but a-a strangler can, literally, not be more than an arm's length from his stranglee, can he? That's what? Two?

JOAN. Mr. Holmes?

SHERLOCK. Two and a half feet? I'm twice that distance from you now. I can see that your eyes are a lovely brown.

EILEEN. I think I'd like you to leave now. 
SHERLOCK. Why? 'Cause I know that you're lying?

JOAN. Mr. Holmes!

EILEEN. No.

SHERLOCK. She is. You can tell by the crucifix. You fiddle with it every time I ask you a question. It's — it's pacifying behavior. It's just

elementary haptic communication. Just read a book, would you? She did see her attacker's face.

JOAN. Sherlock!

SHERLOCK. I think she might even know who he is!

EILEEN. Get out.

SHERLOCK. You realize that because you protected him two years ago, you have the blood of an innocent woman on your hands, don't you?

Perhaps you'd like to go for two or three or four.

JOAN. That's enough! You're done here. Go wait in the car.

Sherlock correctly reads Eileen's body language. He knows she is lying and using a "pacifying behavior" but he is unable to procure the information he requires because of his utter lack of tack and inability to emotionally relate to her predicament. ${ }^{35}$ When Sherlock explains a strangler could not be more than an arm's length away from the victim he moves toward her and reaches out with his arms (IMAGE 1-6), traumatically

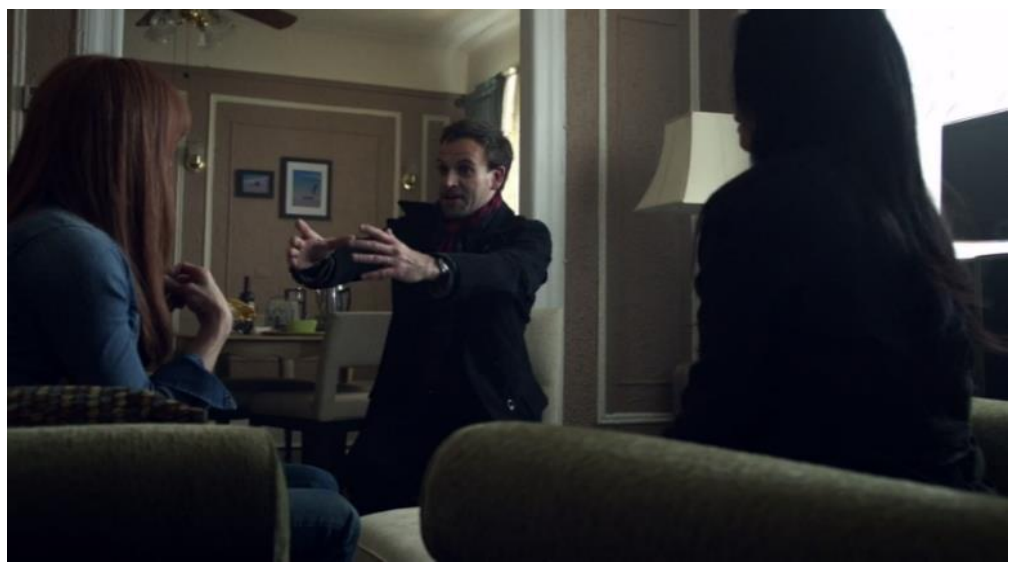

IMAGE 1-6: Sherlock demonstrates the distance of Eileen's attacker (Elementary 1:1) recalling the experience for

Eileen. When he explains

that by not coming

forward, she is guilty for

what happened to the other female victims, Joan ends the interrogation and exiles

him from the room. Minutes later, Joan emerges from the house and relates to Sherlock

that Eileen told her everything. Sherlock responds that he had predicted this would be the

\footnotetext{
35 When compared to Sherlock's relationship with Kitty, his protégé and a victim of abuse in Season 3, the development of his emotional empathy becomes clear.
} 
outcome and his behavior would illicit a bonding experience between the two women that would result in Eileen's confession. Joan responds, “'You are so full of it. You're just embarrassed because I figured out something that you couldn't and now you're making it seem like you planned the whole thing." At this point, Sherlock's phone rings and he completely evades her deduction. Later in the episode, Sherlock admits his fault and confirms Joan's rebuke:

"You were right the other day. About Eileen Renfro. I had no idea she would respond to you the way that she did. I just told you I did because I was embarrassed I'd lost my temper. Would I have gotten to the truth some other way? Of course, but... you got me there faster."

As the case unfolds, Sherlock lands himself in jail ${ }^{36}$ after ramming Dr. Mantlo's car in a fury of frustration. This incarnation of the detective feels and expresses intense emotional reactions; and although he may not always articulate it, through his actions and reactions the audience is aware that he cares deeply about the victims of the cases he investigates. An important break in the case hinges on Sherlock's emotional intelligence, his aptitude for cognitive empathy. As he and Gregson relax at a local bar, Sherlock's attention is drawn to a wrestler on the television. The wrestler's speech emanates rage, “'God, it feels good! Whether it's me, or both of us... your ass is mine! You're both dead!'” which Sherlock correctly identifies and connects to Peter Saldua's overturned washing machine and missing phone. Saldua had become enraged when he discovered he had mistakenly laundered his cell phone, which coupled with his steroid intoxication (courtesy of Dr. Mantlo who had prescribed tranquilizers but supplied him with steroids) led to his violent outburst against the laundry appliance. The missing cell phone turns up in a bag of rice, a natural desiccant. Joan is the one who identifies the incongruence that

\footnotetext{
${ }^{36}$ In the second episode, Sherlock feigns being arrested and in episode four he is almost arrested again.
} 
Peter Saldua was allergic to rice but yet a bag of it was located in his pantry, photographed, and placed in the crime scene file. Dr. Mantlo is no longer able to deny any connection to Peter Saldua (as he previously had) in the face of their recorded conversations. This is an important deviation from Watson's function in the original stories. As already mentioned, Watson and the reader of Doyle's stories are both "left in the dark" regarding Holmes's "line of deduction" (Sparling 203). Elementary fundamentally changes this dynamic. While Sherlock leads the track of the overall investigation, many of the most important features of the case are uncovered by other characters (such as Joan and his later protégé, Kitty). The investigations and their denouement at the close of the episode are both more collaborative.

\section{IRENE ADLER: THE WOMAN, THE DOMINATRIX, THE HEROINE}

Is the great detective capable of personal or emotional attachments? In the original stories, Holmes practices emotional restraint and his disdain for personal attachments is represented as a conscious and rational choice. Emotion, to the nineteenthcentury Holmes, epitomizes a dangerous threat to his rational pursuits. In order to fully understand the adaptation of Holmes's emotional life in Sherlock and Elementary, a closer look at Irene Adler is needed. Adler appears in Doyle's story “A Scandal in Bohemia," in Sherlock's "Scandal in Belgravia" (2:1), and is fused with the Moriarty character in many episodes of Elementary (starting at the end of season one ${ }^{37}$ ).

"A Scandal in Bohemia" was the first short story about Sherlock Holmes and was published after the first two novels. In Doyle's story, Irene Adler is an American opera

\footnotetext{
${ }^{37}$ Although allusions to her character begin in the pilot.
} 
singer who successfully outwits Holmes. Her possession of a photograph of herself and the King of Bohemia represents a danger to his impending royal marriage. She is not actively blackmailing the king; she holds the photo as security, thus, the threat is potential rather than actual. Holmes is hired to recover the material evidence of the royal personage's promiscuity but ultimately he is unsuccessful. Adler is notable for her ability to best Holmes at his own game.

During the course of the investigation, the detective dons two disguises: a "drunken-looking groom" (20) and a "simple-minded clergyman" (29). After uncovering Holmes's fake fire ruse, Adler dresses in her own disguise "a slim youth in an ulster" (35) and follows the pair back to their Baker Street apartment where she then audaciously bids Holmes goodnight by name. Holmes, completely unaware of her identity, remarks "I wonder who the deuce that could have been" (36). Adler uses her theatrical talents, her ability to put on and convincingly carry off a fictional role, to outmaneuver the great detective. Although the threat Adler poses is tempered through the domestication of marriage to Godfrey Norton (which occurs during the story and at which a confused Watson serves as witness), she is a remarkably empowered female character. Her intelligence and ability to read the situation and respond efficiently and effectively are the keys to her success.

Sherlock makes several important changes in adapting this character for the series. Taken as a whole, the representation is problematic and ultimately deprives the character of the power she exhibited in Doyle's story. In "A Scandal in Belgravia," Holmes and Watson are called in by Mycroft and the British government to recover incriminating evidence on an unnamed royal British personage which is in the possession of Irene 
Adler, the dominatrix. Again Irene takes on a role, the role of the sexually deviant dominatrix, but she has no real job or identity aside from this role. She has made a life out of dominating powerful and important people in the bedroom and gaining leverage on these individuals to ensure her own safety. But her representation as a part of the BDSM community is inauthentic and instead plays into stereotypical representations of this group. The performance of sexual deviance in the episode seems to serves the purpose of providing a shock factor rather than an authentic representation of the complexities of such communities and their practices.

The rewriting of Irene as a dominatrix is not in itself a doomed choice. She powerfully takes possession of her own sexuality and body in her first meeting with Sherlock, appearing totally nude. ${ }^{38}$ This stymies his attempts to "read" her, since he is taken aback by her nudity and is left with very little to go on (no clothes or other accessories). Furthermore, she demonstrates a great deal of intelligence as she works a case alongside him. The problems with her interpretation are related to fundamental flaws in the conclusion which rob her of agency. First, although she does outwit (this time, downright manipulate) Sherlock into making deductions which she may use in criminal pursuits, he is able to outwit her right back by gaining access to her locked cell phone, which contains all of her blackmail material. Second, Irene is working with or for (the episode is not entirely clear) Moriarty in trying to trick this information out of Sherlock. Third, Sherlock's cracking of her cell phone passcode ("I am SHERlocked") puts her in danger since the protection such information afforded her secured her sexually deviant (socially unacceptable) lifestyle and staved off repercussions from wronged parties. She

\footnotetext{
${ }^{38}$ Although out of stubbornness, Sherlock himself arrives at Buckingham Palace at the beginning of the same episode clothed in just a bed sheet.
} 
is forced to go on the run. By the conclusion of the episode, Irene has become the "damsel in distress" who must be saved from death at the hands of a Middle-Eastern threat by none other than Sherlock.

In rewriting Irene Adler as a dominatrix, the potentially dangerous message is that female empowerment can only come in the bedroom or by using the female body (and sex) as a weapon. In having Sherlock save Irene from certain death in the end, Sherlock has deprived an intelligent, capable female character of the power and agency she possessed in Doyle's original story. Finally, by wedding female sexual domination to the crime of blackmail, the foundation of consent on which the BDSM community is based, is entirely eroded.

In Elementary, a trauma involving Irene could be the trigger for Sherlock's disdain for attachment. In the first episode, as Sherlock sits in jail, Joan questions him about what happened in London,

SHERLOCK. Actually, you don't need to know anything other than that I'm a recovering addict. You want to know about London because you think it'll connect us in a more meaningful way. But in case you hadn't noticed, I don't have meaningful connections. Why are you smiling? JOAN. Because now I know it was a woman. SHERLOCK. What makes you say that? JOAN. You're trying too hard. Just like you were the other day with that tattooed lady. All that sex is repellent crap. You can connect to people. It just frightens you.

Yet again in this episode, Joan calls Sherlock out on the façade that he attempts to present to everyone else. She correctly reads the mysterious detective and offers her own diagnosis: Sherlock is capable of "meaningful connections" but, out of fear, he has put up walls. Most importantly, his substance abuse and emotional isolation both stem from an encounter with a woman. This early introduction builds to the climactic conclusion of the 
season, in which Irene Adler is revealed to be Moriarty herself. In this adaptation, it is not Sherlock who is resurrected from the dead but Moriarty who is given the miraculous comeback.

The most interesting insights into Sherlock's psyche in this season come from his identification with a murderer ${ }^{39}$ (Daren Sutter) in the episode, "Risk Management" (1:22). Daren is traumatized by guilt after the murder of his sister twenty years ago. As Kate, Sutter's wife reveals, “'his life is divided into two halves: before Leah’s murder, and after." Sherlock's life has similarly been divided in two by the perceived death of Irene Adler and resulting relocation from London to New York. Both Daren and Sherlock have been wracked by guilt for not being able to protect women integral to their lives. Joan's insight into the parallel situations facing Sherlock and Daren leads to the ultimate break in the case:

"What about Daren Sutter? I mean, he's a lot like you. Except he got what he wanted. He's at peace now. We've been trying to identify people who wanted to tear Sutter down, but what if he was tricked into killing Wallace Rourke by someone who wanted to lift him up?"

Joan's observation proves correct and they are able to determine that Kate Sutter, out of a desire to give Daren closure and prevent his potential suicide provoked by despair, provided him with a false perpetrator for his sister's death. What is even more interesting than this startling turn of events is how Joan is able to arrive at this conclusion. Before the quoted lines above, Joan has been pondering Sherlock's own predicament, since Moriarty has been toying with Sherlock during this case. Joan confesses to a weary Sherlock, "II was just thinking how difficult this case is for you. I know how badly Moriarty hurt you,

\footnotetext{
${ }^{39}$ In the season three finale, "A Controlled Descent," Sherlock almost beats a man to death who kidnaps Alfredo (his sponsor) and then relapses.
} 
and I was just thinking, I wish that I could fix it for you."” Joan's deduction that solves the case is contingent on her own emotional empathy with Sherlock. Both Joan and Kate wish to help men in their life who feel they have failed to protect the ones they loved.

Sherlock's lack of empathy is directly addressed when Irene resurfaces in "The Woman" (1:23). Sherlock admits to her, "“You know, you're the only person I ever empathized with." Irene responds with "“Empathy. You have changed." Who is right in this exchange? Has Sherlock undergone some drastic change under the tutelage of Joan Watson and now understands and feels empathy? Or was Sherlock capable of empathy before he partners with Joan, as evidenced by his remark? It is most likely a combination of both. While surely Sherlock's partnership with Joan and his participation in the Narcotics Anonymous program encourages empathetic impulses in the detective that ultimately help in his investigations rather than hinder, this is not to say that the detective was not capable of some empathetic responses prior to meeting her. What is important to remember when considering Irene/Moriarty's comments is that her understanding of the detective is filtered through her own perceptions, much as Watson's descriptions in the original stories. The audience cannot fully understand what Sherlock may have been like prior to the pilot episode and his cohabitation with Joan at the New York Brownstone.

The doubling motif of criminal and detective is here again evoked, as it was in Sherlock. Once Sherlock learns her true identity in "The Heroine" (1:24), they have a heated exchange that centers on their similarities. Moriarty says, "“I know how much pride you take in your uniqueness. But the truth is, I see everything you do. I feel it."' Sherlock asks if she is claiming that they are the same and her response is revealing, I'm saying I'm better and that's why I let you live, back in London. You were not the threat you had been made out to be. So I concluded my 
experiment and resumed my business. You proceeded to prove you were inferior by disappearing into a syringe.

Here Moriarty refers to her seduction of Sherlock as an "experiment" and considers Sherlock's impending substance abuse (and the underlying emotional causes) a sign of his inferiority. Although Sherlock is usually the one represented as cold and unemotional, in comparing him to Moriarty, the show provides evidence that he is capable of great emotional depth. By the conclusion of the episode, Moriarty's façade of cold calculation is also revealed as such. Again, it is Joan's correct reading of Moriarty's emotions that provide the solution. Sherlock explains:

You know... she solved you. The mascot. Watson. She diagnosed your... condition earlier this evening. She realized the real reason you could never... quite bring yourself to kill me. The reason you came back to my life.

The condition that Joan diagnoses Moriarty with is love. She correctly guesses that Moriarty's attempts to represent herself as unemotional were a front just as Sherlock's were, as introduced in the very first episode. Sherlock capitalizes on her weakness by faking an overdose and drawing her to the hospital, where the police arrest her. Both Sherlock and Moriarty claim an unemotional nature but it is a way to protect themselves and insupportable in the face of the true emotion expressed through their actions. Although Sherlock claims that falling in love was their mistake ${ }^{40}$ and asserts that it hinders his investigations, ${ }^{41}$ time and again the duo's detections rely on cognitive and emotional empathy for their solutions. The conclusion of the episode does not show a

\footnotetext{
40 "“We are... the same. You and I. We both made the same mistake. We fell in love. It made us stupid"” ("Heroine" 1:24).

41 " "Watson...most puzzles I see from the outside and it gives me a certain clarity. I am right in the center of this one. It has blurred my vision... to say the least. I just... I just lied to protect you" ("Risk Management" $1: 22)$.
} 
Sherlock once again retreating into his solitude in the face of overwhelming evidence against indulging in emotion. Instead his partnership and growing platonic feelings toward Joan offer hope that not all emotion is damaging. He even names a brand new species of bee after her ("Euglassa Watsonia") and they both sit on the Brownstone roof watching them "crawl their way into sunlight."

\section{CONCLUSION: REASON, EMOTION, AND HUMANITY}

Each incarnation of the famous detective builds on the central nexus of reason and emotion at the heart of the human condition; however, the solutions they provide to the mystery and method of Sherlock Holmes are drastically different. In Doyle's original stories, emotion represents a dangerous threat to the rational process that Holmes seeks to cultivate. It is his conscious choice to avoid such "intrusions," which he believes will cloud his judgment.

In Sherlock, the detective is represented as potentially having a psychological disorder. He is incapable of correctly identifying the emotions of both victims and those in his inner social circle but adept at cognitive empathy when reading the criminal mind (like that of Jefferson Hope). The motif of the criminal and detective doubling in this series represents Sherlock as a potentially dangerous genius. This is especially apparent in a crucial quote from Lestrade. In "A Study in Pink," a frustrated John Watson asks Lestrade why he tolerates Sherlock's eccentricities. Lestrade responds, “"because Sherlock Holmes is a great man. And I think one day, if we're very, very lucky, he might even be a good one." Lestrade's distinction between the "great man" and the "good one" seems paradoxical. Isn't "great" better than "good"? What Lestrade means is that while Sherlock is a "great" in his analytical abilities, he lacks the moral distinction of "good." It 
is through his partnership with John and developing relationships with other characters (Mrs. Hudson, Molly Hooper, Lestrade, and later Mary Morstan) that Lestrade hopes Sherlock will be able to develop a sense of empathy and emotional attachments that could help rather than hinder his life and work.

In the latest episode, "The Abominable Bride," Sherlock travels into his own subconscious mind through the use of his Mind Palace ${ }^{42}$ and some hallucinatory drugs. During the drug trip, Sherlock converses with his own manifestation of John about his capacity for emotion. This is an interesting reversal of the point of view provided in the original stories. There, the reader's understanding of the detective is filtered through the perception and representational strategies of Watson. Whereas in this instance, a representation of John is manifested from Sherlock's mind and their conversation hinges on this changed perspective. John presses Sherlock for an answer to the questions raised in this chapter, "Why do you need to be alone?" Sherlock responds with Watson's own words from Doyle's stories, many of which have here been quoted. Under continued pressure for an answer, Sherlock evades and even threatens suicide with the nearby revolver rather than answer. The conversation is interrupted by the case they are working. Although the questions remain largely unanswered, this exchange reveals that the crucial question of the detective's emotional capabilities is continually raised in this series just to be further frustrated. Additionally, this exchange is evidence that the questions are on Sherlock's mind.

In Elementary, Sherlock has sex, loves, and exhibits a high degree of cognitive empathy from the beginning of the series. Sherlock also proceeds to learn the value of

\footnotetext{
${ }^{42}$ The Mind Palace is Sherlock's updated brain attic. If his brain is a hard drive, as he often says in the show, then the Mind Palace is his cerebral virtual reality.
} 
emotional empathy in his method of deduction through his relationship with Joan Watson and his participation in the Narcotics Anonymous program. In "The Adventure of the Devil's Foot" Holmes makes a startling confession, “I have never loved, Watson"” (1422) but in Elementary's episode "Bella" (3:4), Sherlock directly contradicts this admission. In the episode, Sherlock is confronted with a computer (named Bella) which has potentially achieved artificial intelligence and may be culpable for the murder of its creator. Sherlock is called in to determine if Bella is capable of thinking for itself. Like the confrontation between Moriarty and Sherlock at the end of the first season, the contrast between Sherlock and this other entity is evoked in order to reveal more about

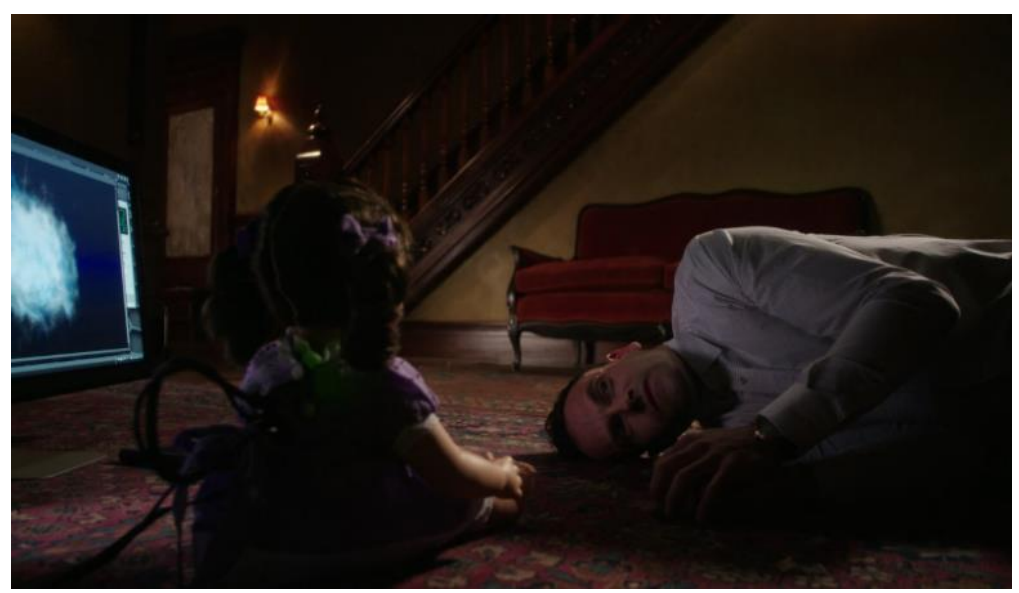
the mystery of the detective's personal relationship to emotion. At the conclusion of the episode, in a solitary moment (IMAGE 1-7),

IMAGE 1-7: Sherlock discusses the concept of love with Bella, the computer (Elementary 3:4)

Sherlock turns to asking

Bella about human emotion:

SHERLOCK. Is love real?

BELLA. I don't understand the question. Could I have more information? SHERLOCK. Love. Surely it's a human construct, a hedge against the terror of mortality. I believe that. But that doesn't account for times I've felt it myself. With my mother. Irene. Even, after a fashion, with Watson. It vexes. Love is either a human construct or it's a real thing, right? I know, you need more information.

BELLA. The question cannot be answered. The concept of "love" exists; therefore, it is useful even if it is a human construct. It exists because it serves a need. A question that can be answered might be, "Why is love needed?"

SHERLOCK. Why is love needed? 
BELLA. I don't understand the question. Could I have more information? In this exchange, Sherlock admits that he has, in fact, loved. He has loved his mother, Irene, and Joan Watson. The computer responds that love is a useful human construct. This mirrors Antonio Damasio's theory: “The strategies of human reason probably did not develop, in either evolution or in any single individual, without the guiding force of the mechanisms of biological regulation, of which emotion and feeling are notable expressions" (xii). Emotion is a product of evolutionary imperatives and trying to be completely rational and objective may not be ideal or even entirely possible. When Sherlock claims, in the concluding episodes of the first season of Elementary, that love is his mistake and has blurred his vision that is not to say that empathy is not a skill that can aid his deductive reasoning process, it is in line with Damasio's conception of the interworking structure of reason and emotion in cognitive processes. He writes:

Traditional wisdom has told us that they [emotions] can [cause havoc in the reasoning process], and recent investigations of the normal reasoning process also reveal the potentially harmful influence of emotional biases. It is thus even more surprising and novel that the absence of emotion and feeling is no less damaging, no less capable of compromising the rationality that makes us distinctively human and allows us to decide in consonance with a sense of personal future, social convention, and moral principle. (xii)

Emotions are not in opposition to the rationality that has historically defined what it means to be human, what sets us apart from the rest of terrestrial life. As revealed in this exchange with an inhuman entity, a true calculating machine, emotions are not only necessary, they are an integral part of what it means to be human. Earlier in this same episode, Mason (a college student working in the field of A.I. whom Sherlock consults) explains the theory that eventually intelligent machines will perceive the destruction of humans as their evolutionary imperative. He says, “'Well, it would escalate quickly. I 
mean, they're computers. They can't be reasoned with. They don't feel pity, or remorse, or fear. And they absolutely would not stop, not ever, until we're dead"' [emphasis added]. Mason's comment here is important. He says “they can't be reasoned with" and then explains this comment by evoking their lack of empathy as detrimental to the reasoning process. This demonstrates a major theme taken up in Elementary and that is the way in which rationality and empathy are both central to the human condition. If "the proper study of mankind is man," as we read when Watson quotes Alexander Pope in $A$ Study in Scarlet (27), then a crucial part of that study is human emotion. 


\section{CHAPTER II}

OPIUM AND TEA:

\section{SHERLOCK HOLMES, SMUGGLING, AND THE CHINESE}

\section{THE OCCIDENT AND THE ORIENT}

In 1929, Ronald A. Knox - a British scholar and author of detective fictionpublished a list of ten rules ${ }^{43}$ for the detective story that has become famous among readers and writers in this genre. Rule number five stated emphatically that "No Chinaman must figure in the story." While the rest of the rules in this decalogue all reinforce the Golden Age's prescription that the detective story be an intellectual puzzle_-"The criminal must be someone mentioned early"; "Not more than one secret room or passage"; "All supernatural agencies are ruled out"-rule five was never explained and has remained largely unintelligible. Knox himself seemed uncertain,

${ }^{43}$ Ronald Knox's Ten Commandments of Detective Fiction:

1. The criminal must be someone mentioned in the early part of the story, but must not be anyone whose thoughts the reader has been allowed to follow.

2. All supernatural or preternatural agencies are ruled out as a matter of course.

3. Not more than one secret room or passage is allowable.

4. No hitherto undiscovered poisons may be used, nor any appliance which will need a long scientific explanation at the end.

5. No Chinaman must figure in the story.

6. No accident must ever help the detective, nor must he ever have an unaccountable intuition which proves to be right.

7. The detective must not himself commit the crime.

8. The detective must not light on any clues which are not instantly produced for the inspection of the reader.

9. The stupid friend of the detective, the Watson, must not conceal any thoughts which pass through his mind; his intelligence must be slightly, but very slightly, below that of the average reader.

10. Twin brothers, and doubles generally, must not appear unless we have been duly prepared for them. (xi-xiv) 
“"Why this should be I do not know,' Knox quickly and alarmingly adds" (Glover 38). But there does seem to be a connection between the Western genre of detective fiction and China, one likely related to the association of the Orient with mystery and inscrutability in the Western imagination. As Edward Said explains in Orientalism, an eighteenth-century definition ${ }^{44}$ identifies "Oriental” as "an amateur or professional enthusiasm for everything Asiatic, which was wonderfully synonymous with the exotic, the mysterious, the profound, the seminal" (51). It is reasonable to assume that Knox foresaw the use of a Chinaman as tantamount to the use of the supernatural, as a shortcut to evoking the unknown. Just two years before Knox's Decalogue, in 1927, Arthur Conan Doyle published his last Sherlock Holmes story. References to China in the original Sherlock Holmes canon are allusive but revealing. China appears as a spiritual and mysterious land while the Chinese in London represent the threat of physical and moral contamination. Not one of the original sixty stories features a central Chinese character. ${ }^{45}$ And yet Chinese characters are being reworked into current adaptations, such as Sherlock and Elementary.

While chapter one considered the crime of murder and the representation of the detective figure, this chapter will shift its focus to an exploration of Orientalism, Chinese criminality and, more specifically, the crime of smuggling. In representing criminality, detective fiction has two strands. One kind exonerates the community of guilt through a process of othering the culprit: they were evil, mentally ill, from somewhere else, etc. This type of detective narratives represents the criminal as a type fundamentally unlike

\footnotetext{
${ }^{44}$ More specifically Said is summarizing the definition put forward in Raymond Schwab's La Renaissance orientale.

${ }^{45}$ Chinese characters are mentioned but they are never described or given an opportunity to speak.
} 
the rest of the community within the story, and, by association, the normative audience. The second kind represents the criminal as one of the community, often a well-respected bourgeois member of society. This second kind of detective fiction indicts society itself and provokes thought about how and why this sort of crime was committed and how it could be prevented from happening in the future. Arthur Conan Doyle's stories and Sherlock represent the criminal as an Other to society, while Elementary explores the larger, systemic problems which have created the conditions for criminal activity.

In this chapter, I will use the crime of smuggling as a lens to examine the Chinese presence first in the original stories and then in Sherlock and Elementary. Smuggling is the illegal transportation of goods or people across national and political borders; it is an importation or exportation that has been banned. As a crime that crosses national borders, smuggling illuminates the contact between different countries and peoples, and the ways legality is both constructed and bound to place. Studying this illegal trade in a specific geographic and historical context can lead to a clearer understanding of complex intersections between morality and economy.

Smuggling is defined as an act of deception, since it has been deemed illegal for those goods or people to cross that particular border. The West has a long history of stereotyping the Chinese as duplicitous, ${ }^{46}$ making a consideration of a crime predicated on deception a fitting nexus for this examination. In fact, a form of smuggling is presented in all three series and specifically associated with the Chinese. In Doyle's canon, smuggling is the underlying historical and economic context between the Chinese

\footnotetext{
46 "[...] one of those Manichean stereotypes - the wily, manipulative, duplicitous, inscrutable Chinaman" (Strahan 304); “[...] upon stereotypes of Chinese women as two-faced and duplicitous" (Lozensky 121); "[...] replaced by a different stereotype, that of the Chinese as duplicitous and backward" (Thompson 432).
} 
and British empires which goes largely unacknowledged. In Sherlock's episode, “The Blind Banker," the Chinese characters are all smugglers for the Black Lotus criminal syndicate, smuggling both drugs and antiquities out of China. In Elementary's episode, "You Do It To Yourself," the smuggling of people, or illegal immigration, to the United States from China becomes a focus.

\section{CHINA AND THE WEST: DRUGS, DISEASE, AND DEATH}

In the original Sherlock Holmes stories, there are three important, albeit marginal, references to China or Chinese immigrants living in London. These references occur in "The Adventure of the Empty House," "The Adventure of the Dying Detective," and "The Man with the Twisted Lip." In "The Adventure of the Empty House," Sherlock's journey to Tibet represents China as a spiritual and forbidden territory. In "The Adventure of the Dying Detective," the Chinese in London are an implied source of physical contamination. Finally, in "The Man with the Twisted Lip," the threat of physical and moral contamination from the Chinese living in London is evoked through the descriptions of the opium den and the drug's debilitating effects.

"The Adventure of the Empty House" was first published in 1903 but the story is set almost a decade earlier, in 1894. In this story, Holmes's first appearance since his "death," ${ }^{47}$ he explains where he has been during what is referred to by readers and scholars of the tales as "The Great Hiatus." ${ }^{48}$ In the narrative, Watson is eager to hear

\footnotetext{
47 The Hound of the Baskervilles (1902) was published in between "The Final Solution" and "The Adventure of the Empty House" but it was set prior to Holmes's death.

48 "The Great Hiatus" spanned a decade in reality (1893-1903) but in the fictional world of Holmes and Watson, it only lasted four years (1891-1894).
} 
what his friend has been doing during these four years apart and presses him for an explanation. Holmes responds:

"Now, my dear fellow, in the matter of these explanations, we have, if I may ask for your co-operation, a hard and dangerous night's work in front of us. Perhaps it would be best if I gave you an account of the whole situation when that work is finished."

"I am full of curiosity. I should much prefer to hear now." (791)

Watson's curiosity mirrors the reader's own need for details about his adventures during this time, which is rewarded with allusions to far-off and exotic locations. Once Holmes explains to Watson how he escaped the Reichenbach Falls encounter with Moriarty, he describes his various travels. He has travelled to Tibet, Persia (Iran), Mecca (in Saudi Arabia), Khartoum (in Sudan), and Montepellier, France. The first four locations are representative of the vast amount of territory labeled as the Orient by the West: the Far East (Tibet), Middle East (Iran and Saudi Arabia), and North Africa (Sudan). He begins in Tibet, "“I travelled two years in Tibet, therefore, and amused myself by visiting Lhassa, and spending some time with the head Lama"” (794). Lhasa is the capital city of Tibet and also home to the Potala Palace, which, at the time, was the Dalai Lama's residence. This one sentence is all the description Watson and the reader are allowed to cover a span of two years in China. It is a brief statement that covers over a complex relationship between the British and Chinese during this time period. Leslie Klinger's annotations to the text are revealing:

In visiting Tibet, Holmes was in fact violating a century-old ban against foreigners, instituted in 1792 after a Gurkha invasion. Tibetans deeply mistrusted a British government not only connected to the Gurkhas but also plainly covetous of a trade route to China through Tibet. (795, note 30) 
In 1903, the same year this story was published, fearing that Russia was gaining more influence over the Dalai Lama, the British government sent a military force into Tibet. Over six hundred Tibetans were killed, the Dalai Lama was forced to flee to Mongolia, and the British were finally able to negotiate a treaty with Tibet. While the reference in the text is brief, the historical context connected to this allusion reveals a nexus of economic, political, and religious strife between China and the British Empire. Tibet is evoked as a forbidden (for the British, at least) and spiritual territory during a time when the detective is in between his own death and resurrection. Holmes continues: "II then passed through Persia, looking in at Mecca, and paid a short but interesting visit to the Khalifa at Khartoum, the results of which I have communicated to the Foreign Office"” (794). Passing through Persia (or modern day Iran), Holmes then pays visit to another holy city, Mecca $^{49}$ (in modern day Saudi Arabia). Khartoum is a city in the North African country of Sudan and Khalifa was the leader of the religious and political movement, the Mahdiyya. Thus, three of the first four locations are coupled with allusions to religion: Tibetan Buddhism, Islam's holy city of Mecca, and the Madhist movement. In contrast, Holmes's time in France is devoted to scientific inquiry, experimenting with coal-tar derivatives.

Sherlock Holmes's time spent abroad during "The Great Hiatus" represents the Orient as a spiritual and forbidden land. The other two stories with Chinese references reflect the contemporaneous fear of contamination from Chinese immigrants living in London. Susan Harris argues in "Pathological Possibilities: Contagion and Empire in Doyle's Sherlock Holmes Stories" that the British feared physical and moral contagion

\footnotetext{
${ }^{49}$ Mecca is Islam's holiest city and the birthplace of the Prophet Muhammad.
} 
(or degeneracy) from peoples, animals, and plants from the colonies and that this fear was both capitalized on and assuaged through "Holmes's role as a specialist whose 'powers' enable him to allay anxieties about the potentially harmful effects on metropolitan culture of England's increasingly intimate contact with the peoples and cultures on the peripheries of the Empire" (448). Both the fake disease in "The Adventure of the Dying Detective" and the opium in "The Man with the Twisted Lip" are represented as poisons and both are connected to the Chinese.

Sherlock feigns illness in "The Adventure of the Dying Detective" 50 in order to entrap Mr. Culverton Smith, a plantation owner turned student of infectious diseases whom Holmes suspects of killing his own nephew. The origin of the feigned disease is unclear, ${ }^{51}$ much as the disparate areas within the Orient are all aggregated into a homogenous whole, but a Chinese source for a deadly disease is twice evoked in the narrative. Mrs. Hudson opens the story by telling Watson that Sherlock contracted the disease while working a case, "“There is little I can tell you, sir. He has been working at a case down at Rotherhithe, ${ }^{52}$ in an alley near the river, and he has brought this illness back with him'” (1342). When Watson meets with the sick detective, Holmes says with confidence, "I know what is the matter with me. It is a coolie disease from Sumatra"” (1343). Once again, this reference to China is assigned to the margin. Leslie Klinger's annotation of the word "coolie" reveals that it may refer to "an unskilled labourer from

\footnotetext{
${ }^{50}$ This story, published in 1913, is one of seven cases published in His Last Bow which are set before the "Great Hiatus." Scholars date its occurrence in the fictional universe of Holmes and Watson between 1887 and 1890 (Klinger 1341).

${ }^{51}$ The disease's origin may be Indonesia, India, or China. It is referenced by Holmes as a "disease from Sumatra," an island in Indonesia. The reference to "coolies" introduces the possibility of it coming from India. Finally, there are two references to Chinese dock workers.

${ }^{52} \mathrm{~A}$ peninsula along the Thames in Southeast London.
} 
Asia. Generally from India or China" (1343, note 6). Later in the story, the ambiguous reference to coolies is replaced by a more specific reference to the Chinese as the source of contamination. First, Watson tells Smith, an expert in Eastern diseases, why he suspects an eastern origin, "'Because, in some professional inquiry, he [Holmes] has been working among Chinese sailors down in the docks"” [emphasis added] (1352). This is later seconded when Sherlock asks about the meeting with Smith and Watson replies, "II told him about the Chinese in the East End"” (1353). Although it is eventually revealed in the denouement that Holmes never contracted a disease from the Chinese sailors and the whole illness was a ruse, the reference to the Chinese represents the threat they posed (at least in the imagination of the average Londoner). China is mentioned once more in the story when Holmes attempts to demonstrate Watson's incompetence in treating infectious diseases by asking him about two specifically, “'Shall I demonstrate your own ignorance? What do you know, pray, of Tapanuli fever? What do you know of the black Formosa corruption? ${ }^{53} ",(1344)$. Tapanuli is in northern Sumatra and Formosa is an island off the coast of China, which is now known as Taiwan. ${ }^{54}$

"The Man with the Twisted Lip" was published in December of $1891^{55}$ in the first installment of twelve stories for The Strand following the initial two novels. In the narrative, two different London gentleman have been morally corrupted by the seedier areas of the city, and their wives beg for their return. The bulk of the story is focused on

\footnotetext{
${ }^{53}$ For more on discussion of these diseases see Vora, Setu K. "Sherlock Holmes and a biological weapon." Journal of the Royal Society of Medicine vol. 95, no. 2, 2002, p. 101-103. and WA Jr., Sodeman. "Sherlock Holmes and tropical medicine: a centennial appraisal." Am J Trop Med Hyg, vol. 50, no. 1, 1994, p. 99-101

${ }^{54}$ Officially known as the Republic of China, Taiwan became home to the leadership, members, and families of China's Nationalist Party who fled the mainland after the Chinese Communist Party won the civil war and established the People's Republic of China in 1949.

${ }^{55}$ The events in the story are set in June of 1889.
} 
the successful apprehension of the man with the twisted lip, Neville St. Clair, who has given up his career in journalism in order to daily disguise himself as a beggar, which he sees as a more lucrative trade. But the story begins with another, parallel missing person case. Isa Whitney, a respectable gentleman, has gone missing, presumably lost in an opium den in East London, and his wife visits Mr. and Mrs. Watson to beg their help in rescuing him. The story starts with a description of his moral descent at the hands of the drug:

Isa Whitney, brother of the late Elias Whitney, D.D., Principal of the Theological College of St. George's, was much addicted to opium. The habit grew upon him, as I understand, from some foolish freak when he was at college [...] He found, as so many more have done, that the practice is easier to attain than to get rid of, and for many years he continued to be a slave to the drug, an object of mingled horror and pity to his friends and relatives. I can see him now, with yellow, pasty face, drooping lids and pin-point pupils, all huddled in a chair, the wreck and ruin of a noble man. (159)

First, Isa Whitney's moral decline is emphasized by foregrounding his filial connection to the Theological College's president, now deceased. It is all the more reprehensible and tragic since the man is connected to a moral pillar of the community. Second, the physical harm of the drug is emphasized in the descriptions of his appearance, "yellow, pasty face, drooping lids, pin-point pupils." Isa Whitney has become "yellow" like the Chinamen who run the opium dens and are associated with the drug. His eyes and stature bespeak a man given over to the perceived lassitude of the East. This is further emphasized once Watson confronts Whitney about his absence for two days. Whitney is dumbfounded and believes he has only been gone a few hours (164). He is both "slave to the drug" and "the wreck and ruin of a noble man." His addiction serves as both a physically and morally debilitating force. 
Two things are important to understanding the historical context of the opium dens. First, the differing opinions in the West about ingesting opium as a pharmaceutical and opium smoking. Second, the Opium Wars and the unequal treaties with the West that resulted are an origin for mutual distrust between China and the West. Ingesting opium in the form of laudanum and other tonics was not only an acceptable practice but widespread in Europe and North America at this time. In Opium: A Portrait of the Heavenly Dream, Barbara Hodgson explains the double standard about opium regarding the method of ingestion, "Not that the whites didn't have their own drug problems; patent medicines containing liberal quantities of alcohol and/or opium were very popular [...] well over 200” (Hodgson 106). Opium eating was a widespread practice among the middle class at this time, with tinctures available even for infants. The drug was accessible for legal consumption in Britain until the $1920 \mathrm{~s}^{56}$ (Hodgson 137).

The moral contextualization of the opium den and the drug's connection with anti-Chinese sentiment covers over the economic context between the Chinese and British empires at this time. In the nineteenth century, the British Empire was engaged in a pyramid trade of opium, farming poppies and manufacturing the drug in India and smuggling it into China via freelance privateers (Hodgson 32-4). The smuggling of opium was a major source of income funding the empire's massive expenses, “Opium revenues are consistently linked to maintaining the Empire by covering the cost of imperialism" (Deming 5). The British resorted to the drug trade because they had begun to accrue a massive trade deficit with China:

The problem with China was that it didn't really want the goods offered by Britain, the United States and European nations in exchange for its

\footnotetext{
56 While the U.S. Congress banned the importation of opium earlier, under the Opium Exclusion Act of 1909.
} 
badly needed tea, silk and rhubarb. So the British, in an effort to maintain a trade balance, focused on the lucrative sale of contraband opium.

(Hodgson 34-35)

The British faced initial setbacks because the Qing dynasty, the ruling Chinese government at the time, made repeated attempts to control the substance and discourage its usage ${ }^{57}$ which eventually led to the First Opium War (Hodgson 34 and 44). After the British won the first war, the territory of Hong Kong was ceded to British rule in the Treaty of Nanking (1842) and this territorial foothold made the smuggling operation easier, "By 1856, with piracy, opium smuggling and addiction were at an all-time high" (Hodgson 46). Sarah Deming argues that the more goods China exported to the British Empire, the more opium was smuggled into China to make up the difference. The British Empire's moral justification for their colonial ventures was hard to reconcile with the drug trade they were engaged in:

Supplying an illegal commodity like opium must have required a fair amount of self-justification on the part of the European officials and traders. Many were God-fearing men who would have been horrified to promote the addictive substance in their own countries. [emphasis added] (Hodgson 41)

The importance here is the location of the drug trade. It was only when the Chinese began immigrating to primarily white-dominated areas that opium and the dens (where it was smoked) became a widespread issue of debate in the West. After the Sino-British trade began, Chinese sailors started living in Limehouse, a small area in east London by the docks.

Consciousness of the Chinese in England and of their opium smoking was related to increased Chinese immigration. It is clear that the number of Chinese settling in London began to expand quite rapidly in the 1860s. In 1861, there were an estimated 147 Chinese in the whole country, by 1881 , 665. (Berridge and Edwards 195)

${ }^{57}$ As early as 1799 the Qing dynasty outlawed the drug. 
At the same time, Chinese immigrants were moving to the United States and Canada for jobs building railroads. Dangerous Chinatowns sprang up in North America (with sprawling populations and a preponderance of opium dens). A strong anti-opium movement developed, largely in response to the growth of Chinatowns in these urban areas, "Chinatowns rapidly became the focus of innumerable newspaper and magazine articles, social investigations, government studies, and the target of countless crusades, largely because of prejudice and the opium curse" (Hodgson 106). The movement immortalized a specific image of the opium den as filthy, carnal, and populated by immoral Chinamen and a few corrupted white men in the anti-opium literature and fictional narratives, such as "The Man with the Twisted Lip."

It is against this backdrop that we need to consider Watson's descriptions of the opium den and their locus within the metropole. The opium den in the story, which is named "The Bar of Gold," is located along the Thames docks in the fictional Upper Swandam Lane:

Upper Swandam Lane is a vile alley lurking behind the high wharves which line the north side of the river to the east of London Bridge. Between a slop shop and a gin shop, approached by a steep flight of steps leading down to a black gap like the mouth of a cave, I found the den of which I was in search. Ordering my cab to wait, I passed down the steps, worn hollow in the centre by the ceaseless tread of drunken feet and by the light of a flickering oil lamp above the door I found the latch and made my way into a long, low room, thick and heavy with the brown opium smoke, and terraced with wooden berths, like the forecastle of an emigrant ship. (163)

If London is the heart of the British Empire in the nineteenth century then the Thames River is its major vein or artery. It was the contact zone between London and the reaches of empire, as ships loaded with goods and people both arrived and left the docks located 
along its banks. Often when the Chinese are mentioned or alluded to in the original Sherlock Holmes stories, they are accompanied by references to the docks along the Thames, a zone of contact between London and the empire's peripheries. As already mentioned, in "The Adventure of the Dying Detective" when Holmes refers to his exposure to a coolie disease, it is through contact with "Chinese sailors at the docks" (1352). In this story, "The Gold Bar" is similarly positioned within this contact zone, which is represented as a site of corruption.

Watson's language here is important. The alley is "vile" and "lurking." The den is associated with the debauchery of drunkenness. It both stands next to a gin shop and the stairs are worn down by "the ceaseless tread of drunken feet." The use of light and dark imagery is also to be noticed. The only light comes from a "flickering oil lamp," which may go out at any time. The stairs end in a "black gap" and the opium smoke is "brown." Dark colors are used in literature throughout this period to represent ignorance, evoke primitive peoples (with non-white skin colors), and to contrast with the perceived enlightenment and purity of the white man. Watson likens his descent down the stairs to entering the "mouth of a cave." This description associates the opium den, and its likely Chinese proprietors ${ }^{58}$ with the primitive and animalistic. It is as if Watson's journey down a flight of stairs is a journey back in time. The simple phrase evokes a fear of regression and degeneracy, often associated with non-European races at the time, "The fear of pollution through opium smoking was extended into a belief that opium smoking was spreading among the white middle-class population. The establishment of such a practice was thought to be an illustration of racial degeneracy" (Berridge and Edwards

\footnotetext{
${ }^{58}$ The attendant in the opium den is Malaysian.
} 
199). Once Watson enters the den, its construction is likened to "an emigrant ship." A previous allusion to the Chinese, the coolie, appeared in "The Adventure of the Dying Detective" and Leslie Klinger's annotation to the text revealed that "conditions of passage for Chinese coolies in particular were horrendous: Thousands died in the crowded, miserable conditions on board the ships" (Klinger 1343, note 6). It is as if the Chinese, after arriving in London, cannot escape their liminal status, even their dens resemble and evoke this difficult passage.

Twice in the story opium is described as a poison. When Mrs. Whitney visits the Watsons, she says her husband is most likely "among the dregs of the docks, breathing in the poison or sleeping off the effects" (161), and once Watson enters the den and describes the scene, "Out of the black shadows there glimmered little red circles of light, now bright, now faint, as the burning poison waxed or waned in the bowls of the metal pipes" (163). Susan Harris argues, "Poison in the Holmes tales thus becomes a metaphor for the physical, moral, and cultural contamination that Britain feared as its empire brought it into closer contact with Asian and African peoples, cultures, and climates" (449). This fear of physical and moral contagion from without is evoked in the story in order to offer a guarantee about its containment in the story's denouement. Rosemary Jann argues, “Among contemporaries unsettled by fears of cultural disintegration, he [Holmes] surely owed much of his popularity to the reassurance offered them by the reiterated spectacles of successful detections, dangers contained, order restored, and values reaffirmed" (6).

Virginia Berridge and Griffith Edwards in "The Myth of the Opium Den” explain the radical transition in representations of opium smoking that took place in the late 
nineteenth century. While earlier portrayals of the opium dens "are notable for their calm descriptions of the practice" (196), "the den as a haunt of evil, the evil and cunning Chinaman wreathed in opium fumes had their origin as public images in the 1870s" (Berridge and Edwards 197). Writers such as Oscar Wilde, Charles Dickens, and Doyle "emphasized the links with mystery and evil, the degrading and demoralizing effect of the drug's use on both English and Chinese smokers" (Berridge and Edwards 196). This established the dens as a locus for a potential double threat of contamination, both physical and moral, from the Chinese and the drug associated with this ethnicity. ${ }^{59}$ Barbara Hodgson seconds the important role that fictional descriptions of the opium dens played during this time:

Writers such as Charles Dickens, Arthur Conan Doyle, and later, Sax Rohmer and Thomas Burke, portrayed Limehouse as one of the most mysterious places on earth. Constantly shrouded in a fog of river mist and opium smoke [...] Opium dens multiplied like a plague of rats, and the heart of the pestilence supposedly was the 'Chinamen.' (123)

This is the effect of Holmes's pronouncement on "The Gold Bar." He tells Watson, "We should be rich men if we had a thousand pounds for every poor devil who has been done to death in that den. It is the vilest murder-trap on the whole of the river-side" (168). The superlative adjective "vilest" both confirms Watson's opening description of Upper Swandam Lane as "vile" and takes it further. Second, both "murder" and a "trap" imply agency and intention. A den cannot be a murder-trap unless there is someone setting the trap and committing the murder. Although this story never once mentions China or the

\footnotetext{
${ }^{59}$ It is important to noteph here that the People's Republic of China has officially recognized 56 different ethnic groups but specific ethnicities for the characters are not provided in the context of the original Doyle stories or the modern adaptations.
} 
Chinese ${ }^{60}$ the connection between opium and the Chinese for the London and American readership during the late nineteenth century would have been evident.

\section{REPRESENTING CHINA IN SHERLOCK AND ELEMENTARY}

Recognizing these marginal but integral instances of Eastern evils within the original Sherlock Holmes canon, illuminates the controversial representation of the Chinese in Sherlock's episode "The Blind Banker" and the way in which the representation of Chinese characters in Elementary's "Pilot" and "You Do It To Yourself" (both from season one) talk back to this inherited discourse of Orientalism. Sherlock deploys Chinese characters and elements through an aesthetic of opposition. By "aesthetic of opposition" I mean that the point in including Chinese characters and motifs in this episode is to use the mere surface appearance to evoke an aesthetic reliant on exoticization and mystery (as opposed to the familiar and commonplace). The Chinese are opposed to the British in their representation as exotic, deadly, and seeminglyindecipherable.

Soo Lin Yao has an important line at the beginning of "The Blind Banker." She says, "Sometimes you have to look hard at something to see its value." Although she is discussing teapots in this scene, it reveals the way every Chinese element and character are treated throughout. The theft of the Chinese hairpin (the impetus for the precipitating murders) is incorrectly valued by Edward Van Coon. Soo Lin Yao initially appears as an innocent but later reveals she has a criminal past of her own. Two other Chinese characters, General Shan and Liang Yao, are smugglers posing as Chinese acrobats. The

\footnotetext{
${ }^{60}$ Leslie Klinger's annotations to the story do fill in some of the context surrounding the Opium Wars and the descriptions immortalized in the literature of this time period.
} 
Suzhou ${ }^{61}$ numerals are both a notation system for Chinese traders and a cipher used in a book $^{62}$ code by the smugglers. All reveal a duplicity of meaning: a surface reading and a deeper, secret meaning beneath, which is eventually uncovered by Sherlock in the episode. As Anne Kustritz and Melanie Kohnen argue in "Decoding the Industrial and Digital City" both incarnations of the famous detective in Doyle's text as well as the $\mathrm{BBC}$ series "offer reassurance about safety in the city by decoding people and places using contemporary technologies" (85). Therefore, what initially appears indecipherable (these Chinese characters and motifs) is, by the close of the episode, correctly decoded by the British detective.

In contrast, Elementary directly confronts Sherlock's reliance on physical appearance and, in the ninth episode, detective fiction's inheritance of what Edward Said calls Orientalism as well as the problematic history of Chinese immigration to the U.S. In the first episode of Elementary, Joan espouses a very different thematic that the show builds upon concerning the relationship between surface appearance and detecting deeper meaning. She says to Sherlock, "It's so incredible, the way that you can... solve people just by looking at them. I noticed you don't have any mirrors around here" ("Pilot" 1:1). Joan not only draws attention to Sherlock's traditional reliance on judgements predicated on surface readings but also draws attention to the detective's own complicated subjectivity. ${ }^{63}$

\footnotetext{
${ }^{61}$ Incorrectly referred to as Hang Zhou numerals in the episode: "The Suzhou numerals (Chinese su1zhou1ma3zi) are special numeric forms used by traders to display the prices of goods. The use of 'HANGZHOU' in the names is a misnomer" (Freytag, McGowan, and Whistler).

${ }^{62}$ The chosen book, London A-Z, is also concerned with place and double meaning. The book is usually a tool that makes navigating or reading the city easier for non-natives but it has been perverted for the function of illegal crime in the city, unbeknownst to the typical Londoner.

${ }^{63}$ The detective's own subjectivity becomes the investigation in Postmodern (or metaphysical) detective fictions: such as Alain Robbe-Grillet's The Erasers, Paul Auster's The New York Trilogy, and Jorge Luis Borges's "Death and the Compass" (for further discussion of this later branch, see Detecting Texts: The
} 


\subsection{Sherlock's Aesthetic of Opposition}

While the historical context of contact between the British and the Chinese reveals the British engaged in smuggling drugs into China, the context of Sherlock's "The Blind Banker" reverses the scenario. In fact, the Black Lotus criminal syndicate is involved in the smuggling of Chinese antiquities into the UK. In this episode, although London and Sherlock's methods for detection have been updated for the contemporary world (the latter at least superficially, through his use of cell phones and internet browsing), the modes of representing China and the Chinese, however, remain firmly rooted in the past.

The structuring of detective fiction necessitates a branching out into the everyday lives of the city's citizens as the investigations involve an untangling of many individuals' activities leading up to the crimes depicted. This feature makes the representation of an urban collective a prerequisite of the stories. In Doyle's Sherlock Holmes adventures, the representation of Victorian London is a crucial element: "Fans and scholars of the original tales often speak of London as the essential third character almost ever-present beside the Doctor and the Detective" (Faye 4). The transformation from an idyllic past to the present necessarily generates critical inquiries into the verisimilitude of the portrayals of these cosmopolitan metropolises and the ideological underpinnings that these representations reflect. How has this third character, the London metropolis, been represented in a twenty-first century context?

Metaphysical Detective Story from Poe to Postmodernism). This is specifically tackled in Elementary with Sherlock's ongoing struggle with drug addiction and recognizes the intervening developments of the genre. Elementary is able to put Doyle's original detective into dialogue with the breakdown of subjectivity that came about in the wake of WWII and the crime and detective literatures of Modernism and Postmodernism. 
When most recent crime dramas on British TV depict an "urban and gritty" London (Kustritz and Kohnen 225) and "cast their maverick heroes as bound by bureaucratic restraints and socio-political pressures" (Kustritz and Kohnen 226), several critics have argued that Sherlock is set in an "imaginary landscape that covers over the social, political, and economic realities of a country torn by immigration and mulitcultural conflicts" (Stein and Busse 224). In fact, Mark Gatiss, one of the show's creators, said that in Sherlock they "wanted to fetishize modern London in the way, I suppose, the period versions sort of fetishize Victorian London." In this episode specifically, the juxtaposition is between the "Big glass and steel cathedrals of finance" (Gatiss in "Unlocking Sherlock") and the ancient, indecipherable, and criminal Chinese. Even the lair of the Yellow Dragon Circus (a cover for the Black Lotus Tong), where General Shan and Zhi-zhu hold Watson and his date hostage, is a stone, cave-like tunnel, opaque and dimly lit. This seems to echo the description of the opium den in "The Man with the Twisted Lip" as a descent into a dark cave. These representations set up Chinese culture, motifs, and people as the outdated side of a certain teleological progression that presents London and the British on the side of progress. Ultimately, the episode's "representations of Chinese culture as fundamentally alien to modern Britain places the viewer in a spectatorial position complicit with Orientalism" (Kustritz 99). In reality, London is a lot more complex and diverse than depicted:

Sherlock seems to highlight the problematic nature of British identity at this cultural moment, when [a] traditional white, English centric view of being British jostle with [a] more modern view of British identity as the center of a global media complex. (Rixon 177)

Therefore, the stereotypical treatment of the Chinese reveals exactly what Homi Bhabha describes as the function of the stereotype in "The Other Question," an underlying 
anxiety that the dominant, white populace are trying to allay (117). In this case, the Chinese are represented as threatening and this threat is assuaged through the construction of a knowable universe and a capable detective-hero who reasserts order in the denouement. "The Blind Banker" left many Londoners descrying this unrealistic portrayal of their urban environment, "This London is not one we in London know, it is not one that really exists" (Rixon 175). The depiction of the Chinese characters (through the use of costume, the framing of the shots, their relationship to setting) is fundamentally reliant on an aesthetic of opposition that presents them as drastically other to white British identity. The episode capitalizes on the difference of the Chinese in order to reassert a stable sense of national identity in the UK, "The myth of historical origination [...] produced in relation to the colonial stereotype functions to 'normalize' the multiple beliefs and split subjects" (Bhabha 106). I have already discussed how the stereotype of the opium-smoking, criminal Chinaman originated during the late nineteenth century when Chinese began immigrating to the West in large numbers. This stereotype of the Chinese is an inheritance from colonialism which continues to inform Sherlock. "The Blind Banker" reasserts a sense of order and structure in its refusal to show British subjects of mixed ethnic backgrounds and instead produces a clear dichotomy between foreign, Chinese and white, British characters.

\subsubsection{Soo Lin Yao Performs Ethnicity}

An analysis primarily focused on the representation of Soo Lin Yao and Liang Yao (alias Zhi-zhu) will illustrate how this dichotomy is constructed in the episode. "The Blind Banker" opens with a scene in the Museum of National Antiquities where Soo Lin 
Yao, a Chinese museum worker, ${ }^{64}$ is performing a teapot seasoning demonstration before a group of enraptured onlookers. Before the viewer ever sees Soo Lin's face, the camera focuses on her hands on the teapots and cuts to the face of a little white girl watching her. The camera cuts from Soo Lin's hands on the teapot to the little girl's face several more

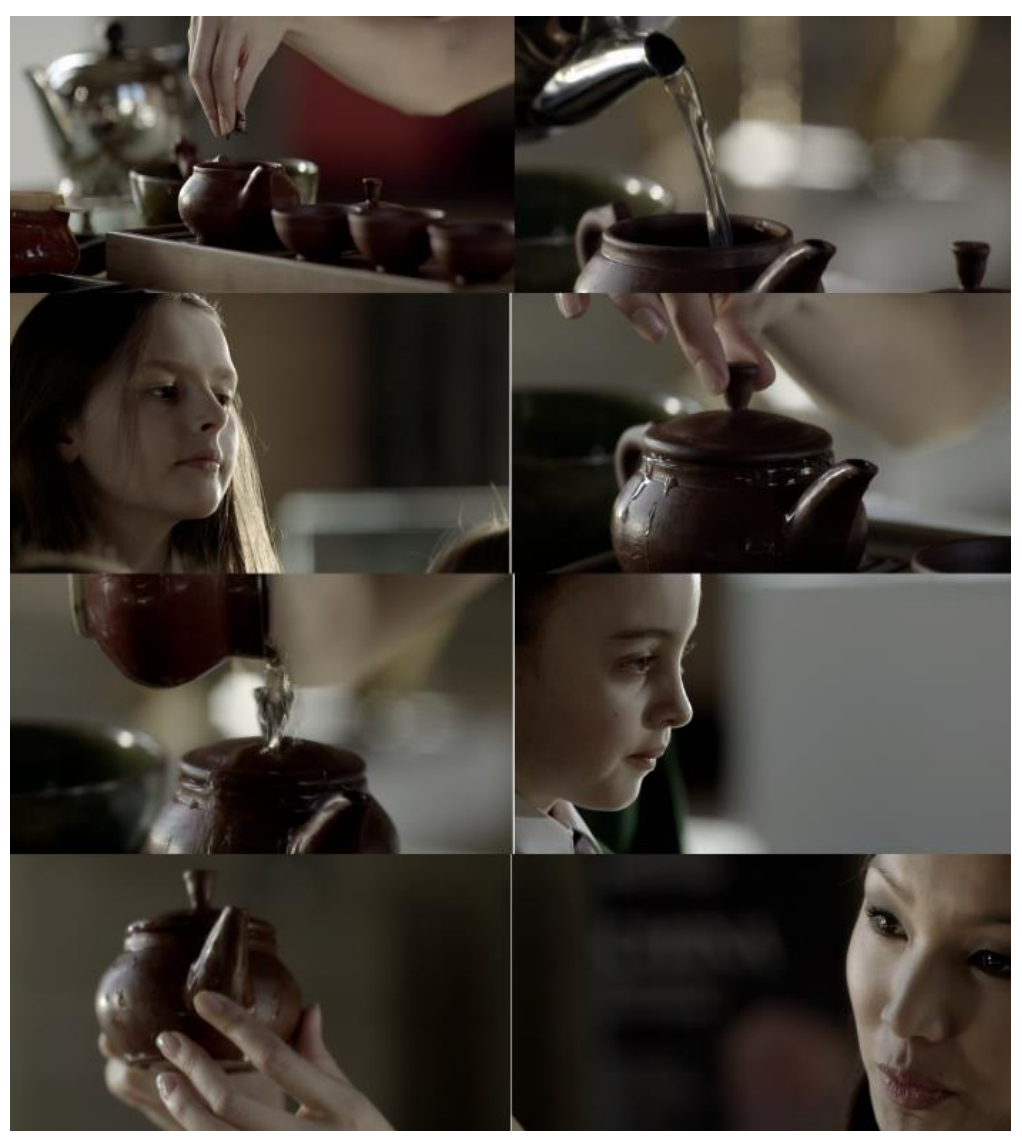

IMAGE 2-1: Soo Lin's teapot demonstration (Sherlock 1:2) times to reinforce that Soo

Lin, like the teapots, is the

center of the gaze (IMAGE

2-1). This opening

sequence forestalls an

establishing shot until

almost a minute in, in

preference of a series of

extreme close-ups, which

has the effect of

establishing a clear

relationship between the teapots and Soo Lin. Both

are objects of the primarily-white gaze. ${ }^{65}$ During this scene, Soo Lin speaks very little.

Here are her few lines as she seasons the teapots:

The great artisans say the more the teapot is used, the more beautiful it becomes. [Long pause.] The pot is seasoned by repeatedly pouring tea over the surface. The deposit left on the clay creates this beautiful patina

\footnotetext{
64 The circumstances of her employment in the UK is left unclear. Is she is in the UK on a work visa or as a naturalized citizen?

65 The association between Soo Lin and the teapots is further emphasized throughout the episode. Twice Andy mentions, after her disappearance, how they were her "obsession."
} 
over time. [Long pause.] For some pots, the clay has been burnished by tea made over four hundred years ago.

The viewer learns from her speech that this practice dates back "over four hundred years" and makes the clay teapots more beautiful. The emphasis is placed on ancient tradition and surface beauty, which parallels the way the Chinese elements and characters are to be used throughout the episode: 1) to evoke the past and 2) to play on a duplicitous meaning (or the relationship between surface and hidden significance). The language used here is vague and cryptic. Who are these "great artisans" and, more importantly, where are they from? At no point during this opening scene, which has the appearance of an educational demonstration (given its location in a museum) is place mentioned. It is only later, after Soo Lin's disappearance when a Ming vase needs an appraisal, that the audience learns Soo Lin Yao was a specialist in Chinese antiquities. Rather than a genuine curiosity about a radically different culture (and its perspective), the use of this Chinese tradition in the episode is superficial; it lacks the specificity to inform or demonstrate authentic interest in the culture and its rich history. Instead, Soo Lin must perform her ethnicity for a primarily-white audience's entertainment. Merging China with the rest of Asia, which is what occurs when the teapot seasoning's originating location ${ }^{66}$ goes unmentioned, is a tactic central to the tradition of Orientalism. ${ }^{67}$ It is also similar to the way the origin of the disease Holmes feigns contracting in the original story is confounded by allusions to several locations in Asia.

\footnotetext{
66 The Yixing teapots (and the seasoning process) are also widely regarded as the first "real" teapots and originated in the Jiangsu province of China in about 1500 (Everage).

${ }^{67}$ Another instance of this occurs later in the episode with the use of folded paper lotuses left at Zhu Zhi's crime scenes. While there is a long tradition of paper folding in China (known as 摺紙), there is a preference for inanimate objects (Temko 123). Plants and animals are subjects more prevalent in Japanese origami.
} 
Soo Lin is further set apart from her audience and coworker by her exotic costuming. She wears a qi pao (or traditional silk Manchu ${ }^{68}$ dress) for her demonstration in the museum. Later, when she sneaks back to continue the restoration in private, she is wearing "normal," Western-style clothes. Kustritz argues:

The series' inclusion of digital technology suggests a progressively modern vision of Sherlock Holmes and London, but this vision can only be sustained by reactivating the processes of exoticization and othering at work in the original Doyle canon. (99)

It seems an odd choice to have a modern woman in London choose to wear a traditional Chinese dress but "colonial discourse produces the colonized as a social reality which is at once an 'other' and yet entirely knowable and visible" (Bhabha 101). Thus, the silk dress is not just an image of Chinese-ness, it is an image of the Chinese that is familiar to the Western viewer, making it "entirely knowable." It at once identifies Soo Lin as foreign and visibly identifiable and makes this distinction clear from the beginning of the episode. The signs of Chinese-ness are at once foreign and exotic and also recognizable and classifiable as such.

After the teapot demonstration, Soo Lin has a short conversation with a white, male co-worker named Andy. Their conversation highlights Soo Lin's physical attractiveness and, although shy and modest, her words signal sex:

ANDY. Four hundred years old, and they're lettin' you use it to make yourself a brew!

SOO LIN. Some things aren't supposed to sit behind glass. They're made to be touched; to be handled. [emphasis added]

Soo Lin is exoticized through both her appearance, her association with the antique tea pots, and also her language. If the teapots are linked to her in the first scene, then the

\footnotetext{
${ }^{68}$ The qi pao became wide-spread in China during the Qing dynasty (1644-1912) which was ruled by the Manchu, a Chinese minority group from the north in Manchuria.
} 
verbs associated with them ("used", "touched", "handled") are transferred to her in the imagination of the viewer. It is unclear if she is aware of the sexual innuendo underlying her comments but the audience does not miss the meaning hidden beneath. Andy seems to take this as encouragement and then tries to ask her on a date but she firmly refuses.

The way this exchange between Andy and Soo Lin is filmed is also significant. During this brief exchange, the camera oscillates between focusing on Soo Lin in the foreground and Andy in the background as they alternate speaking. The choice to rack focus during this scene establishes an aesthetic of opposition which will be used throughout the episode, between the white male characters (like Sherlock and John) and the exotic Chinese characters or artefacts. To enforce the modernity of this Sherlock and his technology, therefore, "The Blind Banker" relies on an opposition with the ancient and exotic Other of Chinese culture. In the process, Soo Lin is objectified through her very close association with the antiquities in the museum, the emphasis on her position as focal point of the gaze, and the sexual allure she represents for Andy. Throughout the episode, Soo Lin is literally framed in the shot by these antiquities. The effect of placing this sequence at the beginning of the episode is that once the camera leaves the museum, Chinese culture is marked off "as something different and separate from $21^{\text {st }}$ century digital London" (Kustritz 99).

Soo Lin Yao is the most sympathetic portrayal of a Chinese character in the episode but eventually it is revealed even she has a criminal past. She too is involved with the smuggling ring and more specifically, drug smuggling. ${ }^{69}$ She explains to

\footnotetext{
${ }^{69}$ Ironically, in spite of Soo Lin's attempts to extricate herself from the Black Lotus Tong, she has rented an apartment located right next door to the Lucky Cat Emporium, the front for the crime syndicate's illegal smuggling trade in antiquities.
} 
Sherlock and John later in the episode, "By the time I was sixteen, I was taking thousands of pounds' worth of drugs across the border into Hong Kong. But I managed to leave that life behind me. I came to England." Hong Kong, a territory ceded to the British after the first Opium War, was the last imperial holding relinquished by the British in 1997. Depending on Soo Lin Yao's age, she was smuggling drugs from China to a British colony (or recently liberated British territory). This is the exact opposite of the historical context of drug smuggling between these two nations during imperialism but this context remains unacknowledged in the episode. Instead, the emphasis remains solely on the wrongdoing of the Chinese; even the sympathetic Chinese character remains tainted by a criminal past.

\subsubsection{Profile of an Atavistic Criminal: Tonga and Zhi-zhu}

The next Chinese character represented in the episode is Soo Lin's brother: Liang Yao ${ }^{70}$ known throughout as Zhi-zhu (蜘蛛 “the spider”). The characterization of Zhi-zhu connects Sherlock to the origins of detective fiction through the "locked room mystery" and its reliance on an agile criminal. Many post-colonial critiques of Doyle's original stories center on the problematic representation of Tonga from The Sign of Four, which is actually a reworking of Edgar Allan Poe's orangutan from "The Murders in the Rue Morgue"71 (1841), and several parallels can be drawn between Tonga and Zhi-zhu. Both characters are described as barely human physically and morally. They are portrayed as

\footnotetext{
${ }^{70}$ His real name is only mentioned once, by Soo Lin, just before she is killed. Therefore, I will refer to him as Zhi-zhu throughout.

${ }^{71}$ See Stephen Bertman's article, "Kindred Crimes: Poe's 'The Murders in the Rue Morgue' and Doyle's The Sign of Four."
} 
small, ${ }^{72}$ agile, deadly, and morally insensible. In order to understand how Sherlock's Zhizhu is connected to these early depictions of othered criminals and why these depictions are problematic, it is important to understand the criminological theories held as valid during the nineteenth century that underpin these depictions in Doyle and Poe's early detective fiction.

Cesare Lombroso's Criminal Man (1876) was a ground-breaking work in the new field of criminology. Two of his theories are important to this discussion, the "born criminal" and the atavistic origins of crime. First, Lombroso distinguished between several different types of criminals: the epileptic criminal, the imbecilic criminal, the criminal of passion, and the "born criminal." The concept of the "born criminal" posited that certain men and women are born with a predisposition towards criminal activity and they may be detected through their various physical anomalies.

This concept was taken up by Havelock Ellis in The Criminal (1890) - the first British book of criminology. This work sets out to enumerate these differences, written on the body, which can reveal a criminal tendency in behavior and make them known to his English readers. Chapter three is entitled "Criminal Anthropology (Physical)" and includes the following sections: Cranial and Cerebral Characteristics, The Face, Anomalies of the Hair, Criminal Physiognomy, The Body and Viscera, Heredity, Tattooing, ${ }^{73}$ Motor Activity, and Physical Sensibility. Wilton Marion Krogman’s article “Sherlock Holmes as an Anthropologist” (1955) concludes that physical anthropology

\footnotetext{
72 An obvious change from the orangutan's "great size" but nonetheless positioning all three at the cusp of human proportions and this is one of the leads in the case that leads to their apprehension.

${ }^{73}$ Interestingly, the Black Lotus requires all of its smugglers to obtain a tattoo of a black lotus. Soo Lin explains: "Every foot soldier bears the mark; everyone who hauls for them."
} 
was Sherlock Holmes's strongest anthropological area of study since he uses it in so many of the investigations.

Secondly, Lombroso claimed an "atavistic origin of crime.” In The Criminal Man he writes, "The criminal is an atavistic being, a relic of a vanished race" (135).

Lombroso, building on nineteenth-century European theories of racial difference, "which sought to establish the innate inferiority of nonwhite and non-European groups by arguing that their closer physical resemblance to animals was a sign of their lower evolutionary status" (Jann 56), argued that both criminal (and "primitive peoples") "represented a distinct physical type that could be recognized by its atavistic resemblance to the ape" (Jann 56). Furthermore, he thought that criminals were akin to "savage peoples" and apes both physically but also morally. Their lack of remorse, or moral insensibility, could be attributed to their closer proximity to the animal kingdom, and lower position on the teleological spectrum of progress and civilization.

Both Tonga and Zhi-zhu are dehumanized by their physical bodies. Their corporeal abnormality is a key in narrowing the suspect pool and their eventual apprehension. In The Sign of Four, while investigating the strange crime scene of Bartholomew Sholto's murder, Sherlock remarks:

There are features of interest about this ally. He lifts the case from the regions of the commonplace. I fancy that this ally breaks fresh ground in the annals of crime in this country-though parallel cases suggest themselves from India, and, if my memory serves me, from Senegambia. (274)

In the Sherlock episode, after the cryptic graffiti left at the bank and library that precipitates the murder of the banker and journalist, the small size of Zhi-zhu's hands and feet is the first real lead in the case. Sherlock breaks into Soo Lin's apartment and notices 
imprints in the rug and then a photograph of Soo Lin and her brother. He says to himself, "Size eight feet. [...] Small, but ... athletic. [...] Small, strong hands. [...] Our acrobat." Small size and agility, here are the key characteristics that will lead to the successful apprehension of the murderer, Zhi-zhu. In both cases, these are the qualities that make the case strange or "lifts it from the commonplace." At the murder scene of Bartholomew Sholto in The Sign of Four, after finding similar evidence of abnormally small feet, Sherlock returns to Baker Street and consults an article from a gazetteer that he remembered reading:

The aborigines of the Andaman Islands may perhaps claim the distinction of being the smallest race upon this earth [...] The average height is rather below four feet, although many full-grown adults may be found who are very much smaller than this. [...] Their feet and hands, however, are remarkably small. (307-308)

The smallness of the islanders is reinforced three times in this passage: "smallest race", "very much smaller", and "remarkably small." Tonga is not just smaller than average, he is so small as to be barely human at all. He exists on the margin of humanity, a statistical outlier, and this physical characteristic makes him suspect from the start.

The extreme agility that both Tonga and Zhi-zhu possess is also emphasized. After the murder of Brian Lukis, Zhi-zhu is described in the press as the "intruder who can walk through walls" and Sherlock remarks "He clings to walls like an insect." Another investigator likens him to Spiderman (foreshadowing Zh i-zhu's moniker). Zhizhu has been able to successfully scale and enter locked rooms several floors above ground and executes an acrobatic ribbon act during the Yellow Dragon Circus performance later in the show (IMAGE 2-2). Tonga similarly murders Bartholomew Sholto after gaining access from a trapdoor in the roof of the Sholto home (SIGN 275). 
When Jonathan Small (a former British soldier, recently returned from India, and more recently a prison in the Andaman Islands) is describing Tonga he says, he "could

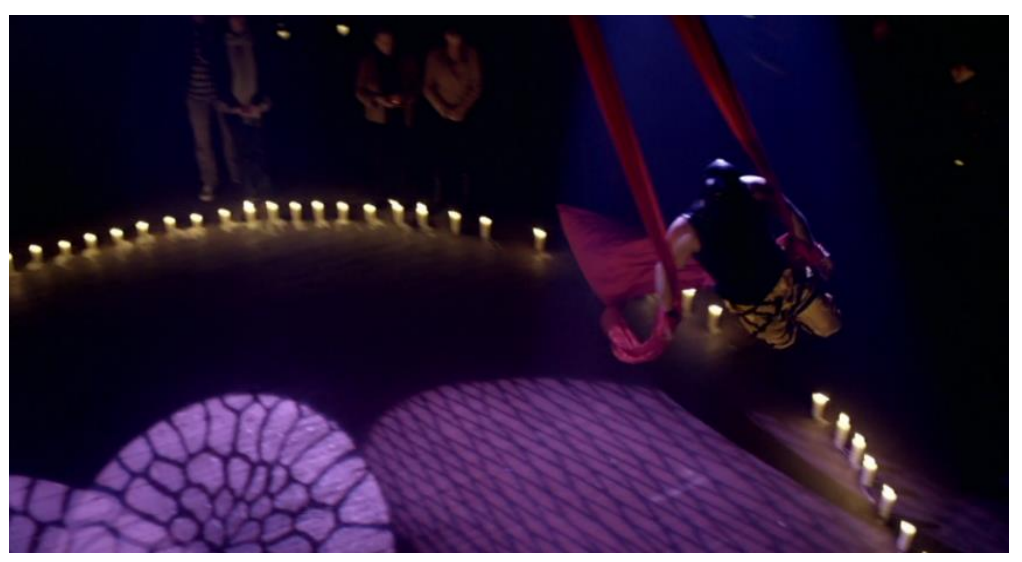

IMAGE 2-2: Zhi-zhu on ribbons during the Golden Dragon Circus performance (Sherlock 1:2)

climb like a cat" (374). This, according to Havelock Ellis, is an attribute associated with the criminal, "extraordinary and ape-like agility has frequently been noted among criminals" (108).

The agile criminal is a staple of locked room mysteries dating back to one of the first detective stories, Edgar Allen Poe's "Murders in the Rue Morgue" (1841). In this story, it is eventually revealed that an orangutan is responsible for the death of two women. A sailor had brought it to the city from a tropical jungle in Southeast Asia (Borneo, or Kalimantan in Indonesia ${ }^{74}$ ) and was nursing it back to health when it escaped. Another dangerous and ultimately lethal element originating in Asia is here employed in detective fiction. As Stephen Bertman points out in his comparative analysis of The Sign of Four and "The Murders in the Rue Morgue": "In each tale the brutal killer is extremely agile, capable of climbing up the outside of a multistoried house [and] entering a room seemingly locked from the inside" (207). An exchange between Dupin and the narrator reveals the key evidence in this investigation:

"Read now," replied Dupin, "this passage from Cuvier."

It was a minute anatomical and generally descriptive account of the large fulvous Ourang-Outang of the East Indian Islands. The gigantic

\footnotetext{
74 Tonga is from the Andaman Islands off the coast of Thailand, also in Southeast Asia.
} 
stature, the prodigious strength and activity, the wild ferocity, and the imitative propensities of these mammalia are sufficiently well known to all. I understood the full horrors of the murder at once. (134)

Both Dupin and Holmes turn to reference materials in researching the case. Holmes turns to a gazetteer, or geographical dictionary, while for Dupin it is the writings of Georges Cuvier. Cuvier was a French naturalist and zoologist, who was famous (among other things) for comparative anatomy. And although an animal is responsible for the two murders (in Poe's story), the confusion in the case hinges on the failure to recognize that the culprit is not human. The trouble is the anthropomorphic qualities of the orangutan, their "imitative propensities." 75 His status as almost human confuses the investigation. Tonga, in contrast, is characterized as almost non-human. They are both situated at the edges of what it means to be human. That the function of Tonga and the orangutan is so similar in both stories is indicative of the problematic linkage between theories of racial difference and criminality concurrent with their publication. To characterize Zhi-zhu as an agile criminal is to connect him back to this complex history of atavistic criminality and the ethnocentric understanding of certain ethnicities as "primitive." Zhi-zhu is not just small and agile (like Doyle's Tonga and Poe's orangutan), he is deadly and "morally insensible" as well.

Tonga, the orangutan, and Zhi-zhu are not just barely human physically, they pose a very real threat. Detective fiction, to be effective, must capitalize on a viable threat to the safety of the characters in the fictional community but also one experienced by the

\footnotetext{
${ }^{75}$ Most importantly, for this case, the ape's ability to mimic the sounds of human language as the witnesses confuse the sounds made during the commission of the crime with various languages, each foreign to their own native tongue.
} 
reader or viewer. Dennis Porter explains this point in his introduction to The Pursuit of Crime:

The importance of popular works resides in their status as meaningsystems that embody implicit world views. Properly interpreted, therefore, they can provide important clues to the anxieties and frustrations, aspirations and constraints, experienced by the mass audience that accounts for their best-seller status. (1)

Susan Harris and Yumna Siddiqi have both examined how the threat from the periphery works in Doyle's canon. As already mentioned, Susan Harris argues that the British feared physical and moral contagion (including degeneracy) from peoples, animals, and plants from the imperial periphery and that this fear was both capitalized on and allayed through the othering strategies used in the text and in Sherlock's successful reading of people and events from the colonies. Yumna Siddiqi in "The Cesspool of Empire: Sherlock Holmes and the Return of the Repressed" examines British characters who return to England after time in the colonies. Siddiqi argues:

In these stories, Doyle depicts the return of colonials in an ambivalent way, portraying some colonials as marginal, physically ravaged characters who threaten the peace, while characterizing others as their respectable counterparts who attain social status by virtue of their colonial wealth. (236)

Either these characters return having made their fortunes and successfully integrate into society or they return tainted from their exposure in a lawless land to lead a life of crime in the metropole.

Both of these discussions are important to understanding the threat of contamination Zhi-zhu and China symbolize in this modern retelling. China is represented as a morally corrupting force and Zhi-zhu is physically deadly. China (and its people by association) represent a moral contamination in that the British journalist 
(Brian Lukis) and the banker (Edward Van Coon) have both been abroad to China, ${ }^{76}$ which allows them to be recruited for smuggling by the Black Lotus ${ }^{77}$ Tong syndicate. Zhi-zhu is introduced by General Shan during the acrobatic performance as the "deadly Chinese bird spider" ${ }^{\prime 78}$ and is responsible for three of the five deaths that occur in the episode. The orangutan in Poe's story is known for his "prodigious strength" and "wild ferocity." Tonga is venomous and compared to a snake: "his venomous, menacing eyes" (155-156) and "he was as venomous as a young snake" (176). Harris argues poison in these stories functions as a "metaphor for the physical, moral, and cultural contamination that Britain feared" (449). While venom is slightly different from the drugs, organic toxins, and infectious agents that Harris is discussing, the venom of exotic animals from the colonial periphery functions similarly in the narratives as a threat to the British body politic. Tonga is literally venomous or poisonous because he carries poisoned dart-thorns but he also represents the danger connected to the perilous outreaches of empire and their

\footnotetext{
${ }^{76}$ The fact that banking life leads to travel abroad is foregrounded early in the episode when Sherlock reunites with his former university mate and now client, Sebastian. Sherlock immediately deduces by the time on his watch that Sebastian has been a frequent traveler.

SHERLOCK. So, you're doing well. You've been abroad a lot.

SEBASTIAN. Well, some.

SHERLOCK. Flying all the way round the world twice in a month?

77 The Black Lotus is a representation of spiritual corruption in the episode. The lotus flower is a traditional symbol of Buddhism (one of the main religions in China) and usually white. Furthermore, the art of paper folding originated in China as a way to honor the ancestors. The most famous example of paper folded flowers was in April of 1976, when Chinese citizens piled mountains of paper folded flowers around the monument of the recently diseased premier, Zhou Enlai (Temko 123) as a sign of respect and also protest (of Mao's regime). It was seen as a protest since the tradition of paper folding was discouraged as a remnant of the culture of the old world after the founding of the People's Republic of China in 1949. This symbol of the criminal syndicate, therefore, represents a corruption of Chinese spirituality and a symbol of hope. The former is also foregrounded later in the episode when Sherlock equates the Black Lotus Tong to a cult, "Not just a criminal organisation; it's a cult."

${ }^{78}$ The "Chinese bird spider," or Haplopelma Schmidti, is, in fact, the English name for this species of "old world" tarantula. They are found in the People's Republic of China and Vietnam and are known to be a potently venomous, fairly large, and highly aggressive species of spider (Animal Corner "Old World Tarantulas").
} 
potential to infect and kill the citizens of the Empire's metropole should they find their way back to the center.

Zhi-zhu is not only extremely deadly like Tonga but also shows signs of moral insensibility. A lack of forethought, lack of regret, or a cheerfulness after the crime are all, according to Ellis, evidence of moral insensibility. Ellis argues that the habitual criminal who exhibits moral insensibility does not value human life the way a normal person does. According to Jonathan Small, Tonga was "strutting about as proud as a peacock" (178) after killing Bartholomew, exhibiting the "moral insensibility," which Ellis connects to the criminal and savage peoples (132). And although the "wild, fierce face" (112) that appears in the window and hastens the death of Major Sholto is actually revealed to be none other than Jonathan Small (the true orchestrator of the plan to steal back the Agra treasure), he is effectively absolved of the murder of Bartholomew by the end of the novel.

Blame is, essentially, shifted to the figure of Tonga, the Andaman Islander. Before meeting Small or Tonga, Holmes says, "'I fancy that, even as it is, Jonathan Small would give a good deal not to have employed him"” (142). Before the duo embark on a boat chase, Sherlock says to John, "'Jonathan I shall leave to you, but if the other [Tonga] turns nasty I shall shoot him dead"' (134). Before ever encountering Tonga, Holmes has already decided he may be too dangerous to apprehend alive and shows no hesitation in taking his life, while Small is represented as capable of redemption or rehabilitation. After Jonathan Small has been taken into custody, he shows righteous indignation at Tonga's murder of Bartholomew and Holmes proceeds to offer him a cigar and swig from his own flask. Jonathan says: 
It was that little hell-hound, Tonga, who shot one of his cursed darts into him. I had no part in it, sir. I was grieved as if it had been my bloodrelation. I welted the little devil with the slack end of the rope for it, but it was done, and I could not undo it again. [emphasis added] (157)

Small, in spite of the remarkable loyalty that Tonga has shown him, proceeds to describe him in demonic and diminutive terms: he is a "little hell-hound" or a "little devil" with his "cursed darts." The effect of "consign[ing] crime to the world of pure evil and individual monstrosity is to isolate it from all economic, social, or political causes and to explain it as a psychopathic and freakish exception to all that we know to be "normal"" (Messent 131). The descriptions that demonize Tonga function in this way: to define crime as pure evil and allay any fears that the corruption comes from within the society. And while Small seems unaffected by his "little chum['s]" (177) death, he says he mourned Bartholomew's passing "as if it had been [his] blood-relation." Holmes even offers to speak on Small's behalf to the authorities if he promises to confess the entire truth of the story: "'I think I can prove that the poison acts so quickly that the man was dead before you ever reached the room"' (157). Tonga is dehumanized and used as the scapegoat at the end of the story. While Jonathan Small, the returned British citizen whose avarice sets in motion the events that lead to the death of two men, appears at the conclusion repentant and relatively unscathed. The threat of the other has been effectively discharged of its power now that the Agra treasure and Tonga (both elements of Indian origin that had entered the metropole) rest at the bottom of the Thames.

What is worse than Zhi-zhu's physical conflation with Tonga and the orangutan through these descriptions, is the Sherlock episode's characterization of Zhi-zhu as morally insensible. Zhi Zhu mercilessly kills his sister “in one of the series' most arrestingly unexpected moments" (Barnes 171) for the Black Lotus Tong. Soo Lin tries to 
appeal to him: “亮 [Liang]...大哥 [Big brother]...请你 [Please]...” Soo Lin pleads with him to not kill her in Mandarin while he offers no words in return. She pauses after each appeal but the silence remains. This is the only time Zhi-zhu's actual name is mentioned in the episode, which could offer an opportunity to humanize him. His failure to offer any sort of reply to her entreaties only further emphasizes his dehumanization and lack of remorse. The only redeeming factor could be his apparent hesitation. The following gunshot that kills Soo Lin is not shown only heard as the viewer is left to see John's facial expression as he realizes what has happened. This is once again signaling that the viewer's identification is with the white, male characters and not the Chinese.

\subsection{Elementary's Articulations of Ethnicity: Joan and Jun}

Part of the difference in affect between Sherlock and Elementary may be due to differences in format of the two shows. Sherlock has only nine episodes with thirteen and a half hours total. In contrast, Elementary has twenty-four episodes per season. With three complete seasons and already airing a fourth, at the end of this season it will have a total of ninety-six hours of content! This allows Elementary to present a much larger pool of criminals, clients, and victims and, by consequence, engages with more people from a larger variety of backgrounds. In contrast to the aesthetic of opposition played out in Sherlock, Elementary offers a refreshing vision of difference based on plural articulations. Homi Bhabha offers the metaphor of 'articulation' as an alternative to the stereotype. He writes, "I want to suggest, however, that there is a theoretical space and a political space for such an articulation - in the sense in which that word itself denies an 'original' identity or a 'singularity' to objects of difference" (96). Bhabha argues that, unlike the stereotype, an articulation 'denies' a concept of originality or singularity. 
Instead, it is based on multiple manifestations or performances linked to the same signifier. If the stereotype is defined by the limitation of signifiying practices it allows the racial signifier, then it imposes singularity on a plurality of experiences. In contrast, plurality seeks to generate different positionalities and these are arranged along a spectrum.

\subsubsection{Joan as every man}

Before Elementary ever aired, there was a backlash against CBS's casting of Lucy Liu as Dr. Joan Watson. A woman of color playing a white, male character from the British canon was bound to elicit some negative reactions. Lucy Liu is a second generation Chinese-American ${ }^{79}$ actress, who has played her fair share of 'dragon lady' roles $^{80}$. Jann argues:

Watson is the voice of public convention [...] His prejudices seem innocuous (if they are even perceptible to us). And because Watson's initial characterizations of people are seldom significantly incorrect, they are more likely to appear simply commonsensical, resting on knowledge available to any reader. As a result, the entire project of stereotyping people by appearance is tacitly reaffirmed as natural and logical. (58)

When Watson is changed from a white male character to a woman of color do these seemingly 'innocuous prejudices' remain? While Sherlock failed to fully interrogate the ideologies that underpinned its modernization of the original text, Elementary, in contrast, succeeds in rewriting many of these offensive propensities and a large part of this is due to the recasting of this central character. Watson has always been the

\footnotetext{
${ }^{79}$ Her parents immigrated to the United States. Her mother is from Beijing and her father is from Shanghai. She was born in Queens, New York. (IMDB.com "Lucy Liu"). The character of Joan Watson is also from a mixed ethnic background. Her mother is Chinese and her father is a white American (his exact lineage is unspecified).

${ }^{80}$ Oren Ishii in Kill Bill Vol $1 \& 2(2003,2004)$ or Madam Blossom in The Man with the Iron Fists (2012)
} 
baseline - the definition of 'normal'—and Elementary remains faithful to this characterization.

The first episode of the series begins with a brief murder scene before introducing its viewers to Joan.$^{81}$ The opening montage of Joan consists in a long sequence of her morning routine that forestalls dialogue in an effort to produce identification between her character and the viewer. Joan begrudgingly wakes up to her alarm clock, then goes for a morning jog through the city, as any typical New Yorker might (IMAGE 2-3). The use of

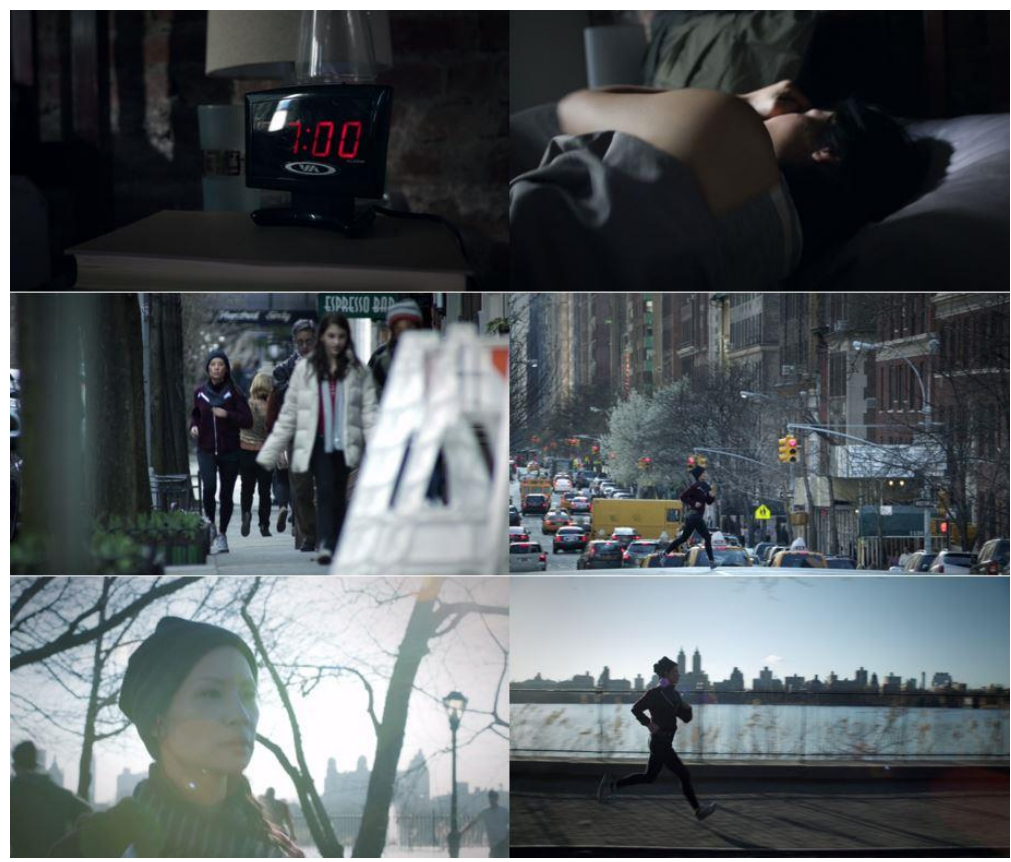

IMAGE 2-3: Joan Watson goes jogging in NYC (Elementary 1:1) a familiar and extremely

popular song ${ }^{82}$ further

enhances viewer

identification with Joan.

Everyone can relate to

having to wake up to an

alarm, jogging, and

listening to an iPod. All of

these normal, everyday

activities establish her as an

\footnotetext{
${ }^{81}$ Interestingly, both Sherlock and Elementary choose to first introduce the audience to their respective Watsons before Holmes, again foregrounding the essential characteristic of Watson as the audience's entry point for identification in the narrative. The way the relationship between Watson and Holmes is foregrounded takes two very different forms. Sherlock opens with a flashback to the Iraq war in John's nightmare followed by a brief session with his psychiatrist, emphasizing his need for companionship in reentering society and finding his place in the world. While Elementary, begins with Sherlock's escape from his rehabilitation clinic and need for Joan's help as a sober companion for successful reentry into society. The first emphasizes John's need while the second, Sherlock's but both shows go on to illustrate the companionship both characters find in the successful partnership that develops.

82 "Young Blood" by New Zealand band, The Naked and Famous, was nominated the U.S. iTunes store "Single of the Week" in March 2011, was certified gold in Australia by RIAA (Recording Industry Association of America), and made the BBC's "Sound of 2011" shortlist.
} 
everyman kind of character from the outset. In an interview with The Wall Street Journal

Liu said,

It feels really good to be [...] trying something new. [...] It's nice to be able to portray an Asian-American on camera without having an accent, or without having to be spoofy. And I think that's a big step forward, because there are still representations of people that are more comedic. And that's not what I'm playing. I'm just playing someone who represents anyone else who $[\ldots]$ is just a regular person.

This statement has a new resonance if one takes into consideration the two

representations of Chinese female characters in "The Blind Banker," Soo Lin Yao

(played by Gemma Chan) and General Shan (played by Sarah Lam ${ }^{83}$ ). Gemma Chan is a

native Londoner, she was born there and yet she is forced to put-on a thick Chinese

accent for her role. The actress Sarah Lam (IMAGE 2-4) is also Chinese-British. It is not

so much that these actresses

are asked to play a Chinese

character but that they

repeatedly appear in these

prescribed roles and

without counter casting that

allows them the chance to

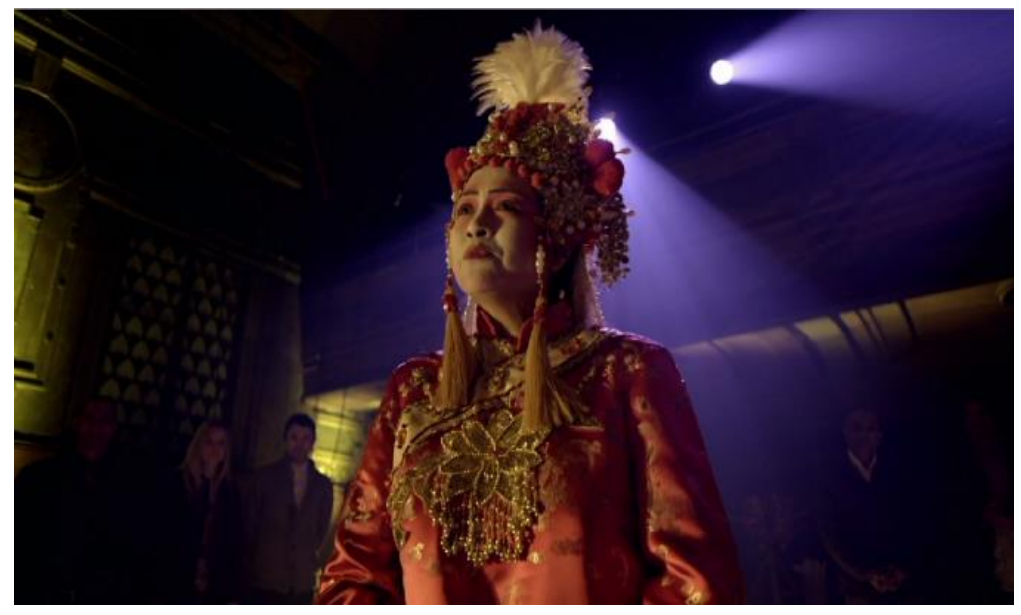

play an "unmarked"

IMAGE 2-4: General Shan in Peking Opera makeup at Yellow Dragon Circus performance (Sherlock 1:2)

positionality, or as Liu says "someone who represents anyone else." These actors,

\footnotetext{
${ }^{83}$ Sarah Lam is incorrectly credited as 'Opera Singer' in "The Blind Banker" credits, rather than 'Chinese circus performer' or 'General Shan.' This is further proof that all the signifiers of Chinese are mixed together without real attention paid to their significance. General Shan performs in a Chinese Circus but both her makeup and the warrior's mask are taken from the Peking Opera tradition, which probably explains the credit 'Opera Singer.' Additionally, the actor who plays Zhi-zhu does not appear in the credits at all.
} 
because of their skin color, are limited to performing their perceived ethnicity and the Chinese-British viewership is likewise denied access to a variety of ethnic experiences. The problem is not that the television media outlets need to be more 'politically correct.' The problem is that by denying these positionalities—-by keeping these representations out - they are already incorrect.

A quick bit of internet research will testify to the concern of Asian-Americans who are vehement about the marginality of representations in Western media to which they can relate. One blogger, Kristen Yoonsoo Kim, in response to the stereotypical representation of Chinese characters and culture in a recent How I Met Your Mother episode,${ }^{84}$ says, "The most respectable depiction of Asians I can think of on television right now is Lucy Liu's character on the Sherlock Holmes adaptation, Elementary. The only problem? Her Asian identity is invisible" (Kristen Yoonsoo Kim- 16 January 2014). Kim's argument is that in trying to avoid a stereotypical representation, the creators of Elementary have completely erased Joan's ethnic heritage. However, in the ninth episode of the first season, "You Do It To Yourself," Joan and Sherlock come into direct contact with Asian and Chinese characters, Chinatown, and Joan's relationship to her heritage and intersectional identity.

This episode revolves around the investigation of a murder. An East Asian Studies professor at a local university (Trent Annunzio) has been shot in a gambling establishment in Chinatown and the body deposited elsewhere. While the Chinese characters are pulled into the investigation as suspects, they ultimately serve the purpose of red herrings. While some Chinese characters are guilty of running an illegal gambling

84 "Slapsgiving 3: Slappointment in Slapmarra" (airdate: 13 January 2014) 
operation (IMAGE 2-5), ${ }^{85}$ they are not explicitly guilty of murder. The expectation that

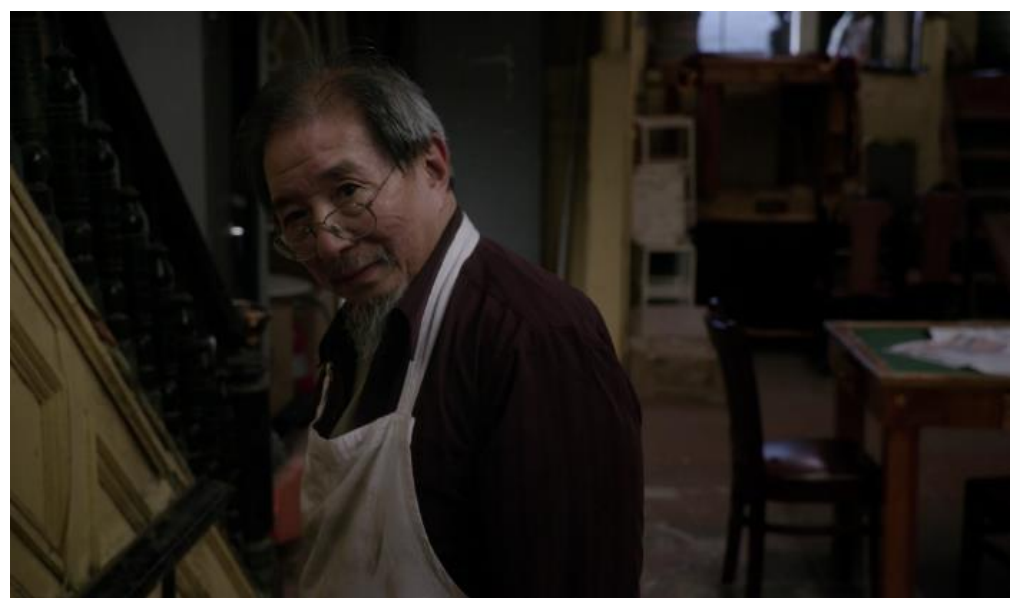

the "foreigner" is

criminally suspect is an

expectation in Western

detective fiction that is here

evoked and only to be

refuted. In fact, Annunzio’s

IMAGE 2-5: Owner of Mahjong gambling house in NYC's Chinatown (Elementary 1:9)

murder only took place in

Chinatown, by chance. ${ }^{86}$

The idea that Chinatown exists solely as a locus for vices is a stereotype inherited from

the nineteenth century: "Most accounts of nineteenth-century Chinatowns give the

impression that these communities existed solely for the trinity of vice-drugs,

prostitution and gambling. In truth, Chinatowns were complex societies, and not all

residents condoned the criminal activities that took place there" (Hodgson 106-108). This

stereotype of Chinatown has been carried into films of the twentieth and twenty-first

century in the West. Although this amalgamation of Chinatown and crime is evoked

through the mahjong gambling house it is balanced in the episode by the actual or

implied presence of Chinese characters that are law abiding citizens, Joan and Jun

\footnotetext{
${ }^{85}$ Sherlock's confrontation of the owner of the gambling house reveals several deceptions. The owner pretends to be a janitor, he and his employees feign not understanding English, he pretends someone vomited rather than was shot (his explanation for the use of bleach on the floor), and he has a surveillance camera disguised as a smoke detector. In addition, it is hinted that the owner and "his people" are capable and willing to commit greater crimes, like murder. When the owner refuses to rescind the other tape that has captured the identity of the shooter, Sherlock says, "Yes, I know, you prefer to keep his face to yourself. You probably have your colleagues searching for him as we speak."

${ }^{86}$ Later, Sherlock realizes the shooter, in killing Annunzio at the mahjong gambling house, departed from Annunzio's plan out of greed (in order to steal the establishment's profits), thereby compromising Annunzio's original intention of shifting the blame to Brendan O'Brien, his teaching assistant, and perhaps Jun.
} 
Annuncio ${ }^{87}$ figure prominently in the episode and other ethnically Chinese characters (i.e., Joan's mom and Sherlock's chef friend) are alluded to.

In the course of the episode, Jun Annunzio (IMAGE 2-6), played by Kristy $\mathrm{Wu}$,

becomes a suspect in

Trent's murder. Jun is

originally from Thailand.

She met Trent in Beijing

and he brought her back to

the United States, where

they now have a young

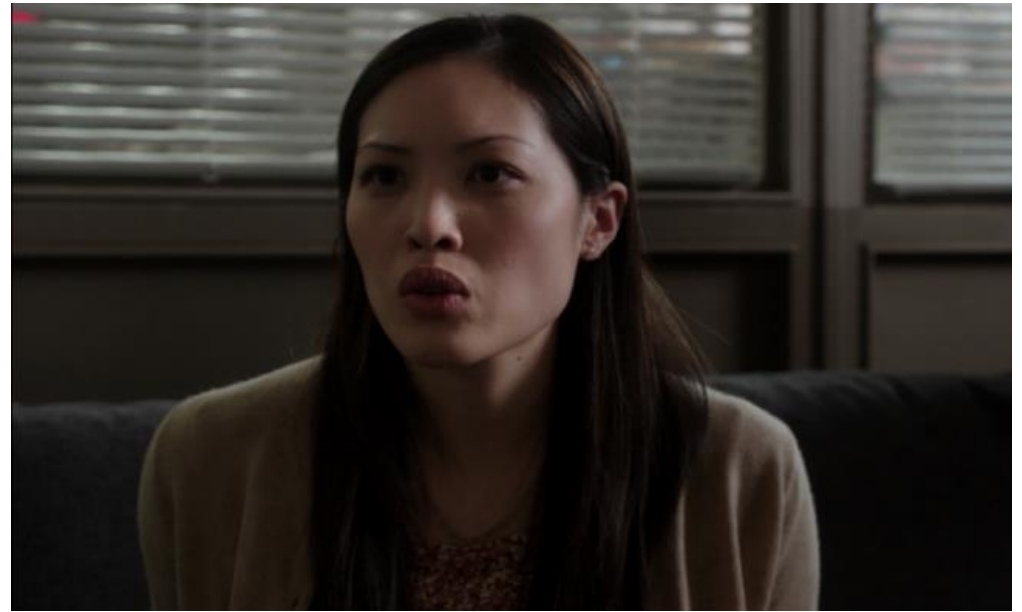

IMAGE 2-6: Jun Annunzio, "wife" of the murder victim (Elementary 1:9)

child together. It turns out she has motive for Trent's death. Jun explains:

This is an old manual given to Chinese political police. It teaches how to beat a suspect, but leave no marks. He [Trent] used these techniques to hurt me. And he also made me do things. Sex things, horrible things while he taped them.

Rather than the 'complicit Orientalism' (Kustritz 99) of Sherlock, this plot structure reveals a direct confrontation of the exoticization of an Asian woman by a white man and an underlying power structure of oppression. Trent refused to marry Jun in order to maintain his position of superiority and her status as an illegal immigrant ensures that she has no legal recourse to report his abuse.

In addition, positioning Trent Annunzio as a sadist and pervert in possession of a Chinese police manual highlights the cruelty to be found in both cultures, American and Chinese. The additional fact that Annunzio is taping these sex acts and storing them

\footnotetext{
${ }^{87}$ Jun was born in Thailand but has emigrated from Beijing, where she met Trent.
} 
under a folder on his computer labeled "Cultural Revolution," 88 ultimately casts suspicion on Annunzio’s “academic interest” in Asia and his relationship with Jun. He shows a complete disregard for the suffering of thousands of Chinese citizens (especially intellectuals, like himself) in the actual Cultural Revolution at the hands of the Chinese Communist Party under Mao Zedong's regime. In the course of the episode, it is revealed that Annunzio orchestrated his own death ${ }^{89}$ because he was dying from cancer. Annunzio arranges to be shot in both eyes to hide that he has uveal melanoma (a cancer of the eyes). This small detail seems to imply that this white, male academic is being karmically killed for his own Oriental scopophilia.

In fact, both this episode and "The Blind Banker" contain images of violence done to white, male ocular organs. The title, "The Blind Banker," is a reference to the vandalism at the Shad Anderson Investment Bank on a portrait of a white man. A straight line has been drawn through both eyes. This graffiti serves as a warning to Edward Van Coon, who is killed shortly after, that violence to white men is coming and it will be exacted by a non-white attacker (represented by the Suzhou numerals, used by the Tong syndicate). Both “The Blind Banker" and "You Do It To Yourself” represent images of white men with violence done to their eyes in a plot concerning the depiction of Asian characters. This strategy is effective both because of the threat that China poses to the West economically and militarily and also because there is a long tradition of stereotyping and exoticizing the East in Western fiction (and placing them at the center of

\footnotetext{
${ }^{88} \mathrm{He}$ deleted them before his death but this is where Jun claims they had been stored previously. ${ }^{89}$ The episode's title "You Do It To Yourself" is related to both the plot and the subplot. The murder victim's orchestration of his own death is the connection between the main plot and the title, while the subplot involves Joan's former boyfriend's return and request for help with his ongoing drug addiction. She agrees to meet him at a drug rehabilitation clinic at the end of the episode but he never shows.
} 
the gaze). The plot in this episode of Elementary provokes thought and asks some of the probing questions that riddle ethnic tensions in the U.S. today. What are the motives for the West's interest in the Other? Is Western interest engendered by a genuine thirst for knowledge and mutual understanding? Is it for entertainment or pleasure (as in cultural appropriation or sexual fantasies)? Is it a fantasy of control over difference ${ }^{90}$ that both reveals a power structure and serves to stabilize white identity?

Finally, at one point during "You Do It To Yourself," Sherlock is speaking Mandarin on the phone to a Chinese acquaintance (described as a talented chef). When he gets off the phone Joan expresses surprise that he knows the language. Sherlock asks if she knows Mandarin and she reveals that she doesn't know "as much as her mother would like."91 This episode reveals Joan's complicated negotiation of an intersectional identity poised between Chinese heritage and the place she's lived her whole life, the United States. It is a real position to which many Chinese-Americans can relate.

When the characters visit Chinatown in this episode it is not so demarcated from the rest of the city (as in "The Blind Banker") and seems just another part of New York City, rather than an oasis of foreign elements within the familiar cityscape. The episode does not rely on an aesthetic of opposition; the transition is seamless. There is a cut to Joan's phone, which reveals a text from Sherlock. The camera pans up to reveal she is now standing in Chinatown. The street noises predominate the audio track; people are heard speaking Mandarin before the first image of Chinatown is shown. Non-diegetic

\footnotetext{
${ }^{90}$ Bhabha writes, "By acceding to the wildest fantasies (in the popular sense) of the colonizer, the stereotyped Other reveals something of the 'fantasy' (as desire, defence) of that position of mastery" (117).

${ }^{91}$ Similarly, in "All In" (4:19) Lin Wen, Joan's half-sister, is first introduced in a phone conversation with her mother at the beginning of the episode. She says to her mom, "When you start talking Mandarin, I know it's time to hang up."
} 
music does start to play when Sherlock and Detective Bell appear, but this music is characteristic of the normal upbeat soundtrack for Elementary (like its theme song). It is not music from East Asia characterized by instruments like the Chinese zither. But Chinese music does fade in shortly after, as the characters approach the door to the mahjong gambling house, but it quickly fades out as they enter the establishment (revealing it was diegetic music).

In "The Blind Banker," there is a dramatic transition that occurs as John and Sherlock enter Chinatown. The first image of Chinatown is of a sign reading "Far East Restaurant" and a shot predominated by red lanterns. Chinese music (meant to evoke mystery) begins to play and eventually drowns out the street noises. There are several focused shots of Chinese people sitting and standing around but they all seem sad or suspicious. As Sherlock's reflected image comes into view through the Lucky Cat Emporium's front window, the music finally fades. Sherlock's presence seems to signal the dissolution of the music, and by association, the mystery. In contrast, in Elementary, everyone is busy going about their own business in the background (IMAGE 2-7).

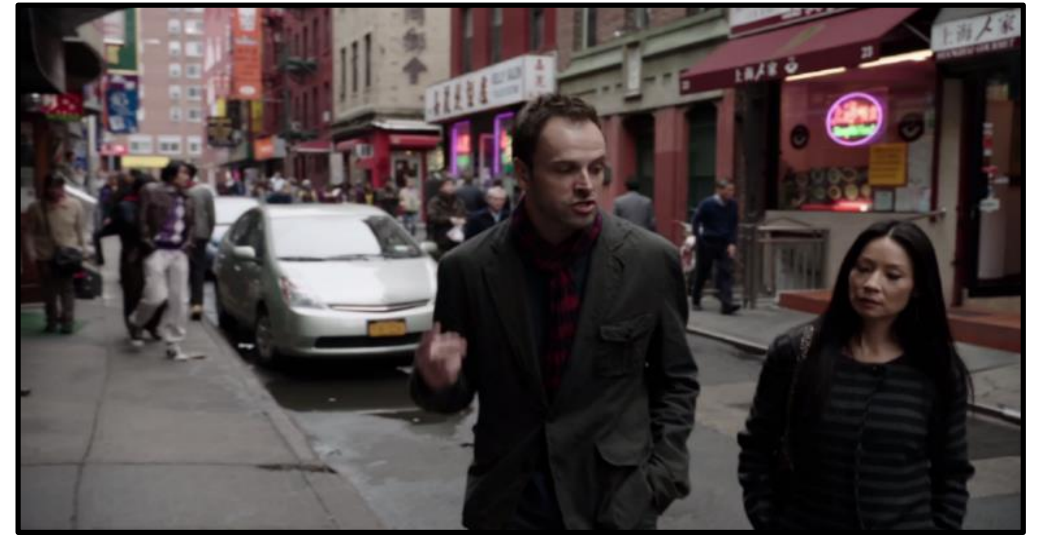

IMAGE 2-7: NYC's Chinatown (Elementary 1:9)

\subsubsection{Chinese Tea}

The Chinese teapot seasoning demonstration is characteristic of the way China is evoked in "The Blind Banker." The appearance of Chinese culture is deployed in order to 
activate an aesthetic of opposition. China is represented as ancient and mysterious in order to demonstrate how London has become modernized and how its white, British detective can dispel the mystery and reinstate order. Chinese tea is also used as a metaphor in "You Do It To Yourself." In the original story, "The Adventure of the Dying Detective," Sherlock feigns contracting a disease from some place in the Orient. In this episode of Elementary, Sherlock has also fallen ill and Joan makes him Chinese herbal tea, which correlates with his convalescence. In the canon, China is represented as a source of disease and contamination, whereas, in Elementary, China can be a source of medicine and healing. Ultimately, in this episode, the Chinese tea becomes a symbol for the relationship between Joan and Sherlock throughout the first season, which takes the form of a cycle in each episode: resistance, apology and acceptance, change and growth.

First, Sherlock resists change and insists his way is best. Joan or another character will challenge his way of doing things or offer an alternative method that Sherlock will initially shoot down, ${ }^{92}$ as in the scene when the tea first appears:

SHERLOCK. Ugh, what-what is that? I asked for coffee. JOAN. Well, you asked for coffee but you got tea. SHERLOCK. No, I'm British-this is not tea.

${ }^{92}$ Another example of this occurs in the third episode of season one, "Child Predator." In this episode Joan teaches Sherlock her trick for staying awake to cram in med school. To get the blood flowing she would do a hundred squats. At first Sherlock expresses incredulity, "This is what they taught you at medical school?" but he joins in shortly after. Later in the episode, Sherlock thanks her for her help on the case:

SHERLOCK. Mm, I'm sore. I only did about a thousand squats last night. Listen. I wanted to thank you for all of your help.

JOAN. I'm always happy to listen.

SHERLOCK. No no, actually, Watson, I was the one who listened last night, and I heard someone who was willing to accommodate the difficult process of a difficult person for the greater good. It's a rare quality in my experience. And... I may even listen to you again in the future. Not your sobriety twaddle, just your... thoughts on cases.

Again, the squatting exercise becomes a metaphor in the episode for Sherlock's acceptance of other's help and advice. 
JOAN. There's some traditional Chinese herbs in there. I poked around the stalls in Chinatown while I was waiting for you. I found the ingredients for the same tea my mom used to make me when I was sick. SHERLOCK. Well, all due respect to your mother, I would prefer something proven by a scientific method.

JOAN. The herbs in that tea have been proven scientifically to inhibit the movement of neutrophils, improve the function of protective cilia, and contribute to longer-lasting, more vasodilated erections.

SHERLOCK. By your mother?

JOAN. Just shut up and drink it.

This exchange raises two important points. First, tea is central to British and Chinese identity. The trade deficit caused by the importation of goods from China, such as tea, has already been discussed. While the historical and economic situation surrounding tea during British imperialism highlights the strained relationship with China, it is also a potential site of affinity between the two cultures. Second, in this exchange Sherlock attempts to pit Eastern and Western medicine against each other, as antithetical. He snarkily replies that he prefers medicine proven by the "scientific method," evoking the rationality of the Western world, the tradition upon which this detective's method is based. Joan's reply is telling. Joan posits that Chinese and Western medicine need not be at odds but can mutually inform one another. The exchange also reveals that she has researched the overlap between her medical training in the West and her Chinese heritage.

Next Sherlock admits fault, asks for forgiveness, and often help. In short, Sherlock learns from his mistakes (both socially and intellectually). Socially, Sherlock often cedes that his behavior in initially rejecting a differing viewpoint was uncalled for and usually reflective of a deeper problem he is facing personally. Intellectually, he often 
cedes the point and finds a new approach to detection, life, etc. ${ }^{93}$ In this episode, the Chinese herbs are first mentioned in the exchange between Sherlock and Joan but later actually play a role in cracking the case they have been working.

SHERLOCK. The M.E. found dried chrysanthemum and mulberry leaf in his stomach contents.

JOAN. Oh, those are both-

SHERLOCK. Medicinal Chinese herbs. Yes, well aware. This particular combination is used to treat eye pain.

JOAN. How did you know that?

SHERLOCK. I may have done some research into the efficacy of Chinese medicine after the herbs that you gave me had a positive correlation with my recovery.

The realization that Trent Annunzio had been taking Chinese herbs to treat his secret eye cancer forces Sherlock to acknowledge that he has researched the Chinese tea Joan made for him. That Sherlock has taken the time to research Chinese medicine demonstrates that he values Joan's perspective, believes they may have contributed to his recovery, and illustrates he is open to changing his mind. The hesitancy Sherlock displays in admitting his research ("I may have") only enhances the realization that he has ceded to a different method.

Finally, Sherlock and Joan grow and learn with and from each other. It's no mistake that his biggest admission of fault is directly followed by a reference to the Chinese tea. After Sherlock realizes Jun is not responsible for Trent Annunzio's murder, he laments that by accusing her of murder he has generated the circumstances that will lead to her deportation:

\footnotetext{
${ }^{93}$ A good example of this occurs in the second episode of season one, "While You Were Sleeping" (1:2) when Joan forces Sherlock to attend an Narcotics Anonymous meeting, Elaine, a recovering drug addict, tells the story of how she used her romantic relationship with a doctor to feed her drug addiction. By listening to her testimony, Sherlock makes a break in the investigation. He realizes that Yvette Ellison (a coma patient and murderer) used her relationship with her doctor (who put her in and out of a drug-induced coma) as an alibi for committing murders. While he abruptly leaves the meeting, he later again admits that listening to others can be beneficial to his work and life.
} 
Because, upon further examination of the facts, I now have reason to believe that I was wrong, and that in accusing her, I may have inadvertently positioned the United States Immigration and Customs Enforcement Agency to separate an innocent woman from her infant daughter on a very permanent basis. That tea that you made the other day, could you make some more of it? [emphasis added]

In this admission, Sherlock cedes "he was wrong" about Jun and also about the Chinese tea. In asking for more tea, he has gone further than recognizing he "may" have researched it and now affirms a degree of belief in its efficacy and perhaps preference for it over traditional Western medicine (since he is never seen taking pharmaceuticals in the episode - although, it should be acknowledged, this is also likely an extension of his abstention from narcotics). Furthermore, Sherlock recognizes the crux of crime and national borders. Although Jun is illegally living in the United States, her guilt is allayed in light of Trent's — and presumably the U.S. government's — more heinous crimes. ${ }^{94}$ Sherlock indicates this by calling her an "innocent woman."

There is a long history of anti-Chinese immigration legislation in the United States. Many laws have been passed dating back to the mid-nineteenth century limiting or outright banning the immigration of Chinese into the United States, largely in response to the Gold Rush and use of cheap labor for railroad construction. ${ }^{95}$ The Page Act of 1875 was meant to reduce "undesirable" immigration from Asia. It restricted immigration of forced Asian workers (such as coolies) and any Asian woman suspected to become involved in prostitution after entry to the U.S. In the mid-nineteenth century, "most of the

\footnotetext{
94 Trent's attempt to foil Jun's future happiness by framing her and her lover (Brendan O'Brien) for his murder from beyond the grave and what Sherlock paints as the U.S. government's perceived future subscription to an inhumane policy that would separate a mother from her child through deportation. ${ }^{95}$ See also the Scott Act (1888), which prohibited Chinese who had visited China from reentry to the United States. California, where the largest percentage of Asian immigrants settled, has passed legislation at the state level against Chinese immigration.
} 
Chinese women in the United States worked as prostitutes: a major contributing factor to their portrayal" (Stewart 121). This law was a response to the prevalence of Asian female sex workers at the time; however, it also reveals the white American exoticization of Asian women which allowed for these circumstances. In effect, this legislation curbed the immigration of Asian women and resulted in a large disparity between Asian males and females in the United States. In 1882, the U.S. Congress took matters further and passed the Chinese Exclusion Act, which "prohibited Chinese labor migration to the United States and barred Chinese residents from obtaining U.S. citizenship" (Hooper and Batalova). The legislation was originally meant to last only for a period of ten years but was renewed in 1892 under the Geary Act and made permanent in 1902. It was not repealed until 1943.

While detective fiction in the West has traditionally relied on a resolution that exonerates the white, middle-class community of its guilt by exorcising a foreign criminal, here the reverse is presented. Both the pilot episode and this episode of Elementary furnish white-American, male criminals from the professional class (a psychiatrist and a university professor) who frame for murder socially othered individuals (a violent sex offender and an illegal Thai immigrant) out of greed or revenge, respectively. While Soo Lin Yao is victimized, it is at the hands of her own people (the Chinese Black Lotus Tong) and ultimately her own family since her brother is her murderer. She is depicted as a victim of the circumstances of growing up in corrupt and criminal China. Although they fail, Sherlock represents Holmes and Watson as her paternalistic saviors, who feel it their duty to rescue her from her criminal past. In Elementary, Jun is victimized by Trent and her crime of illegal immigration is sidelined 
by the bigger systemic issues of Asian immigration and sexual victimization. Arguably, the Chinese are represented as criminals in the Chinatown gambling establishment but this criminality is balanced by other ethnically Chinese characters who are law abiding citizens (Sherlock's chef friend and Joan herself). Elementary represents several differing articulations of Chinese ethnicity rather than stereotypes inherited from the texts born during colonialism.

\section{CONCLUSION}

In conclusion, the original context of the Opium Wars reveals both the hypocrisy of the British Empire's "civilizing mission" as well as how the stereotype of the Chinese became linked with criminality through their association with opium dens and the rise of Chinatowns. The history of representations of the Chinese by the West continues to inform adaptations of Sherlock Holmes on television today. While many viewers have criticized CBS for capitalizing on the BBC's success with Sherlock in their creation of the series Elementary, the shows take very different stances in relation to Doyle's original text, the historical context between China and the Occident, and the way the Chinese elements are deployed.

In its modernization of the original detective, Sherlock reiterates imperialistic propensities that were present in Doyle's text through its reliance on an aesthetic of opposition drawn along the lines of ethnic difference. In contrast, Elementary, through its direct confrontation of the tradition of Orientalism, the casting of Lucy Liu, and the dynamics of her partnership with Sherlock has succeeded in offering a more pluralistic and positive notion of ethnic difference. It could be argued that Elementary represents the 
American national myth of a "melting pot" nation where race is invisible. But, in representing Sherlock's initial rejection and then struggle to accept different perspectives (those of Joan and also Detective Marcus Bell ${ }^{96}$ ) and collaborate, I argue, it avoids this categorization.

In Elementary, the denouement of most episodes is a collaborative speech in which Sherlock, Joan, Marcus, Gregson, and later Kitty take turns explaining the different twists and turns that led to the solution of the investigation. In addition, the leads in the case are found by various characters besides Sherlock. The show often presents stereotypical criminals as suspects, only to complicate these expectations about the inherent criminality of the non-normative - the Other. Therefore, the larger themes of the show resist offering this easy reassurance and covering over contemporary American society's racial tensions. Bhabha writes, “The stereotype requires, for its successful signification, a continual and repetitive chain of other stereotypes" (110). In order to move away from stereotypical representation of cultural difference, the media must break this tradition and strive instead for articulations of difference that recognize the complicated and often intersectional relationship between crime, place(s), and identities.

\footnotetext{
${ }^{96}$ Played by black, American actor, Jon Michael Hill
} 


\section{CHAPTER III \\ THE CRIMES OF THE POWERFUL: \\ SOCIAL CLASS, THE STATE, AND CORPORATIONS}

\section{CRIME AND CLASS}

In The Crimes of the Powerful: Marxism, Crime, and Deviance, where Frank Pearce first coined the phrase, he argues that a Marxist analysis should explain "law and criminality in terms of the dominant mode of production and the class nature of society" (14) and treat "the law as a class instrument used to help reproduce a social order which benefits one class over others" (52). The goal of this chapter is to elucidate these connections between social class, state-sanctioned power, and the economic context of capitalism in Sherlock Holmes narratives. In the nineteenth century, the analysis centers on an examination of hereditary titles (peerage and gentry) and the government. In the context of the twenty-first century, the focus is on the government institutions and corporate power because as David Whyte explains "state institutions and corporations $[\ldots]$ are key and central agents of power in contemporary societies" (3). I consider the ways in which Doyle's Holmes stories built on the tradition of the amateur detective to reconcile criminal detection to the moral good and the socio-economic context of the nineteenth century which gave rise to his position as consultant as well as the continued preference to so position him in these recent adaptations, Sherlock and Elementary. 
This chapter is organized around two central questions: First, to what degree does Holmes (and the televisual interpretations of his character) reinforce or challenge thestructures of power and the status quo? And second, what is the relationship between Holmes's role as a "consulting detective" and the powerful? In this chapter I examine one of the most adapted of the stories, The Hound of the Baskervilles, and the two television episodes which share approximately the same title, Sherlock's "Hounds of Baskerville" (2:2) and Elementary's "Hound of the Cancer Cells" (2:18).

I have chosen The Hound of the Baskervilles as the focus for analysis in this chapter since both the victims and the criminal in this investigation are from the same family. This recognition is made apparent in the end when Watson sees both Henry and Jack seated side-by-side and describes them as "the murderous host [Jack Stapleton] and the unconscious guest [Henry Baskerville]" (HOUN 586). The heart of the mystery centers on the inherited title of the baronetcy of Baskerville Hall. A baronet is the only hereditary title in England that is not part of the peerage (Encyclopedia Britannica "baronet"). Therefore, this title is a part of the landed gentry just like Holmes's family. As we learn in “The Greek Interpreter," Holmes's ancestors were “country squires” (636) also belonging to the landed gentry. In the social hierarchy, landed gentry are in between the nobility and the middle class. In the novel, Charles and Henry possess the good qualities of both the nobility and middle class while Stapleton and Hugo are wicked and deceitful but all four are part of the same family. As already discussed, Holmes similarly has the potential for either great good or evil. By making the Baskervilles baronets, Doyle is able to continue the ambivalence about hereditary power structures still dominant in England in the late nineteenth and early twentieth centuries. In order to illuminate the 
ways in which the reader's sympathies are aligned with Henry Baskerville and displaced from Jack Stapleton (his first cousin), I will focus on the use of character descriptions. Furthermore, I will briefly examine the development of the relationship between Holmes, Scotland Yard, and the British government. ${ }^{97}$

My consideration of the detective's position as consultant in Sherlock is more oriented towards his position in relationship to the government, whereas in Elementary the focus is on the greed of corporate America. I will argue that in Sherlock Holmes's brother, Mycroft, while initially threatening becomes a symbol of the paternalistic government who has the citizens' best interest at heart. In Elementary, I will examine Sherlock's clear disdain for private corporations as endemically immoral and stemming from the drive for profit built into the capitalist structure. Sherlock's relationship with this power structure is similarly illustrated through his relationship with a family member, his father (Morland Holmes).

\section{MR. SHERLOCK HOLMES, THE CONSULTING DETECTIVE}

In over half of the original sixty Sherlock Holmes stories, the detective's clients are part of this group, the powerful. Corporate, bureaucratic, and aristocratic characters are clients in thirty-nine of the sixty cases. While it may seem that since clients in the original stories "come from a diverse set of backgrounds" (O’Brien xix) Holmes maintains a certain level of class equality, Rosemary Jann argues that throughout the first twelve short stories, published collectively as The Adventures of Sherlock Holmes, there is a clear social class bias and the proletariat as client only appears in four cases. But

\footnotetext{
${ }_{97}$ Another variable to consider in this study would be the intersection of gender and power structures but it is not central to the argument set forth in this chapter and is, instead, considered elsewhere.
} 
understanding Holmes's attitude towards social class across the entire canon resists such easy classification. In "The Adventure of Black Peter," ${ }^{98}$ Watson directly contradicts this understanding that Holmes has a class bias:

So unworldly was he - or so capricious - that he frequently refused his help to the powerful and wealthy where the problem made no appeal to his sympathies, while he would devote weeks of most intense application to the affairs of some humble client whose case presented those strange and dramatic qualities which appealed to his imagination and challenged his ingenuity. (976)

This reinforces the idea that Holmes stands apart from society and its class biases. He is interested in the work much more than the people involved or any social advantages he may garner from helping such powerful friends. Far from providing a clear understanding of the relationship between social class and inner morality, Holmes's own generalized statements directly contradict one another. In "The Adventure of the Naval Treaty," in discussing Lord Holdhurst, Holmes states that "he seemed to represent that not too common type, a nobleman who is in truth noble" (694). Here Holmes opines that a noble and moral individual among the upper classes is, in fact, a rare phenomenon. Whereas, in the last published case, "The Adventure of Shoscombe Old Place," he states the exact opposite: "Sir Robert is a man of honourable stock. But you do occasionally find a carrion crow among the eagles" (1720). Here, Holmes directly contradicts his previous statement by explaining that it is rare to find a corrupt nobleman among the upper class. If we consider the publication history of the stories as well as the perceived order of events within Holmes's lifespan, the quotes appear in the following order:

\footnotetext{
${ }^{98}$ First published in 1904 after the "Great Hiatus" and collected in The Return of Sherlock Holmes.
} 
Title

of Story

"The Adventure of the Naval Treat"

"The Adventure of Black Peter"

The Adventure of Old Shoscombe Place"
Publication

Year

1893

1904

1927
Life of Sherlock Holmes ${ }^{99}$ 1889

1895

1902

Although the year of publication and the time setting within the diegesis are different for each story, the sequence of these three stories is the same along both time frame considerations. Therefore, the disjunction of Holmes' statement about the rare occurrence of immorality among the upper classes may represent a trend towards conservatism in terms of Doyle's thinking as well as Holmes's.

In order to more fully comprehend Sherlock Holmes's initial role as a "consulting detective" and his relationship to the powerful it is important to understand the historical context of the late nineteenth century and the rise of detective fiction from the rogue literature which existed previously. According to Dennis Porter, "From early on in the nineteenth century $[\ldots]$ crimes by and against the state, existed alongside anxiety at the random, individual violence of murder, rape, abduction, burglary, and street theft" (1617). Historically speaking, the plain clothes detectives which sprang up in Britain and the United States were initially met with great trepidation as foreign spies or manifestations of the state's power to control the individual citizen. For a populace unaccustomed to a police presence, detectives represented "the idea of an occupying army and [were associated with] the centralized institutions of Revolutionary and Napoleonic France" (Porter 150). Many critics have argued that the shift in public opinion regarding the historical detective figure was greatly influenced by the development of detectives in

\footnotetext{
${ }^{99}$ Dates for the ordering of the stories within the life of Sherlock Holmes are based on the chronological table provided by Leslie Klinger (The New Annotated Sherlock Holmes, vol. 1 751-776).
} 
fiction. One of the ways this occurred was by turning the detective and the criminal into symbolic counterparts of a larger cosmic battle between the moral and the immoral:

The detective, most often depicted in individualized combat with the criminal, has from his inception as a type worked to deflect examination of the legitimacy of law or consideration of the social and historical roots of crime by turning detection into a stand off between good and evil. (Jann 40)

Doyle's detective "may appear to stand outside the law on a higher moral ground, but his actions are based on a careful and ultimately comforting calculation of the risks involved for the status quo" (Jann 81). Holmes's status as an amateur detective makes him appear the autonomous and disinterested agent.

Holmes seems to stand above or outside petty economic considerations; detection is a moral obligation rather than an occupation performed for wages. And although this may be the effect of the stories when taken as a whole, at the individual level this is not always the case. The conclusion of A Study in Scarlet provides a good example. When Holmes and Watson read the Echo article which details how Enoch Drebber has been apprehended, the credit is awarded to Gregson and Lestrade of Scotland Yard. The final words of the novel are the Latin that Watson quotes to Holmes, "'Populus me sibilat, at mihi plaudo ipse domi simul ac nummos contemplor in arca" (202) which means "The people hiss at me but I applaud myself in my own home, as I gaze fondly at the coins in my strongbox" (202, Klinger note 262). Holmes claims he is a consulting detective because he doesn't need the money or the accolades, however, this first case ends with an evocation of both. Watson offers the former as a consolation for the absence of the latter. Doyle's detective is both aligned with the state apparatus, working with and for Scotland Yard in many of the cases, but also stands outside the official police as 
demonstrated by his early condescension to their methods and refusal to supply the culprit in several instances. ${ }^{100} \mathrm{He}$ is perfectly poised to uphold the status quo without appearing to do so. Over the forty-year span in which the cases were published, the relationship between Holmes and Scotland Yard undergoes a substantial shift. A characteristic example of the disdain ${ }^{101}$ with which Holmes treats the police can be found in The Sign of Four:

"The only unofficial consulting detective," he answered. "I am the last and highest court of appeal in detection. When Gregson or Lestrade or Athelney Jones are out of their depths - which, by the way, is their normal state - the matter is laid before me. I examine the data, as an expert, and pronounce a specialist's opinion. I claim no credit in such cases. My name figures in no newspaper." (217)

Holmes is "unofficial" in his own estimation for several important reasons: 1) so that he can stand above the institution (as the "highest court of appeal"), 2) because he does not care for the credit that comes along with solving the cases, and 3) because his methods are those of an "expert" while Lestrade and Gregson are "shockingly conventional" in their thinking (STUD 49). The added complexity of an investigation often proves too difficult for the straight-forward tactics of Lestrade and Gregson.

Already by The Hound of the Baskervilles (1902), the air of superiority which accompanies his early remarks about the police is being tempered and replaced with mutual respect. ${ }^{102}$ Holmes says, "“He [Lestrade] is the best of professionals, I think, and we may need his assistance"" (576). Watson offers further insight into this relationship:

\footnotetext{
${ }^{100}$ Most notably in "The Adventure of the Blue Carbuncle" (1892), a story in which Holmes does not turn the thieves over to the authorities but lets them go, at least nominally, in the spirit of the Christmas season. ${ }^{101}$ Another indication of this occurs in A Study in Scarlet. Holmes takes the case but says, "I may have a laugh at them, if I have nothing else" (50) in reference to Gregson and Lestrade.

${ }^{102}$ It is important to note that although The Hound of the Baskervilles was published during the "Great Hiatus," the story, in fact, was set much earlier. The investigation of The Sign of Four took place in 1888. Klinger's Appendix 5 to The Hound of the Baskervilles is revealing. Many chronologists date the events
} 
I saw at once from the reverential way in which Lestrade gazed at my companion that he [Lestrade] had learned a good deal since the days when they had first worked together. I could well remember the scorn which the theories of the reasoner used to excite in the practical man. (580)

Although it is not the final story to be published, "His Last Bow: The War Service of Sherlock Holmes" ${ }^{103}$ (1917) is the last to occur within the timeline of Holmes's life. The story is set in August of 1914 and features a retired Holmes who conducts some espionage on behalf of the British government. Published during the First World War, it seems Doyle could no longer afford for Holmes to remain the distant amateur criticizing the methods of British institutions and so he is recruited by the crown to spy on the Germans. At the conclusion of the story, Holmes explains to Watson:

"There's an east wind coming all the same, such a wind as never blew on England yet. It will be cold and bitter, Watson, and good many of us may wither before its blast. But it's God's own wind none the less, and a cleaner, better, stronger land will lie in the sunshine when the storm has cleared." (1443)

The east wind is representative of the hope that the Allied Powers will be victorious in The Great War. This metaphor of the east wind is resurrected in Sherlock's conclusion to season three. Here, Sherlock Holmes himself is cast as the east wind, who will smite the wicked and ensure the triumph of the morally good. Sherlock explains to John that the story of the east wind was one that Mycroft used to tell him in order to scare him into behaving. Later as John tells Mary that if Moriarty has returned "he'd better wrap up" because "there's an east wind coming," the pronouncement corresponds to the return of the plane that was carrying Sherlock away to begin some undercover work in Eastern

contained within The Hound of the Baskervilles to 1889, just one year later but there are inconsistencies that cast this dating into question. Among those listed are the detective's relationship with Lestrade (626). ${ }^{103}$ The subtitle appeared when published in the Strand Magazine. 


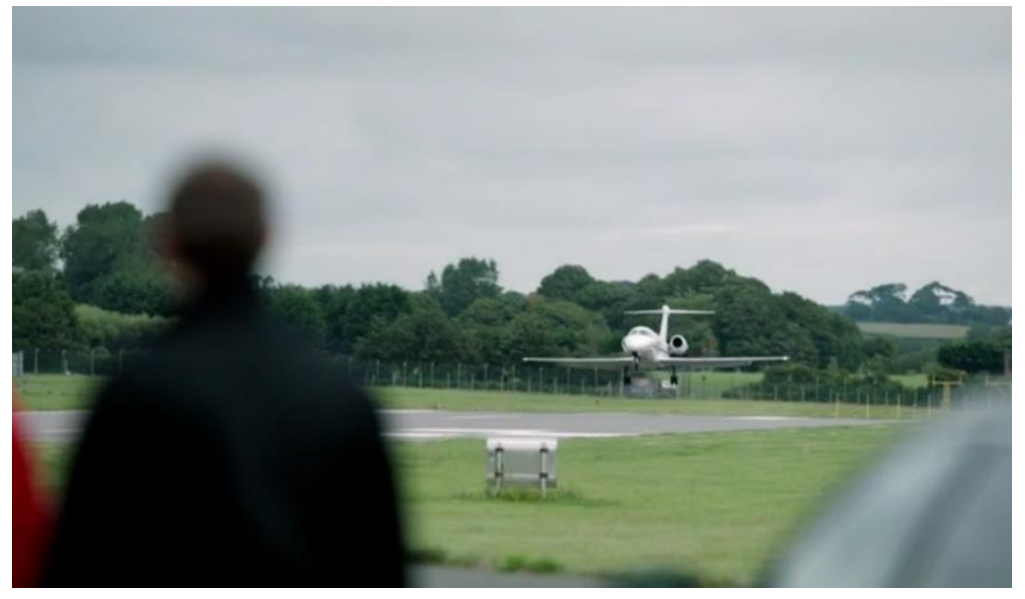

IMAGE 3-1 Directly before the audience sees this shot, John says to Mary, "There's an east wind coming." (Sherlock 3:3)
Europe (IMAGE 3-1). In

Sherlock, the detective

figure has become justice

personified as signaled here

by the synchronicity

between the audio and

visual tracks.

\subsection{An Analysis of The Hound of the Baskervilles}

As a case study The Hound of the Baskervilles provides an excellent opportunity to examine the questions central to this chapter. Doyle's novel is focused on an upper class family, the Baskervilles, that has produced both good heirs (Charles and Henry) and evil criminals (Rodger or Stapleton and Hugo). It is a perfect example, then, to consider the nexus between criminality, nobility (in both the social and moral sense), and power is represented in the Holmes stories. But if nobility and criminality are hereditary or tied to social status, then how can this upper class family give birth to both upright and despicable characters? And more importantly, how does the novel forestall the questioning of a system of hereditary authority which perpetuates the holding of power by the wealthy, aristocratic elite? The ability of the detective, and by association the reader, to correctly read the inner morality of the upper class characters becomes crucially important. Even though a system of hereditary power relinquishes such control to the next heir, regardless of their individual moral worth, the signs of their morality or 
immorality may still be correctly read by the individual who practices careful observation.

As Dennis Porter has argued, in detective fiction, character descriptions are verbal portraits, which "always orient the reader's feelings" (43). Although Porter is specifically examining the use of character descriptions in the hard-boiled novels of Dashiell Hammett and Raymond Chandler, this technique is prevalent in the Sherlock Holmes stories as well. Porter explains the function of such descriptions:

It [the character portrait] usually appears when a new character is introduced and may be defined as a verbal construct designed to leave the reader with a strong impression of a human or social type. It presupposes the selection of certain widely recognizable cultural signs that enable the reader to make the appropriate determinations. Depending to some extent on the importance of the character in the story, it runs to roughly a paragraph in length. It also usually fulfills the expectation that it will communicate certain kinds of information about sex, age, physique, size, taste and social situation, as well as some insight into moral character. (4445)

Upon the passing of Sir Charles Baskerville and the impending arrival of the heir to Baskerville Hall (Henry), Dr. Mortimer seeks out the help of Dr. Watson and Sherlock Holmes. The reader never gets a direct description of Charles. Absent from the portrait are his physical attributes but the importance of his financial position and moral character are supplied. Dr. Mortimer's short description of the late Sir Charles Baskerville is the first mention of the murder victim, "He was a strong-minded man, sir, shrewd, practical, and as unimaginative as I am myself" (398). This description serves two main functions. It demonstrates, first, that Charles Baskerville was not likely to believe in a legend of a gigantic hound unless he had good reason. Second, although ostensibly from the upper classes, Charles becomes aligned with the values of the middle class; he is a "shrewd" and "practical" man. Jann argues that "The real appeal of [Holmes's] character lies in its 
ability to satisfy a middle-class ideal of preeminence earned by talent rather than by birth while still retaining the trappings of older, leisured aristocratic ideals" (39). Although Jann is concerned with the detective's character, these are reconciled perfectly in Charles Baskerville, who inherits his title but seems to have earned his wealth.

The importance of "talent" or merit is reinforced by the obituary Dr. Mortimer has brought with him from the local newspaper, the Devon County Chronicle, which follows just after this description: "In these days of nouveaux riches it is refreshing to find a case where the scion of an old country family which has fallen upon evil days is able to make his fortune and bring it back with him to restore the fallen grandeur of his line" (407). The loaded language which appears in this quote demonstrates a clear class bias. Although Charles has earned his money through "South African speculation" (407), he is opposed to the "nouveaux riches" with its derogatory connotation. "Fallen" appears twice in this short excerpt. The second time it is used it modifies "grandeur of his line," which Charles is credited with restoring.

Two other important details are revealed in the newspaper article. First, his remarkable "amiability of character and extreme generosity had won the affection and respect of all who had been brought into contact with him" (407). Second, he was a "probable Liberal candidate for Mid-Devon" (407). This is important when coupled with Pearce's analysis of the powerful, which explains there is a marriage between the reigning class and the hegemonic class fraction. In Pearce's analysis, "The group actually holding the reins of government may not be ruling the country. Those ruling the country may only be holding power in the interests of some other group, the hegemonic fraction of the ruling class" (61). He turns to Marx and his case study of Britain at the end of the 
nineteenth century, as offered in Capital as an example. Pearce quotes from Nicos Poulantzas's explanation, "There the hegemonic class was the financial (banking) bourgeoisie, while the upper personnel in the administration, army, diplomatic corps, etc. was recruited from within the aristocracy which thus occupied the position of reigning class" (208).

Taken in sum, the descriptions of Charles Baskerville both enunciate the power structure at work in the late nineteenth century, which demonstrates this alignment between the upper classes, capitalist financial gain, and state power, while also legitimizing such a consolidation of power in the positive portrayal of his moral character. All three are actually located within the figure of Charles Baskerville. He inherits his baronetcy (old money), he has redeemed his family's "fallen grandeur" by means of capitalist enterprise, and he was probably going to run ${ }^{104}$ for government office. According to Pearce, "The state is an essential mode(s) of production found within any society. Its objective function is to guarantee the reproduction of the economic system" (61). This is the relationship between the base and the superstructure. Both the political system and literature are part of the superstructure and share the same function: the maintenance of the economic status quo. The murder of Charles Baskerville is, at least partly, more horrific due to its potential to upset the reproduction of the economic and political system, the latter depending on the former for its continued stability.

Charles's nephew and successor, Henry Baskerville, although from the upper classes, is similarly aligned with bourgeois moral values (such as hard work and

\footnotetext{
${ }^{104}$ And most likely win, since Sir Charles is particularly skilled at efficiently winning the "affection and respect" (407) of those he comes into contact with. He seems perfectly suited to win a political election.
} 
directness). The first description of the heir is also supplied by Dr. Mortimer. He informs Holmes and Watson that Henry "had been farming in Canada. From the accounts which have reached us he is an excellent fellow in every way" (419). The superlative terms in which Henry is described leave little room to doubt his character and his honest occupation of farming seems to dispel the image of the privileged and spoiled member of the titled gentry. Watson provides a more detailed portrait of "the young baronet" 105 (430) when he first meets him:

a small, alert, dark-eyed man about thirty years of age, very sturdily built, with thick black eyebrows and a strong, pugnacious face. He wore a ruddy-tinted tweed suit and had the weather-beaten appearance of one who has spent most of the time in the open air, and yet there was something in his steady eye and the quiet assurance of his bearing which indicated the gentleman. (430)

Germane to this consideration is the way in which Henry seems to straddle two social classes. He is a gentleman of the upper class (a baronet), which is slipped in at the end of Watson's description but he is also firmly aligned with the lower classes and hard work in his farmer's appearance. He is "sturdily-built," his suit is "ruddy-tinted" like the earth, he looks "weather-beaten" and has most likely spent a lot of time in the "open air." All of these features reinforce the image of him as a farmer and a hard worker. Furthermore, his "steady eye" and "quiet assurance" seem to demonstrate his familial resemblance to his "shrewd and practical" deceased uncle.

Later in the novel, when Watson and Henry investigate the strange noises occurring at night, Watson describes the situation: "We had arranged no plan of campaign, but the baronet is a man to whom the most direct way is always the most

\footnotetext{
${ }^{105}$ Klinger's note to the text reveals that a baronet is "a hereditary rank, not nobility" (430, note 61$)$. Thus, Henry would be located in the social class directly beneath the nobility but above the middle class.
} 
natural" (508). Although it is a passing comment, the assessment is striking when combined with the early descriptions about the new baronet and in direct contradistinction to his cousin's (Stapleton's) deceptive ways. Henry's preference for directness affirms the implications about his honest trade of farming and the accompanying simple life. Like his uncle, Henry appears to the reader worthy of his inheritance because he has earned it by virtue of his strong moral character, primarily his honesty and work ethic.

Jack Stapleton, the entomologist living near Baskerville Hall at Merripit House is eventually revealed as the true criminal mastermind behind the murder of Sir Charles Baskerville, attempted murder of Henry Baskerville, and the inadvertent murder of the escaped convict (Selden). It is also discovered that he has been living under the assumed name of Stapleton and was born Rodger Baskerville II. He is the son of Rodger Baskerville I, the youngest brother of Sir Charles and the "black sheep of the family" (420), "who made England too hot to hold him" (420) and "fled with a sinister reputation to South America" (603).

Rodger (A.K.A. Jack Stapleton) is described as "this very wily man" (580), "that desperate and defiant villain" (593), "that complex and dangerous man" (593), and has a "fiery soul which his self-contained manner so cleverly concealed" (611). As Holmes explains to Watson, "never yet have we helped to hunt down a more dangerous man" (600). The clearest indictment of his moral fiber, however, is his physical resemblance to his ancestor, Hugo Baskerville. This is the crucial development that leads to Holmes's solution to the mystery. When Holmes eventually arrives at Baskerville Hall and lays eyes on the old portrait of the progenitor and source of the curse, he says, "'He seems a 
quiet, meek-mannered man enough, but I dare say that there was a lurking devil in his eyes. I had pictured him as a more robust and ruffianly person"” (572).

After Holmes reveals how Rodger has deceived the community by introducing his wife as his sister, Watson's descriptions of Rodger are altered retrospectively: “In that impassive colourless man, with his straw hat and his butterfly-net, I seemed to see something terrible - a creature of infinite patience and craft, with a smiling face and a murderous heart" (555). Holmes's description of Hugo Baskerville and Watson's description of Rodger are parallel in their focus on the cultivated image they attempt to present to society versus the inner immorality which may be revealed upon closer inspection. Porter writes:

there is also a well-known circularity in the typical strategy of realist fiction that details the physical characteristics of a character as signifiers of moral propensities and then goes on both to name those propensities directly and to show them acted out in a scene. (96)

Although the dissonance between appearance and inner morality is complicated in the case of Rodger and Hugo, this is what makes their criminality more dangerous, its potential to go undetected. As Jann points out, "The magnitude of their wrongdoing also reinforces the view voiced elsewhere that when they do go wrong, higher-class characters [...] make the most dangerous crooks" (81-82). Ultimately, Holmes concludes that the uncanny resemblance between "the wicked Hugo" (572) and Rodger Baskerville II "is an interesting instance of a throwback, which appears to be both physical and spiritual [...] the fellow is a Baskerville - that is evident"' [emphasis added] (572), which seems to affirm this reliance on outward appearance as an indication of moral character or lack thereof. The difference between hereditary and experiential influences on criminality is further complicated in the novel when we consider that both Henry and Jack have 
returned to England after time abroad (Canada and South America, respectively). As already mentioned in chapter two, Yumna Siddiqi has argued that Doyle's representation of characters who have returned from the colonial periphery does not follow a consistent trend. Sometimes characters return to the metropole and become fully acclimated members of society. While other characters return only to pursue a life of crime and destruction.

Watson's continued preference to refer to the central orchestrating criminal as "Stapleton" rather than his given name "Rodger Baskerville" may indicate a class bias on his part. Watson's choice appears a refusal to acknowledge Rodger's kinship to Charles and Henry. Another telling feature of the case is the treatment and descriptions of Selden, the escaped convict and brother of Mrs. Barrymore (a servant at Baskerville Hall). Selden's criminality is clearly written in his physical features, as demonstrated by Henry’s discussion with Mr. Barrymore. Henry says, “"The man is a public danger. There are lonely houses scattered over the moor, and he is a fellow who would stick at nothing. You only want to get a glimpse of his face to see that"' [emphasis added] (523). When Selden is accidentally killed by the hound, who mistakes him for Henry Baskerville (since he is wearing Henry's old clothes and smells like him), Watson very nearly rejoices that it was not the baronet. Watson says, "The tragedy was still black enough, but this man had at least deserved death by the laws of his country. I told Holmes how the matter stood, my heart bubbling over with thankfulness and joy" [emphasis added] (562). At another point in the novel, Selden is described as "half animal and half demon" (568) a trend which emerged in the analysis of Tonga in chapter two. By comparison, when discussing Stapleton, Holmes remarks to Watson "we have never had a foeman more 
worthy of our steel" (566). The lower class criminal (Selden) is represented as demonic, beastly, and non-human much like the hell-hound. ${ }^{106}$ Rodger, however, uses the hound to carry out his crimes but is characterized as a worthy opponent and remains free from prosecution by the laws of man in the end; instead, meeting his demise in the Grimpen Mire.

\section{SHERLOCK, MYCROFT, AND THE WAR ON TERROR}

Sherlock alters the original title of Doyle's novel by making "Baskervilles" singular and "hound" plural; the changes to the title indicate that the focus is no longer on the descendants of a upper class family. In the episode, the murder of their client's (Henry Knight's) father twenty years prior to the events of the episode is traced back to the continuation of experimentation into a chemical weapon. "Hound" is pluralized since it has been changed into an acronym. H.O.U.N.D. are the first letters of the names of the five originating scientists who first worked on the project. The "hounds" from the episode's title, then, are the five scientists who are responsible for the original chemical research.

Baskerville is still the setting of the story but it no longer represents the seat of a grand line but rather the Baskerville Army Base. The location of Dartmoor remains a constant in the adaptation. I argue that within this episode, the series flirts with the idea of a critique of the government but ultimately resurrects the trend in Doyle's stories, which falls back on blaming the individual rather than indicting the system. The tendency in "the Adventures [is] to avoid challenging the institution or social bases of power by

${ }^{106}$ As quoted in Chapter 2, Tonga is described as "that little hell-hound" (SIGN 157). 
implying that the reform of individuals, and not structures, is all that is needed to correct society's problems" (Jann 116). Although in Sherlock the detective is situated in modern London as a consulting detective, his role with the government (as opposed to Scotland Yard) becomes more prevalent and important, which is plainly evidenced by Mycroft Holmes's larger role in the series than in the stories. This episode from season two, in which Sherlock and Watson investigate the Baskerville Army Base, demonstrates a shift from concern for the safety of London in season one to national and international concerns in seasons two and three, ${ }^{107}$ in which terrorism becomes the pressing threat.

The Baskerville Army Base is first introduced through a documentary video that Henry Knight brings to his consultation with John and Watson and its secrecy is foregrounded. The very first description provided for the viewer is that "Dartmoor's also home to one of the government's most secret of operations" and later John remarks “Technically Baskerville's an army base, so I guess they’ve always been keen to keep people out." Corporal Lyons, ${ }^{108}$ an employee at the base, expresses astonishment at Sherlock and John's ruse that they have been sent for a random inspection: "It's just we don't get inspected here, you see, sir. It just doesn't happen.” The utmost secrecy with which Baskerville operates becomes suspect from the start and raises questions about what and why such secrecy may be necessary. This secrecy is also the shroud which Sherlock and John will penetrate in order to get to the truth of what happened twenty years ago when Henry's father was killed.

\footnotetext{
${ }^{107}$ Although, as demonstrated in chapter two, the criminals that proliferate in the first season are almost all of foreign ethnicity. This arguably sets up the extended scope, the international concerns, which will become the major focus of the subsequent seasons.

${ }^{108}$ In Doyle's novel, Mrs. Lyons is a female character (manipulated by Stapleton) who is attempting to divorce her husband. She unknowingly plays a role in luring Charles Baskerville out of his home and to his death. She is a character from the original stories who demonstrates the vulnerability of the female sex in the late nineteenth century. In this episode, she is adapted into a strong but ultimately minor character.
} 
In the series, Sherlock's brother serves an important thematic role: Mycroft represents the government. Though this episode contains only a few brief scenes with Sherlock's brother, his presence looms large throughout this episode and the series more generally. Once Sherlock and John arrive at the base, they use one of Mycroft's identification badges which Sherlock has pilfered from his brother without his knowledge:

JOHN. You've got ID for Baskerville. How?

SHERLOCK. It's not specific to this place. It's my brother's. Access all areas.

$[\ldots]$

JOHN. Mycroft's name literally opens doors!

SHERLOCK. I've told you — he practically is the British government. In "The Bruce-Partington Plans" Holmes explains: "occasionally he is the British government" (1302). The change in adverb, while a minor point grammatically, signals a drastic change in meaning. In the Doyle story it seems Mycroft steps in as representative of the interests of the government or as wielder of its power on a temporary basis. In this Sherlock episode, the meaning is substantially different. The use of "practically" signals that the difference is not between a frequency of instances when Mycroft wields this power but rather that for all intents and purposes, "in practice," Mycroft is the British government. Sherlock's response to John echoes his comments about his brother from the very first episode. There Mycroft claims to "occupy a minor position in the British government." But Sherlock clarifies to John, "He is the British government, when he's not too busy being the British Secret Service or the CIA on a freelance basis." In this instance, Mycroft unambiguously (without adverb) is the British government. But in addition, Mycroft can be any other number of government intelligence agencies depending on who needs him at the time. The fact that Mycroft's identification card is 
"not specific to this place" but provides "access [to] all areas" (2:2) validates Sherlock's claim that Mycroft wields a great deal of sway in the government. ${ }^{109}$

Mycroft Holmes appears in only three of the sixty original stories (Klinger 663): “The Greek Interpreter," "The Bruce-Partington Plans," and "The Empty House."110 By comparison, Mycroft has been in every episode of Sherlock with the exception of "The Blind Banker" (1:2). In addition, he has been developed from a minor character in season one to a central player in season three. Although his role has expanded, his relationship with Sherlock has remained the same: the protective big brother. He is rewritten into several of the most famous cases in which he originally makes no appearance: A Study in Scarlet, "A Scandal in Bohemia," and The Hound of the Baskervilles.

In "A Study in Pink," when Mycroft learns Sherlock is renting a flat with John he mysteriously "kidnaps" him. As John walks down the street alone, each telephone he passes begins to ring. Eventually John answers one inside a telephone booth. Mycroft refuses to identify himself. Interestingly, Mycroft's introduction to John signals his role

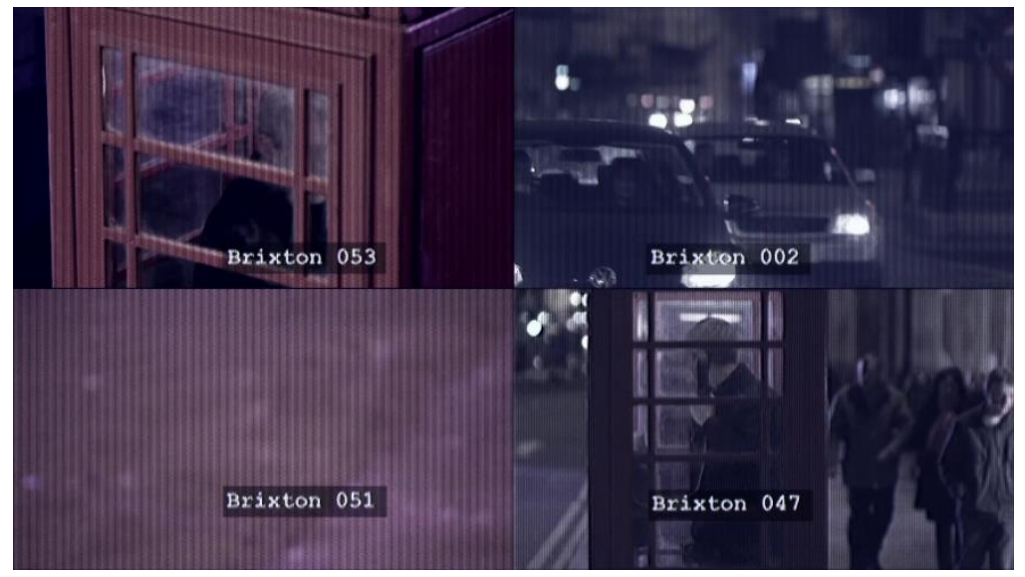

as watcher. During the conversation Mycroft directs John's attention to various CCTV cameras (IMAGE 3-2) which one by one pan away from IMAGE 3-2 John asks of the mysterious caller, "How are you doing this?" (Sherlock 1:1)

John. This is drawing on

\footnotetext{
${ }^{109}$ Further confirmation is in "His Last Vow" (3:3) when Mycroft arranges for Sherlock to do wet work for MI-6 rather than be sent to prison for murder.

${ }^{110}$ In the last story, he is only mentioned.
} 
the description of Mycroft in "The Bruce-Partington Plans" where Holmes explains that while "All other men are specialists, his specialism is omniscience" (1302). He sees (and knows) all. When they meet face to face shortly after this scene, Mycroft explains that Sherlock would identify him as his "arch-enemy" and John later admits he took him for a "criminal mastermind." Thus, he is initially introduced as a potentially threatening and very powerful man but later represented as a paternalistic overseer who looks out for Sherlock, often from afar. The conception of Mycroft as potentially dangerous is foregrounded in "The Greek Interpreter" when Holmes says, "my brother would be the greatest criminal agent that ever lived" (638-639). The language used here is unequivocal. Holmes does not say "could be" but rather he undeniably "would be" if he applied himself to crime. Additionally, this mirrors Watson's description of Holmes already quoted in chapter one from The Sign of Four. ${ }^{11}$

When "A Scandal in Bohemia" was adapted by the series into "A Scandal in Belgravia" (2:1) the royal personage being blackmailed is rewritten from the King of Bohemia to an unidentified member of the British royal family and Mycroft serves as an intermediary between Sherlock and this royal client. Mycroft's short appearances in "The Hounds of Baskerville" are less important than the thematic function he provides as a symbol of the government. Later in this episode, when Lestrade shows up in Dartmoor, Sherlock accuses him of working for Mycroft as his "handler." Ultimately, Mycroft has his younger brother's best interests at heart, as demonstrated in the show's most recent episode "The Abominable Bride" (4:0). When Sherlock doses himself with narcotics in an effort to discern if Moriarty's resurrection from the grave is plausible, Mycroft

\footnotetext{
111 "I could not but think what a terrible criminal he would have made had he turned his energy and sagacity against the law, instead of exerting them in its defense" (277).
} 
explains to John how he has looked out for Sherlock since finding him years ago after an overdose. Now he requires Sherlock to make a list of whatever drugs he has ingested, "We have an agreement, my brother and I, ever since that day. [...] Wherever I find him $[\ldots]$ whatever back alley or doss house $[\ldots]$ there will always be a list." The episode concludes with Mycroft's final words to John as he and Sherlock exit the plane: "Doctor Watson? Look after him...please?" Mycroft is the paternalistic and ever present Big Brother, whom we love to hate but is there when we need him most.

In "The Hounds of Baskerville," Baskerville is more than just an army base; it is a research facility specializing in the development of chemical and biological weaponry. When John begins to question Lyons about the specifics of the experimentation being conducted, her justification for their experiments and the base's secrecy is that when "One war ends, another begins, sir. New enemies to fight. We have to be prepared." This echoes the description of Baskerville from the documentary:

[Baskerville is a] chemical and biological weapons research centre which is said to be even more sensitive than Porton Down. ${ }^{112}$ Since the end of the Second World War, there've been persistent stories about the Baskerville experiments: genetic mutations, animals grown for the battlefield.

World War II provides the context for the beginning of the experimentation at the base and seems to provide a historical justification for such research. But World War II and the development of the nuclear bomb should also serve as a reminder of the ethical cost of justifying scientific advancements in the pursuit of war. Hidden within Lyons' comment is the implication that if World War II is the war that has ended, the war on

\footnotetext{
${ }^{112}$ A UK government military science park
} 
terror is the one being waged today. And, in fact, this episode is couched between two other episodes which both hinge on terrorist activities.

In the first episode of season two, "A Scandal in Belgravia," Irene Adler is in possession of compromising information about a bomb on a passenger jet, which she tricks Sherlock into decoding for her. In "The Reichenbach Fall” (2:3) Moriarty is on trial but uses the proceedings to advertise his computer code which is at least described as able to break through any layer of security. ${ }^{113}$ When Sherlock uncovers his advertising scheme, Moriarty explains that his client list includes "rogue governments, intelligence communities...terrorist cells" 2:3). While "The Hounds of Baskerville" seems like an interlude in the local and rural Dartmoor, the themes with which it engages (warfare, scientific advancements, government secrecy) demonstrate its connection to the rest of the UK and the world, as well as the season. (Chapter four will examine in more detail season three's focus on the control of information and the clash between the global threat of terrorism and the threat to individual privacy.)

Ultimately, through the episode's resolution, criminality is located within an individual and not the system. The crime being investigated by Sherlock and John is not the ethics of government research or oversight but rather the individual murder of Henry Knight's father, which was committed seemingly without the government's knowledge. ${ }^{114}$ The ethical problems surrounding Project HOUND are clearly foregrounded after Stapleton, Watson, and Sherlock gain access to the classified files on the experiments. Sherlock explains the effects of the drug:

\footnotetext{
113 The code itself was an elaborate ruse as Moriarty explains in "The Reichenbach Fall" (2:3), "There is no key, doofus! Those digits are meaningless. They're utterly meaningless. You don't really think a couple of lines of computer code are gonna crash the world around our ears? I'm disappointed.

114 This is never specifically addressed in the episode.
} 
SHERLOCK. Project HOUND: a new deliriant drug which rendered its users incredibly suggestible. They wanted to use it as an anti-personnel weapon to totally disorientate the enemy using fear and stimulus; but they shut it down and hid it away in 1986.

STAPLETON. Because of what it did to the subjects they tested it on. SHERLOCK. And what they [the subjects] did to others. Prolonged exposure drove them insane-made them almost uncontrollably aggressive.

The project was a colossal failure not just because of the effects on the subjects involved but also on those who became the victims of their aggression. The viewer is confronted with chemical configurations, brain scans, and descriptions of the experiment proceedings labeled "Day One" and "Day Four" (the print of the log is too small and gone too quickly to read). The largely visible onscreen text during this scene details the goals of the study (IMAGE 3-3): "extreme suggestibility," "fear and stimulus,"

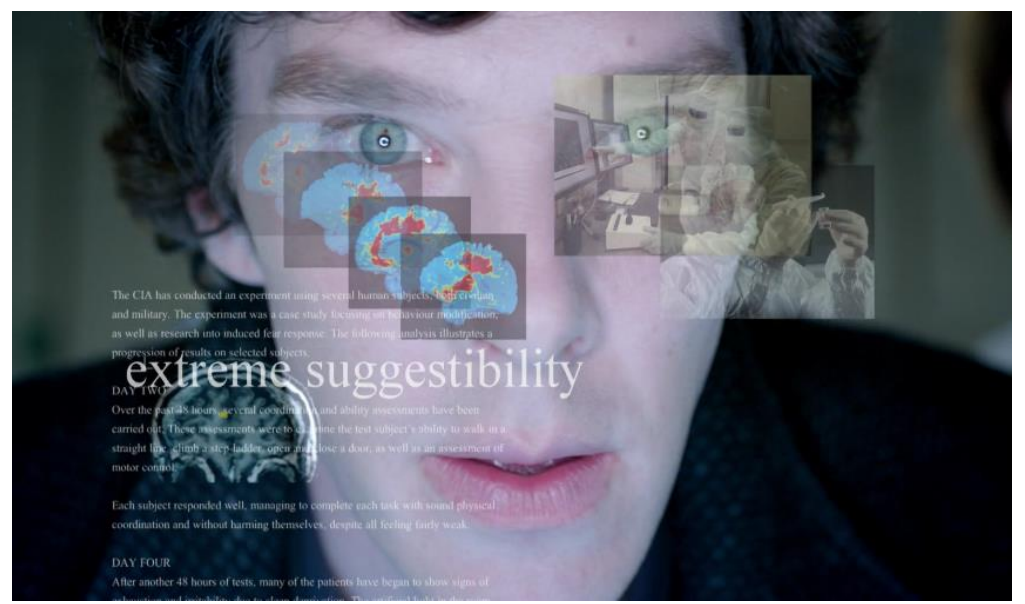

IMAGE 3-3 Sherlock has just gained access to the classified files on the HOUND Project and the information on the computer screen he's looking at overlays his image. (Sherlock 2:2) "conditioned terror," “aerosol dispersal.” Shortly following this, another bombardment of information overlays the image of Sherlock and details the negative effects on the test subjects: "paranoia," "severe frontal lobe damage," "blood-brain," "dangerous acceleration," "gross cranial trauma," and "multiple homicide."

Later, Sherlock explains how Frankland used the chemical minefield to manipulate Henry and distort his memory. The minefield is a series of pressure plates that releases the drug, which induces hallucinations, suggestibility, and heightens fear. It is 
the "murder weapon and scene of the crime all at once" as Sherlock muses. Sherlock says to Henry, "You'd started to piece things together, remember what really happened here that night. It wasn't an animal, was it, Henry? Not a monster...A man.” A man is guilty for the murder of Henry's father and for the continued experimentation of the HOUND research, which was first sanctioned by the CIA in Liberty, Indiana. Continuing a trend began in season one, the threat to the community is from a foreign, outside influence. As Dr. Stapleton ${ }^{115}$ explains to Watson, "the only limits [on the research] are ethics and the law, and both those things can be...very flexible. But not here—not at Baskerville.” Although ostensibly, the unethical experimentation has been continued at Baskerville, it seems Frankland has been acting alone and without the approval of official sanctions. ${ }^{116}$ His coworkers and the oversight of Baskerville Army Base both appear to be in the dark about the continuation of the HOUND research but, again, this is not clarified. The only indication that he has been working on his own is that he is employed at the base as a virologist and not a chemical weapons researcher. But Sherlock says, "he's never lost the certainty, the obsession that that drug really could work." No follow up interrogation of the brass is conducted by Sherlock and Watson or even Mycroft. The possibility, then, that the government may be culpable is dismissed entirely in the episode's denouement.

Frankland dies, like Stapleton in The Hound of the Baskervilles, ${ }^{117}$ trying to escape the detective and prosecution by the law. He flees into the nearby minefield and

\footnotetext{
${ }^{115}$ Dr. Stapleton is a female researcher at the base and becomes a suspect but not the criminal in this variant of the story.

${ }^{116}$ Although Sherlock, Watson, and Stapleton discover the particulars about the experiments by using Major Barrymore's password, there is no indication that he is at all cognizant of the project. Having access to this information does not mean he is aware of or has sanctioned its continuation.

${ }^{117}$ Watson explains why they assume Stapleton is now dead: "If the earth told a true story, then Stapleton never reached that island of refuge towards which he struggled through the fog upon that last night.
} 
remnant of World War II, where he is blown up by a mine. In Doyle's novel, the ending seems to suggest that Nature has punished Stapleton for crimes against herself: his use of the hound and the natural landscape of the moor to commit and hide his crimes against fellow man. In this episode, Frankland falls victim to the weapons of war, which he has tried to advance in his experiments. Both seem to suggest that no crime goes unpunished, at least not on a cosmic scale. And while World War II may have formally ended and the War on Terror begun, as Lyons points out at the beginning of the episode, this does not mean we are free from the repercussions of this devastating chapter in human history. More specifically, the innovations in advanced weaponry during World War II—most notably the atomic bomb - continue to affect and shape our present day. Weapons technology created decades ago is still capable of killing us now and preventing a brighter future.

\section{SHERLOCK, MOORLAND, AND CORPORATE AMERICA}

Sherlock's detective is at least partially influenced in his decision to work outside the establishment by his brother's role in the government, and familial relationships have also influenced his positioning in Elementary. In Elementary, Sherlock is a consulting detective in response to the corruption of big business and government bureaucracies. His anti-capitalism stems from two influences: thematically it is an inheritance of the American hard-boiled tradition and within the show's diegesis it is a response to his father's role as a corporate consultant. When Morland Holmes finally appears in season

\footnotetext{
Somewhere in the heart of the great Grimpen Mire, down in the foul slime of the huge morass which had sucked him in, this cold and cruel-hearted man is for ever buried" (599). Although Stapleton's body is not recovered, Watson's words appear fairly unequivocal, especially considering his beginning words - "if the earth told a true story"- and the Sherlock's reading footprints on the ground or floor in other stories, a method which is usually verified by eyewitness accounts in the denouement.
} 
four, ${ }^{118}$ Sherlock's disdain for global corporations is explained via his relationship to his father:

It is true, I am not the first consultant in the family, but the title is where the similarities end. Father's business exists to grease the skids so that politicians and corporations can operate around the globe. Sometimes these are noble ventures. More often, they are not. But they happen because Father is an influence peddler par excellence. (4:2)

Morland's clients are politicians and corporations, their scope is global, and his job is to advocate for their interests. It becomes clear that Sherlock's anti-capitalist stance is strongly influenced by his impressions of his father and the nature of his occupation. Furthermore, although Sherlock is from a wealthy family, his drug addiction and his sexual predilections ${ }^{119}$ affirm his status as social deviant and provide a dual perspectivefamiliar with the ways of the powerful but preferring to give the lower classes and the social nonconformists the benefit of the doubt.

Within the development of detective fiction, the police procedural was a response to private-eye crime fiction. It was a shift away "from the rule-bending individualism and extra-systemic freedom manifested by" the private-eye protagonists (Messent 128).

Although in many ways Elementary seems to be the common police procedural, which has made CBS so successful, ${ }^{120}$ Sherlock's position as a consulting detective complicates such an easy categorization. In the series, Joan and Sherlock draw the majority of the cases, which form the major plots of the episodes, through their consulting relationship with the NYPD. The investigations which stem from clients outside of this relationship

\footnotetext{
118 Although allusions to Morland appear from the beginning, as early as the pilot episode.

${ }^{119}$ When Joan first enters the Brownstone (where Sherlock lives) she runs into a woman who is putting her clothes back on and later the viewer is provided a shot of a ladder with handcuffs attached. The implication is that Sherlock has engaged in BDSM as a sub.

${ }^{120}$ CBS is responsible for the enormously popular CSI franchise: CSI: Crime Scene Investigation (20002015), CSI: Miami (2002-2012), NCIS (2003-Present), CSI: NY (2004-2013), NCIS: Los Angeles (2009Present), NCIS: New Orleans (2014-Present), CSI: Cyber (2015-Present)
} 
usually form the subplot of the episodes. In spite of this close relationship with the police department, Sherlock acknowledges at several poignant moments in the series their ultimate position as outsiders. In season two, Sherlock explains to Joan that the official police "is a fraternity to which - my countless contributions notwithstanding - I will always remain an outsider ("The Hound of the Cancer Cells" 2:18). At the conclusion to season three, when their relationship with the NYPD is in jeopardy because Captain Gregson may step down as the department head, Sherlock tells Joan, "You and I exist outside of the bureaucracy of the department and that is by design" ("Absconded" 3:23). While in the first instance Sherlock seems to regret his status as outsider, this second instance demonstrates that Sherlock is affirmed in the relative autonomy such a position offers him. For instance, in "Murder ex Machina" (4:9), federal agents pull Sherlock and his NYPD associates from an investigation of a Russian oligarch's murder because it has been deemed a "sensitive diplomatic situation." Detective Marcus Bell picks up on Sherlock's refusal to stop investigating and warns him of the consequences: "We're supposed to be done with that." Sherlock responds "No, you, a policeman with orders from above, are done with it. Watson and I are private citizens and can do in our free time as we wish." Of course he continues his pursuit and his successful solution helps circumvent an international fiasco, which the viewer is left to intuit would have ensued if the matter had been left solely in the hands of the federal agents.

Sherlock's stance against big business, Wall Street, and privatization is clear and reflects the American detective tradition. While the American author, Edgar Allan Poe, is often credited with writing the first detective story, the genre was successively taken up by British writers (like Doyle) who perfected the format. "A truly American crime story 
[...] breaking completely with European tradition, appeared in the twenties" (Symons 123) and this was the hard-boiled detective story. Both Dashiell Hammett and Raymond Chandler, the two cornerstone authors of the hard-boiled tradition, contained within their works a critique of "unregulated industrial capitalism, which acknowledges no limits to the pursuit of private wealth" (Chernaik 116). This focus on crime as stemming from the drive for increased profits in capitalist societies can also be seen in Elementary. Sherlock's displacement to New York City seems to invite a consideration of the intervening developments in the genre since the classic detective, and, especially in the American context, a consideration of the hard-boiled. A large part of this inheritance is the idea that the hard-boiled private eyes are particularly positioned against "the powerful;" they "always manage in the end to have the last word against the class enemies of ordinary people - the rich, the powerful, and the official police" (Porter 174). Elementary attempts to wed Holmes, a quintessentially classic detective, to this stance against capitalist greed and its long-reaching influence into the corporate and bureaucratic structures in the United States.

The viewer's introduction to Sherlock's anticapitalistic stance comes through first in his contact with bankers in the fourth episode, "The Rat Race" (1:4). Prior to their consultation with the bank, Canon Ebersol, he says to Joan, "I loathe bankers. They rig the roulette wheel of commerce, very nearly destroy the world economy, and they still think if they wear suits they'll be treated like respectable folk instead of the crooks that they are" (IMAGE 3-4). The privatization of the prison system is equally abhorrent to him, "Privatized prisons, capitalism at its most cynical. Profits are tied to filling the beds, so public policy that puts more people behind bars is good, and prevention and 
rehabilitation are bad"

("The Best Way Out Is

Always Through" 3:22).

Agrochemical corporations

that develop pesticides, like

AgriNext in season three,

threaten agriculture, the

environment, and the bee

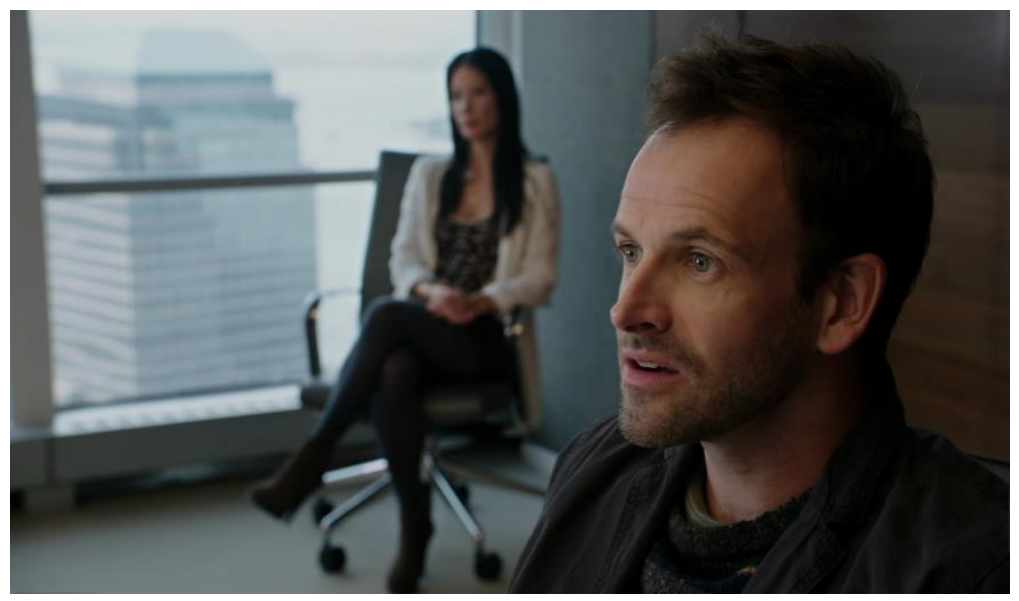

IMAGE 3-4 In between smacking his chewing gum Sherlock interrupts the introductions of the bank's board members: "Yup, you're all chief of something. What do you want?" (Elementary 1:4)

population:

"Quite the corporate monstrosity, AgriNext, hmm? In addition to your dominance in agricultural industries, there is powerful evidence to suggest that your neonicotinoid insecticides are the culprits in the ongoing bee genocide known as colony collapse disorder. Would you care to comment on that?" ("Seed Money" 3:10)

Unchecked capitalism is dangerous because it puts increased profit margins above all other concerns. Bankers are guilty of destroying the global economy. Prisons, when privatized, are run as businesses and profit from rising incarceration numbers.

Agrochemical companies often neglect the side-effects their products have on the ecosystem. At least according to the dynamics of the show, ethics are sidelined when profit is promoted as a priority. As Pearce argues in "Crime and Capitalist Business Corporations", "as formal organizations, with particular goals such as the maximization of profits, growth, and survival, other things have ethical value for business corporations only insofar as they are instrumental in furthering their ultimate goals" (113). Finally, the case study for this section is Sherlock's stance in regards to Big Pharma and the US healthcare system which serves as the focus in "The Hound of the Cancer Cells" (2:18). 
As in "The Hounds of Baskerville," the investigation in this episode of Elementary revolves around scientific research. Instead of advanced weaponry, the focus is on the development of "the Hound" (a breathalyzer designed to detect cancer). Joan and Sherlock are initially called in to investigate the murder (framed as a suicide) of Barry Granger. Granger was running the clinical trials for the breathalyzer. The episode contains several false solutions, which gesture outward toward larger systemic problems in the American health care system. The first theory is that Granger was killed by Adam Peer (or A. Peer), an anonymous tipster who's “been quite an irritant to the research community. He reads scientific and medical journals; he spots errors and fraud from the comfort of his undisclosed sofa, and then e-mails his criticisms via an anonymous server." Peer had recently published an article discrediting Granger's study by claiming he falsified his results. Although the motive for Peer killing Granger seems weak, the first important task Joan and Watson have is discovering the true identity of this whistleblower. A. Peer is eventually revealed to be a team of two people working together, Barry Granger and Miss Buckner (IMAGE 3-5). The latter is a high-ranking executive at the pharmaceutical company Merrill-Grand. The second potential theory is that Granger was killed for his role as Adam Peer. Elementary represents America's healthcare

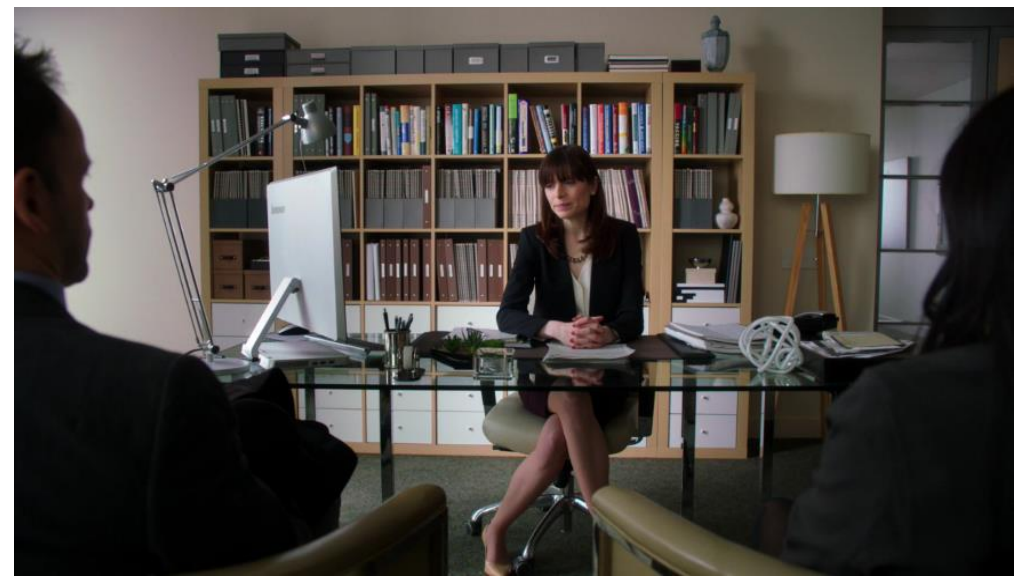

IMAGE 3-5 In response to questions about A. Peer's first exposé on MerrillGrand, Buckner responds, "Toproxefin was an embarrassing chapter... for me and for the whole company. But it was never willful fraud, not at the corporate level. Sometimes when there's that much money at stake, you develop a kind of selective deafness." (Elementary 2:18) 
system as so corrupt that those "few good souls who remember why they got into healthcare" have to anonymously point out flawed medical research and may be killed for doing so. Merrill-Grand is described in the episode as "a company so poisoned by profits" and Buckner has "headed a panel examining the corrosive effect of profit margins on American health care." Buckner reveals that she and Granger decided to work together to uncover malpractice in medical research studies because they "shared a lot of the same concerns...including the influence of money on good science."

The third explanation that Joan and Sherlock entertain is that the murder is somehow linked to corporate espionage, a possibility which Sherlock is not pleased to consider: "loathe as I am to admit it, Granger's benefactor, Hank Prince, may be right when he sees himself as the victim in all this." Sherlock and Joan set out to discern who has the most to gain from discrediting the Hound study and setting back the clinical trials. They learn that Radner Science has been working toward a comparable medical development and could benefit from being the first to market such a product. Sherlock stays up that night educating himself on Radner Science:

"I read the autobiography of its CEO, Charles 'Call me Chuck' Hammond, and he's just the kind of Sun Tzu-quoting, take-no-prisoners corporate executive that one might expect to ignore all boundaries of moral decency. Plus, the company is developing a device in direct competition to the Hound."

There is no mistaking the animosity with which Sherlock views corporate executives and the capitalist drive for profit which displaces all other considerations. After meeting with Hammond in person, Sherlock is forced to cede this potential solution as well. Hammond reveals that if Hank Prince's company had successfully approved the validity of the Hound, they would merely have bought the company. This demonstrates another central 
problem with the idea that a free market economy regulates itself. Legislative changes concerning mergers and acquisitions in the US at the end of the nineteenth century is responsible for creating these circumstances:

[The removal of these constraints enabled] a large number of small and medium-size corporations [to be] quickly absorbed into a small number of very large ones $[\ldots]$ In less than a decade the U.S. economy had been transformed from one in which individually owned enterprises competed freely among themselves into one dominated by a relatively few huge corporations." (Bakan 110)

Smaller companies, which are largely responsible for innovations and have the potential to displace the monopolizing influence of large conglomerates, but are often swallowed up by these larger corporations.

The final solution to Granger's murder shows a similar shift as in the Sherlock episode, from the culpability of the system to that of an individual. Hank Prince, Granger's benefactor, is the author of the discrediting article on the Hound and responsible for the murder of Granger and his own wife, the latter occurs during the course of the investigation. ${ }^{121}$ Sherlock and Joan recapitulate the motivation that led to these atrocious crimes:

SHERLOCK. We met Chuck Hammond this morning. Colorful chap. He was kind enough to give us this. It is Radner Science's financial analysis of your company, complete with a handy graph plotting its projected value over time. If The Hound proves to be as successful as Barry Granger's research suggested it would be, you stand to become a very wealthy man. JOAN. Your problem is that you were in the middle of a divorce. Your wife's lawyers were busy trying to figure out how much you would be worth in the future so they would know how much you would have to share. You wanted your future to disappear, but only temporarily.

\footnotetext{
121 Prince takes advantage of the detectives' theory that he is being targeted and has his wife murdered, hoping the police will believe it was another attack against him.
} 
Prince's personal greed, his desire to retain the potential profits of his company for himself, is the motivating factor for the crimes he has committed. While in some sense this serves as a further indictment of the corrupting influence of capitalism on corporate executives, it also follows the trend of locating the source of the problem ultimately within an individual criminal, who was acting alone.

For the careful observer of the episode, this serves as an indication that profit covers over moral concerns: the bottom dollar justifies the means. Although it is never directly addressed in the episode, Granger and Prince's wife are not the only victims; Hank Prince compromises the lives and suffering of countless others in his ploy: the cancer patients who could be helped by this medical advancement. As Whyte and others have argued, "Crimes committed by states and corporations undoubtedly do kill more people, maim more people, rip off and steal from more people than crimes committed by individuals (Box, 1983; Friedrichs, 1996; Tombs and Whyte, [2015])" (Whyte 3). Part of the critique of Big Pharma is clear: for company executives the profit of the company becomes indistinguishable from their own personal financial gains, which are directly linked. Absent from the denouement is any sort of consideration of how corporate oversight may have made such crimes impossible for Prince. In spite of this shift from systemic to individual culpability, the episode's outward gesturing toward the many problems inherent to the healthcare system in the US (medical research malpractice and corporate espionage, for instance) provide a greater critique of crimes of the powerful than in Sherlock, where government secrecy is seemingly justified by the threat of terrorism and made palatable in centering such power in the paternalistic older brother, Mycroft. 


\section{CONCLUSION}

In the two modern adaptations of the Holmes novel, little seems to remain from Doyle's narrative; however, while the overall plot has been drastically changed, thematically the episodes share some important characteristics from the original. In Television and the Moral Imaginary Tim Dant argues television is "a key way in which a modern society tells itself just what it is" (3). As he explains, "The moral order created within the diegesis raises questions and problems with which the audience can engage; their curiosity about what happens next is linked to their interest in seeing the logic of the moral order being played out" (34). In adapting this novel from the nineteenth century, it is important to understand what elements of the original have found resonance with modern societies as well as what possible conclusions have been foreclosed.

Sherlock retains the unethical manipulation of human emotions: fear is again the modus operandi. The criminal murders by means of the hound in the original and in Sherlock through chemically-induced hallucinations. Additionally, both Jack Stapleton and Dr. Frankland sacrifice the lives of others. Frankland kills Henry's dad and compromises his mental health in the name of the greater good - the "war on terror." While Elementary retains personal greed as a motivation that outweighs the value of human lives. Jack Stapleton kills his uncle, Selden, attempts to kill his cousin, and perhaps countless other lives as Holmes suggests in the novel's denouement:

"From his knowledge of our rooms and of my appearance, as well as from his general conduct, I am inclined to think that Stapleton's career of crime has been by no means limited to this single Baskerville affair. [...] I cannot doubt that Stapleton recruited his waning resources in this fashion, and that for years he has been a desperate and dangerous man." (608) 
Here, Holmes speculates about Stapleton's other potential crimes and congratulates himself on having finally caught a criminal, who has left a trail of bloodshed and proved elusive to the authorities until now.

Throughout the history of criminology, crime has consistently been linked to the lower social classes, what has been called the "downward gaze of criminology" (Whyte 1). Coined in the 1970 's, "crimes of the powerful" is a relatively new area of study in criminology. And although "it has been pretty routine [...] to find in criminology textbooks an acknowledgement that goes something like 'state and corporate crime cause more deaths than all other forms of crime put together" the study of these criminal behaviors is still "treated at best as a mildly interesting diversion from the real business of crime and criminal justice" (Whyte 1). While Sherlock initially seems to suggest a critique of the government and its secrecy in the name of protecting "the free world", it stops short of such a critique in the episode's resolution. It is treated merely as "a mildly interesting diversion," a red herring. By retaining the poetic justice of the original ending - in which the naturalist is punished by Nature for crimes against her and the weapons researcher is punished by weapons remaining from World War II-it seems to reiterate the idea that "murder will out." Additionally, the lack of any repercussions for the government or the army base stave off questioning the guilt of oversight that may have prevented the continuation of the HOUND experiments in the first place. At the conclusion, the government and military are simply "off the hook." In Elementary, as already mentioned, Prince not only murders Barry Granger and his wife, but also delays cancer development from the world in his pursuit of personal profit. Throughout the episode, the thematic focus is on the corruption of science by the drive for profit inherent 
to capitalism. And although culpability is once again located within an individual by the conclusion, the questions raised about the American healthcare system during the course of the investigation linger long after the denouement. 


\section{CHAPTER IV \\ SHERLOCK HOLMES AND METAFICTION: \\ BLACKMAIL, JOURNALISM, AND DETECTION}

\section{APPEARANCE AND REALITY}

One of the most fascinating aspects of detective fiction is its penchant for uncovering secrets. Stories in the genre often reflect upon the way we divide our lives into public and private realms while, at the same time, they shatter this carefully constructed division. The private spills out in to the public as a crime ruptures the social fabric and threatens the status quo. J.K. Van Dover describes this as a metaphysical "twoworld phenomenon":

The deep structure of all detective stories implies a dualism: there is always a world of reality beneath a world of appearance. These two worlds ordinarily coincide: what you see is what there is. The detective story is about those moments when they diverge, when appearances prove to be deceiving and reality seems inaccessible. (130)

If Van Dover is correct and the exposure of private reality behind the false public appearance is a fundamental part of all detective fiction, this duality is further emphasized when veracity is complicated by multiple, varying narratives of "the truth." The use of the press and the crime of blackmail are two metanarrative devices that raise epistemological problems in the Sherlock Holmes stories. The search for the truth beneath the surface is the goal of the detective but also that of the journalist and the blackmailer. This affinity explains the prevalence of the press in detective fiction. 
Furthermore, detective stories with blackmail plots are more expressly focused on a secret story which lies beneath the deceptive "world of appearance." In theory, the journalist wants to uncover and publish the truth. The blackmailer wants to uncover the truth with the intention of threatening to publish. Whereas, the consulting detective uncovers the truth in order to practice discretion about whether to make this story public or cover it again. As Holmes explains, "I am much more anxious to hush up private scandals than to give them publicity. If, as I imagine, there is no breach of the law in this matter, you can absolutely depend upon my discretion and my co-operation in keeping the facts out of the papers!'” (MISS 1151-1152).

This chapter is organized around several central questions. First, why is the press such a prevalent element in the Sherlock Holmes stories and how does it function within these narratives? Second, why does Holmes hate blackmail above all other crimes or what makes it the most abhorrent? And third, how have the social distinctions between public and private identities changed or remained the same from the nineteenth century to today? In this chapter, I will focus on metanarrative devices (mainly in the form of blackmail plots and press accounts) in the Sherlock Holmes stories, which, ultimately, reveal anxieties about publicity and narration in the nineteenth century and the twentyfirst.

Doyle's stories are often self-reflexive in their opening lines about their status as publications but this use of metadiegesis serves to enhance the verisimilitude of the narratives. The stories are filled with metadiegetic elements since most contain long narrations by clients or Watson himself, as in The Hound of the Baskervilles in which he writes and mails accounts of his inquiries to Holmes. Metadiegesis is a central element of 
their formal composition. The modern television adaptations Sherlock and Elementary share this metadiegetic (as in formally self-reflexive) gesture in their use of on-screen screens — as broadcast and digital media — to varying degrees of disruption and verisimilitude but use these tactics to enunciate different problems central to the division between public and private today.

The three installments I have chosen to examine in this chapter are Doyle's "The Adventure of Charles Augustus Milverton" (1904), Sherlock's "His Last Vow" (3:3) and Elementary's "We Are Everyone" (2:3). In "The Adventure of Charles Augustus Milverton," Holmes is represented as a hero who can protect his client's identity and reputation. The threat of social exposure itself is a central concern in Doyle's stories. Sherlock and Elementary expand the scale of impact for the blackmail to consider national and international consequences. Both shows raise questions about the government's right to secret knowledge in the service of national security and the role of the media in shaping public opinion in the context of terrorist threats. Additionally, both episodes considered in this chapter choose to adapt real life public scandals of recent events.

In Sherlock's "His Last Vow" characteristics of Rupert Murdoch, the Australia media baron, are grafted onto the Milverton character, which results in Charles Magnussen (the criminal nemesis of season three). Magnussen, like Murdoch, poses a threat to the UK's national security because of the control he exercises over individual government officials. His power derives from his ownership of the newspapers, which he uses to "own" people in key places. The press becomes not only suspect but inimical to the public good. Sherlock represents the immateriality of the digital age to voice the fear 
that the press no longer requires proof to back the claims it prints. The conclusion of the episode serves to thematically validate the British government's secreting of information from its citizens in light of larger looming threats to national security.

Elementary's "We are Everyone" adapts the very recent scandal of Edward Snowden, ${ }^{122}$ a former NSA contractor turned whistleblower, in the character of Ezra Kleinfelter. It also adapts the hacktivist group Anonymous, renaming them "Everyone." The Snowden scandal is extremely controversial and public opinion has oscillated between whether to label him as a hero or traitor. The American government is represented as a secretive and suspect entity, but Sherlock seems equally fed up with Kleinfelter's extortion of the US government and the vaguely explained murder of Vanessa Hiskie. ${ }^{123}$ This episode of Elementary takes up the controversy but sidelines a discussion of the morality of whistleblowing in its refusal to provide the context for Kleinfelter's decision to publicize government overreach. The contents of the leaked information and the motivations, which led the real life Snowden to reveal such information, are simply elided from the text. The veiled references to Snowden's own motives for leaking the information only serve, in this episode, to unite Sherlock with the hacktivist group Everyone, who shares his belief in government transparency and accountability. Ultimately, Sherlock critiques the press today as a dangerous enemy to be overcome by the British government with help from the detective while Elementary

\footnotetext{
122 "We are Everyone" aired on October 10, 2013. The first article The Guardian published with information garnered from Snowden was on Verizon's involvement and was published on June 5, 2013.

123 This is an embellishment of the story which heightens the suspense by providing a timeline for the chase. In the episode, Kleinfelter threatens to release the identities of undercover international agents, which Snowden never attempted.
} 
represents the (at least partial) triumph of the press and the democracy of the internet (by means of Everyone) over the perceived secrecy and abuses of the US government.

\section{HOLMES AND METAFICTION IN THE NINETEENTH CENTURY}

The Sherlock Holmes stories by Doyle are expressly interested with the division between public and private knowledge. The elision between these two societal spheres takes place on many levels and is often enunciated at the beginning of the stories. For instance, Watson begins "The Adventure of the Solitary Cyclist" with the following reflection,

From the years 1894 to 1901 inclusive, Mr. Sherlock Holmes was a very busy man. It is safe to say that there was no public case of any difficulty in which he was not consulted during those eight years, and there were hundreds of private cases, some of them of the most intricate and extraordinary character, in which he played a prominent part. (901)

Here, Holmes's career itself is divided between public and private cases. A Study in Scarlet is a perfect example of a public case. In that investigation, Holmes works for and with Scotland Yard and the story is capped at both ends with newspaper reportage of the murder and apprehension of the murderer. It's important to consider how Watson's narratives themselves are involved in the process of making public that which has remained private. For example, in "The Resident Patient," Watson concludes the narration by explaining that the preceding story "has never until now been fully dealt with in any public print" [emphasis added] (631).

A prevalent feature of Holmes's status as consulting or amateur detective is his ability to practice discretion in the private cases, which are (as we've just read) the majority. Discretion may be defined as 1) the detective's ability to avoid revealing private information about his clients, and 2) his freedom to decide what should be done relative 
to the situation. Holmes's positioning as a consultant—and not part of the official police - makes it possible for him to use discretion in both senses. There are numerous examples of the former. ${ }^{124}$ Often, much to the chagrin of those involved, Holmes invades the private realm and seeks out secrets. These attempts earn him the moniker "Holmes the busybody" (SOLI 925, BLAN 1498, and MAZA 1521). Holmes explains his frequent reluctance to bring the police into an investigation, "To inform the police must, in the long run, mean to inform the public" (SECO 1191) because "when once the law is evoked it cannot be stayed again" (3STU 1066). Understanding his relationship to the police - his status as outside the official machinery of justice - is crucially important to understanding Holmes's relationship to publicity and privacy. His reluctance to involve the police is clearly articulated in "The Adventure of the Abbey Grange":

"Once or twice in my career I feel that I have done more real harm by my discovery of the criminal than ever he had done by his crime. I have learned caution now, and I had rather play tricks with the law of England than with my own conscience. Let us know a little more before we act." (1181)

There are instances in which it is beneficial for Holmes to have a much clearer understanding of the facts of the case and where the true guilt lies in order to practice discretion in this second sense of the word: his freedom to decide what is right and just relative to the specific investigation. Later, in the same investigation, he explains the difference between his position and that of Inspector Stanley Hopkins:

"What I know is unofficial, what he [Hopkins] knows is official. I have the right to private judgment, but he has none. He must disclose all, or he is a traitor to his service. In a doubtful case I would not put him in so painful a position, and so I reserve my information until my own mind is clear upon the matter." (1182)

\footnotetext{
${ }^{124}$ The second meaning of discretion has already been discussed in Chapter 3. There are two specific cases in which Watson and Holmes set up a mock trial and act as judge and jury (3STU and ABBE).
} 
By remaining a free agent, Holmes is allowed to choose with which characters he sympathizes and whether he will reveal or cover over the particulars. Although Holmes often practices discretion and neglects to reveal the details to the public - to the police or the press-Watson's publication of the private cases stands in opposition to this drive toward concealment. Watson begins one of the later stories, "The Adventure of the Devil's Foot" (1910), by explaining that the reduced frequency of his publications is not due to a lack of material but rather to Holmes's "own aversion to publicity": "My participation in some of his adventures was always a privilege which entailed discretion and reticence upon me" (1392). Although they are often published long after the events, and names are frequently changed or never revealed at all, the act of revelation is stillhowever partially—fulfilled in the telling.

A connection can be drawn here to the way secret knowledge in a blackmail plot functions. Alexander Welsh writes that "the public would really like to know what the blackmailer threatens to tell them" (84) just as the reader of Holmes's private investigations is complicit in this hunger for revelation. The stories fulfill this uncovering at the same time that they espouse Holmes's desire for upholding secrecy. One gets the impression that the truth of these private cases can only be narrated carefully, discreetly, and with an understanding of the dangerous scandal which would ensue without the discretion and reticence that Watson possesses.

\subsection{Holmes and Newspapers}

Newspapers are a prevalent feature in the original stories. The Ultimate Sherlock Holmes Encyclopedia entry for "newspapers" references thirty-five of the sixty Doyle stories (Tracy 259-261). The entry covers most of the stories that feature or reference 
newspapers but not all. According to my research, the newspapers are referenced in fortythree of the sixty stories. ${ }^{125}$ Newspaper clippings are interspersed in the narration of ten investigations (BRUC, LAST, BOSC, HOUN, NORW, NOBL, FIVE, SIGN, STUD, NAVA). Holmes baits a suspect using newspaper advertisements in the agony columns of the newspaper in four cases (STUD, SIGN, NAVA, BLUE) and other characters use agony column advertisements to send coded messages, such as in "The Adventure of the Bruce-Partington Plans" and "The Adventure of the Red Circle." Of the twenty stories in which newspapers are not in some way referenced, eight mention a "scandal" that may ensue if information is made public. In this way, the newspapers are implied in the text as the means of dissemination of the sensational. Again, this role is twofold, as both a means of representing the community and as an indication of the strength of social conformity by means of the force of public opinion, in much the same way D.A. Miller ${ }^{126}$ argues detective fiction itself functioned in the nineteenth century.

In the Victorian Era, the newspapers "embodied public consciousness" (Welsh 60). In that respect, they are an important way that Doyle evoked the larger community within which the crime has been perpetrated. The representation of the community is a significant element in detective fiction. The weight of public opinion cements, for the reader, the necessity for secrecy that often motivates the characters' criminal behavior within the story. Characters may be motivated to commit crime in order to maintain their secrecy or, equally, the fear of public opinion may prevent crime. Holmes's puzzling

\footnotetext{
${ }^{125}$ Tracy does not mention 3GAB, ABBE, LAST, PRIO, REDC, SOLI, STOC, or VALL. "The Adventure of the Three Gables" mentions the "garbage papers" or tabloids, which may explain its elision. In "The Adventure of the Red Circle" and The Valley of Fear the press plays an important role. In the former, a husband and wife on the run from the mafia communicate via advertisements in code. In the latter, the press are victims of Scowrers' attacks. The other six stories neglected from Tracy's entry contain brief allusions to the press.

${ }^{126}$ The Novel and the Police (1989)
} 
declaration that rural areas are more dangerous than urban illustrates this relationship between the force of public opinion and crime in the stories. Astonishingly, Holmes explains to Watson that "The lowest and vilest alleys in London do not present a more dreadful record of sin than does the smiling and beautiful countryside" (COPP 363). His reasoning for this phenomenon is directly tied to public opinion: "The pressure of public opinion can do in town what the law cannot accomplish" (COPP 363). In addition, detective fiction capitalizes on the anxieties of its audience, which is mirrored by the social upheavals recounted through newspaper clippings or characters' discussions of this reportage. Holmes also makes use of the threat of publicity as a tactic to uncover the truth in "The Man with the Twisted Lip." Holmes coerces the disguised man to reveal his true identity as Neville St. Clair, the man for whom Holmes has been looking. He threatens to go to the press and the threat is not lost on Neville, who happens to be a former newspaper journalist himself.

Lastly, blackmail is a crime that directly depends on shaming and the force of public opinion and its threat is given power through the press and the possibility of publication. Welsh argues that the nineteenth century marks the rise of the information age, which is signaled by the greater distribution of information through the press. Blackmail enlists the power of the many against the few in order to shame the victim: "the power of public opinion depends on the rise of information in the modern world but also on information in the sense of possible indictment. It is in the nature of public opinion to depend more on shame than on morality" (Welsh 204). This fear of "possible indictment" resulting from the publication of a scandal is based on a belief that more often than not the facts and individuals involved will be misrepresented. In "The 
Adventure of the Gloria Scott," Mr. James Armitage writes a letter to his son, Victor Trevor, to supplement the narration of his story by others: "I should wish you to read this, that you may know straight from me how far I have been to blame" (515). Armitage proceeds to narrate the story of his crime, conviction, and assumption of a false identity. It is important to Armitage, once he knows the truth will be found out, that his son understand the story from his perspective without embellishment or misrepresentation. Armitage displays both a great anxiety and a strong desire to control the narration of his identity and life, even after his death and especially to his son.

There are many varied ways that newspapers show up in the stories. Often, a story opens with Holmes and Watson reading the newspapers or learning about a specific case from within their pages (i.e., COPP and ENGR). As mentioned in Chapter 3, The Hound of the Baskerville opens in this way with the client (Dr. Mortimer) arriving at Baker Street with newspaper clippings of the mysterious death of Sir Charles Baskerville. This is also the situation in "The Adventure of the Red-Headed League," "The Solitary Cyclist," and "The Three Garridebs," which all begin with the client's curiosity about a newspaper advertisement. In these instances, the newspapers serve as a way to orient both Holmes and Watson, as well as the reader, to the basic facts and public understanding of the events that have already occurred or as a means by which the client becomes involved with new and strange individuals.

Second, newspapers are a vitally important part of Holmes's research method. As Holmes explains to Watson "The Press [...] is a most valuable institution, if only you know how to use it" (SIXN 1046). Holmes keeps a meticulous filing system at his flat in Baker Street, which contains newspaper clippings relevant to his cases or ones that may 
be of interest at a later date. This is alluded to in "The Adventure of the Six Napoleons" when Watson explains how "Holmes spent the evening in rummaging among the files of the old daily papers with which one of our lumber-rooms was packed" (1050). In "The Noble Bachelor," Watson describes how he had "surrounded [himself] with a cloud of newspapers" (292). Similarly, in "The Adventure of the Copper Beeches," Holmes "had been buried in the morning papers" (362) on the train ride into the countryside. Holmes often displays his brilliance at being able to recall a newspaper article with bearing on the case (STUD) but Watson also demonstrates this ability in "The Adventure of the Creeping Man." He recalls the name "Lowenstein" from his own "brain-attic" (STUD 9). It was from "some snippet of a newspaper which spoke of an obscure scientist" (CREE 1662) who sought an elixir of life. Watson is proved correct since Lowenstein is the one responsible for the strange occurrences in the story.

Third, similar to Holmes's study of tobacco ash (STUD 24) and seventy-five perfume types (HOUN 609), the "detection of [newspaper font] types is one of the most elementary branches of knowledge to the special expert in crime" (HOUN 435). In "The Silver Blaze," Watson reveals that he and Holmes have their own news agent and their research often entails the perusal of several news accounts of the same crime: "Fresh editions of every paper had been sent up by our news agent, only to be glanced over and tossed down into a corner" (387). Again, this points to an anxiety about the relationship between a narration and the truth as Holmes and Watson must read many versions of the same story to get a clear picture of the events.

Fourth, the tabloids and agony column is of vital importance to Holmes's research in both a passive and active capacity. Holmes explains that he only reads criminal news 
and the agony columns (NOBL 293), although this does not seem to be the case. The detective uses them in a passive way as a place to gather research. For example, in "The Adventure of the Red Circle," Watson explains Holmes's daily cataloging of their contents:

He took down the great book in which, day by day, he filed the agony columns of the various London journals. "Dear me!" said he, turning over the pages, "what a chorus of groans, cries, and bleatings! What a rag-bag of singular happenings! But surely the most valuable hunting-ground that ever was given to a student of the unusual!" (1278)

In this story, Holmes deciphers coded messages that are being passed among the strange lodger and her husband, who are both in hiding from the Italian mafia. But Holmes also uses the advertisements in the agony columns as a tool to ensnare. As already mentioned, sometimes Holmes takes out an advertisement in the agony columns to trap the culprit, unbeknownst to them until after they arrive at Baker Street. As in A Study in Scarlet when he places an ad for a lost wedding ring, which he cleverly neglects to mention was found at the scene of a murder. Holmes uses another hunting metaphor to describe the agony columns when he says "They are my favourite covert for putting up a bird" (3GAR 1586). Since so many of the cases hinge on mistaken or falsified identities and the newspapers are a facilitator of anonymity — a place where strangers may come togetherthe inclusion of these advertisements is a frequently used narrative device.

Another important connection between Holmes's method and the tabloids is Langdale Pike, the tabloid journalist. Although he is only mentioned in "The Adventure of the Three Gables," it is unclear in how many other investigations Holmes may have appealed to him for knowledge. Pike is described by Watson as Holmes's "human book of reference upon all matters of social scandal" (1545) and given the centrality of scandal 
and public opinion in the canon, it is feasible that Holmes may have turned to his expertise more times than Watson records. Pike is both the "receiving-station" and the "transmitter" for all "gossip of the Metropolis" (1545). In limiting his purview to London's social elite and the rumors and gossip surrounding them, Pike appears allknowing. Watson says "If ever, far down in the turbid depths of London life, there was some strange swirl or eddy, it was marked with automatic exactness by this human dial upon the surface" (1545). There are several points of interest here. First, the description of "turbid depths" seem to imply that even the vaguest and minutest of rumors does not escape Pike's notice. Second, the "automatic exactness" and comparison of Pike to a "dial" represent him as a precise instrument ${ }^{127}$ that records instantaneously and without embellishment. Finally, and perhaps most importantly to this discussion, Watson reveals that "Holmes discreetly helped Langdale to knowledge, and on occasion was helped in turn" (3GAB 1545). It is understandable that Holmes would turn to an expert in the field for whatever knowledge he needs to acquire and again the centrality of social scandal in the original stories seems to necessitate this connection between the detective and the tabloid reporter. However, what is most interesting here, is that despite Holmes's and Watson's repeated emphasis on their discretion, Holmes is indeed sharing private information with a garbage paper reporter!

There is one final connection between Holmes and the newspapers in the original stories and that is the way the detective turns up in their pages. In "The Empty House," Holmes informs Watson that when he read of Sigerson, the Norwegian explorer, he was

\footnotetext{
${ }^{127}$ This description of Pike recalls the description of Holmes himself quoted in chapter one: "Grit in a sensitive instrument, or a crack in one of his own high-power lenses, would not be more disturbing than a strong emotion in a nature such as his" (SCAN 5).
} 
in fact reading of Holmes. Holmes manipulates the press in several cases in order to mislead the public. He fakes being near death in "The Adventure of the Dying Detective" and "The Illustrious Client." In the latter, a startled Watson reads the headline "Murderous Attack on Sherlock Holmes" (IMAGE 4-1) and subsequently rushes off to learn that Holmes has exaggerated his injuries as a strategic move.

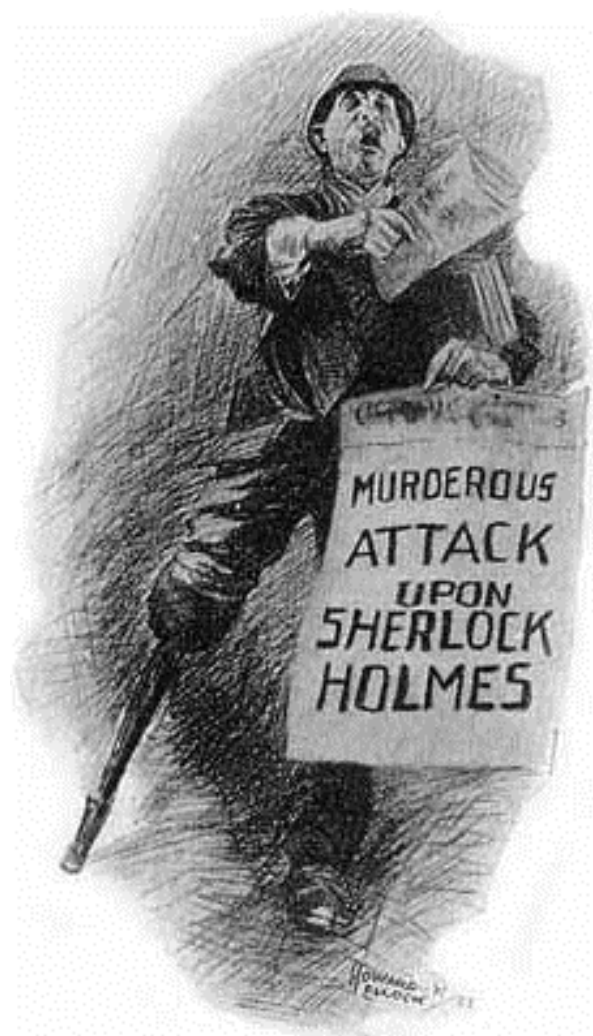

IMAGE 4-1: Illustration by Howard K. Elcock from ILLU.

\subsection{Holmes and Blackmail}

While newspapers are mentioned in seventy percent of the stories, blackmail occurs in just under twenty percent. Nevertheless, it is the best crime with which to interrogate nineteenth century notions of public and private spheres, which are central to many of the other stories. Eleven of the sixty Sherlock Holmes narratives mention or contain allusions to the crime of blackmail (CHAS, 3GAB, SECO, YELL, SCAN, REDC, BOSC, VALL, HOUN, REIG, GLOR). In The Valley of Fear and center on the activities of criminal syndicates (the Scowrers and the Italian mafia, respectively), blackmail appears alongside other crimes such as homicide, robbery, and assault. In "The Adventure of the Gloria Scott," "The Boscombe Valley Mystery,"128 and

\footnotetext{
128 "The Adventure of the Gloria Scott" and "The Boscombe Valley Mystery" both represent "the common vector of nineteenth-century blackmail, which is the threat of secrets from the past" (Welsh 19). Both blackmail victims are living under assumed names, are motivated by the desire to keep their past secreted from their children, and are shielded from exposure and legal consequences by the victim's death or impending death.
} 
"The Reigate Squires" wealthy men are blackmailed by men from the lower classes who know of their past criminal indiscretions and levy that information in exchange for a comfortable life. In The Hound of the Baskervilles, Holmes claims he cannot initially travel to Dartmoor to investigate because he is working to defend "one of the most revered names in England" (33), who has fallen victim to a blackmailer. "A Scandal in Bohemia" is unique in the canon for it contains the potential for the crime of blackmail and, if enacted, would be perpetrated by a female character against a male victim.

In contrast, there are four cases which capitalize on the vulnerability of women during the nineteenth century by representing female victims of blackmail: "The Adventure of the Yellow Face," "The Adventure of the Three Gables," "The Adventure of the Second Stain," and "The Adventure of Charles Augustus Milverton." In the first two, blackmail is mentioned but the plot hinges on a different revelation or crime. "The Adventure of the Yellow Face" is one of the investigations representative of the detective's limitations as he erroneously guesses that Effie Munro is being blackmailed after requesting a large sum of money from her husband, no questions asked. In "The Adventure of the Three Gables," Holmes berates Isadora Klein for working with a "band of rascals who may blackmail or give [her] away" (1551), although this does not occur. In "The Adventure of the Second Stain," Lady Hilda Trelawney Hope commits a theft because she is being blackmailed. Finally, the key case to examine the crime of blackmail is "The Adventure of Charles Augustus Milverton." 129

\footnotetext{
129 "The Adventure of the Illustrious Client" is also worth mentioning here. Although it contains no explicit reference to blackmail, Baron Gruner's book could provide an abundant source for the crime. Within the story, Baron Gruner is known to have a book with notes and even photographs of all of the women with whom he has slept.
} 


\subsection{Holmes and Milverton}

True to form, this story begins with Watson's seemingly requisite disclaimer about the duo's dislike of publicity and how he may discreetly publish a narration of one of their private cases:

It is years since the incidents of which I speak took place, and yet it is with diffidence that I allude to them. For a long time, even with the utmost discretion and reticence, it would have been impossible to make the facts public; but now the principal person concerned is beyond the reach of human law, and with due suppression the story may be told in such fashion as to injure no one. It records an absolutely unique experience in the career both of Mr. Holmes and of myself. The reader will excuse me if I conceal the date or any other fact by which he might trace the actual occurrence. (CHAS 1006)

While the journalist Langdale Pike is required to publish the gossip and rumors he accrues with an immediacy, as the value of news depreciates over time, Watson is setting his publication in a different light. His intention is not to give an "old scandal [...] a new lease on life" (BLAC 991) but rather to present the investigation for its unique qualities. Furthermore, it is important that in response to this different thrust of the narrative, Watson refuses to reveal names and dates that may lead to the discovery of those involved. The reference that the "principal person" is "beyond the reach of human law" is opaque but the most likely explanation would be that the unnamed murderess of Milverton is now deceased.

The eponymous Charles Augustus Milverton (IMAGE 4-2) is the principle criminal in this case but perhaps the most interesting feature of this narrative is that he compels Holmes and Watson break the law. Milverton is described in superlative terms: he is "the worst man in London" (1007), "the king of blackmailers" (1008), and "as cunning as the Evil One" (1010). Hyperbolic language is not a strange feature in the 


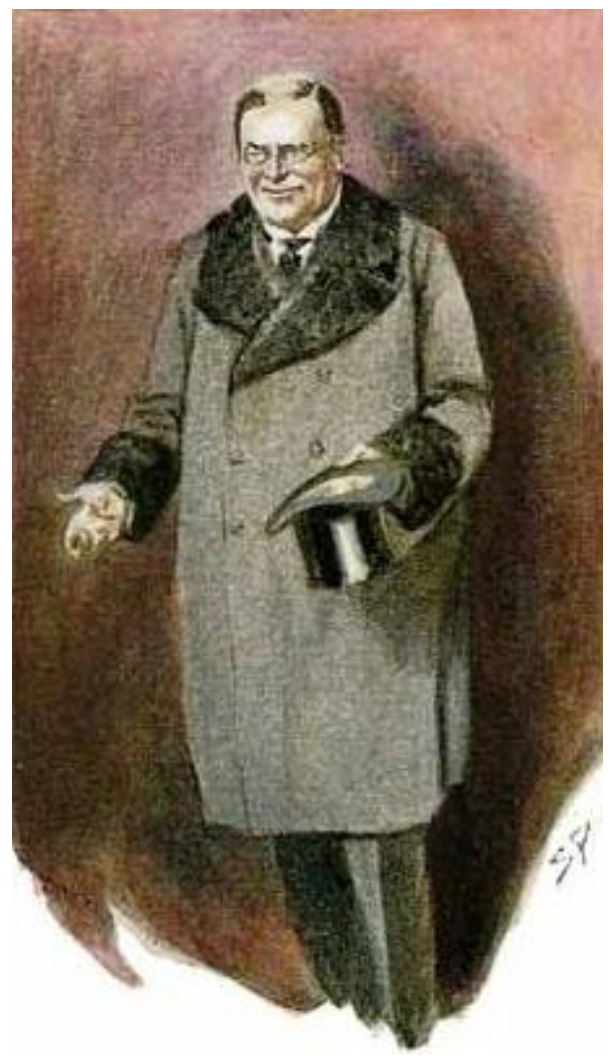

IMAGE 4-2: "Charles Augustus Milverton." Illustration by Sidney Paget. stories since Watson is often given to exaggeration but these descriptions are, in fact, supplied by

Holmes. Holmes explains to Watson at the beginning of the story how Milverton is different from other criminals:

"I have said that he is the worst man in London, and I would ask you how could one compare the ruffian who in hot blood bludgeons his mate with this man, who methodically and at his leisure tortures the soul and wrings the nerves in order to add to his already swollen money bags?" (1009).

Holmes compares Milverton to the criminal who murders in a crime of passion but only one of the sixty cases actually deals with a crime of passion: "The Cardboard Box." This story was famously

excluded from the first British collection of The Memoirs of Sherlock Holmes on Doyle's request because of its violence. Holmes argues here that Milverton is substantially different from the criminal who bludgeons but he does not, in fact, usually work these sorts of cases. The source of Holmes's repulsion must be more than just Milverton's rational, premeditated brand of criminality.

Holmes seems to understand a fundamental difference between blackmail and murder, which falls in line with a trend in the stories: many of the murders in the canon are committed in order to prevent or stop blackmail and the potentially ensuing scandal (COPP, for example). Holmes's particular disdain for blackmail seems to explain his justification for not handing blackmail-victims-turned-murderers over to the police. 
Holmes is ranking blackmail as a worse crime than murder. Alexander Welsh observes that "at the beginning of the [twentieth] century blackmail was popularly referred to as 'moral murder"' (234). While murder is a violence enacted on the physical body, blackmail enacts violence on the mind and soul. The more lasting internal damage of this crime to the victim, then, seems to account for Holmes's disgust with blackmail. As Victor Trevor, son of a blackmail victim, laments "This is worse than death, for it means disgrace as well" (GLOR 514).

Several of Holmes's investigations involve blackmail but Milverton is remarkable since he has made a professional career of this crime. The great criminals in the original stories often invert the methods of the detective himself. Irene Adler disguises herself and fools Holmes, the master of disguise. Moriarty is a consulting criminal as Holmes is a consulting detective. Here, Milverton and Holmes both derive their power from the acquisition of information. Rosemary Jann writes that "In the world of detection, knowledge is power" (119) and Caroline Reitz argues that the modern detective was so effective because "his authority stemmed from knowledge rather than force" (xiv). According to Alexander Welsh, the difference between the detective and the blackmailer is one of motive:

[The detective] intends to discover and then reveal, at the appropriate moment, the concealed crime. The [blackmailer] much more ambiguously needs to discover and threatens to reveal an incriminating fact or action, but shares his victim's interest in concealment, without which he would gain nothing. (8-9)

The blackmailer, as Welsh argues, derives his power from the latent quality of the information; it has value and power in its secrecy. The blackmailer and the victim are united in their desire for the knowledge to remain latent and private; its value is in 
potential rather than actual revelation. Welsh argues that the detective is equally interested in uncovering private secrets, which explains the crime and accompanying causal circumstances. But Holmes's status as consulting detective complicates this easy understanding for he is often called upon for his discretion, or for keeping secrets.

But Milverton is also an exception to this rule: he is a professional blackmailer. He explains how he may just as well benefit from an exposure in this case with Lady Eva Blackwell, Holmes's client. Milverton says, "An exposure would profit me indirectly to a considerable extent. I have eight or ten similar cases maturing" (1013). The exposure of "several imprudent letters [...] written to a impecunious young [country] squire" (1010), which Milverton is leveraging over Lady Blackwell, would help to bring home the severity of his threat to his other victims: coercing them into pay the requisite amount of money to avoid such scandals.

In addition to Milverton's status as a professional blackmailer and the way in which he may profit from either outcome (exposure and publicity or leveraging information in exchange for a sum), he is also deplorable because of the additional vulnerability of his victims. Milverton's two victims in the case, Lady Blackwell and the "principle person" who is now beyond "human law," are both women of the upper class. As Holmes remarks in the story, "Heaven help the man, and still more the woman, whose secret and reputation come into the power of Milverton!" [emphasis added] (1008). Male characters in the original stories may leave England and journey to the outer reaches of empire as sailors, soldiers, or business men but the female characters are more susceptible to a ruined reputation because they have less recourse to mobility and the new identities travel may bring. One of the major trends in the original stories is the return of 
colonials to the Metropole. Although as Yumna Siddiqi argues in "The Cesspool of Empire: Sherlock Holmes and the Return of the Repressed," such characters may equally return having made their fortunes or as broken men. Charles Baskerville is an excellent example of the former. He is able "to restore the fallen grandeur of his line" (9) through African speculation as described in the Devon County Chronicle. The female characters are simply not afforded the same opportunities to redeem their- or their families'— ruined reputation.

This increased vulnerability of the female gender is reflected in the chivalric metaphors used throughout the investigation, which represents Holmes and Watson as knights protecting damsels in distress. ${ }^{130}$ The safe, which holds the compromising letters leveraged against Lady Blackwell, is described as the "green and gold monster, the dragon which held in its maw the reputation of many fair ladies" (1021). Blackmailers in the canon, when they take upper class female victims, use compromising letters as leverage not only against their reputation but also their marriage. If the lady is unmarried, as Lady Blackwell in this instance, then the exposure may prevent the nuptials. Milverton explains, "My dear sir, it is painful to me to discuss it, but if the money is not paid on the $14^{\text {th }}$, there certainly will be no marriage on the $18^{\text {th }}$, $(1011)$. A similar situation occurs in the famous "A Scandal in Bohemia" and in the lesser known, later story "The Adventure of the Second Stain." In the latter, the main crime is the theft of a diplomatic letter, but it is stolen by the wife of the government official (Trelawney Hope) who is being

\footnotetext{
${ }^{130}$ In the earlier novel The Sign of Four, the investigation is compared also compared to a romance and the detecting partners to knights:

"It is a romance!" cried Mrs. Forrester. "An injured lady, half a million in treasure, a black cannibal, and a wooden-legged ruffian. They take the place of the conventional dragon or wicked earl."

"And two knight-errants to the rescue," added Miss Morstan with a bright glance at me.
} 
blackmailed by Eduardo Lucas. The leveraged material is a compromising letter written to another man before her marriage. The specific contents are similarly not revealed in the story.

Both cases seem to recall the premise of Edgar Allen Poe's Dupin tale "The Purloined Letter." This letter is stolen by Minister D and Dupin recovers it to prevent the exposure of a female royal personage's indiscretions (though, again, what these may be is elided from the text). ${ }^{131}$ The domestic and private social spheres in Victorian England were divided along gendered lines, which further explains the vulnerability of these female characters. The domestic or private sphere was that of the female, which meant sexual scandals represented a greater danger for that gender because the publicity the blackmailer threatens would pull the female characters from the domestic into the public sphere, where their private lives should not be the subject of examination and discussion.

Both the vulnerability of Milverton's victims and the professional career he has made on the profits of blackmail are central to understanding the threat of social exposure in the original stories. But the force of this threat is brought home by the way in which Holmes and Watson break the law in order to prevent such publicity. Watson says, "I understood he had opened his campaign against Charles Augustus Milverton; but I little dreamed the strange shape which that campaign was destined to take" (CHAS 1015). The "strange shape" which Watson alludes to takes several forms. Doyle is known to have objected to his brother-in-law's short stories of the fictional thief, Raffles. Doyle famously complained to E.W. Hornung that "You must not make the criminal a hero"

\footnotetext{
${ }^{131}$ This absent presence accounts for much of the theoretical interest in the story by both Lacan and Derrida.
} 
(Symons 85). But this case seems to support the idea that there are instances when criminality is justifiable for the heroic character.

After speaking with Milverton and learning that he will release the information in lieu of receiving his seven thousand pound sum, Holmes decides to burgle Milverton's home. Holmes cultivates a romantic relationship with Agatha, one of Milverton's servants, and even proposes to her just to gain entry to his home. ${ }^{132}$ Holmes explains his reasons for the burglary to an incredulous Watson "the action is morally justifiable, though technically criminal" (1016). This is certainly not the only instance in which Holmes burgles a house. Another notable example occurs in "The Illustrious Client." In that investigation, Holmes is attempting to prevent a marriage of an upper class lady to Baron Gruner, "a man to whom violence is familiar and who will literally, stick at nothing" (1452). Holmes sends Watson in to the man's home to distract him while he sneaks in and takes Gruner's book of sexual exploits.

The Milverton case takes an even stranger turn, however, once the two "felons in the eyes of the law" (1019) have successfully broken into the abode. Milverton enters the study and Holmes and Watson hide behind a curtain while he meets with another of his female victims, the "principal person" alluded to in the opening of the story. They witness Milverton's gruesome murder at the hands of his female victim. She shoots him multiple times before crushing his face beneath her shoe. It is one of the most graphic crimes in the canon. Welsh explains that "Killing the blackmailer has the practical motive, then, of stopping payment and also the social motive, not applicable to killing informers, of attacking someone who professes neither private nor public loyalty to

\footnotetext{
${ }^{132}$ This is another example in the stories of unethical manipulation of a female character by a male one, this time by the detective himself.
} 
anyone" (287). Some people may only have private loyalties; friends and families are the most important relationships. Others may only have public loyalties: devotion to work, politics, or the nation. Most people have some combination of both public and private; to have neither is unnatural, suspicious, and dangerous to society.

In addition to burglary, Holmes and Watson add tampering with evidence and impeding an investigation to their list of possible charges. At the conclusion of the story, Inspector Lestrade comes to the Baker Street apartment to enlist the famous detective's help in the investigation of Milverton's murder. What are so often the opening circumstances of the story, here serve as the closing. Holmes's refusal to help Lestrade investigate reinforces a trend analyzed in chapter three: in Holmes's role as consulting detective he may work outside the law and practice his own sense of discretion. Even Lestrade admits that Milverton was "a bit of a villain" (1029).

In order to fully understand why Holmes refuses to help Lestrade, we must return to the crucial moments just after Milverton is murdered. When Watson starts out from behind the curtain in Milverton's study to intervene, Holmes draws him back. He does not speak but Watson offers an explanation for Holmes's decision: "I understood the whole argument of that firm, restraining grip — that it was no affair of ours; that justice had overtaken the villain" (CHAS 1026). As already mentioned, there are several instances in the original stories in which Holmes fails to give the police the full details of the crime that has been committed out of a sense of higher justice. The difference in this case is that the crime is committed in the present and Holmes and Watson are both eyewitnesses. The other instances in which this deception by omission occurs is usually 
in relation to a crime that has already been committed and Holmes only learns the details after the fact.

Furthermore, Holmes's acceptance of Lady Blackwell as a client has already entangled him in the related criminal activity of the murder victim. Holmes and Watson by working outside the law, seem to be upholding their professional and moral obligation to their client. That their allegiances are already pledged to Blackwell rather than the law becomes clear back in Milverton's study just after he is murdered. Their original intention — to procure the incriminating letters — had not yet been fulfilled. Watson remarks that they must not lose sight of "our own duties and our own objects" (1026). Having taken Lady Eva's case, their first responsibility is to ensure the safety of her reputation and good name.

When Holmes declines to help Lestrade, he tells him that his "sympathies are with the criminals rather than with the victim" (1029). His choice is to shield not only Watson and himself from prosecution but the unnamed murderess, their client, and their reputations as well. He explains his decision by saying "I think there are certain crimes which the law cannot touch, and which therefore, to some extent, justify private revenge" (1029). Holmes's role in the original stories, as in the case of "Charles Augustus Milverton" is to avoid scandal ${ }^{133}$ : "He thus again serves in his usual unofficial role of protecting prominent members of society from scandal and enabling private forms of revenge to take their course" (Jann 90). As already discussed, Holmes position is informed by the increased vulnerability of Milverton's female victims in this historical

\footnotetext{
${ }^{133}$ Twenty-six of the sixty stories mention "scandal." They are: 3GAB, 3STU, ABBE, BERY, BLAC, BLAN, BOSC, BRUC, CHAS, CREE, CROO, DANC, EMPT, FIVE, HOUN, ILLU, MISS, NOBL, NORW, PRIO, RETI, SCAN, SECO, SHOS, VALL, and VEIL.
} 
context as well as the blackmail king's decision to form a professional career around, what Holmes (if not the law ${ }^{134}$ ) viewed as, such a heinous crime-a moral murder.

\section{SHERLOCK AND METATELEVISION IN THE DIGITAL AGE}

The relationship between fact and fiction, or reality and story, is also given prominence in the two adaptations of Sherlock Holmes considered here. Sherlock and Elementary make use of both print and digital media or metatelevision but while Sherlock makes a balanced use of print and broadcast media, Elementary focuses on metatelevision, emphasizing the use of electronic screens in the frame. As Scott R. Olson writes, "Metafiction is fiction that investigates its own nature" (284). But what is the nature of televisual and digital detection narratives? Sherlock and Elementary lay bare the way digital media (such as cell phones, computers, the internet, and television) create meaning and the way this knowledge is used in society. In "A Study in Pink," Sherlock turns to his cell phone during the crime scene investigation for weather reports and the viewer is given access to the contents of text messages as on-screen text. In fact, the detective first appears as an implied presence through his use of text messaging during a press conference. Elementary is more interested in foregrounding the use of digital communications, often between Joan and Sherlock (IMAGE 4-3).

Most of the time the use of these metadiegetic elements in the shows and stories is to enhance the verisimilitude of the fictional world the characters inhabit; however, in focusing on the way meaning is constructed in everyday life through narrative and visual techniques, the reader and viewer is interpolated as the subject reading and watching.

\footnotetext{
${ }^{134}$ Blackmail was not written into law as a criminal act in England until the Theft Act of 1968 in Sections 21(1) and (2).
} 


\section{Brad Chrisholm}

articulates this apparent

dichotomy between

artifice and realism

engendered by

metafictional techniques:

“At times, [on-screen

IMAGE 4-3: Picture message from Sherlock to Joan to practice "flash analysis." (Elementary 2:3).

screens] may do little

more than serve as background props in the interest of verisimilitude; in other cases they may play key roles in eliciting a self-consciousness about the medium" (16). In this attempt at faithfulness to reality, the shows have the ability to highlight the way truth is always constructed, framed, and disseminated by broadcast and print media in the very act of narration. Olson writes "Metafiction undermines the illusion of realism, because it draws attention to the very devices used to create the illusion, making the reader more aware of the artifices of fiction while reading" (284). The use of metatelevisual elements is able to draw attention to the viewer's status as viewer. Chrisholm delineates four different ways that metatelevision (in the form of on-screen screens) may be used: 1) framing, 2) the film or video "look" (characterized by graininess), 3) split screen (which provides multiple views on the same action), and 4) "the roving eye." Both television shows make ample use of framing with television programs and news reporting often playing in the background of the scenes.

The "roving eye" often shows up in detective fiction, such as Sherlock and Elementary, as surveillance footage. As discussed in chapter three, the introduction of 
Mycroft in Sherlock is through his implied presence as the unseen seer watching John in the phone booth on a London street corner. There is an obvious connection between Holmes and this concept of hidden surveillance. As Dennis Porter explains "by the time of Doyle, the Great Detective of fiction had himself the essential qualities of the unseen seer, who stands at the center of the social Panopticon and employs his 'science' to make all things visible on the behalf of the forces of order" [emphasis added] (124-125). Additionally, in The Hound of the Baskervilles, Holmes observes the trajectory of the investigation Watson is embedded in from the cool distance of the moor. Before Watson knows the identity of this solitary figure he espies him from a distance and refers to him as "the unseen watcher" (77). In this episode of Sherlock, the viewer is similarly placed in this spectatorial position as they are provided with several shots of the security footage of John. This is an example of "the roving eye," which recruits the audience as a voyeur. Another example of metatelevision, the "video look," may be found in "The Reichenbach Fall" when Moriarty ${ }^{135}$ is on trial for his multiple security breaches of important British institutions. The camera provides a series of shots of the reporters on the steps outside the courthouse before a series of three newspaper broadcasts take over the screen and offers the audience the perspective of a television viewer within the narrative (IMAGE 4-4). The shot cuts from one news anchor's report to the next before signaling the transition to the main frame story with an image of electronic noise. In this way, the series "force[s] us to posit a diegetic world inside of and subordinate to another one" (Chrisholm 16). The news broadcasting, like the use of newspaper articles in the original series, functions as a metadiegetic device that signals this duality between the

\footnotetext{
${ }^{135}$ Moriarty also signals his apparently miraculous resurrection at the conclusion of "His Last Vow" through a video recording.
} 


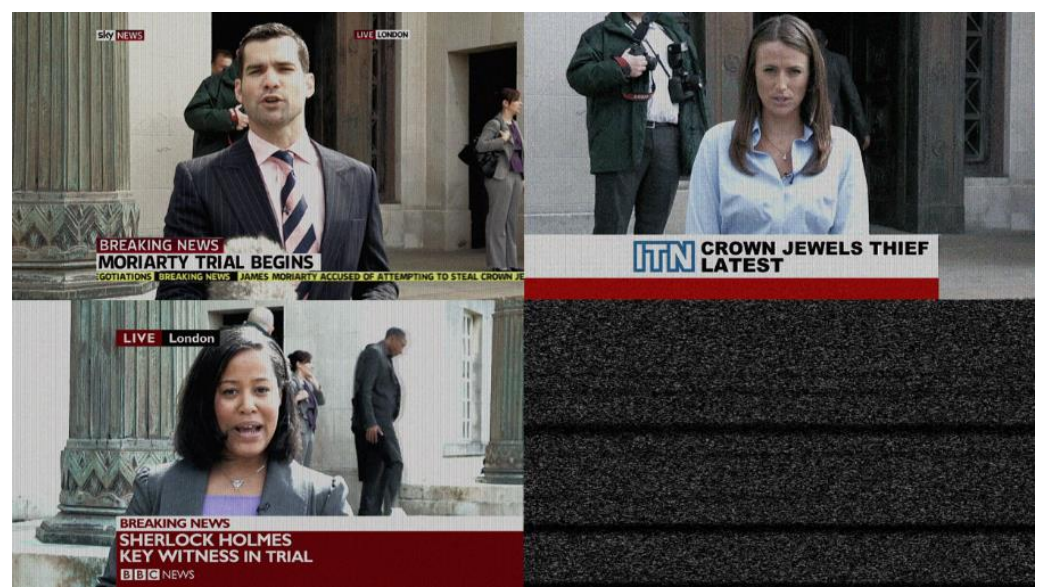

IMAGE 4-4: News anchors reporting on Moriarty's trial. (Sherlock 2:3). public understanding of the investigation (or publicized trial in this case) and the private knowledge to which the viewer is privy.

The use of

metatelevision becomes even more pronounced in Elementary, which tends to emphasize electronic screens more than print media. A good example of framing, already mentioned in chapter one, is when Joan first meets Sherlock. He is staring at multiple screens playing various video feeds and attempting to divide his focus among them all $-\mathrm{a}$ pronounced example of framing. This video screen setup is used in later episodes as well and seems to suggest that within the show the Baker Street lumber room (once filled with newspapers) has been replaced with these displays, an update to reflect the same selfreflexive gesture to its own medium. The viewer watches the detectives watching just as the reader of the stories read of Holmes and Watson reading newspapers. In the episode “The Internal Audit," Joan makes use of the video room to pour over hours of user-posted internet skateboard videos (IMAGE 4-5). Security footage is often used as an investigative tool by both Sherlock and Joan and, like the Mycroft example

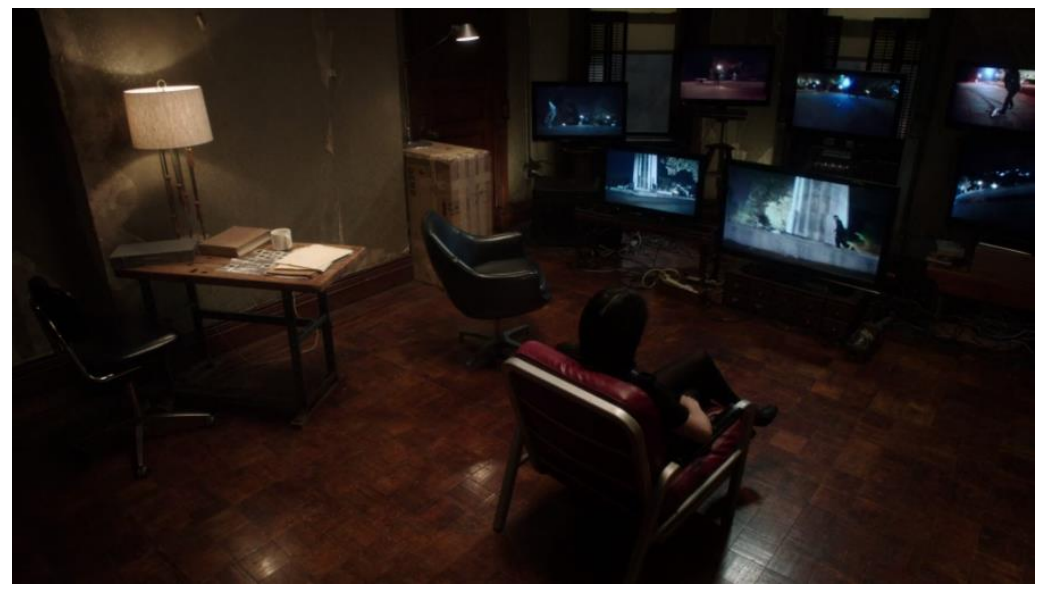

IMAGE 4-5: Joan watching skateboard videos posted online (Elementary 2:11) 
from Sherlock, may be an instance of "the roving eye." When the shows take advantage of security footage which invades the entirety of the screen, "the viewer is then particularly conscious of both that camera's existence and its placement" (Chrisholm 18). The viewer is placed, as the detective often is, in the position of undetected observer. And in Elementary's “The Long Fuse" (1:8), Sherlock reveals his regular hobby of studying police interrogations videos from the seventies and eighties. In a society which increasingly makes use of screens and recording devices, the detectives will increasingly make use of this material as a means of gathering information and for its status as potential evidence. Furthermore, the pilot episode of the series even ends with the Elvis Costello song "Watching the Detectives" in which the narrator of the song becomes frustrated with his girlfriend's preoccupation with watching a detective show rather than paying attention to him. The inclusion of this song signals from the start of the series its preoccupation with watching and its metadiegetic self-reflexive gesture as played out in later episodes.

The larger thematic stance towards the press in the two television adaptations could hardly be more different. In "His Last Vow" the press is the enemy and in "We are Everyone" the press represents a check to government power. In the third season of Sherlock, the press is set up as the nemesis to the government — and even detection itself—as Magnussen is pitted against Sherlock. The press has become inimical to national and international security as Magnussen uses government officials for his own ends. Similarly, the real life Murdoch is suspicious for the influence he exerts on UK government officials and his family's control of News Corp, an international media conglomerate with substantial holdings in both the US and UK. Magnussen's power 
stems from his control of the narration of current events and, by association, the sway of public opinion. The contents of the blackmail material supplied for the viewer, like the original Milverton story, involve the private (sexual) lives of government officials. Their public position has made their private lives susceptible to scrutiny in a way that detracts from more important political issues. Sherlock critiques the role of the press in the digital age as too powerful, too often unsubstantiated by material proof, and hopelessly focused on the wrong issues.

Elementary presents a partial triumph of the press in an American context, ${ }^{136}$ but it misses an important opportunity to critique the US government's lack of transparency and the larger debate about the pervasive government surveillance of its own citizens. In adapting the Snowden controversy, "We are Everyone” sidelines Snowden's original motivation for whistleblowing and the contents of the leaked material. Ultimately, this episode is a missed opportunity for Elementary to capitalize on important themes carried on throughout the series, such as digital surveillance and the monopoly of the press by the powerful (i.e., big business and the government). The show's refusal to interrogate the latter is most likely a consequence of Elementary's own entanglement in the American media complex. Elementary is a CBS television product. The CBS network is part of the CBS Corporation that is owned by National Amusements Inc., one of the five or six media conglomerates which collectively monopolize the majority of US media outlets.

\footnotetext{
${ }^{136}$ Although interestingly, Snowden released his story to The Guardian and fled to Hong Kong and cited their "strong tradition of free speech" in his video interview with Glenn Greenwald.
} 


\subsection{Magnussen and Ownership}

After Holmes defeats Moriarty in season two of Sherlock, a new criminal mastermind emerges, the Danish media magnate Charles Magnussen (IMAGE 4-6).

Magnussen is a blended adaptation of the fictional

Charles Augustus

Milverton and the real life

Rupert Murdoch. In

Doyle's story, Holmes

describes Milverton as a

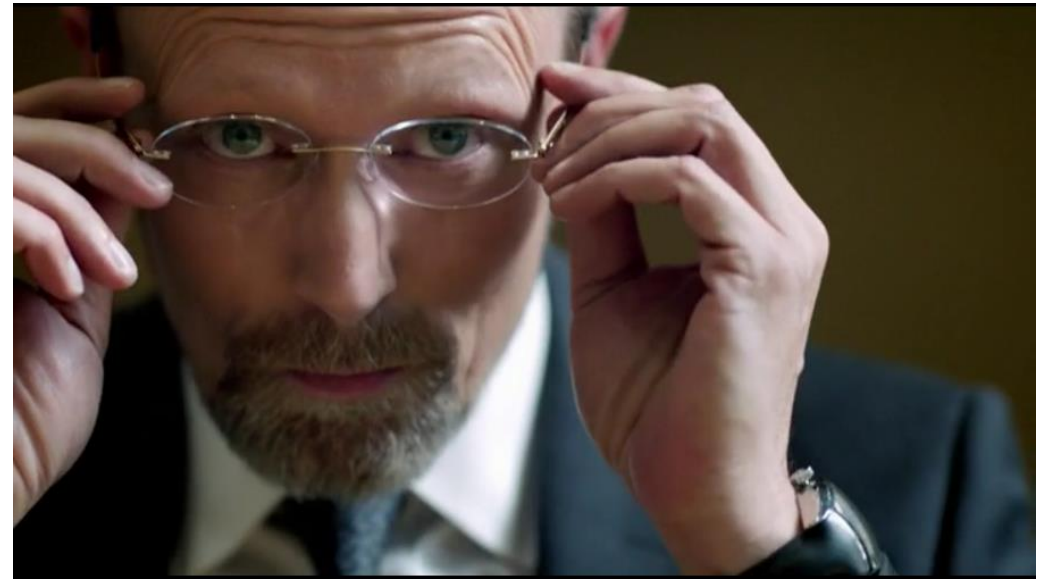

IMAGE 4-6: Charles Augustus Magnussen (Sherlock 3:3)

snake, the "slithery, gliding, venomous creatures, with deadly eyes and wicked, flattened faces" (1007). In this episode, Sherlock compares him to another cold-blooded animal, a shark with "those floating flat faces, those dead eyes" (3:3) but the effect is the same: "repulsion" (1007). Again, Sherlock explains how Magnussen stands apart from the other criminals he has encountered in his career: "I've dealt with murderers, psychopaths, terrorists, serial killers. None of them can turn my stomach like Charles Augustus Magnussen." Once more, Sherlock makes a comparison to evil incarnate, remarking later in the episode that he has made "a deal with the devil." He tells John later that "Magnussen is quite simply the most dangerous man we've ever encountered, and the odds are comprehensively stacked against us."

When John comes out and asks Holmes why he hates a man who seems like his "usual kind of puzzle" Sherlock explains it is "because he attacks people who are different and preys on their secrets." This is a different understanding of Holmes's hatred 
of Milverton. In the original, Holmes compares blackmail (a moral murder) to physical murder and his hatred seems to stem from the damage done to the soul and mind rather than the body, coupled with Milverton's monetary motive. Here, Sherlock is explaining that Magnussen's victims will be those individuals who do not fully conform to social mores and his choice in victim seems to be the focus of the detective's dislike. There is an obvious connection to chapter one, as Sherlock himself is represented as different from the normative in this series. There are several other important changes in adapting the adventure of Milverton.

While Milverton has made blackmail his career, Magnussen, on the other hand, owns several news outlets which facilitate his blackmail endeavors. The connection between the newspapers and blackmail is a practical one; blackmail relies on the threat of publication. The connection between the detective and the blackmailer is emphasized by Magnussen's pronouncement that "It's all about knowledge. Everything is. Knowing is owning." At first Sherlock and the viewer believes that Magnussen stores the proof of this secreted knowledge (or at least accesses it remotely) through his spectacles as the on screen text seems to signal (IMAGE 4-7). The plot hinges on the revelation that the

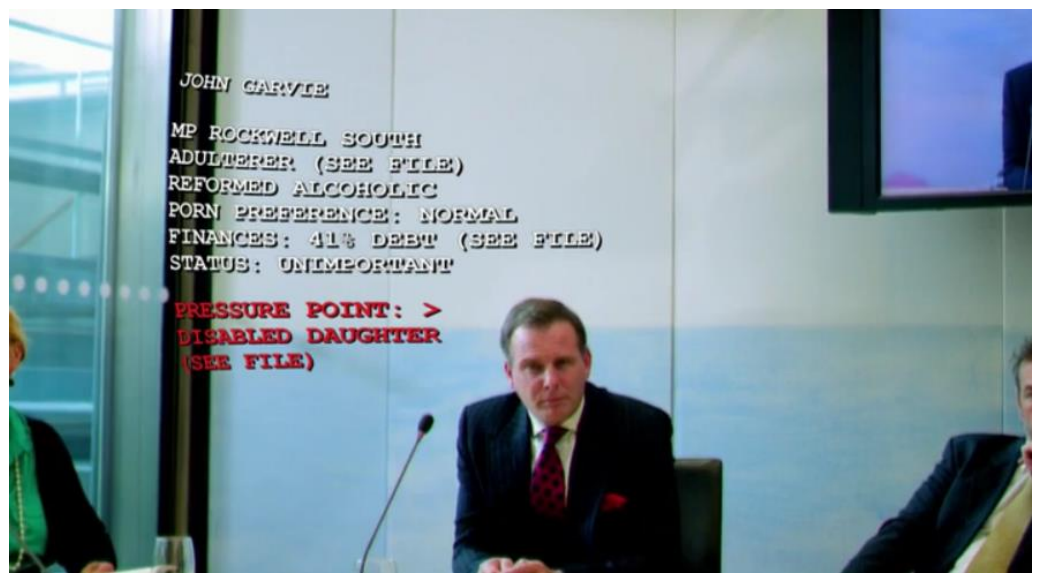

IMAGE 4-7: Magnussen analyzes John Garvie for a weakness (Sherlock 3:3) electronic screen built into his glasses was actually a mental simulation of electronic media. The Magnussen character demonstrates how computer media 
operations (such as selection, compositing, and teleaction) shape our ways of thinking in the digital age, as described by Lev Manovich in The Language of New Media:

While operations are embedded in software, they are not tied to it. They are employed not only within the computer but also in the social world outside it. They are not only ways of working with computer data but also general ways of working, ways of thinking, and ways of existing in a computer age. (118)

This serves as another example of how Sherlock's adversary has inverted one of his own methods. As Stein and Busse have argued, the use of onscreen text in the series visualizes Sherlock's mental processes: "[his] dependence on the protocols of search and filter [...] highlights the way in which, according to Lev Manovich (2001), digital logics become cultural logics become personal logics" (11). The show signals the presence of this "digital logic" by referencing the Mind Palace.

Magnussen reveals a white room empty save for a single chair and explains "The Appledore vaults are my Mind Palace. You know about Mind Palaces, don’t you, Sherlock?" The audience has been deceived. The scenes of Magnussen perusing physical files of information, shown earlier in the episode, was a trick; this was all occurring within his own Mind Palace. Like Sherlock, Magnussen’s “knowledge is no longer located in his 'brain attic' but in the digital 'cloud" (Stein and Busse 11). The shift from the "brain attic" to the "Mind Palace" marks this epistemological shift to the digital age. When Magnussen reveals that he has no safe or computer server replete with indicting evidence against his victims, the anxiety of our cultural moment about the immateriality of digital information is foregrounded.

In the digital age, when so much information is stored as ones and zeros in binary code, one cause for anxiety is that the media will influence public opinion without the 
material proof to back the claims. Aside from the ubiquity of the internet and our growing dependence on digital technologies, this anxiety is the product of several related aspects of digital information: the high degree of verisimilitude of the digital image coupled with its ease of manipulation, the dissemination of publication platforms made available through the internet (which potentially erodes checks and balances on veracity), the need for rapidity engendered by the simultaneity of the internet, and the increased vulnerability to hacking. Magnussen says, "Proof? What would I need proof for? I'm in news, you moron. I don't have to prove it-I just have to print it" (Sherlock 3:3). This resonates with viewers of the show who watched as Moriarty was able to fabricate a false identity and manipulate the public perception of Sherlock Holmes at the end of season two in "The Reichenbach Fall" (2:3), which makes extensive use of images of newspaper front

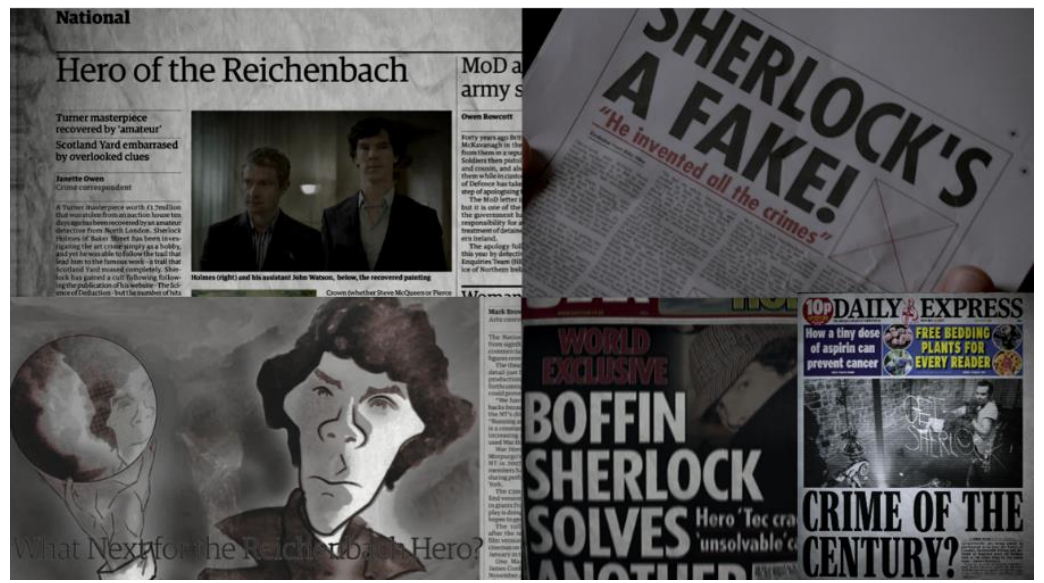

IMAGE 4-8: Newspaper headlines illustrating Sherlock's growing fame (Sherlock 2:3) pages (IMAGE 4-8). As

Moriarty gloats to

Holmes "“Genius

detective proved to be a

fraud.' I read it in the

paper, so it must be

true...I love newspapers, fairy tales."

While Magnussen ultimately reveals that his power stems from the mere knowledge of "pressure points" rather than material proof, a twisted perversion of the detective's coupling of focus on visual, material evidence and authority stemming from knowledge and intelligence. The episode nevertheless provides the contents of the secret 
knowledge which is omitted in the original stories. In the episode, Lady Smallwood (instead of Lady Blackwell) is Sherlock's client, Magnussen's victim, and a British government official. Smallwood's pressure points are some compromising letters written by her husband to a minor. This is a dramatic reversal from the scenarios played out in the canon. In the original story, the unnamed murderess is actually the wife of a "great nobleman and statesman" with a "time-honoured title" (1031) and it is implied that she is being blackmailed for her own indiscretions. Here, the series inverts the gendered categories and represents an influential female government official as vulnerable because of her husband's sexual malfeasance.

Magnussen claims to "own" people rather than blackmail them: "Of course it isn't blackmail. This is...ownership.” By “owning” important and powerful people in key positions he can leverage entire countries. Sherlock remarks “I'm not exaggerating when I say that he knows the critical pressure point on every person of note or influence in the whole of the Western world and probably beyond. He is the Napoleon of blackmail" (3:3). Even Mycroft warns Sherlock away from pursuing Magnussen. Mycroft cautions Sherlock by saying Magnussen is off limits and "under his protection" but Sherlock wittily retorts that he thinks Mycroft is, in fact, “under [Magnussen's] thumb." This conversation foreshadows what is to come since Magnussen's end goal is to gain control of Mycroft and-by association-England itself.

The idea that the revelation of the secrets of powerful individuals can potentially have national and international consequences finds precedence in the original stories. Specifically, in "The Adventure of the Beryl Coronet" when the theft "threatened to raise a scandal which would convulse the nation" (330). The difference is that in the original 
stories the revelation of private secrets (such as putting up a national treasure as collateral or its ensuing theft) in the form of a scandal would have national and international consequences. By contrast, Magnussen exerts his influence over nations and the world in the continued concealment of this information. His power is a secreted leverage over people that branches outward to include the fate of the nations they govern. As he says in the episode, "This is what I do to people. This is what I do to whole countries" (3:3). Magnussen represents a greater danger to the England and the world in this episode of Sherlock than he ever did in the original story. He talks with disdain of the country and its people. According to Magnussen, they are "domesticated," "a nation of herbivores," and their country isn't a "real country" but rather a testing ground for his tactics: a "petri dish to the Western world." Rupert Murdoch's support for the UK's withdrawal from the EU seems to echo this stance. He claimed, "When I go into Downing Street they do what I say; when I go to Brussels they take no notice."

Magnussen's threats are not idle as is proved later in the episode when his news channel covers the arrest of John Garvie on charges of corruption. John Garvie is a Member of Parliament who shows up in the beginning of the episode to interrogate Magnussen's potential hold over UK government officials (see IMAGE 4-7). Garvie asks "Do you think it right that a newspaper proprietor, a private individual and, in fact, a foreign national should have such regular access to our Prime Minister?” Magnussen smugly deflects by apologizing for being foreign and Smallwood follows up with another targeted question about the magnate's sway over the UK's political officials, which most likely puts her in his cross-hairs. The interruption of the show's narrative by this later media coverage makes evident the power of Magnussen's threats in much the same way 
that Milverton describes the value of leaking information about one victim: it ensures the complicity of his other victims. What becomes clear is that blackmail is a crime to which the rich and powerful are especially susceptible. The more wealth and power an individual accrues, the more damaging allegations - whether true or false — can be to their reputation. Publicity is a double-edged sword.

In this episode, however, Magnussen is also set up as a rich and powerful individual. Sherlock explains, "He uses his power and wealth to gain information. The more he acquires, the greater his wealth and power." While the press has the potential to expose the problems endemic to the system of government and the mechanisms for power, the episode does not capitalize on this opportunity. There seem to be no dangerously explosive secrets to expose about Magnussen and no way to combat the press he has at his disposal. Magnussen owns the press and, therefore, controls the narrative. His power goes unchecked because he controls the apparatus which influences public perception.

While Holmes is drawn into his "campaign" (CHAS 1015) against Magnussen by Lady Smallwood, Holmes's real interest in his demise stems from Mary and John's involvement. Magnussen has knowledge of Mary's past life as an assassin. He leverages this information and her desire to keep this past secreted from John. Even after Sherlock tricks Mary into revealing her past to John, Magnussen threatens to disclose her whereabouts to those she has wronged:

It works like this, John. I know who Mary hurt and killed. I know where to find people who hate her. I know where they live; I know their phone numbers. All in my Mind Palace - all of it. I could phone them right now and tear your whole life down. 
When the threat of exposing her past to John ceases to sway events in his favor,

Magnussen resorts to the threat of physical violence. Moriarty also uses extortion to manipulate Holmes in "The Reichenbach Fall” (2:3).

As Moriarty explains to Sherlock in the episode, "every person has their pressure point, someone that they want to protect from harm." In order to win the trial in the beginning of the episode, Moriarty kidnaps and threatens the jury member's loved ones. At the conclusion of the episode, Moriarty threatens to have John, Lestrade, and Mrs. Hudson killed if Sherlock does not commit suicide. The lynchpin that ensures Sherlock's victory is that Moriarty overlooks someone of importance to the detective: Molly Hooper. Magnussen's hold on Mary is strategic, the first link in a chain of pressure points leading to control of Mycroft:

For those who understand these things, Mycroft Holmes is the most powerful man in the country. Well...apart from me. Mycroft's pressure point is his junkie detective brother, Sherlock. And Sherlock's pressure point is his best friend, John Watson. John Watson's pressure point is his wife. I own John Watson's wife...I own Mycroft. He's what I'm getting for Christmas.

By controlling Mary, he controls John. By controlling John, he gains control of Sherlock and surprisingly enough, Sherlock is Mycroft's weakness. Magnussen plays a video of John almost being killed in a bonfire on Guy Fawkes Day from the first episode of the season, "The Empty Hearse" revealing that Magnussen has been plotting this scheme across the entirety of season three. As the video plays Magnussen says, "Very hard to find a pressure point on you, Mr. Holmes [...] but look how you care about John Watson. Your damsel in distress." On the surface this is one more innuendo about a romantic relationship between Holmes and Watson but it also revives and amends the chivalric metaphors of the original story. Lady Eva/Elizabeth is no longer the damsel in distress, 
the focus and danger has shifted closer to home - to John. The earlier conversation between Mycroft and Sherlock is replete with chivalric metaphors as well:

MYCROFT. [Magnussen is] A necessary evil - not a dragon for you to slay.

SHERLOCK. A dragon slayer. Is that what you think of me? MYCROFT. No. It's what you think of yourself.

In the original story, the safe in which Milverton stored his proof was described as a dragon. Holmes and Watson break and enter his home to burgle the contents, thus slaying the dragon. Once Magnussen reveals that the only proof exists within his own mind, he becomes the safe and, by association, the dragon to be slain.

Magnussen has become the dragon and as a result he is shot by Sherlock and not the high-ranking unnamed murderess. He must be slain by the knight or dragon slayer, which the viewer understands to be Sherlock's role. While the Milverton story represents one of Holmes's most blatant infractions of the law in the Doyle's stories, Sherlock takes it further by making the detective a murderer. When Magnussen taunts Sherlock that he can't be the hero this time because he holds all the cards, Sherlock responds that he has never been a hero, he's just a "high-functioning sociopath." There is a certain symmetry to the declaration since this description of the detective was introduced in the very first episode of the series but there is a disjunction between this statement and the audiences' understanding of Sherlock. It seems as though everyone else knows him better than he knows himself and his reluctance to call himself a hero in this moment serves only to further reinforce that understanding of his character. He is introduced as a dragon slayer and Mycroft explains that he thinks Sherlock sees himself this way. But if Sherlock sees himself as a heroic man then somehow that diminishes our understanding of his heroism, 
which partially explains his self-effacing statement that he is simply a sociopath. But how can a denouncement of heroism seem to signal the opposite?

This scene represents “The Last Vow” of the episode's title. Sherlock's vow is his defining statement about his own identity. In one sense, Sherlock's murder of Magnussen is a selfless act, committed to protect those he loves and countless unknown others from Magnussen's control. But, in another sense, Sherlock's words and actions in this scene are completely self-centered. In order to understand what I mean we have to consider the literary context of Doyle's Holmes character and the resonances with heroism from season two of Sherlock. Doyle's detective grew out of two literary traditions:

Romanticism and Realism. Chapter one discussed the curious blend of art and science, imagination and ratiocination in the Holmes character. In terms of characterization, his romantic inheritance is the conception of his character as a superior genius hero while his realist inheritance is the flawed and self-effacing statements that seep into some of Watson's narrations and, often more pronounced, in the few stories written from his point of view. For example, in "The Adventure of the Three Gables," ${ }^{137}$ Holmes says "I am not the law, but I represent justice so far as my feeble powers go" [emphasis added] (3GAB 1550).

At the end of season two in Sherlock, Moriarty calls newspapers "fairy tales," completely fictional and easily manipulated. Moriarty is jubilant in his ability to become the author of the newspapers articles about Sherlock Holmes, which ruin his reputation and precipitate his "suicide." Moriarty lost his life but was able to, at least temporarily, author Holmes's public identity in drastic ways; he reshaped public opinion against the

\footnotetext{
${ }^{137}$ According to Leslie Klinger's introduction to the story, scholars doubt Watson is the narrator of this investigation (1534).
} 
detective. Magnussen is similarly attempting to write Sherlock's narrative and define his character. He taunts Sherlock, “Oh, I'm not a villain. I have no evil plan. I'm a businessman, acquiring assets. You happen to be one of them! Sorry. No chance for you to be a hero this time, Mr. Holmes." In this larger context it becomes clear that Sherlock is reacting against the identities that others have put on him and reclaiming his own selfhood in this statement. Magnussen will not own Sherlock and he will not control his narrative. Sherlock's response to Magnussen is similar to his response to John in "The Great Game" (1:3): "Don't make people into heroes, John. Heroes don't exist and if they did, I wouldn't be one of them." Therefore, Sherlock's last vow, denying his own heroism, may be seen as a heroic statement of individualism when considered in this context. Sherlock will not let the Press, Moriarty, Magnussen, or even John control his identity and the story of his life.

It is also important to recognize the ordering of the sequence after Sherlock shoots Magnussen. The audience sees a solemn, adult Sherlock kneeling before the government assault team and his brother hovering in the helicopter above, hair blown back by the propellers and laser sights focused on his face. Then, the audience is given Mycroft's perspective and he sees a scared little boy with the same curly hair and tears streaming down his cheeks (IMAGE 4-9). This continues a trend mentioned in chapter three: identifying Mycroft as a symbol of the British government and representing him as paternalistic. It seems to be demonstrating that in spite of how things may appear-in the press and to the public - the government really only wants to protect its citizens in the same way that Mycroft wants to protect his little brother. 


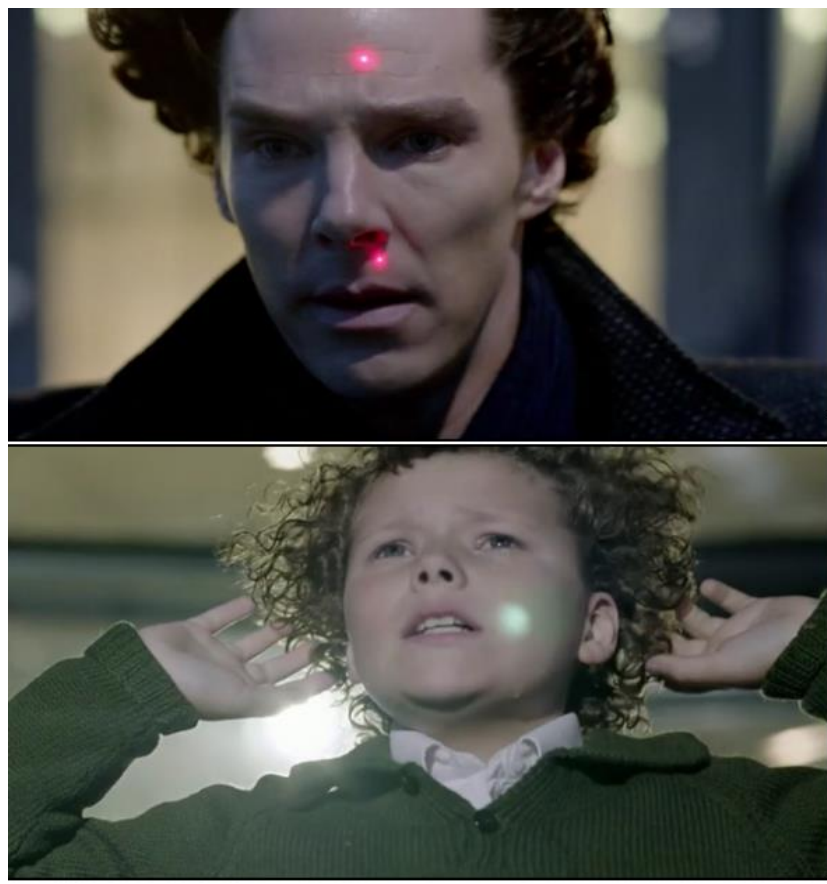

IMAGE 4-9: Sherlock as seen by Mycroft (Sherlock 3:3)
In Doyle's story, Milverton's death is excused by Holmes's remark that sometimes private revenge is justified but in this adaptation, the death is excused in the light of the threat Magnussen posed to national security. The episode seems to exonerate Sherlock's actions through Mycroft's conversations with government officials, including Lady

Smallwood. Mycroft explains Sherlock's importance to the country, "As my colleague is fond of remarking, this country sometimes needs a blunt instrument. Equally, it sometimes needs a dagger — a scalpel wielded with precision and without remorse.” This echoes Mary's earlier line in the episode: "People like Magnussen should be killed. That's why there are people like me."

Rewriting Mary as a spy is an important change to the story being told about the detective and the affinities between the two characters gives weight to her justification of Magnussen's murder. Mary and Sherlock, the spy and the detective, share much in common as characters; this goes a long way in explaining their surprisingly immediate understanding of one another (i.e., Sherlock understanding that Mary shot him to save him earlier in the episode). Many histories of detective fiction include the spy novel as a later outshoot of the genre. Julian Symons includes the spy story and thriller as well as the crime and detective stories in his Bloody Murder because "The tree is sensational 
literature, and these are among its fruits" (4). Symons sees their common content (crimes) as the unifying characteristic. Dennis Porter in Pursuit of Crime explains that both spy and detective stories are progeny of the adventure story, which explains their affinities. While recognizing the difference in "history and rationale" Charles Brownson, however, more specifically considers the similarities between the two characters:

In comparing the spy to the detective, for example, it is worth noting what has happened to the word intelligence. This used to be an attribute and a working tool of the detective in solving crimes. For the spy it means information and this is a property of the external world. The detective embodies intelligence. The spy seeks what he has not: intelligence. [...] The spy, like the Classic detective is concerned with the getting and deployment of knowledge. (114)

Like the other characters which are the focus of this chapter (the journalist, blackmailer, and detective), the spy is in pursuit of knowledge. Equally, the spy is often called on to eliminate someone who knows too much. Mary and Sherlock are mirror characters in their work (pursuit and practical use of information) and their personal affection for John. Thus, Sherlock's actions seem condoned in retrospect by the adaptation's changes to Mary's story. By making Mary a previous black-ops agent and ensuring viewer identification with her character through her sympathetic representation, Sherlock's murder of Magnussen is seen in a similar light as her past "indiscretions": justified. Mary's backstory strengthens the implied message of Magnussen's death: some people deserve to die and the only way to achieve this is by working outside the law.

In spite of Mycroft's earlier remonstrations to his younger brother to leave Magnussen alone, Mycroft's reaction proves that he was a threat to the country. The message is clear: Sherlock's murder is defensible because Magnussen posed a greater threat to national security and the world. This is reinforced by Lady Smallwood's earlier 
frustrated appeals "No one stands up to him. No one dares. No one even tries [...] There isn't a man or woman in England capable of stopping that disgusting creature." Furthermore, since Sherlock is responsible for Magnussen's leverage over Mycroft, the murder seems justified as an act of redemption and penance for his recklessness. Sherlock is undoing the damage he has unwittingly caused and removing England from the precarious position he has placed her in. ${ }^{138}$ As Mycroft remarks earlier in the episode "the security of the free world" depends on his laptop and Magnussen now possesses that device. In the wake of Sherlock's act of murder, Mycroft defends his brother's actions to his government colleagues "There will always come a time when we need Sherlock Holmes." Instead of sending Sherlock to prison, where he jokes Sherlock would likely start a riot every day, Mycroft and the others agree to send him to Eastern Europe on the undercover assignment discussed earlier in the episode, from which he is unlikely to return alive.

Just as in "The Hounds of Baskerville," the episode seems to validate government secrecy in the face of certain larger threats. In the context of an international threat, Sherlock is recruited for espionage, just as in "His Last Bow: The War Service of Sherlock Holmes" (1917). As mentioned in chapter three, this story was published late into World War I and the detective is recruited as a spy to outmaneuver the Germans. In the context of this historical moment, terrorism threatens the Western World and Sherlock becomes the type of hero needed. He is the type of hero that will "do what needs to be done." Sherlock is the scalpel that will strike with precision in service to the

\footnotetext{
${ }^{138}$ A trend also present in "A Scandal in Belgravia" (2:1), when Sherlock hastily solves Irene's puzzle and inadvertently hands over important information to Moriarty. He then must solve the passcode to unlock her phone to redeem himself.
} 
greater good and regardless of the legal ramifications he might personally incur. In Sherlock's adaptation of the themes of "His Last Bow" and the international threat, the detective story is blended with the political morality of the spy genre, which "assert[s] the necessity of covert, essentially nondemocratic activities in the name of state security" (Thompson 94). The link between the two stories can be found even at the superficial level of the titles. "His Last Bow" is a tale of how Sherlock returns from retirement for one last story of triumph over an international, rather than the usual domestic, threat. Doyle's use of "bow" in the title indicates the characteristic showmanship of the detective and the security that comes from the optimistic resolutions. "His Last Vow," on the other hand, signals the change in tone. The emphasis is less on the assured triumph of the detective and more on his loyalty: public and private. The detective's vow seems to be to ensure the safety—no matter the cost—of England and those he loves.

\subsection{Kleinfelter, Whistleblowing, and Hacktivism}

Elementary's episode from season one, “Dead Man's Switch,” is the show's most direct adaptation of the "Charles Augustus Milverton" story; however, it is less central to the discussion about public and private realms that is the focus of this chapter. In order to illuminate a more accurate comparison of the themes presented by the Sherlock episode and the crucial nexus of public and private in the digital era, this chapter will instead shift its focus to "We Are Everyone" from season two.

Normally the whistleblower makes different use of secret information than the blackmailer. The whistleblower goes public with information in order to expose corruption and abuse in governments and corporations. Like blackmail, it is a tactic often used against structures and people in power. "We are Everyone" is the story of a 
whistleblower who turns to murder and blackmail in his flight from the US government. Whether or not Robert Doherty (the shows' creator) or Craig Sweeny (the episode's writer) intended to adapt the story of real life whistleblower, Edward Snowden, in this episode, "We are Everyone" aired a mere four months after the Snowden scandal hit the press. As a result, the viewers' understood the episode as an adaptation of the real life events, an example of "pop culture timeliness" (Huard).

"We are Everyone" features Ezra Kleinfelter, former CIA contractor turned whistleblower, murderer, and blackmailer. Like the controversy surrounding Snowden as a public figure, Kleinfelter's position in the show is foregrounded in his interpretation as either a hero or a traitor. In addition, it features Everyone, an adaptation of the real life hacktivist group Anonymous. As signaled by the name of the collective, Everyone attempts to represent the public (or at least the public's interests) in their pursuit of freedom of information and exposure of the abuses of power structures. In his flight from the US government (represented in the episode by the nefarious Elliot Honeycutt), Kleinfelter murders Vanessa Hiskie (a member of Everyone who had been hiding him). The circumstances surrounding her death and Kleinfelter's motives for the crime are never satisfactorily clarified. Sherlock speculates about what may have happened but the episode closes in an unusual way, that is, without a final confrontation between Kleinfelter and the detective. The confession which occurs in the denouement is related second-hand, through press reportage. In fact, he remains an absent presence throughout most of the episode. In addition to murder and in response to it, Kleinfelter turns to blackmailing the US government for his freedom. He leverages the lives of fourteen American operatives undercover overseas by threatening to release their identities to the 
world. Finally, this episode is important to a discussion of the interplay between public and private for its subplot, which focuses on Sherlock's and Joan's private lives. Joan sets up an online dating profile, which is hacked by Everyone. Sherlock reveals he has been receiving letters from Jamie Moriarty in prison. At the very end of the episode and in the first nod to the original point of view of Doyle's stories, Joan privately contemplates writing her own version of their investigations entitled "The Casebook of Sherlock Holmes." $" 139$

Sherlock and Joan's involvement in the investigation of this episode is complicated. They are hired by Mr. Mueller of Brussels, but both Joan and Sherlock have reservations about taking the case. Joan expresses astonishment that Sherlock accepts it. Joan's reservations are about Kleinfelter while Sherlock's are about Mueller. “Sounds like aiding and abetting a fugitive" she says after Mueller leaves. As he then proceeds to explain to Joan, they have only agreed to take the case in order to put Mueller at ease so that they might investigate his ulterior motives in apprehending Kleinfelter. Mr. Mueller claims to represent a consortium of like-minded citizens" who "are concerned about $\mathrm{Mr}$. Kleinfelter's safety." This initial meeting foregrounds the notoriety Kleinfelter has achieved in such a short time period as Mueller passes a magazine with his image on the cover to Sherlock with "Kleinfelter inspires wave of online hacking" printed across the bottom (IMAGE 4-10). Later in the episode, a frustrated Sherlock argues that Kleinfelter shouldn't be hard to find since he is "on the front of every bloody newspaper." To emphasize this point, Marcus Bell then reaches over and picks up a copy of a newspaper called "Village Dispatch" with Ezra's picture and a headline reading "The Man Behind

\footnotetext{
139 The title of the final collection of twelve Sherlock Holmes stories by Arthur Conan Doyle, serially published between 1921 and 1927.
} 


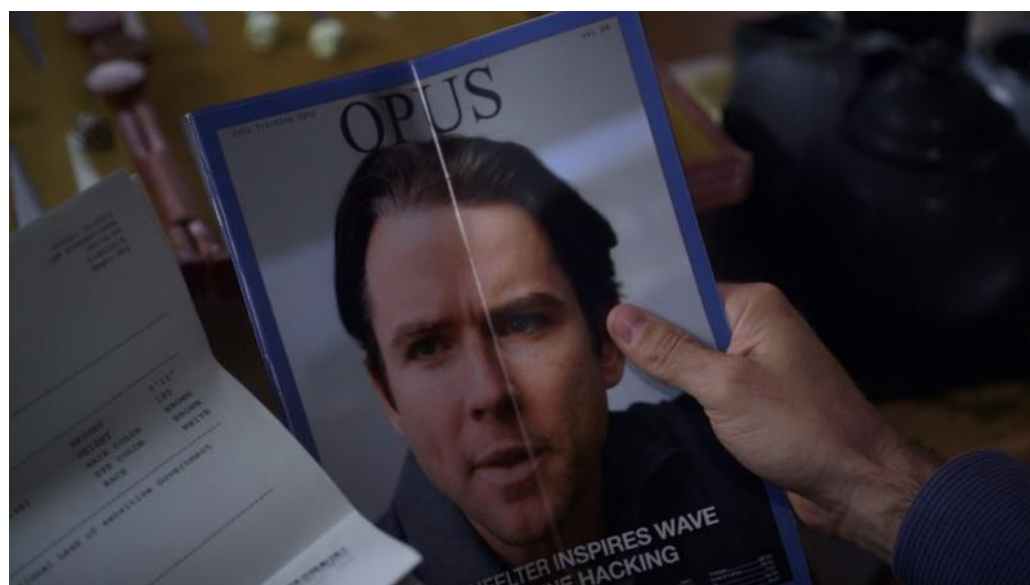

IMAGE 4-10: Kleinfelter in the press (Elementary 2:3) the Leak" across the front page. After the meeting, Sherlock takes advantage of a previous favor and sends a photo of Mueller discreetly snapped on his cell camera during the conversation to the developer of some facial recognition software. Minutes later his suspicions are proved correct as he tells Joan, "Yep, there are no recent photos of anyone matching our man on public record. But the orbital ridge doesn't lie. I give you Elliot Honeycutt, as he looked when he entered Officers' Candidate School in 1975." It is then revealed that Honeycutt is the vice president of corporate counterintelligence at Redding Enterprises, the same CIA contracted company where Kleinfelter worked, until recently. This is a unique set of circumstances. Sherlock and Joan take a case with a client they don't trust and possibly want to work against from the outset. The scene ends with Sherlock's clarification that Honeycutt "is not looking to bring Ezra Kleinfelter to justice. He's looking to eliminate him." The opening title sequence follows after these words and the audience is given a moment to conclude that Honeycutt's motivations are clearly not condoned by the detective and puzzled about how this case departs from the usual formula. Will Kleinfelter become the new client? Are Joan and Sherlock going to work against Honeycutt to save him from the government and ensure his safe extraction?

Thankfully Joan voices the audience's confusion in the following scene. She has started researching Kleinfelter's online presence by paying a visit to his blog. She 
questions Sherlock on their position in the case in light of their client's deception about his identity and motives:

JOAN. Hey, we never talked about what we're going to do with him. SHERLOCK. We are going to gather data on him, and then we're going to use that data to extrapolate his current whereabouts.

JOAN. No, I'm talking about after that. I mean, Ezra exposed some pretty terrible stuff. Some people think he's a hero.

SHERLOCK. Yet some would like to see him hung from the nearest yardarm. You're asking where I stand? I'm fairly certain that he doesn't deserve to be stalked and possibly executed by his former employers.

Sherlock's response is evasive. He clearly wants to foil the government's "nefarious" plans and Honeycutt (his supposed client). His repetition of this adjective is pointed out by a frustrated Joan, 'I'm not arguing that [Mueller's] a good guy. Can you just stop saying 'nefarious'? That's like fifteen times in the last ten minutes." On the other hand, Sherlock does not seem to condone Kleinfelter's actions or even respect him as an individual.

Before Joan asks what they will do with the fugitive once they find him, both Joan and Sherlock take potshots at Kleinfelter. Perusing the blog entries Joan jokes that "most of Ezra's thoughts on a broken world have to do with how he can't get a date with his neighbor." Expecting to find serious discussion of government abuses and political commentary, Joan's comment seems to belittle Kleinfelter's whistleblowing activities and cast suspicion on his motivations. At worst, Kleinfelter is a womanizer and, at the least, isn't capable of keeping things professional in his relationships with women. It is insinuated that he has romantic or sexual relationships with both Celia Carroll and Vanessa Hiskie, the two women aiding him. Later in the episode, when Sherlock ties Kleinfelter to the journalist Celia Carroll, Joan insinuates that his interest was more than professional: "Oh. Well, she looks like that," turning the computer screen to show an 
online photo of Carroll. This is followed up in the line of questioning Sherlock takes when they meet her. Celia denies any romantic relationship or even further communications with Kleinfelter. Joan thinks she is lying but does not make clear about which part. Later, Sherlock also explains the motives behind Vanessa Hiskie's murder in terms of Kleinfelter's sexual appetite. One of the episode's preoccupations, then, is the relationship between Kleinfelter's public and private identities.

Kleinfelter also quotes Ayn Rand heavily in the blog. Sherlock derisively retorts that Ayn Rand is "philosopher-in-chief to the intellectually bankrupt." In addition, Celia reveals that Kleinfelter had originally planned to leave the country before she published but was forced into hiding when his employer, Redding, discovered he was downloading classified files. Both Sherlock's comment and the failure to hide his downloading activities from Redding represent him as lacking the intellectual prowess to outmaneuver those he is up against. Snowden's whistleblowing disclosures, in contrast, were marked by patience and cautious planning. He refused to talk to Glenn Greenwald or Laura Poitras until they had first installed encryption software that would ensure the privacy of their communications. In "How Edward Snowden Changed Journalism," Steven Coll cites Snowden's insistence on private and secure communications with the press as crucial to the successful publication of the leaked information: "the steps he took to protect his data and his communications with journalists made it possible for The Guardian and The Post to publish their initial stories and bring Snowden to global attention." Coll goes even further to argue that through this emphasis on secure information exchange with the press, Snowden "has influenced journalistic practice for the better by his example as a source." In other words, Snowden's impact on journalism 
has been positive and one specifically marked for the strategic planning and foresight which it entailed. Alternatively, Kleinfelter is established as a character who seems to think he is smarter than he proves to be. Aside from this conversation and Sherlock's later comment to the authorities that they are hindering him from his "pursuit of an actual enemy of your state," the episode contains no real reflections on whistleblowing or the underlying catalyst for such an act. As Katie Kulzick writes in her blog on the episode, "After the teaser, it's a surprise to get so little time with him [Christian Campbell who plays Kleinfelter], and so little discussion or examination of Joan's and especially Sherlock's thoughts on him." Considering Sherlock's usual position of siding with an underdog, his typical bias against the powerful, and usually opinionated personality, Elementary's refusal to provide Sherlock with a clear perspective is puzzling to say the least.

The most insight into Kleinfelter and his possible motivations is offered in the opening voiceover. The episode begins by panning down the side of some New York skyscrapers to a street corner where a taxi pulls up. In voiceover, Kleinfelter reads the latest message he has been composing on his tablet:

I act of sound mind and without remorse. The word traitor will, no doubt, be used, but who is the traitor here? Who arrogates the power to spy on the earth and merely shrugs their shoulders when they are caught red-handed? Who took an oath to defend the US constitution, only to feed the invisible beast of secret law devouring it alive from the inside out? It is our government that is the traitor. Those in power have declared war on whistleblowers. I can assure you it's a battle they are going to lose.

It's weird to think that everyone on the street...everyone in this city...soon they're gonna want to know: Who is Ezra Kleinfelter?

What kind of man puts his country's secrets out there for anybody to read? 
The audience is provided with a shot of the tablet as Kleinfelter types the words he is now speaking. The shot of the tablet screen is brief. These opening words are the closest the episode comes to providing a rationale for Kleinfelter's actions but they appear at the very beginning of the episode and are quickly over and forgotten.

The first impression of this passage is the defensive tone of the prose. Kleinfelter is already worried about how his story will be told and the weight of public opinion. His focus is on his own personal identity and how people will think of him. Traitor shows up in the entry but it is not balanced by the possibility of heroism. The question has shifted from "is he a traitor or hero?" to "is he a traitor or not?" Or, alternatively, "who is the traitor: the whistleblower or the government?"

Furthermore, Snowden's decision to not conceal his identity was unique to whistleblowers, who usually attempt to remain anonymous, at least for as long as possible. When questioned about his decision to come forward with his own identity, Snowden explained how the government will use the press to frame individuals as enemies who go public with such information: "That falls to individual citizens but they're typically maligned and it becomes a thing of 'these people are against the country. They're against the government.' But I'm not." From the tablet entry, it seems clear that Kleinfelter, like Snowden, has decided to not remain anonymous but this decision is not given any context as a brave move motivated by the public perception of the act and agent.

Kleinfelter is represented as pretentious and self-aggrandizing. For instance, his question, "Who took an oath to defend the US constitution, only to feed the invisible beast of secret law devouring it alive from the inside out?" is cryptic and convoluted. 
What is "the invisible beast of secret law"? It's possible that the line is meant to evoke

Prism. Prism was a covert program of collaboration between the government and software companies over the requisitioning of user data which was exposed by Snowden's documents:

Secret courts were compelling telecoms providers to hand over data. What's more, pretty much all of Silicon Valley was involved with the NSA, Snowden said - Google, Microsoft, Facebook, even Steve Jobs's Apple. The NSA claimed it had "direct access" to the tech giants' servers. (Luke Harding)

If the episode is meant to evoke this context, it is a veiled and too brief reference which is likely lost on most viewers. Furthermore, Kleinfelter says, "It's weird to think that everyone on the street...everyone in this city...soon they're gonna want to know: Who is Ezra Kleinfelter?" It appears Kleinfelter is, at the least, preoccupied with fame and, at worst, in direct pursuit of it. In contrast, Snowden de-emphasized his individuality:

I'm no different from anybody else. I don't have special skills. I'm just another guy who sits there day to day in the office watching what's happening and goes "this is something that is not our place to decide. The public needs to decide whether these programs and policies are right or wrong."

While both Snowden and Kleinfelter are focused on the public and their reaction to the information they will reveal, Kleinfelter seems more focused on his own personal identity and how this will affect his life.

Kleinfelter's tone is cocky and pugnacious as evinced by his remark that "Those in power have declared war on whistleblowers. I can assure you it's a battle they are going to lose." The episode is framed by these opening words on the tablet. Although much of the audience will miss or forget this entry by the conclusion of the episode, it serves to orient the viewer to what kind of character Kleinfelter is and it is the only real 
glimpse into his motivations that is provided. Kleinfelter's taunt is at complete odds with Snowden's sobering words when asked about possible government retaliation. He said, "You can't come forward against the world's most powerful intelligence agencies and be completely free from risk because they're such powerful adversaries that no one can meaningfully oppose them. If they want to get you, they'll get you in time." Snowden represents himself as a man who does not underestimate the US government nor does he seem to antagonize; he seems resigned to the decision he has made in light of the larger public interests at stake.

In the course of the investigation, Joan and Sherlock figure out that Kleinfelter has been in communication with only one news reporter (Celia Carroll) rather than disseminating the leaked information through multiple channels. After surveilling Celia's movements they find their first break in the case. Hector, her security guard, is the means by which the two have been communicating and he is revealed as a member of the "cyber activist" group, Everyone. Sherlock makes use of digital media in a way similar to the detective's use of newspaper advertisements in the original. In this investigation, Sherlock stays up all night in a chat room (Jamaica Quay) frequented by Everyone in order to gather evidence from the group and make contacts. The next morning Sherlock and Joan are victims of cyber-hacking on a large scale, especially Joan as her new dating profile on TrueRomantix is hacked. Sherlock uses this as a teaching moment and explains that Joan should try to keep "a discreet digital footprint" like him, to avoid falling prey to digital attacks. A recurrent theme in the show is the vulnerable position one puts themselves in by revealing private information online. Even signing user agreements for applications can wind up providing unexpected evidence, as in "Terra Pericolosa" $(3: 6)$ 
when Margaret Bray agrees to provide her fingerprints to a travel app. But Sherlock also falls prey to Everyone when they plant false information (four plans to assassinate the US president) by spoofing his IP address. The secret service interrogates him and he reveals that he is pursuing Kleinfelter, whom he describes as "an actual enemy of your state" in contradistinction to himself (whom they are wasting their time interrogating).

The real significance of the episode to the larger story arcs of the show is the introduction of Everyone. This significance is signaled in the episode's title and also in the opening lines of Kleinfelter's voiceover. He repeats "everyone" twice in the message ("everyone on the street...everyone in this city"), which evokes the community and their forthcoming response. In spite of the initial animosity between Joan and Sherlock and Everyone, the detectives form a working relationship with the hacktivists in succeeding episodes. Everyone has almost become a part of the detective's "Irregulars." In "The Many Mouths of Aaron Colville" (2:19) Sherlock enlists their help to solve a murder and in "You've Got Me, Who's Got You" (4:17) Sherlock reveals he has just helped Everyone "out of a spot of bother with the NSA." Everyone is often used as a source of comedic relief as their payment is public humiliation. At the end of "We are Everyone" Sherlock admits, "[I] might have sent them a photograph of myself with a shoe on my head to hasten the reconciliation." In "The Many Mouths of Aaron Colville," Sherlock is asked to don a pink ball gown and sing "Let It Go" from Disney's Frozen, which unfortunately occurs off-screen. Everyone feeds on public shame. Finally, in a nod to Holmes's manipulation of the press in the original, Joan tricks a culprit into revealing his true nature while Everyone watches via teleconferencing in the aforementioned Brownstone room filled with screens (IMAGE 4-11). The underlying message seems 


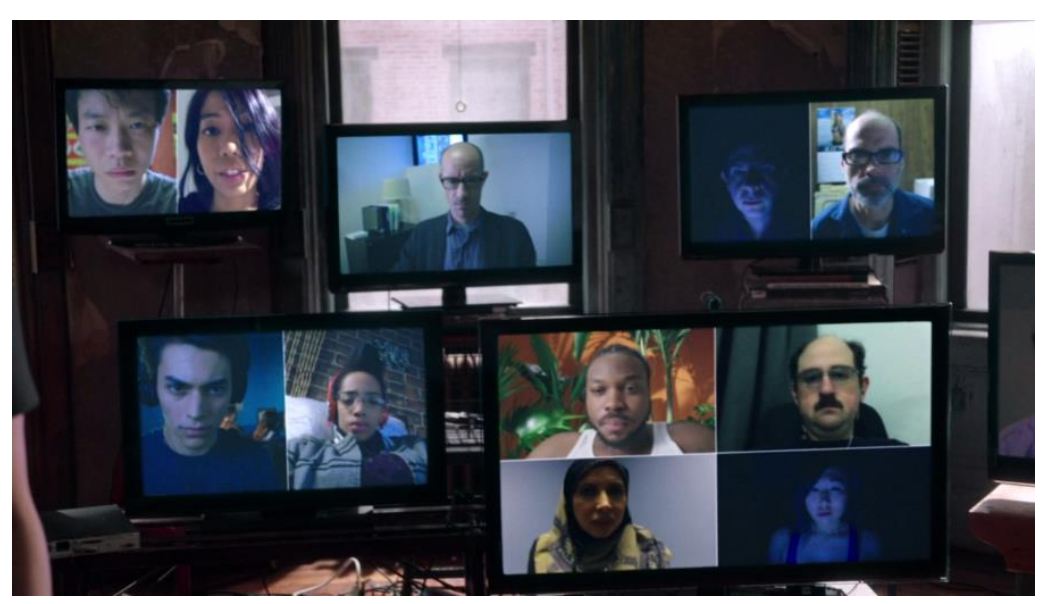

IMAGE 4-11: Everyone via chat as Tim Sherrington threatens Joan with violence (Elementary 2:24) clear: Sherlock is not on the side of the US government unilaterally and he is not de facto on the side of the individual looking to foil the government. Sherlock is on the side of "everyone,"

of the people, of the individual citizen. Kleinfelter ceased to be a part of everyone in his criminal activities but this leaves the remaining question: does Sherlock see Kleinfelter's initial action - the publication of the government files - as whistleblowing or espionage, as a crime or a just act?

The criminalization of Kleinfelter resolves Sherlock's and Joan's ambiguous positioning in the investigation. Several viewers connected this move in the episode to a fusion of Kleinfelter's story with that of Julian Assange: "So now we've overlapped with Julian Assange of Wikileaks fame. Instead of an alleged rape in Scandinavian climes, this is a possible murder by our elusive butterfly of chaos" (David Marshall). This mashup makes sense given the publicity of both but the effect of criminalizing Kleinfelter is to stifle other conversations about the morality of revealing secreted government abuses. After eventually tracking him to Vanessa Hiskie, the detectives arrive at her apartment only to find her dead body. Sherlock explains "There are skin fragments beneath her fingernails. I'm confident those will yield the attacker's DNA." Gregson voices the viewer's confusion over Kleinfelter's motivations for the murder: "The whole world's 
looking for this guy, she's willing to put him up and he kills her?" Sherlock explains that the murder wasn't premeditated, "No, something went wrong between them. Most likely a spurned romantic overture, yes. Kleinfelter grew insistent, Ms. Hiskie resisted...But we needn't have a Socratic dialogue, Captain, 'cause we have DNA." Sherlock's refusal to get to the bottom of Hiskie's murder in this scene is puzzling. Normally, he is the first to question assumptions and explain inconsistencies. This confusion is dispelled in the conclusion in which he "makes certain" (through Joan's assistance) of Kleinfelter's culpability. Marcus Bell explains to Joan, Sherlock, and Gregson that they do not have any DNA on file for Kleinfelter since he "doesn't have any priors" and while "He was fingerprinted for his security clearance, $[\ldots]$ he doesn't have a DNA sample on file. In spite of his earlier reservations about motive, the scene ends with Gregson suggesting, "Let's get word out that Kleinfelter is a person of interest in a homicide." The evidence connecting Kleinfelter to Hiskie's murder is circumstantial and the lack of DNA evidence is sidelined in pursuit of finding a lead on his new whereabouts. Joan eventually steals Kleinfelter's watch as she emphatically bluffs to him "It doesn't matter where you go, we know you killed Vanessa Hiskie and we'll prove it." The irony is that she is gathering the proof she's talking about as she makes this statement. The DNA on the watch, despite its illegal acquisition, connects him to the murder in the episode's conclusion.

What is the effect of criminalizing the whistleblower in this episode? As one poster remarks on the r/Elementary ${ }^{140}$ discussion of the episode, "we have a thinly disguised Snowden made unquestionably villainous by the inevitable murder" (tedtutors). And as Katie Kulzick writes, "While changing up the narrative with a murder puts the

\footnotetext{
${ }^{140}$ The Reddit discussion board dedicated to the television show.
} 
episode more squarely in the show's usual format, it also takes away any moral murkiness." Whistleblowing is morally ambiguous, as is enunciated at the beginning of the episode: is Kleinfelter a traitor to the US or not? In making Kleinfelter a murderer, this ambiguity is eroded and Sherlock is not aligned with this character or his actions. After Vanessa Hiskie's murder, it becomes clear that Sherlock cannot help Kleinfelter to safety; he must face justice for this crime. Sherlock's relationship to Honeycutt, and by association the US government, however, is still unresolved.

In a strange turn of events, the US government becomes the victim of blackmail and Sherlock works with Honeycutt to save American lives. After some online research in Jamaica Quay frequented by members of Everyone, Sherlock alights on a name: Darragh O'Connor, a billionaire software developer. Sherlock determines O'Connor is the most likely person to help Kleinfelter flee the country since he is a known advocate for freedom of information and owns a private jet. When Sherlock and the authorities arrive to arrest him, Kleinfelter resorts to another crime to elude apprehension, blackmail:

KLEINFELTER. You people are persistent, I'll give you that. But I'm still getting on this plane, and I'm flying to Caracas.

BELL. I can tell you two things wrong with that sentence.

KLEINFELTER. Arrest me and fourteen innocent men and women will lose their lives.

Once again, Kleinfelter is represented as confident, audacious, and primarily concerned with saving his own life. In order to secure his own freedom, Kleinfelter turns to blackmailing the government with the classified information he has at his disposal. When Snowden was asked how he might have used his security clearance differently if his motivation had truly been to harm or work against the US government, he mentions his knowledge of intelligence assets overseas: "I had access to, you know, the full rosters of 
everyone working in the NSA, the entire intelligence community and undercover assets all around the world, the locations of every station we have, what their missions are and so forth." While Snowden explains how he could have used this information against the government and didn't, Kleinfelter does leverage this knowledge in pursuit of his own freedom.

After Kleinfelter's daring move at the airport, Sherlock pays a visit to Honeycutt in an attempt to "give our client a status update," save the lives of the fourteen government agents, and apprehend the whistleblower turned blackmailer. Sherlock summarizes the recent developments:

Ezra Kleinfelter, as we speak, is on his way to Venezuela. It seems he will escape justice and whatever fate you had in mind for him. We can tie him to the murder of Vanessa Hiskie, but if we do, he will release the contents of several stolen files. They contain the names of fourteen clandestine operatives.

Sherlock goes on to explain that he has "no intention of letting Ezra Kleinfelter get away with murder" and retorts, with a rather cliché remark, that he always gets his man. Honeycutt seems incredulous that the detective would sacrifice so many innocent lives in pursuit of Kleinfelter. Sherlock bets that Honeycutt will do the right thing based on his past service record: “you know what it means to serve. You won't leave those men and women to their fates." The conversation between the two, again, sidetracks the morality of whistleblowing. Instead, the emphasis is on the privatization of government intelligence.

Honeycutt works for a government contractor, Redding Enterprises, and must serve their interests; he is beholden to a board of directors. The juxtaposition is between the government and the corporation, rather than the government and the public whose 
interests it is supposed to serve. Honeycutt does follow through and warns the government of the identities of the undercover foreign operatives. As David Marshall claims, "the ultimate nail in the coffin of the supposed mystery element is the decision to make the whistleblower genuinely 'evil' and to show the CIA as placing more value on human life than the obsessive preservation of every last secret." Honeycutt, like Mycroft in Sherlock, becomes a stand-in for the government in the episode. While he is introduced from the outset as nefarious and suspicious, this understanding of his character and the greater entity represented is reversed by the conclusion. Honeycutt is humanized in this scene with Sherlock. His beneficence is unexpected and leaves a more lasting impression on the viewer than Kleinfelter's diatribe at the opening of the episode.

In the next scene, the TV news report of Kleinfelter's arrest takes the place of the usual denouement. Normally each episode concludes with Sherlock and Joan apprehending the suspect. The perpetrator, events leading up to the crime, and the motive are revealed through a combination of confession and explication by those involved in the investigation (Joan, Sherlock, Marcus Bell, Kitty, and Captain Gregson). In this episode, however, the audience is removed from the direct action of the arrest and the TV report takes the place of our narrative in the first degree signaled by the news coverage which takes over the screen in another example of the video "look." Next, the audience is provided with a shot reverse shot of Sherlock watching the television broadcast in his room in the Brownstone with multiple TV screens (IMAGE 4-12). Although the arrest is a consequence of the detective's planning, Sherlock's serious expression seems to belie this triumphant moment. A reporter provides a summary of the arrest and Kleinfelter's fate: 
This was the scene at Miami National Airport, as federal agents took Ezra Kleinfelter into custody early this morning. Federal sources say that Kleinfelter confessed to the murder of Vanessa Hiskie in exchange for a guarantee that he won't face capital punishment for espionage. The former assistant... [Joan walks in and interrupts]

Kleinfelter's narrative in the press has changed substantially. Throughout the episode,

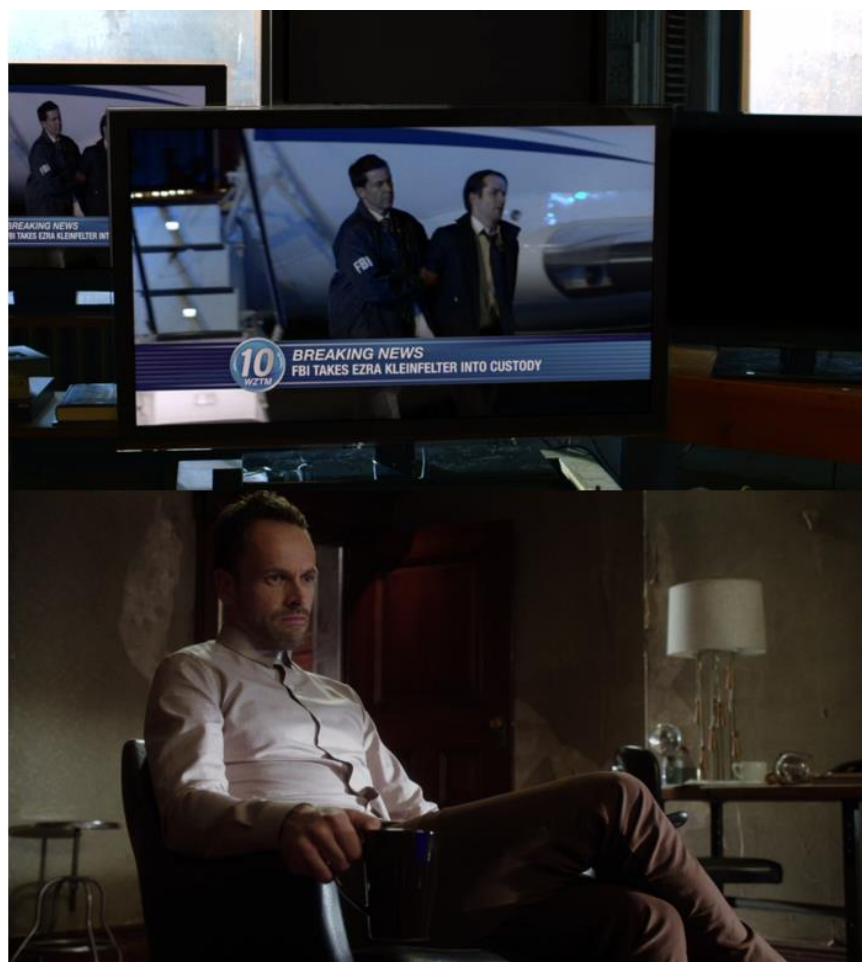

Kleinfelter has been defined by his public presence. When he is first mentioned in the beginning, Sherlock grumbles about the "incessant news coverage" of his story. In the other publications mentioned, he has been heralded as the progenitor of a grass roots movement against unchecked government and corporate power.

IMAGE 4-12: Sherlock watches Ezra Kleinfelter's arrest on the news (Elementary 2:3)

Here, the press re-contextualizes his story through the charge of espionage. What started out as a potentially liberating act against secret abuses of power has become another crime alongside murder and blackmail. Even Everyone has abandoned him as Sherlock remarks "Ezra's confession [to Hiskie's murder] has dampened Everyone's enthusiasm for him.” After learning of the murder and Kleinfelter's possible culpability, earlier in the episode members of Everyone were incredulous and suspected he had been framed for the crime.

Sherlock weighs in to this debate (taking place in the chatroom, Jamaica Quay) over a possible framing of Kleinfelter, “Are governments capable of evil? Yes, of course 
they are. All institutions are...but they're more capable of incompetence." Sherlock's pronouncement is later validated when the detectives find that Kleinfelter has been hiding out in an old Office of Civil Defense bunker which was overlooked by the government. As Sherlock explains, "They must have just simply lost track of it." This lends credence to Sherlock's substitution of the evil government for the incompetent one. But viewers, like Everyone (in the episode), were slow to accept this conclusion. As RefuseBit commented on r/Elementary:

I really enjoyed the episode, but I found it incredibly hard to believe that the hacker collective simply let Sherlock off the hook because the Snowden character was charged with murder. They would never believe that he wasn't framed (not sure I would either).

Kleinfelter's culpability rests entirely on the DNA evidence. On the one hand, the fact that Kleinfelter's DNA sample is not available to test against the skin cells found under Hiskie's nails represents another hurdle the detectives must overcome in apprehending their suspect. On the other hand, the government may have forestalled access to the DNA sample in order to buy more time in framing their suspect. The DNA testing and results are not shown or discussed in the episode. The viewer is left to fill in the blanks and assume that the DNA was a match. Furthermore, the illegal acquisition of the DNA sample (Joan stealing Ezra's watch) seems justified by the end result that pronounces him guilty.

The most important effect of "We are Everyone" classifying the whistleblower character as a criminal is that it silences a deeper discussion of the ethics of such acts of revelation and an examination of the nature of power in contemporary society. One fan 
expresses disappointment at the lack of Sherlock's reflection on whistleblowing by

alluding to the Mycroft character:

Sherlock Holmes's thoughts on the leaking of classified information would actually be very interesting, particularly given his touchy relationship with Mycroft, keeper of state secrets and orchestrator of many nefarious scheme[s] (at least in the novels). It's a shame Elementary takes the simplified, safe route instead. (Kulzick)

This is especially interesting in light of the move made in Sherlock to enhance the role of Mycroft and the denouement of "His Last Vow" that justifies Sherlock's illegal murder of Magnussen in light of the threat he posed to national security. One of the elements lost in scapegoating Kleinfelter in the episode is Snowden's perceived anxiety that motivated him to publish the classified materials:

GREENWALD. Why should people care about surveillance? SNOWDEN. Because even if you're not doing anything wrong, you're being watched and recorded and the storage capability of these systems increases every year consistently by orders of magnitude. To where it's getting to the point you don't have to have done anything wrong. You simply have to eventually fall under suspicion from somebody, even by a wrong call, and then they can use the system to go back in time and scrutinize every decision you've ever made, every friend you've ever discussed something with, and attack you on that basis to sort of derive suspicion from an innocent life and paint anyone in the context of a wrongdoer. [emphasis added]

Snowden's anxiety seems to be that the government has a level of omniscience and authority over the details of our lives that is an abuse of power. In storing all of this communication data, the NSA is headed toward what he labels at the close of the interview "turnkey tyranny." Massive collections of aggregated information give them control over an individual citizen's narrative. According to Snowden, the justification for this acquisition of information is national security:

NSA, and the intelligence community, in general, is focused on getting intelligence wherever it can, by any means possible, that it believes on the 
grounds of self-certification, that they serve the national interest. Originally we saw that focus very narrowly tailored as foreign intelligence gathered overseas. Now, increasingly, we see that it's happening domestically and to do that they, the NSA specifically, targets the communications of everyone. [emphasis added]

The problem, for Snowden, is that the government keeps extending its powers and reach. The most blatant example of this overreach is the movement from collecting digital information overseas to domestic surveillance. It is important to consider that Snowden was a contractor for the NSA while the Kleinfelter character works for the CIA. This change from a domestic to a foreign intelligence agency is important. It is another aspect of the episode that sidetracks a discussion of the actual contents of the Snowden story: the US government's pervasive domestic surveillance.

A connection can be made to the imperial context of Doyle's original stories. In the nineteenth century, "Making a distinction between the epistemologies of domestic policing and imperial administration enabled a reassuring compartmentalization of what was in actuality threateningly interdependent" (Reitz xvii). In other words, foreign and domestic policing strategies are often considered separate and different when in reality they mutually inform one another. During British imperialism and concurrent with the rise of the Sherlock Holmes stories, tactics of surveillance and control used in the colonies were increasingly imported back to the metropole to ensure order and prevent crime domestically. This is the same sort of movement being described by Snowden: the international threat of terrorism has justified foreign surveillance but now those same surveillance tactics are being used within national borders as well.

The refusal of "We are Everyone" to provide any significant reflection on pervasive domestic surveillance by the American government is interesting in light of the 
thematic interest of later episodes. It is, in fact, directly in line with the argument Sherlock makes about the private sector tech company, Zooss, in "A View from Olympus" (3:18). Zooss (pronounced "Zeus," like the Greek god) has developed a rideshare application, which collects and stores the GPS movements of its users. One of their employees uses the data to find, track, and blackmail users. After seeing the

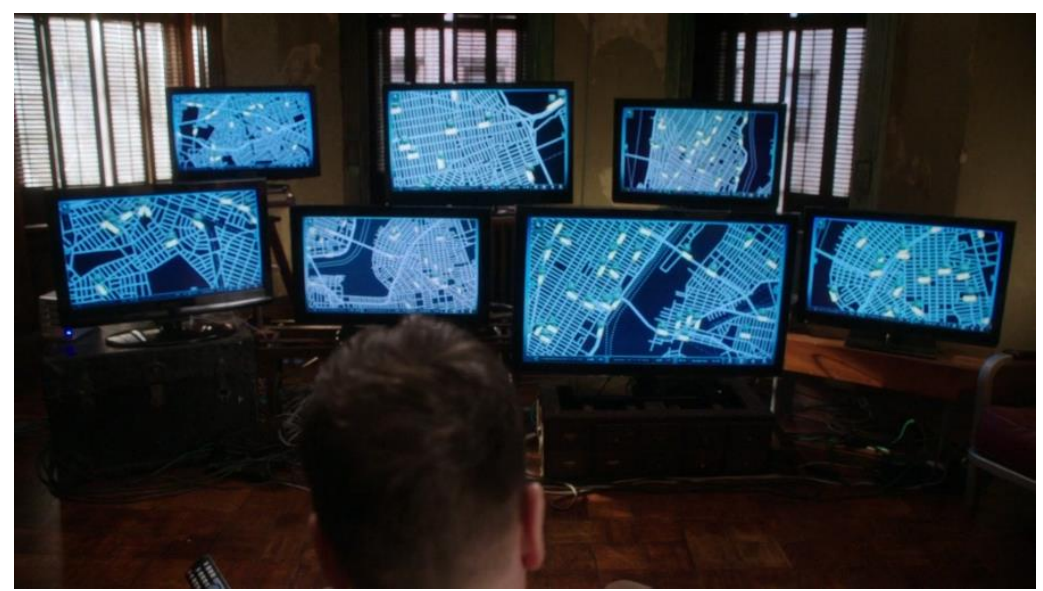

IMAGE 4-13: Sherlock going over Zooss's GPS tracking information on its users. (Elementary 3:18)

real-time map of their data (IMAGE 4-13), Sherlock berates them for attaining a "level of omniscience that's traditionally ascribed to God and Father Christmas." The clear implication is that no one should have control of that much knowledge because someone will abuse it. Thematically, this is directly in line with Snowden's rationale for coming forward with the classified materials. One of the major revelations from the Snowden material was Prism, a program of collaboration between the US government and nine US tech companies: Microsoft, Google, Yahoo!, Facebook, PalTalk, Youtube, Skype, AOL, and Apple. Finally, Sherlock seems to chide both Zooss and the viewers' naiveté in willfully agreeing to user agreements of this kind. He sardonically remarks, "We are Big Brother incarnate, but trust us because our motives are purely financial." This allusion to domestic government surveillance, "Big Brother," is interesting in light of the show's earlier reluctance to adapt Snowden's motivations for whistleblowing and present Kleinfelter as a terrorist and murderer. Dennis Porter claims that "The detective story 
promises the 'heroization' of the agent of surveillance in his struggle against threats from within" (125) and perhaps this is why Elementary and Sherlock, while featuring technologies of surveillance, resist a critique of these forms of power.

\section{CONCLUSION}

The conclusion of "We are Everyone" further illustrates the considerations set forth at the beginning of this chapter: the relationship between form and content in the process of making meaning in Sherlock Holmes narratives. The episode enunciates the ways in which the formal device of metanarrative may be used to highlight content elements such as: the construction of identity through narration, the epistemological role of the media in society, and the dichotomy of public and private knowledge. Joan, alone in her bedroom at the Brownstone, types on the laptop before her "The Casebook of Sherlock Holmes." She then deletes "The Casebook of" which leaves only "Sherlock Holmes" remaining. It seems to signal that Joan is contemplating her partner's identity and their relationship. There is no other text in the document yet, she has only typed these few words. This is the first nod to the original point of view of Doyle's stories: the narration of the investigations by Watson. Fans of the show were forced to wait a whole season before another reference was made to Joan's narratives. In "Rip Off" (3:5), the casebook once again becomes a topic of discussion. At the conclusion of season two Joan moved out of the Brownstone and Sherlock headed off to London. At the beginning of season three, Sherlock returns to New York City with a protégé, Kitty. In "Rip Off" Sherlock finds a 474 page manuscript in the recycle bin of a laptop he had loaned Joan. This manuscript is the same document Joan began at the conclusion of "We are Everyone.” 
In The Sign of Four, Holmes criticizes Watson's narratives by explaining they have been "tinge[d] with romanticism" (SIGN 95). The careful reader of Doyle's stories will understand Watson idealizes Holmes, sometimes by omission since Holmes freely admits that many of his investigations "were complete failures, and as such will hardly bear narrating" (THOR 1602). Sherlock's reaction to Joan's manuscript is substantially different from this original context. In "Rip Off" Kitty recognizes that he is more irritable than usual and Sherlock explains, "If you must know, I am raw from a recent violation. It's come to my attention that my last protégée was engaged in literary espionage." Sherlock calls Joan's memoirs "espionage" because he feels that his privacy has been violated. Later in the episode, he reveals that he has not read past the first page. In spite of his excuse that he hasn't "had the time," Kitty sees past this and provides the real reason:

I know why you haven't read it yet, you know. Watson's book. [...] You're afraid. [Of] her... assessment, her judgment. [...] You didn't know about her writing. You don't know why she kept it a secret. Maybe the answers lie within. But then, so may other surprises.

Sherlock is understandably upset that Joan has been secretive about her literary pursuits. In Doyle's stories, Watson freely shares the narratives with Holmes. In Sherlock, John's blog is read by Sherlock, Scotland Yard, and the public. Elementary, however, problematizes this act of narration. Sherlock is anxious about Joan's assessment of him. It reveals an anxiety about how our story will be told and how our life may be recontextualized by and for others.

In season four, Sherlock and Joan's stories are appropriated for profit by Joan's stepfather, Henry Watson. In "Miss Taken" (4:7), Joan learns that a novel, The Heart 
Bled Blue, published by Grover Ogden is a fictional retelling of Joan and Sherlock's partnership. This time, however, Sherlock remains unfazed by the revelation that his life has been co-opted for fiction and Joan is the one outraged at the violation of privacy:

HENRY. I was honoring you. The choices you make, the work you do, I think it's wonderful.

JOAN. Really? So that's why you didn't ask my permission. That's why you used a pseudonym. Because you knew how honored I would be [...] It's ridiculous. Sherlock and I do not run around with guns and we don't get into Kung Fu fights with criminals and we sure as hell do not sleep together.

Like Sherlock, Joan's feelings of betrayal stem from the steps Henry took to conceal the narrative from her. And in an interesting reversal from the original, Joan is berating her father for his embellishments of the investigations. Unlike Henry, Joan does not publish her casebook and even dumps it in the recycle bin of her computer. She does not even tell Sherlock she has been writing it. After Joan vents her outrage at what she interprets as a betrayal, Henry asks if Sherlock has read the book. Joan explains that she has no intention of telling him about it: "He is the most private person that I know. He would freak if he found out." But as Joan learns later in the episode, Sherlock has known about its existence longer than she has. In contradistinction to his reaction to her casebook, Sherlock is not bothered by Henry's novel at all:

It's hardly the first time I've inspired a writer, Watson. I am actually the basis for several fictional characters across various media. It's one of the by-products of my success as a detective. I fascinate; this cannot be helped. You yourself once wrote about me: The Casebook of Sherlock Holmes.

This is a nice intertextual nod to the long history of adaptation of the Sherlock Holmes character, by the character himself. In addition, Sherlock directly compares Henry's book to Joan's manuscript, thereby revealing his knowledge of her narrative act. Before Joan 
can recover from her astonishment that he has read her casebook, he continues to explain his different reactions to each:

I was displeased because you used my real name and you shared my real history. Your father's magnum opus, on the other hand, is the very opposite of real. Look no further than chapter thirty-two, where we make love beneath a footbridge in Central Park.

Sherlock's displeasure with Joan's manuscript is that people may recognize her writing as truth since it is so close to reality. She uses his "real name" and "real history." This is a puzzling critique but logical when examined in light of this chapter's considerations. Sherlock is anxious about the representation of his person and life. Joan has betrayed his trust. She has lived with him and he has allowed her more access to his private thoughts, drives, and perspective on life than anyone else. As Joan points out earlier, Henry and Sherlock barely know each other. This leads back to "We are Everyone."

While Joan types "The Casebook of Sherlock Holmes" on her keyboard, the contents of Jamie Moriarty's letter to Sherlock is read as a voiceover. She says "Is it possible to truly know another person? Is it even a worthwhile pursuit?" Joan's narratives are a betrayal to Sherlock because he fears her understanding of him will not be in line with his own perception of himself. This would either mean that she, like others, does not really know him or, equally frightening, he does not know himself. The Heart Bled Blue is not a frightening read because Sherlock does not expect to find himself in its pages but, rather, a character inspired by his life. In an episode considering the dividing line between public and private selves, perception, and ways of knowing it makes sense that the concluding words would reflect on the ability to probe beneath the public appearance of a person to their private life and the secrets they keep. The anxiety over truly knowing 
or accurately narrating is enunciated through the proliferation of metadiegesis in the form of the press, the crime of blackmail, metatelevisual techniques, and narratives about the detectives themselves. 


\section{REFERENCES}

"The Abominable Bride." Sherlock, created by Mark Gatiss and Steven Moffat, performance by Benedict Cumberbatch and Martin Freeman, season four, episode 0, BBC and PBS, 2016. Amazon Instant Video.

Adams, Guy. Sherlock: The Case Book, BBC Books, 2012.

Adorno, T.W. "How to Look at Television." The Quarterly of Film Radio and Television, vol. 8, no. 3, 1954, pp. 213-235. JSTOR.

Ahmed, Riz. "Typecast as a Terrorist." The Guardian, 15 September 2016, https://www.theguardian.com/world/2016/sep/15/riz-ahmed-typecast-as-aterrorist. Accessed 1 Oct. 2016.

Arnheim, Rudolf. Film as Art, UC Press, 1957.

Asmus Freytag, Rick McGowan, and Ken Whistler. "Unicode Technical Note \#27: Known Anomalies in Unicode Character Names.” Unicode.org, 8 May 2006, http://unicode.org/notes/tn27/. Accessed 22 Nov. 2015.

Bakan, Joel. "The Corporation: The Pathological Pursuit of Profit and Power." Crimes of the Powerful: A Reader, edited by David Whyte, Open UP, 2009, pp. 106-111.

Barnes, Alan. Sherlock Holmes on Screen, Titan Books, 2012.

"Baronet (title)." Encyclopedia Britannica. https://www.britannica.com/topic/baronet. Accessed 29 Oct. 2016.

Batalova, Kate and Jeanne Hooper. "Chinese Immigrants in the United States." Migration Policy Institute, 28 Jan. 2016, http://www.migrationpolicy.org/article/chineseimmigrants-united-states. Accessed 5 Dec. 2015.

Berridge, Virginia. "Chapter 15: The Myth of the Opium Den in Late Victorian England." Opium and the People: Opiate Use and Policy in the 19th and Early 20th Century Britain, Free Association Books, 1998, pp. 195-202.

Bertman, Stephen. 'Kindred Crimes: Poe's 'the Murders in the Rue Morgue' and Doyle's 'The Sign of Four."' The Edgar Allan Poe Review, vol. 15, no. 2, 2014, pp. 205210. Project Muse.

Bhabha, Homi. "The Other Question: Stereotype, Discrimination, and the Discourse of Colonialism." The Location of Culture, Routledge, 1994, pp. 94-120.

Black, Joel. The Aesthetics of Murder: A Study in Romantic and Contemporary Culture. Johns Hopkins UP, 1991. 
Brackett, Marc A. and Peter Salovey. "Emotional Intelligence." Encyclopedia of Social Psychology, edited by Roy F. Baumeister and Kathleen D. Vohs, Sage Publications, 2007, pp. 293-294.

Braudy, Leo. "Rethinking Remakes.” Play It Again, Sam: Retakes on Remakes, edited by Andrew Horton and Stuart Y. McDougal, University of California Press, 1998, pp. 327-334.

Brilliantes, Miriam. “Lucy Liu Puts a New Spin on Sherlock Holmes's Sidekick Watson.” The Wall Street Journal, 29 Aug. 2012, http://blogs.wsj.com/speakeasy/2012/08/29/lucy-liu-puts-a-new-spin-on-sherlockholmess-sidekick-watson/http://blogs.wsj.com/speakeasy/2012/08/29/lucy-liuputs-a-new-spin-on-sherlock-holmess-sidekick-watson/. Accessed 5 Dec. 2015.

Brownson, Charles. The Figure of the Detective: A Literary History and Analysis. McFarland, 2014.

Broyles, Britney. "From Opium Den to Partner-in-Crime...Solving: The Chinese Presence in Sherlock Holmes Adaptations." Textus, vol. 27, no. 2, 2014, pp. 147-168.

---. "Introduction: The Literary, Televisual and Digital Adventures of the Beloved Detective." Sherlock and Transmedia Fandom: Essays on the BBC Series. McFarland, 2012, pp. 9-24.

Chernaik, Warren L. "Mean Streets and English Gardens." The Art of Detective Fiction, edited by Warren L. Chernaik et al., St. Martin's Press, 2000, pp. 104-123.

Chrisholm, Brad. “On-Screen Screens.” Journal of Film and Video, vol. 41, no. 2, 1989, pp. 15-24. JSTOR.

Clowes, Simon. "A Discussion with Creative Director Simon Clowes of Prologue." Interview by Ian Albinson, Art of the Title, 21 May 2013, http://www.artofthetitle.com/title/elementary/. 8 Aug. 2016.

Damasio, Antonio. Descartes' Error: Emotion, Reason, and the Human Brain. Penguin Putnam, 1994.

de Lauretis, Teresa. "Imaging." Alice Doesn't: Feminism, Semiotics, Cinema, Indiana UP, 1984, pp. 37-69.

Deming, Sarah. "The Economic Importance of Indian Opium and Trade with China on Britain's Economy." Economic Working Papers, vol. 25, 2011, pp. 1-17, https://www.whitman.edu/economics/Workingpapers/content/WP_25.pdf. Whitman College.

Dixon, Hayley. "Sherlock Holmes Is Autistic, Leading Charity Claims." The Telegraph, 16 Dec. 2013, http://www.telegraph.co.uk/culture/10521128/Sherlock-Holmes-isautistic-leading-charity-claims.html. Accessed 29 October 2016.

Dover, J.K. Van. "4: 'All Men by Nature Desire to Know': The Metaphysics of the Detective Story." We Must Have Certainty: Four Essays on the Detective Story. Susquehanna UP, 2005, pp. 130-165. 
Doyle, Arthur Conan. The Adventures of Sherlock Holmes and the Memoirs of Sherlock Holmes, edited with annotations by Leslie S. Klinger, vol. I, Norton, 2005. The New Annotated Sherlock Holmes: The Complete Stories.

---. The Return of Sherlock Holmes, His Last Bow, and the Case-Book of Sherlock Holmes, edited with annotations by Leslie S. Klinger, vol. II, Norton, 2005. The New Annotated Sherlock Holmes.

---. The Novels: A Study in Scarlet, The Sign of Four, The Hound of the Baskervilles, and The Valley of Fear, edited with annotations by Leslie S. Klinger, Norton, 2005. The New Annotated Sherlock Holmes.

Elementary, created by Robert Doherty, performance by Lucy Liu, Johnny Lee Miller, Natalie Dormer, and Kristy Wu, season one, CBS, 2013.

--, created by Robert Doherty, performance by Lucy Liu, Johnny Lee Miller, and Christian Campbell, season two, CBS, 2014.

--, created by Robert Doherty, performance by Lucy Liu, Johnny Lee Miller, and Ophelia Lovebond, season three, CBS, 2014.

--, created by Robert Doherty, performance by Lucy Liu, Johnny Lee Miller, and John Noble, season four, CBS, 2015. Amazon Instant Video.

Ellis, Havelock. The Criminal, Scribner's Sons, 1892.

Everage, Laura. "Teapots through the Ages: A Brief History." Fresh Cup: Specialty Coffee and Tea Trade Magazine, vol. December, 2006, https://theteaspot.com/media/wysiwyg/news/storyId-16.pdf. Accessed 1 Oct. 2016.

Faye, Lyndsay. "Prologue: Why Sherlock? Narrator Investment in the BBC Series." Sherlock and Transmedia Fandom: Essays on the BBC Series, edited by Louisa Ellen Stein and Kristina Busse, McFarland, 2012, pp. 1-8.

Frank, Lawrence. Victorian Detective Fiction: The Scientific Investigations of Poe, Dickens and Doyle, Palgrave Macmillan, 2003.

Gilbert, Gerard. "The Elaborate TV Title Sequence Fell out of Favour- but Now It's Back." The Independent, vol. 2016, 4 Sept. 2015, http://www.independent.co.uk/arts-entertainment/tv/features/the-elaborate-tvtitle-sequence-fell-out-of-favour-but-now-it-s-back10482172.htmlhttp://www.independent.co.uk/arts-entertainment/tv/features/theelaborate-tv-title-sequence-fell-out-of-favour-but-now-it-s-back-10482172.html. Accessed 8 Aug. 2016.

Glover, David. "The Writers Who Knew Too Much: Populism and Paradox in Detective Fiction's Golden Age." The Art of Detective Fiction, edited by Warren L. Chernaik et al., St. Martin's Press, 2000, pp. 36-49.

Greenfield, Mat. "We Shouldn't View Sherlock as an Autistic Savant." The Huffington Post, 1 Jul. 2014, http://www.huffingtonpost.co.uk/mat-greenfield/sherlock-notautistic_b_4548520.htmlhttp://www.huffingtonpost.co.uk/matgreenfield/sherlock-not-autistic_b_4548520.html. Accessed 9 Jan. 2016. 
Harding, Luke. "How Edward Snowden Went from Loyal NSA Contractor to Whistleblower." The Guardian, 1 Feb. 2014, https://www.theguardian.com/world/2014/feb/01/edward-snowden-intelligenceleak-nsa-contractorextracthttps://www.theguardian.com/world/2014/feb/01/edward-snowdenintelligence-leak-nsa-contractor-extract. Accessed 19 Jul. 2016.

Harris, Susan Cannon. "Pathological Possibilities: Contagion and Empire in Doyle's Sherlock Holmes Stories." Victorian Literature and Culture, vol. 31, no. 2, 2003, pp. 447-466. JSTOR.

Hirano, Itaru. "The Privileged Visual Sense," translated by Richard Sams, http://www.andreas-kaufmann.com/eng hirano-kaufmann.pdf. Accessed 29 Oct. 2016.

Hodges, Sara D. and Michael W. Myers. "Empathy." Encyclopedia of Social Psychology, edited by Roy F. Baumeister and Kathleen D. Vohs, Sage Publications, 2007, pp. 296-298.

Hodgson, Barbara. Opium: A Portrait of the Heavenly Dream, Chronicle Books, 1999.

Hooper, Kendall. "The Naked and Famous 'Young Blood' Certified Gold." The AU Review, 27 Mar. 2011, http://www.theaureview.com/the-goss/the-naked-andfamous-young-blood-certified-goldhttp://www.theaureview.com/the-goss/thenaked-and-famous-young-blood-certified-gold. Accessed 24 Nov. 2015.

Huard, Michael. “"Elementary' season 2 episode 3 recap: 'we are everyone'.” Neon Tommy- Annenberg Digital News, University of Southern California, 11 Oct. 2013, http://www.neontommy.com/news/2013/10/elementary-season-2-episode3-recap-we-are-everyone. Accessed 19 Jul. 2016.

Hutcheon, Linda. A Theory of Adaptation, 2nd edition, Routledge, 2006.

Ickes, William and Marianne Schmid Mast. "Empathetic Accuracy." Encyclopedia of Social Psychology, edited by Roy F. Baumeister and Kathleen D. Vohs, Sage Publications, 2007, pp. 294-296.

Jann, Rosemary. The Adventures of Sherlock Holmes: Detecting Social Order, Twayne Publishers, 1995.

---. “Sherlock Holmes Codes the Social Body.” ELH, vol. 57, no. 3, 1990, pp. 685-708. JSTOR.

Kim, Kristen Yoonsoo. "\#How I Met Your Racism, Yellowface and Asians on American TV.” Myspace Editorials, 16 Jan. 2014, https://myspace.com/article/2014/01/16/how-i-met-your-mother-apologizes-foryellowface-racism-slapsgiving-episode. Accessed 16 Jan. 2014.

Knox, Ronald A. "Introduction." The Best English Detective Stories of 1928, Liveright, 1929, pp. vii-xxiii.

Kohnen, Anne Kustritz and Melanie E.S. "Decoding the Industrial and Digital City: Visions of Security in Holmes' and Sherlock's London.” Sherlock and 
Transmedia Fandom, edited by Kristina Busse and Louisa Ellen Stein, McFarland, 2012, pp. 85-101.

Konnikova, Maria. Mastermind: How to Think Like Sherlock Holmes, Viking Adult, 2013.

Kracauer, Siegfried. Theory of Film: The Redemption of Physical Reality, Oxford UP, 1960.

Krogman, Wilton Marion. "Sherlock Holmes as Anthropologist." The Scientific Monthly, vol. 80, no. 3, 1955, pp. 155-162.

Kulzick, Katie. “Elementary Ep. 2.03, 'We Are Everyone’ Continues Show’s Strong Sophomore Season." Pop Optiq 12 Oct. 2013, http://www.popoptiq.com/elementary-ep-2-03-we-are-everyone-continues-showsstrong-sophomore-season/. Accessed 19 Jul. 2016.

Lombroso, Cesare. Criminal Man, briefly summarized by Gina Lombroso, G.P. Putnam's Sons, 1911. Archive.org, https://archive.org/details/criminalmanaccor00lomb. Accessed 29 Oct. 2016.

Lozensky, Christopher. "Chinese Early LGBTQ History in the United States." Proud Heritage: People, Issues, and Documents of the LGBT Experience, edited by Chuck Stewart, 3rd edition, ABC-CLIO, LLC, 2015, pp. 113-122.

Lycett, Andrew. The Man Who Created Sherlock Holmes: The Life and Times of Sir Arthur Conan Doyle, Free Press, 2007.

Manovich, Lev. The Language of New Media, MIT Press, 2001.

Marshall, David. "Elementary: Season 2, Episode 3. We Are Everyone (2013).” Thinking about Books, 12 Oct. 2013, https://opionator.wordpress.com/2013/10/12/elementary-season-2-episode-3-weare-everyone-2013/https://opionator.wordpress.com/2013/10/12/elementaryseason-2-episode-3-we-are-everyone-2013/. Accessed 19 Jul. 2016.

Meng, Kevin Yao and Meng. "China October Economic Activity Shows Downward Pressures Persist." Reuters/China Daily, 11 Nov. 2015, http://www.reuters.com/article/us-china-economy-activityidUSKCN0T00G520151111http://www.reuters.com/article/us-china-economyactivity-idUSKCN0T00G520151111. Accessed 22 Nov. 2015.

Messent, Peter. "Authority, Social Anxiety and the Body in Crime Fiction: Patricia Cornwell's Unnatural Exposure." The Art of Detective Fiction, edited by Warren L. Chernaik et al., St. Martin's Press, 2000, pp. 127-137.

Miller, J. Hillis. "Narrative." Critical Terms for Literary Study, Second Edition, edited by Frank Lentricchia and Thomas McLaughlin. University of Chicago Press, 2010, pp. 66-79.

Mitten, Mandi. “Old World Tarantulas.” Animal Corner, https://animalcorner.co.uk/animals/old-world-tarantula-spiders/. Accessed 12 May 2015. 
Moffat, Steven. "Highlights from Crimefest: Creating Sherlock." Sherlockology, 2013 http://sherlockology.tumblr.com/post/52045455826/crimefest-report. Accessed 8 Jan. 2016.

Nünning, Birgit Neumann and Ansgar. "Metanarration and Metafiction." The Living Handbook of Narratology, edited by Peter Hühn et al., Hamburg UP, 2016, http://wikis.sub.uni-hamburg.de/lhn/index.php/Metanarration_and_Metafiction. Accessed 29 Oct. 2016.

O'Brien, James F. The Scientific Sherlock Holmes: Cracking the Case with Science and Forensics, Oxford UP, 2013.

Olson, Scott R. "Meta-Television: Popular Postmodernism.” Critical Studies in Mass Communication, vol. 4, 1987, pp. 284-300.

Pearce, Frank. Crimes of the Powerful: Marxism, Crime and Deviance, Pluto Press, 1976.

---. "Crime and Capitalist Business Corporations." Crimes of the Powerful: A Reader, edited by David Whyte, Open UP, 2009, pp. 112-116.

Poe, Edgar Allan. "The Murders in the Rue Morgue." The Complete Tales and Poems of Edgar Allan Poe, Castle Books, 2002, pp. 117-139.

---. "The Purloined Letter." The Complete Tales and Poems of Edgar Allan Poe, Castle Books, 2002, pp. 185-197.

Porter, Dennis. The Pursuit of Crime: Art and Ideology in Detective Fiction, Yale UP, 1981.

Porter, Rick. "Broadcast Live +7 Ratings, Week 7: 'Elementary' Is Still a Strong DVR Show." TV By the Numbers. http://tvbythenumbers.zap2it.com/dvrratings/broadcast-live-7-ratings-week-7-nov-2-8-2015/. Accessed 25 November 2015.

Poulantzas, Nicos. “On Social Classes.” Poulantzas Reader: Marxism, Law, and the State, Verso, 2008, pp. 186-219.

Reitz, Caroline. Detecting the Nation: Fictions of Detection and the Imperial Venture, Ohio State UP, 2004.

Rixon, Paul. "Sherlock: Critical Reception by the Media." Sherlock and Transmedia Fandom, edited by Kristina Busse and Louisa Ellen Stein, McFarland, 2012, pp. 165-178.

Said, Edward W. Culture and Imperialism, Vintage Books, 1994.

Sherlock, created by Mark Gatiss and Steven Moffat, performance by Benedict Cumberbatch and Martin Freeman, Gemma Chan, Sarah Lam, Mark Gatiss, season one, BBC and PBS, 2010.

---, created by Mark Gatiss and Steven Moffat, performance by Benedict Cumberbatch, Martin Freeman, Mark Gatiss, Andrew Scott, and Laura Pulver, season two, BBC and PBS, 2012.

---, created by Mark Gatiss and Steven Moffat, performance by Benedict Cumberbatch and Martin Freeman, Mark Gatiss, season three, BBC and PBS, 2014. 
"Sherlock Holmes Awarded Title for Most Portrayed Literary Human Character." Guiness World Record News 14 May 2012, http://www.guinnessworldrecords.com/news/2012/5/sherlock-holmes-awardedtitle-for-most-portrayed-literary-human-character-in-film-tv-41743/. Accessed 12 Aug. 2016.

Siddiqi, Yumna. "The Cesspool of Empire: Sherlock Holmes and the Return of the Repressed." Victorian Literature and Culture, vol. 34, no. 1, 2006, pp. 233-247. JSTOR.

Sparling, Tawnee. "Rationalism and Romanticism in Detective Fiction." Andererseits, vol. 2, no. 1, 2011, pp. 201-208.

Stein, Louisa Ellen and Kristina Busse. "Introduction: The Literary, Televisual, and Digital Adventures of the Beloved Detective." Sherlock and Transmedia Fandom, edited by Louisa Ellen Stein and Kristina Busse, McFarland, 2012, pp 9-24.

---. "Conclusion: Transmedia Sherlock and Beyond." Sherlock and Transmedia Fandom, edited by Louisa Ellen Stein and Kristina Busse, McFarland, 2012, pp. 224-231.

Strahan, Lachlan. "Reflections 1972-1994." Australia's China: Changing Perceptions from the 1930s to the 1990s, Cambridge UP, 1996, pp. 290-321.

Symons, Julian. Bloody Murder: From the Detective Story to the Crime Novel: A History, Viking, 1985.

tedtutors. "Elementary s02x03 we are everyone discussion." Reddit.com, 2013, https://www.reddit.com/r/elementary/comments/1o6qez/elementary_s02x03_we are_everyone_discussion/. Accessed 29 Oct. 2016.

Temko, Florence. "History of Paperfolding." Paper Pandas and Jumping Frogs, China Books and Periodical, 1986, pp. 123-126.

Thomas, Roland. Detective Fiction and the Rise of Forensic Science, Cambridge UP, 1999.

Thompson, Glen L. "How Jingjiao Became Nestorian: Western Perceptions and Eastern Realities." From the Oxus River to the Chinese Shores: Studies on East Syriac Christianity in China and Central Asia, edited by Li Tang and Dietmar W. Winkler, LIT Verlag, 2013, pp. 417-440.

Thompson, Jon. Fiction, Crime, and Empire: Clues to Modernity and Postmodernism, University of Illinois Press, 1993.

Tracy, Jack. The Ultimate Sherlock Holmes Encyclopedia, 1st edition, Empire Pub Service, 1987.

Turvey, Brian. "Chapter 5: An Introduction to Behavioral Evidence Analysis." Criminal Profiling: An Introduction to Behavioral Evidence Analysis, Elsevier, 2012, pp. 121-140.

Welsh, Alexander. George Eliot and Blackmail, Harvard UP, 1985. 
Whyte, David. "Introduction: Studying the Crimes of the Powerful." Crimes of the Powerful: A Reader, edited by David Whyte, Open UP, 2009, pp. 1-4.

Žižek, Slavoj. Looking Awry: An Introduction to Jacques Lacan through Popular Culture. MIT Press, 1991. 


\section{APPENDIX A:}

\section{TITLE ABBREVIATIONS FOR DOYLE'S SHERLOCK HOLMES STORIES}

\begin{tabular}{|c|c|c|}
\hline CODE & $\begin{array}{l}\text { PUBLICATION } \\
\text { DATE }\end{array}$ & TITLE \\
\hline ABBE & Sept. 1904 & The Abbey Grange \\
\hline BERY & May 1892 & The Beryl Coronet \\
\hline BLAC & Feb. 1904 & Black Peter \\
\hline BLAN & Oct. 1926 & The Blanched Soldier \\
\hline BLUE & Jan. 1892 & The Blue Carbuncle \\
\hline BOSC & Oct. 1891 & The Boscombe Valley Mystery \\
\hline BRUC & Dec. 1908 & The Bruce-Partington Plans \\
\hline CARD & Jan. 1893 & The Cardboard Box \\
\hline CHAS & Mar. 1904 & Charles Augustus Milverton \\
\hline COPP & June 1892 & The Copper Beeches \\
\hline CREE & Mar. 1923 & The Creeping Man \\
\hline CROO & July 1893 & The Crooked Man \\
\hline DANC & Dec. 1903 & The Dancing Men \\
\hline DEVI & Dec. 1910 & The Devil's Foot \\
\hline DYIN & Nov. 1913 & The Dying Detective \\
\hline EMPT & Sept. 1903 & The Empty House \\
\hline ENGR & Mar. 1892 & The Engineer's Thumb \\
\hline FINA & Dec. 1893 & The Final Problem \\
\hline
\end{tabular}




\begin{tabular}{|c|c|c|}
\hline FIVE & Nov. 1891 & The Five Orange Pips \\
\hline GLOR & Apr. 1893 & The "Gloria Scott" \\
\hline GOLD & July 1904 & The Golden Prince-nez \\
\hline GREE & Sept. 1893 & The Greek Interpreter \\
\hline HOUN & Aug. 1901 & The Hound of the Baskervilles \\
\hline IDEN & Sept. 1891 & A Case of Identity \\
\hline ILLU & Nov. 1924 & The Illustrious Client \\
\hline LADY & Dec. 1911 & $\begin{array}{l}\text { The Disappearance of Lady } \\
\text { Francis Carfax }\end{array}$ \\
\hline LAST & Sept. 1917 & His Last Bow \\
\hline LION & Nov. 1926 & The Lion's Mane \\
\hline MAZA & Oct. 1921 & The Mazarin Stone \\
\hline MISS & Aug. 1904 & The Missing Three-Quarter \\
\hline MUSG & May 1893 & The Musgrave Ritual \\
\hline NAVA & Oct. 1893 & The Naval Treaty \\
\hline NOBL & Apr. 1892 & The Noble Bachelor \\
\hline NORW & Oct. 1903 & The Norwood Builder \\
\hline PRIO & Jan. 1904 & The Priory School \\
\hline REDC & Mar. 1911 & The Red Circle \\
\hline REDH & Aug. 1891 & The Red-Headed League \\
\hline REIG & June 1893 & The Reigate Squires \\
\hline RESI & Aug. 1893 & The Resident Patient \\
\hline RETI & Dec. 1926 & The Retired Colourman \\
\hline SCAN & July 1891 & A Scandal in Bohemia \\
\hline
\end{tabular}




\begin{tabular}{|c|c|c|}
\hline SECO & Dec. 1904 & The Second Stain \\
\hline SHOS & Mar. 1927 & Shoscombe Old Place \\
\hline SIGN & Feb. 1890 & The Sign of Four \\
\hline SILV & Dec. 1892 & Silver Blaze \\
\hline SIXN & Apr. 1904 & The Six Napoleons \\
\hline SOLI & Dec. 1903 & The Solitary Cyclist \\
\hline SPEC & Feb. 1892 & The Speckled Band \\
\hline STOC & Mar. 1893 & The Stock-broker's Clerk \\
\hline STUD & Nov. 1887 & A Study in Scarlet \\
\hline SUSS & Jan. 1924 & The Sussex Vampire \\
\hline THOR & Feb. 1922 & The Problem of Thor Bridge \\
\hline $3 \mathrm{GAB}$ & Sept. 1926 & The Three Gables \\
\hline 3GAR & Oct. 1924 & The Three Garridebs \\
\hline $3 \mathrm{STU}$ & June 1904 & The Three Students \\
\hline TWIS & Dec. 1891 & The Man With the Twisted Lip \\
\hline VALL & Sept. 1914 & The Valley of Fear \\
\hline VEIL & Jan. 1927 & The Veiled Lodger \\
\hline WIST & Aug. 1908 & Wisteria Lodge \\
\hline YELL & Feb. 1893 & The Yellow Face \\
\hline
\end{tabular}


APPENDIX B:

SHERLOCK EPISODES

$\begin{array}{lll}\begin{array}{l}\text { SEASON/ } \\ \text { EPISODE }\end{array} & \text { AIRDATE } & \text { EPISODE TITLE } \\ 1.1 & \text { 24 Oct. } 2010 & \text { A Study in Pink } \\ 1.2 & \text { 31 Oct. } 2010 & \text { The Blind Banker } \\ 1.3 & \text { 7 Nov. } 2010 & \text { The Great Game } \\ 2.1 & \text { 6 May } 2012 & \text { A Scandal in Belgravia } \\ 2.2 & \text { 13 May } 2012 & \text { The Hounds of Baskerville } \\ 2.3 & \text { 20 May } 2012 & \text { The Reichenbach Fall } \\ 3.0 & \text { 19 Jan. } 2014 & \text { Many Happy Returns } \\ 3.1 & \text { 19 Jan. } 2014 & \text { The Empty Hearse } \\ 3.2 & \text { 26 Jan. } 2014 & \text { The Sign of Three } \\ 3.3 & \text { 2 Feb. } 2014 & \text { His Last Vow } \\ 4.0 & \text { 1 Jan. } 2016 & \text { The Abominable Bride }\end{array}$


APPENDIX C:

ELEMENTARY EPISODES

\begin{tabular}{|c|c|c|}
\hline $\begin{array}{l}\text { SEASON/ } \\
\text { EPISODE }\end{array}$ & AIRDATE & EPISODE TITLE \\
\hline 1.1 & 27 Sept. 2012 & Pilot \\
\hline 1.2 & 4 Oct. 2012 & While You Were Sleeping \\
\hline 1.3 & 18 Oct. 2012 & Child Predator \\
\hline 1.4 & 25 Oct. 2012 & The Rat Race \\
\hline 1.5 & 1 Nov. 2012 & Lesser Evils \\
\hline 1.6 & 8 Nov. 2012 & Flight Risk \\
\hline 1.7 & 15 Nov. 2012 & One Way to Get Off \\
\hline 1.8 & 29 Nov. 2012 & The Long Fuse \\
\hline 1.9 & 6 Dec. 2012 & You Do It to Yourself \\
\hline 1.10 & 13 Dec. 2012 & The Leviathan \\
\hline 1.11 & 3 Jan. 2013 & Dirty Laundry \\
\hline 1.12 & 10 Jan. 2013 & M. \\
\hline 1.13 & 31 Jan. 2013 & The Red Team \\
\hline 1.14 & 3 Feb. 2013 & The Deductionist \\
\hline 1.15 & 7 Feb. 2013 & A Giant Gun, Filled with Drugs \\
\hline 1.16 & 14 Feb. 2013 & Details \\
\hline 1.17 & 21 Feb. 2013 & Possibility Two \\
\hline
\end{tabular}




\begin{tabular}{|c|c|c|}
\hline 1.18 & 14 Mar. 2013 & Déjà vu All Over Again \\
\hline 1.19 & 4 Apr. 2013 & Snow Angels \\
\hline 1.20 & 25 Apr. 2013 & Dead Man's Switch \\
\hline 1.21 & 2 May 2013 & A Landmark Story \\
\hline 1.22 & 9 May 2013 & Risk Management \\
\hline 1.23 & 16 May 2013 & The Woman \\
\hline 1.24 & 16 May 2013 & Heroine \\
\hline 2.1 & 26 Sept. 2013 & Step Nine \\
\hline 2.2 & 3 Oct. 2013 & Solve for $\mathrm{X}$ \\
\hline 2.3 & 10 Oct. 2013 & We Are Everyone \\
\hline 2.4 & 17 Oct. 2013 & Poison Pen \\
\hline 2.5 & 24 Oct. 2013 & Ancient History \\
\hline 2.6 & 31 Oct. 2013 & An Unnatural Arrangement \\
\hline 2.7 & 7 Nov. 2013 & The Marchioness \\
\hline 2.8 & 14 Nov. 2013 & Blood Is Thicker \\
\hline 2.9 & 21 Nov. 2013 & On the Line \\
\hline 2.10 & 5 Dec. 2013 & Tremors \\
\hline 2.11 & 12 Dec. 2013 & Internal Audit \\
\hline 2.12 & 2 Jan. 2014 & The Diabolical Kind \\
\hline 2.13 & 9 Jan. 2014 & All in the Family \\
\hline 2.14 & 30 Jan. 2014 & Dead Clade Walking \\
\hline 2.15 & 6 Feb. 2014 & Corpse de Ballet \\
\hline 2.16 & 27 Feb. 2014 & The One Percent Solution \\
\hline
\end{tabular}




\begin{tabular}{|c|c|c|}
\hline 2.17 & 6 Mar. 2014 & Ears to You \\
\hline 2.18 & 13 Mar. 2014 & The Hound of the Cancer Cells \\
\hline 2.19 & 3 Apr. 2014 & The Many Mouths of Andrew Colville \\
\hline 2.20 & 10 Apr. 2014 & No Lack of Void \\
\hline 2.21 & 24 Apr. 2014 & The Man with the Twisted Lip \\
\hline 2.22 & 1 May 2014 & Paint It Black \\
\hline 2.23 & 8 May 2014 & Art in the Blood \\
\hline 2.24 & 15 May 2014 & The Grand Experiment \\
\hline 3.1 & 30 Oct. 2014 & Enough Nemesis to Go Around \\
\hline 3.2 & 6 Nov. 2014 & The Five Orange Pipz \\
\hline 3.3 & 13 Nov. 2014 & Just a Regular Irregular \\
\hline 3.4 & 20 Nov. 2014 & Bella \\
\hline 3.5 & 27 Nov. 2014 & Rip Off \\
\hline 3.6 & 4 Dec. 2014 & Terra Perricolosa \\
\hline 3.7 & 11 Dec. 2014 & The Adventure of the Nutmeg Concoction \\
\hline 3.8 & 18 Dec. 2014 & End of Watch \\
\hline 3.9 & 8 Jan. 2015 & The Eternity Injection \\
\hline 3.10 & 15 Jan. 2015 & Seed Money \\
\hline 3.11 & 22 Jan. 2015 & The Illustrious Client \\
\hline 3.12 & 29 Jan. 2015 & The One That Got Away \\
\hline 3.13 & 5 Feb. 2015 & Hemlock \\
\hline 3.14 & 12 Feb. 2015 & The Female of the Species \\
\hline 3.15 & 19 Feb. 2015 & When Your Number's Up \\
\hline
\end{tabular}




\begin{tabular}{|c|c|c|}
\hline 3.16 & 5 Mar. 2015 & For All You Know \\
\hline 3.17 & 12 Mar. 2015 & T-Bone and the Iceman \\
\hline 3.18 & 2 Apr. 2015 & The View from Olympus \\
\hline 3.19 & 9 Apr. 2015 & One Watson, One Holmes \\
\hline 3.20 & 16 Apr. 2015 & A Stitch in Time \\
\hline 3.21 & 23 Apr. 2015 & Under My Skin \\
\hline 3.22 & 30 Apr. 2015 & The Best Way Out Is Always Through \\
\hline 3.23 & 7 May 2015 & Absconded \\
\hline 3.24 & 14 May 2015 & A Controlled Descent \\
\hline 4.1 & 5 Nov. 2015 & The Past Is Parent \\
\hline 4.2 & 12 Nov. 2015 & Evidence of Things Unseen \\
\hline 4.3 & 19 Nov. 2015 & Tag, You're Me \\
\hline 4.4 & 26 Nov. 2015 & All My Exes Live in Essex \\
\hline 4.5 & 10 Dec. 2015 & The Games Underfoot \\
\hline 4.6 & 17 Dec. 2015 & The Cost of Doing Business \\
\hline 4.7 & 7 Jan. 2016 & Miss Taken \\
\hline 4.8 & 14 Jan. 2016 & A Burden of Blood \\
\hline 4.9 & 21 Jan. 2016 & Murder Ex Machina \\
\hline 4.10 & 28 Jan. 2016 & Alma Matters \\
\hline 4.11 & 4 Feb. 2016 & Down Where the Dead Delight \\
\hline 4.12 & 11 Feb. 2016 & A View with a Room \\
\hline 4.13 & 18 Feb. 2016 & A Study in Charlotte \\
\hline 4.14 & 25 Feb. 2016 & Who Is That Masked Man? \\
\hline
\end{tabular}




$\begin{array}{lll}\text { 4.15 } & \text { 3 Mar. 2016 } & \text { Up to Heaven and Down to Hell } \\ 4.16 & \text { 10 Mar. 2016 } & \text { Hounded } \\ 4.17 & \text { 20 Mar. 2016 } & \text { You've Got Me, Who's Got You? } \\ 4.18 & \text { 27 Mar. 2016 } & \text { Ready or Not } \\ 4.19 & \text { 10 Apr. 2016 } & \text { All In } \\ 4.20 & \text { 10 Apr. 2016 } & \text { Art Imitates Art } \\ 4.21 & \text { 17 Apr. 2016 } & \text { Ain't Nothing Like the Real Thing } \\ 4.22 & \text { 24 Apr. 2016 } & \text { Turn It Upside Down } \\ 4.23 & 1 \text { May 2016 } & \text { The Invisible Hand } \\ 4.24 & 8 \text { May 2016 } & \text { A Difference in Kind }\end{array}$




\section{CURRICULUM VITAE}

NAME: $\quad$ Britney Broyles

ADDRESS: $\quad$ University of Louisville

Department of Comparative Humanities, HM 212

Louisville, KY 40292

EDUCATION: $\quad$ Ph.D., Comparative Humanities

University of Louisville

December 2016

M.A., Humanities

Concentration in Cultural Studies

University of Louisville

May 2012

B.A., English and Humanities, magna cum laude

Concentration in Disciplinary Studies

Minor in Chinese Studies

University of Louisville

May 2008

EXPERIENCE: UL Comparative Humanities Department

Teaching Assistant

2014-2016

UL Athletics Department

Tutor \& Mentor

2011-2013

\section{PUBLICATIONS:}

"From Opium Den to Partner-in-Crime...Solving: The Chinese Presence in Sherlock Holmes Adaptations." Textus 27.2 (2014): 147-168. Print.

\section{CONFERENCE PAPERS:}

"Truth and Power in Assassin's Creed," MPCA, Chicago, IL, October 2016.

"Surrealism, Metaphysics, and Indeterminacy in True Detective," H.E.R.A.: Beyond the

Binary, San Francisco, CA, April 2015. 
"Prospero the Wise: Resolving Confusion in The Tempest," H.E.R.A.: Humane, Inhumane, Human, Washington, D.C., March 2014.

"The Inherited Detective: Inspector Bucket and Officer McNulty," University of California LB: 49 Annual Comparative Literature Conference, Long Beach, CA, May 2013.

"In the Arms of a Loving Mother: The Motherly Embrace in the Divina Commedia and the Scrovegni Chapel," H.E.R.A.: Sacred Places and Spaces, Houston, TX, March 2013.

“A Moral Crossroads: Bloodlust of the Victorian Masses," H.E.R.A.: Crossroads, Salt Lake City, UT, March 2012.

AWARDS: $\quad$ Delphi Center for Teaching and Learning Faculty Favorite

2015-2016

Outstanding Graduate from Humanities Ph.D.

December 2016

UL GTA Academy

2014-2015

UL Honors Scholar Travel Seminar

Spring 2007

UL Trustees Scholarship

2004-2008

\section{PROFESSIONAL SOCIETIES:}

Humanities Education \& Research Association (Membership Chair)

Popular Culture Association

Modern Language Association 